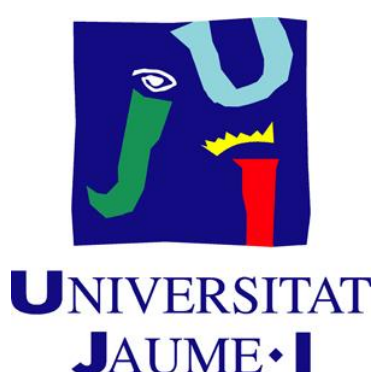

Facultad de Ciencias Humanas y Sociales

Departamento de Traducción y Comunicación

\title{
La traducción audiovisual y el perfil del traductor audiovisual en Rumanía
}

\author{
TESIS DOCTORAL \\ Elena Laura Vulpoiu
}

\author{
Dirigida por: \\ Prof. Dr. Beatriz Cerezo Merchán \\ Prof. Dr. José Luis Martí Ferriol
}

Castellón de la Plana, enero de 2018 

A mi familia y a mi hija Alexandra 



\section{AGRADECIMIENTOS}

La presente tesis doctoral es el resultado de todas las personas que me ayudaron y me animaron en este camino para llegar a la meta. Personas a las que puedo nombrar y otras que prefieren quedar en el anonimato, pese a que esto no quita el gran apoyo que me han brindado.

En primer lugar, expresar mi profunda gratitud a mis directores de tesis Dra.Beatriz Cerezo Merchán y Dr. José Luis Martí Ferriol por sus sabios consejos, revisiones, paciencia y su apoyo incondicional durante estos dos años. Más que mis directores, han sido mis compañeros de recorrido, porque durante este tiempo hemos formado un equipo con un mismo objetivo: aportar nuevos e interesantes datos a esta disciplina.

Al Dr. Fede Chaume por ser mi mentor, por haberme iniciado y acompañado durante los últimos cuatro años en el camino de la traducion audiovisual, por creer en mi cuando yo misma dudaba, por transmitirme su entusiasmo y su pasión por la investigación en este ámbito.

A la Dra. Ana Gimenez Adelantado por estar siempre a mi lado, en los buenos y en los malos momentos de este recorrido investigador, por su paciencia y por su colaboración.

A Irina Margareta Nistor, crítica de cine y traductora, un referente para la traduccción audiovisual rumana, la voz inconfundible de las películas y dibujos emitidos en el régimen comunista. Gracias por haber aceptado colaborar con nosotros en esta investigación y aportar valiosos datos, que abogan nuestro estudio por su vasta experiencia y profesionalidad en este ámbito.

Al grupo de profesionales de traducción audiovisual y de empresas empleadoras de Rumanía, que han participado en nuestras entrevistas y cuestionarios. Gracias por el tiempo y esfuerzo dedicado a este estudio, porque sin su colaboración nada de esto hubiera sido posible.

A mis amigas Embarka Hamoudi y María Jesus Sales por au apoyo, por la ayuda prestada y por estar siempre allí para animarme. 
A mi familia por ser el soporte fundamental en este trayecto, por confiar en mí y darme furzas para seguir adelante. Y especialmente, a mi hija Alexandra, que pese a su corta edad siempre estaba preocupada por la calidad de mis "deberes".

\section{¡Muchas gracias a todos!}




\section{ÍNDICE}

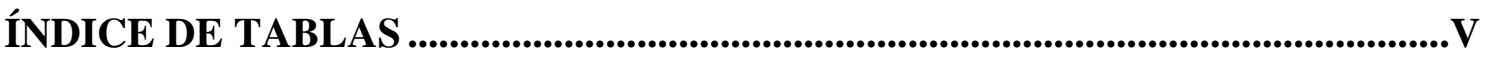

ÍNDICE DE FIGURAS ........................................................................................... VII

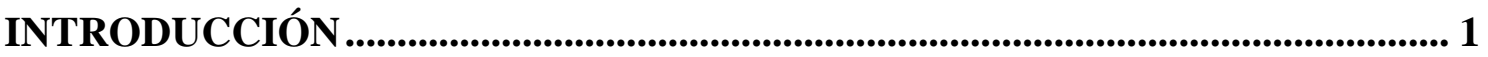

CAPÍTULO 1: HISTORIA DEL CINE RUMANO .......................................................... 7

1.1. Un breve recorrido por la historia de Rumanía..................................................................................7

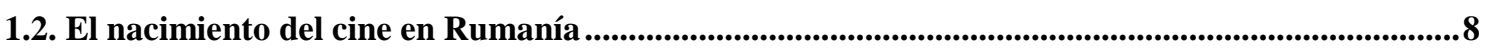

1.3. El cine rumano durante la Primera Guerra Mundial .............................................................................13

1.4. El cine rumano entre las dos guerras mundiales ....................................................................15

1.5. El cine rumano durante la Segunda Guerra Mundial...............................................................................22

1.6. El cine rumano después de la Segunda Guerra Mundial.......................................................................25

1.7. El cine rumano durante la dictadura ...........................................................................................................31

1.8. La censura sobre la producción y traducción de obras cinematográficas durante la dictadura

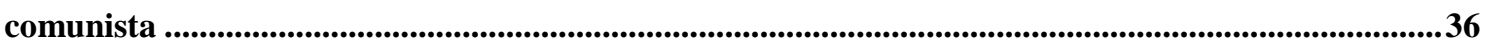

1.9. El cine rumano después de la revolución del año 1989 y en la actualidad.......................................43

1.10. Síntesis y conclusiones ..................................................................................................................50

CAPÍTULO 2: LA TRADUCCIÓN AUDIOVISUAL EN RUMANÍA.................... 53

2.1. Las modalidades de la traducción audiovisual en Rumanía ...........................................................53

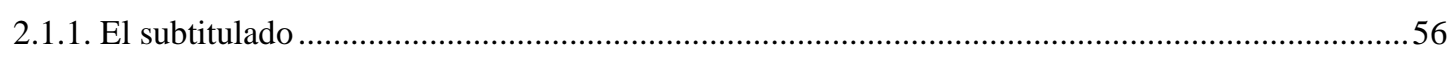



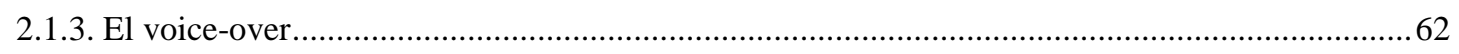

2.2. Las razones del triunfo del subtitulado en Rumanía ...................................................................664

2.3. Los medios que utilizan la traducción audiovisual en Rumanía ...............................................66

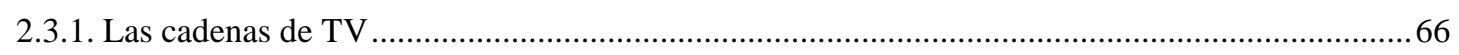

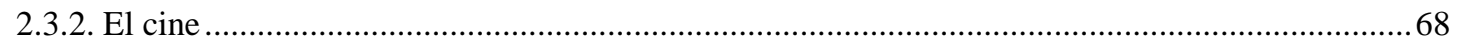




\section{CAPÍTULO 3: EL ENTORNO PROFESIONAL DE LA TRADUCCIÓN}

3.1. El proceso de subtitulación y el papel del traductor ..........................................................

3.2. El proceso de doblaje y el papel del traductor .....................................................................8

3.3. Tiempo de elaboración de la traducción para el subtitulado y doblaje ....................................87

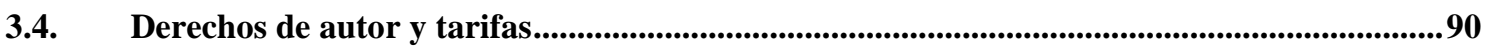

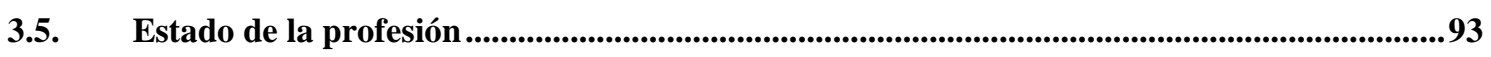

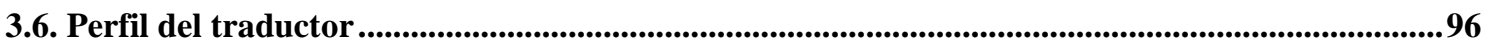



CAPÍTULO 4: METODOLOGÍA ....................................................................... 107

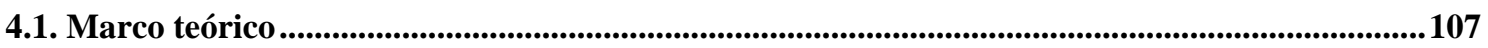

4.1.1. Las preguntas de la investigación ........................................................................................ 107

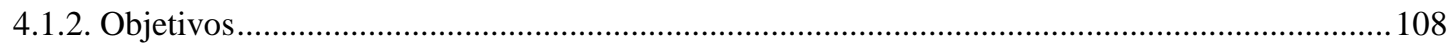





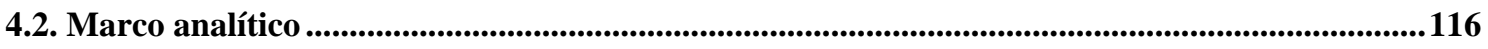

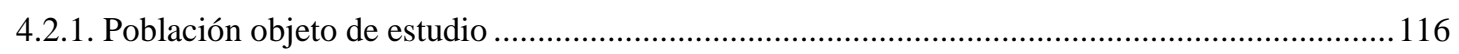

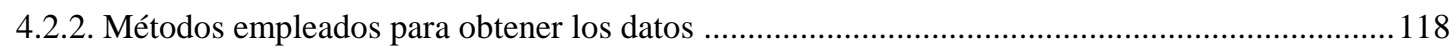

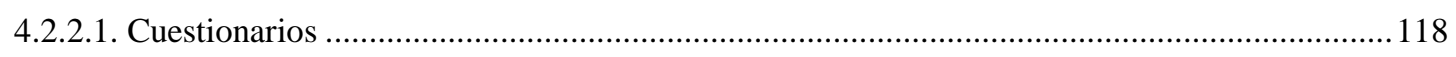

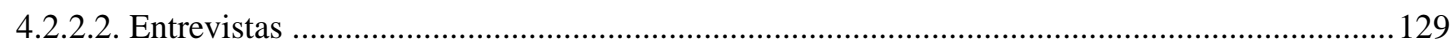

\section{CAPÍTULO 5: ANÁLISIS DE DATOS E INTERPRETACIÓN DE}

RESULTADOS ................................................................................................................... 135

5.1. Análisis de datos e interpretación de resultados: traductores de textos audiovisuales...............135

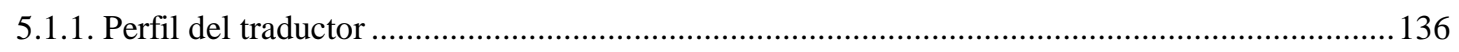

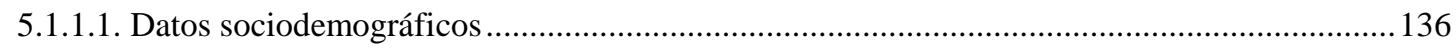

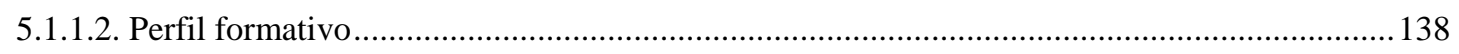

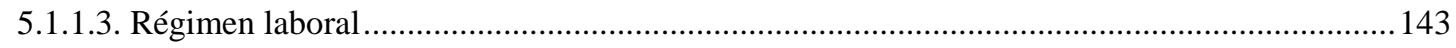


5.1.1.4. Recursos tecnológicos y programas informáticos ........................................................... 152

5.1.1.5. Normas, convenciones y especificidades de la profesión en la TAV .................................... 154

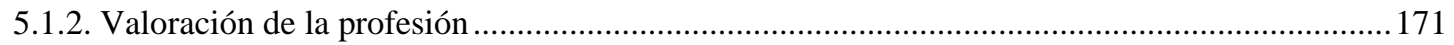

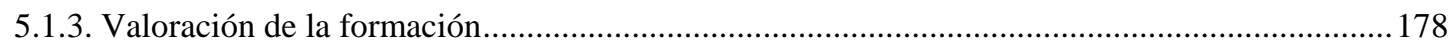





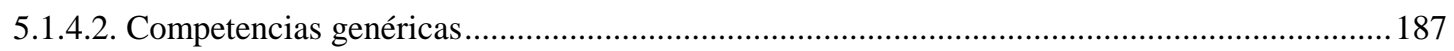

5.2. Análisis de datos e interpretación de resultados: empresas empleadoras de traductores



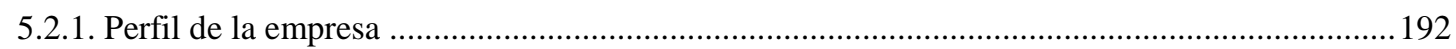

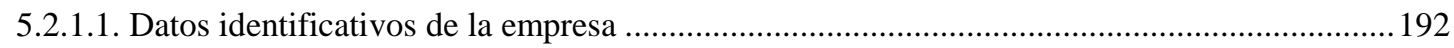

5.2.1.2. Relación con los traductores y las universidades .................................................................... 195



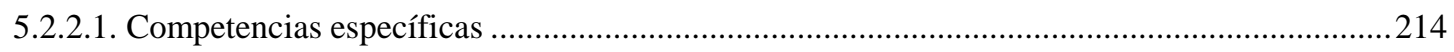



CAPÍTULO 6: CONCLUSIONES Y PERSPECTIVAS DE FUTURO ................. 223

6.1. Valoración de objetivos y resultados alcanzados ................................................................223

6.1.1. Objetivo específico 1: Describir y destacar las modalidades de traducción audiovisual que se



6.1.2. Objetivo específico 2: Estudiar el entorno laboral de la traducción audiovisual en Rumanía ...225 6.1.3. Objetivo específico 3: Determinar las competencias que ponen en ejercicio los traductores en su actividad profesional y requieren las empresas empleadoras

6.1.4. Objetivo específico 4: Describir el entorno formativo de la traducción audiovisual en Rumanía

6.1.5. Objetivo específico 5: Conocer el perfil laboral de las empresas que proporcionan servicios de traducción audiovisual en Rumanía 


\section{Índice de tablas}

Tabla 1. Lista de películas rumanas realizadas entre los años 1920-1930.......................................... 19

Tabla 2. Lista de películas rumanas realizadas entre los años 1946-1964..............................................30

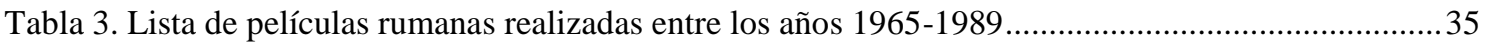

Tabla 4. Lista de películas rumanas relevantes realizadas entre los años 1990-2016.............................49

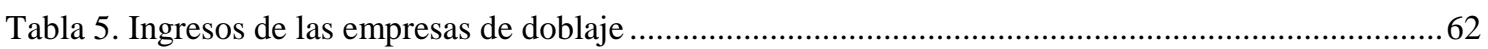

Tabla 6. Año de aparición de diversas cadenas de TV privadas en Rumanía.........................................67

Tabla 7. Evolución del número de salas de cine en Rumanía (fuente: CNC) .......................................69

Tabla 8. Procedencia de los filmes exhibidos en Rumanía entre 2011 y 2015 (fuente: CNC) ..................70

Tabla 9. Principales distribuidoras de cine en Rumanía entre 2011-2015 (fuente: CNC) .......................71

Tabla 10. Progresión en el número de títulos de filmes editados en diferentes soportes en Rumanía.........72

Tabla 11. Progresión del número de cintas editadas en diferentes soportes por el CNC ..........................73

Tabla 12. Número de empresas que comercializan cintas de video, DVD, CD, UMD y BD..................73

Tabla 13. Número de empresas que alquilan cintas de video, DVD, CD, UMD y BD ...........................73

Tabla 14. Empresas distribuidoras de cintas de video, DVD, etc. y número de títulos editados ................73

Tabla 16. Comparación de las etapas de investigación de los enfoques cuantitativo y cualitativo

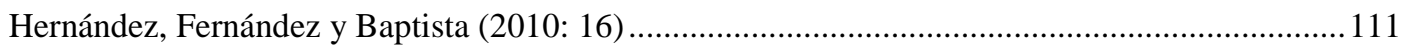



Tabla 18. Ventajas y retos del uso del cuestionario (Hernández, Fernández y Baptista, 2010: 271) .......120

Tabla 19. Ejemplo de pregunta de elección única ............................................................................. 122

Tabla 20. Ejemplo de pregunta de elección múltiple..................................................................... 122

Tabla 21. Ejemplo de pregunta de escala tipo Likert ........................................................................ 123

Tabla 22. Bloque, ítems y objetivo del cuestionario dirigido a los traductores .................................. 125

Tabla 23. Bloque, ítems y objetivo del cuestionario dirigido a las empresas .........................................125

Tabla 24. Guía de entrevista dirigida a los traductores................................................................... 132

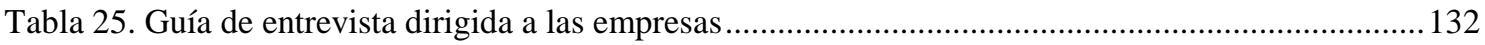

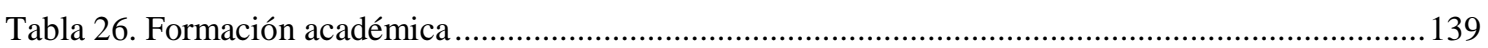

Tabla 27. Cursos específicos de traducción audiovisual ..................................................................... 140

Tabla 28. Modalidad de traducción audiovisual empleada con más frecuencia .....................................147

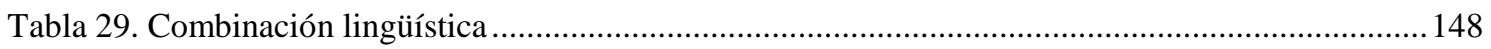

Tabla 30. El destinatario de los productos audiovisuales en la lengua meta (profesionales).................. 149

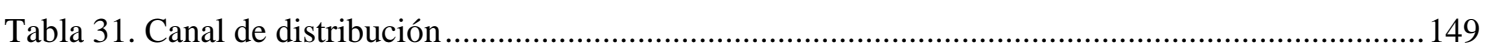

Tabla 32. Tipos de programas empleados para realizar las traducciones ............................................. 152

Tabla 33. Programas específicos de traducción audiovisual ............................................................. 153

Tabla 34. Tipo de material que recibe previamente .......................................................................... 154

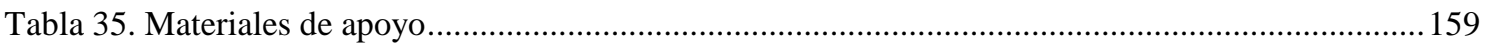

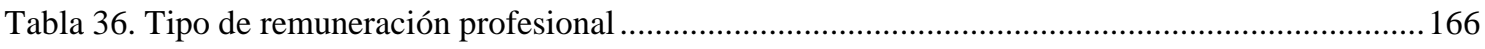

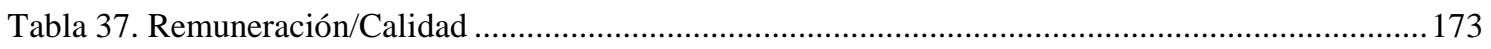

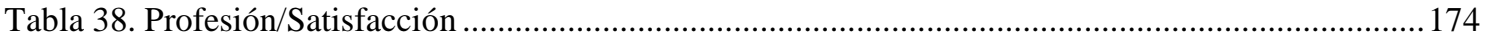


Tabla 39. Influencia de la piratería

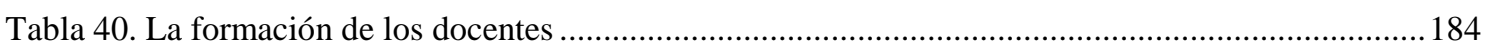



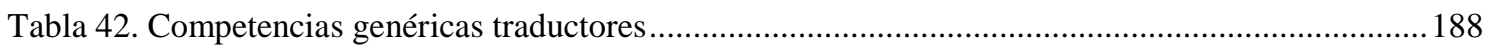

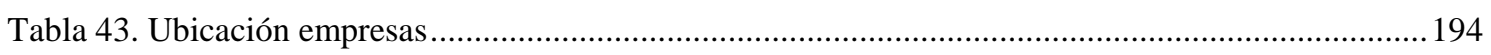

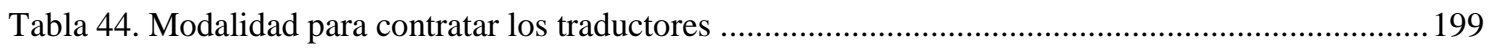

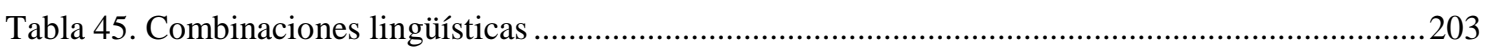

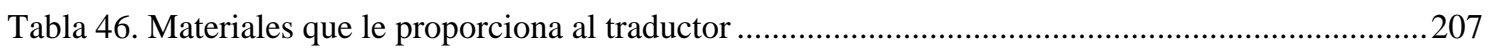

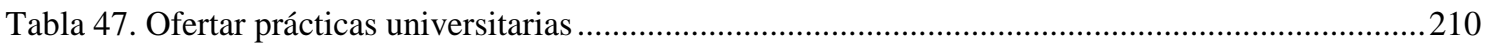

Tabla 48. La adecuación de la formación universitaria en la traducción audiovisual en Rumanía ...........211





Tabla 51. Competencias específicas valoradas por grupo de población ..............................................228

Tabla 52. Competencias genéricas valoradas por grupo de población ................................................230 


\section{Índice de figuras}

Figura 1. La competencia traductora, según Kelly (2002: 17-18) ................................................... 100

Figura 2. Modelo holístico de la competencia traductora, según PACTE (2003: 57-58) ...................... 102



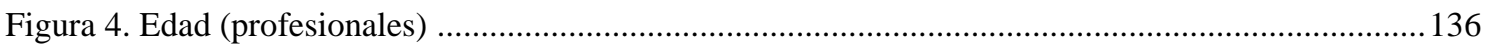

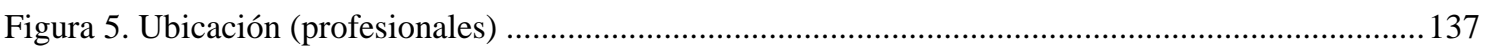



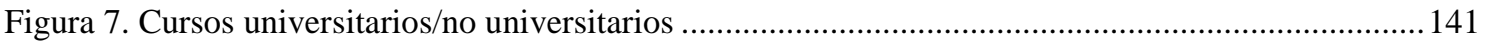

Figura 8. Formación en modalidades de traducción audiovisual ........................................................... 142

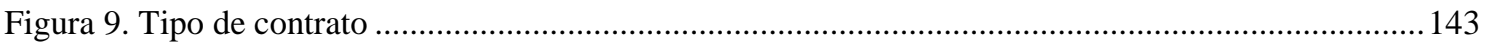

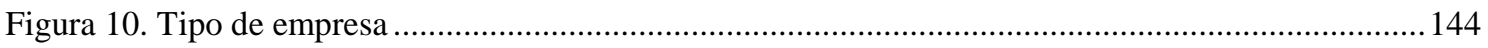

Figura 11. El porcentaje que la empresa dedica a la traducción audiovisual.........................................145

Figura 12. Porcentaje dedicado a la traducción audiovisual y otras actividades ................................. 146

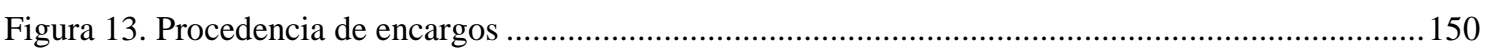

Figura 14. Justificación de empleo de estos programas .................................................................. 154

Figura 15. Vía recepción de material.................................................................................... 155

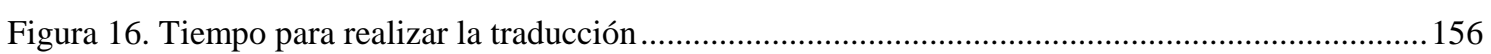

Figura 17. Estimación del tiempo para realizar la traducción ............................................................... 157

Figura 18. Estimación de la repercusión tiempo/calidad .............................................................. 158

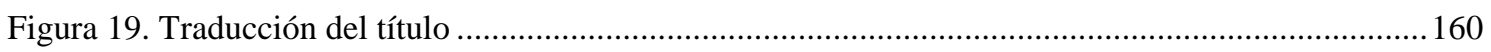

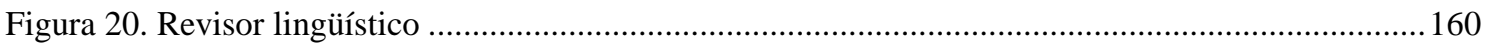

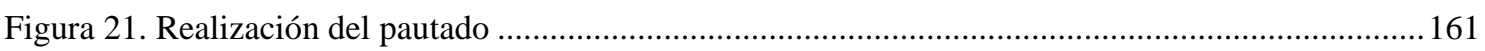

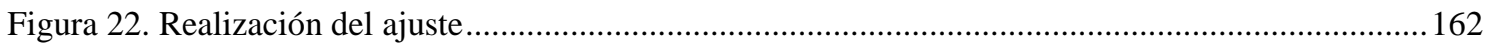

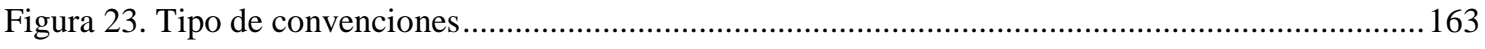

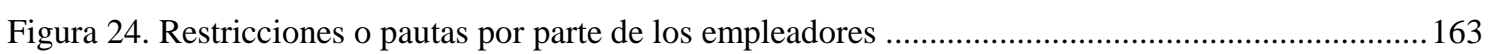

Figura 25. Repercuten en el trabajo final estas restricciones/pautas................................................. 164



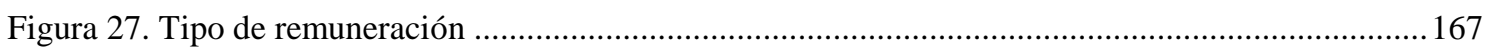



Figura 29. Calidad traducción/éxito de producto audiovisual .............................................................. 172

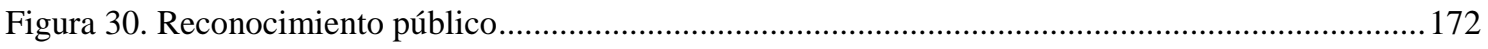

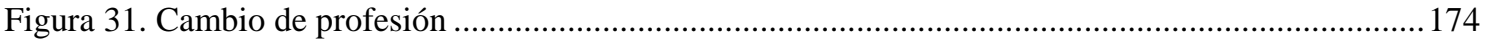

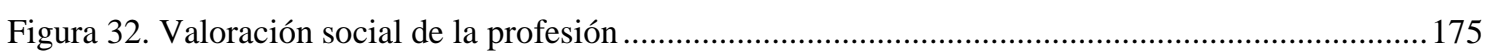

Figura 33. Valoración de la formación académica ….................................................................... 179

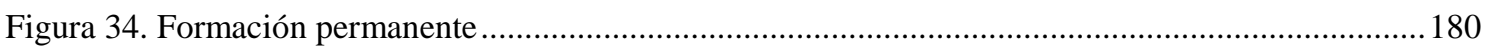

Figura 35. Número adecuado de cursos específicos ........................................................................ 181

Figura 36. Valoración de los equipos técnicos de los cursos universitarios ....................................... 183

Figura 37. Antigüedad de la empresa en el mercado ....................................................................... 193

Figura 38. Tipo/s de empresa/s que suele/n solicitar su colaboración .................................................. 194 
Figura 39. Número de empleados.



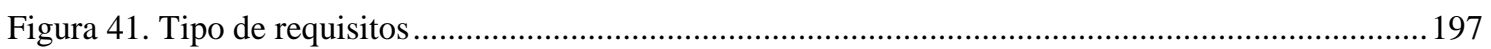

Figura 42. Otras variedades de traducción ..................................................................................200

Figura 43. El destinatario de los productos audiovisuales en la lengua meta ......................................201

Figura 44. Modalidad de traducción audiovisual empleada ............................................................201

Figura 45. Los tipos de programa los impone la empresa ................................................................203

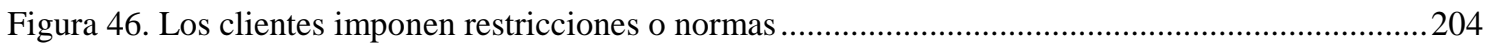

Figura 47. Las empresas imponen restricciones o normas a los traductores ......................................206

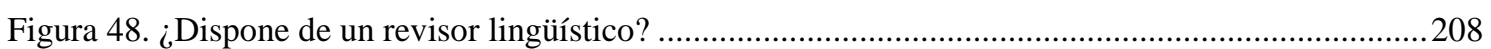

Figura 49. Relación de la calidad de la traducción con el éxito del producto en la lengua meta..............209

Figura 50. Oferta de formación continúa a los traductores por parte de las empresas............................211 


\section{Introducción}

\section{Motivación personal}

La traducción audiovisual forma parte de nuestra vida cotidiana, es un producto del que disfrutamos a diario, independientemente de nuestras edades. Un producto que puede variar nuestro estado de ánimo, que influye en nuestras vidas y que sin darle mucha importancia, a veces, tiene detrás un gran equipo humano que hace posible que nosotros como público disfrutemos de su producto final: películas, series, documentales, dibujos animados, videojuegos, etc.

En todo este trayecto, el primer escalón pertenece al profesional de traducción audiovisual, el eje fundamental de cuyo trabajo dependen las siguientes etapas del proceso.

La importancia de este tipo de profesión y la escasez bibliográfica sobre este tema, especialmente en Rumanía, nos han llevado a realizar este análisis que aportará datos concretos y fiables sobre la traducción audiovisual y el perfil del traductor de textos audiovisuales en este país. Con este estudio esperamos cambiar su estatus de “invisibilidad", tal como lo definía Venutti (1995), y darle visibilidad delineando las características de su perfil socioprofesional y académico en Rumanía.

\section{Antecedentes}

Cuando iniciamos esta investigación, que en un principio se materializó en un trabajo fin de máster bajo la dirección del Dr. Frederic Chaume Varela, no pudimos localizar bibliografía sobre este tema, ni en Rumanía ni en España. Actualmente, tampoco tenemos constancia de que existan trabajos específicos sobre él.

No obstante, durante la elaboración de esta tesis fue de gran ayuda la consulta de obras de referencia sobre traducción audiovisual y sobre el perfil socioprofesional de los traductores en España y otros países. Asimismo, determinadas obras como las de Díaz Cintas (2003), Díaz Cintas y Remael (2007) o Chaume (2004, 2012), que describen los procesos de subtitulación y doblaje y que incorporan información sobre el perfil del traductor audiovisual en España, constituyeron una importante fuente de información utilizada a lo largo de nuestro estudio y nos permitieron cotejar los datos recabados en este. 
Además, los amplios estudios sobre las competencias específicas y genéricas que reúnen generalmente los traductores, como por ejemplo los de Kelly (2002, 2005), PACTE (2003) o Cerezo Merchán (2012) nos ayudaron a diseñar y formular la parte de esta tesis centrada en las destrezas y habilidades necesarias para el profesional de la traducción audiovisual.

Asimismo, puesto que la presente tesis se sustenta también en el ámbito de las Ciencias Sociales, estudios realizados por Mayoral (1999) y Gambier y Gottlieb (2001), así como por Yániz (2004), Monzó (2006) y Panaia (2007), nos guiaron a la hora de delinear la actividad profesional y el perfil socioprofesional del traductor audiovisual en Rumanía.

\section{Objetivos}

Dado que no existen estudios específicos sobre el perfil del traductor audiovisual en Rumanía, nos planteamos en nuestra investigación, como objetivo general:

- Describir y analizar el perfil formativo y socioprofesional del traductor audiovisual en la actualidad en Rumanía.

Este objetivo general se complementa con cinco objetivos específicos:

- Describir y destacar las modalidades de traducción audiovisual que se utilizan en Rumanía.

- Estudiar el entorno laboral de la traducción audiovisual en Rumanía.

- Determinar las competencias que ponen en ejercicio los traductores en su actividad profesional y requieren las empresas empleadoras.

- Describir el entorno formativo de la traducción audiovisual en Rumanía.

- Conocer el perfil laboral de las empresas que proporcionan servicios de traducción audiovisual en Rumanía.

\section{Metodología}

La fundamentación metodológica de esta tesis se inscribe en el ámbito de las Ciencias Sociales, puesto que se trata de un estudio empírico-descriptivo mediante el cual pretendemos descubrir y analizar datos nuevos (Williams y Chesterman, 2002: 58) que caracterizan al profesional de la traducción audiovisual en Rumanía. 
La parte empírica de esta tesis se estructura en tres fases de estudio:

1) El marco teórico en el que, partiendo de la cuestión de investigación y los objetivos establecidos, argumentamos teóricamente las estrategias de obtención de datos que hemos seleccionado y empleado en este estudio.

2) El marco metodológico en el que describimos la población objeto de estudio, así como los métodos empleados para obtener los datos.

3) La fase interpretativa en la que realizamos el análisis e interpretación de los datos recabados.

Tras analizar los tipos de diseño de investigación, que proponen Creswell y Clark (2011), en nuestro estudio aplicamos el método secuencial explicativo, ya que iniciamos la búsqueda y la recolección de datos cuantitativos, continuada y complementada por la fase cualitativa.

A efectos prácticos, recopilamos datos cuantitativos y cualitativos a través de cuestionarios y entrevistas, los cuales nos ayudan a profundizar en el análisis y la descripción del perfil socioprofesional del traductor audiovisual en Rumanía.

En cuanto a la población objeto de estudio, hemos seleccionado dos grupos de estudio: profesionales de traducción audiovisual y empresas empleadoras en Rumanía. Tal como afirma De Barrera (2008: 141), en caso de que la población sea tan grande o inaccesible que no se pueda estudiar toda, entonces el investigador tendrá la posibilidad de seleccionar una muestra. Por tanto, en este estudio utilizamos una muestra dirigida (Hernández, Fernández y Baptista, 2006: 241), entendida como el subgrupo de la población en la que la elección de los elementos no depende de la probabilidad, sino de las características de la investigación.

Por lo que respecta al enfoque de investigación, utilizamos un enfoque mixto, en el que nos valemos del concepto conocido como triangulación. Empleamos la triangulación de métodos de recogida de datos para obtener información a partir de la recopilación y el análisis de información teórica que define este gremio, así como de los cuestionarios y las entrevistas. Esta triangulación de métodos de recogida de datos, según apuntan Hernández y Mendoza (2008), nos ayuda a recabar información heterogénea y contrastada (de tipo cuantitativo y cualitativo) sobre nuestro grupo de estudio, lo cual nos permitirá estudiar y describir el perfil actual del traductor de textos audiovisuales en Rumanía. 
Por lo que respeta el diseño de los cuestionarios, hemos construido un modelo congruente con el planteamiento del problema (Brace, 2008), con preguntas breves, claras, precisas y comprensibles para los sujetos encuestados. Para ambos cuestionarios utilizamos la herramienta Google Forms, que permite crear cuestionarios online de manera gratuita. La elección del cuestionario electrónico como herramienta de recogida de datos se debe a su sencillez y facilidad de acceso, dado que nuestra intención inicial fue conseguir el mayor número posible de encuestados de los que actualmente en Rumanía cumplen los requisitos del estudio. En total, nuestra muestra se compone por 9 traductores y 5 empresas empleadoras. En cuanto las entrevistas, en nuestro estudio hemos empleado las entrevistas semiestructuradas, que nos han permitido crear una guía de preguntas predeterminadas estructurada en diferentes bloques y con ítems similares a las preguntas formuladas en los cuestionarios, con el fin de profundizar en algunos aspectos, sobre todo en aquellos que se podrían considerar "censurados" en este país. En total, contamos con 4 entrevistas, 3 del grupo de traductores y 1 de las empresas empleadoras. Estas entrevistas, pese a su número reducido, nos han aportado información enriquecedora, puesto que la selección de los entrevistados se ha realizado con el objetivo de aportar información desde varias perspectivas, así como ampliar la información que consideramos significativa de los ítems formulados en las encuestas.

En su totalidad, nuestra muestra puede parecer reducida, sin embargo nuestro propósito no es generalizar, sino analizar y describir el perfil del traductor audiovisual en este país, puesto que se trata de un estudio exploratorio y no experimental.

La última parte de nuestra tesis está dedicada al análisis de los datos recabados, a la interpretación de los resultados a partir de los cuales expondremos las conclusiones finales, y a la formulación de futuras líneas de investigación.

\section{Estructura del trabajo}

El presente trabajo se compone de siete capítulos, que describiremos brevemente para ofrecer una visión integral de todos los aspectos abordados.

El Capítulo 1, Historia del cine rumano, se inicia con una breve descripción de Rumanía, dado que hemos considerado oportuno presentar los rasgos geográficos y culturales de este país para comprender, describir y posteriormente analizar el objetivo general de nuestra tesis. Además, en este capítulo hemos realizado una síntesis del cine 
rumano desde su inicio hasta la actualidad, centrándonos en los cambios políticos e históricos que repercuten en la realización del producto audiovisual, así como en el perfil y la labor de los profesionales de este ámbito.

El Capítulo 2, La traducción audiovisual en Rumanía, describe y define las modalidades de traducción audiovisual que se utilizan actualmente en este país (subtitulación, doblaje y voice-over). A lo largo de este capítulo se reflexiona sobre el cambio del sistema económico-político del año 1989 en Rumanía, que influye en el ámbito audiovisual rumano, de modo que en los primeros años que transcurren a partir de esta fecha, los medios audiovisuales sufren su propia revolución y evolución. Asimismo, definimos las características y la disminución o aumento de público y de beneficios económicos de los medios audiovisuales más destacados en la actualidad en este país (cadenas de televisión, cine y la industria del DVD).

El Capítulo 3, El entorno profesional de la traducción audiovisual en Rumanía, se centra en el rol que ejerce el traductor en el proceso de traducción audiovisual en Rumanía, en concreto en el papel que desempeña en las dos modalidades de traducción audiovisual más empleadas actualmente en este país: la subtitulación y el doblaje. Asimismo, hemos considerado necesario exponer algunas cuestiones que generalmente caracterizan esta profesión (tiempo de elaboración de la traducción, derechos de autor y tarifas). Por último, hemos definido las habilidades y competencias que requiere esta profesión, para describir y analizar posteriormente las competencias específicas y genéricas que definen este gremio en Rumanía.

El Capítulo 4, Metodología, se estructura en dos subcapítulos que describen el marco teórico y el marco analítico de nuestro estudio. En el marco teórico plantemos la cuestión de la investigación, nuestros objetivos y justificamos teóricamente la elección de la metodología y de las estrategias para recabar los datos. En el marco analítico describimos la población objeto de estudio, el diseño y la aplicación de los instrumentos que vamos a utilizar para la obtención de datos: cuestionarios y entrevistas.

El Capítulo 5, Análisis de datos e interpretación de resultados, presenta el análisis interpretativo de los datos recabados mediante los cuestionarios y las entrevistas.

El Capítulo 6, Conclusiones y perspectivas de futuro, expone las conclusiones finales de este estudio retomando, para ello, los objetivos planteados a su inicio. Asimismo, se sugieren las líneas de investigación futuras que se derivan de este estudio. 
El Capítulo 7, Bibliografía, presenta la lista bibliográfica empleada en esta investigación. 


\section{Capítulo 1: Historia del cine rumano}

En el presente capítulo realizaremos un breve recorrido por la historia del cine rumano desde su inicio hasta la actualidad. Han sido periodos duros de guerras, de pobreza, de dictadura y de transición, y todos estos cambios históricos han influido en el argumento y la técnica de las películas. Para ello, partimos de los inicios del cine rumano, donde cualquier invención y recurso valía con tal de cubrir las carencias técnicas y económicas. A continuación, atravesamos las dos guerras mundiales, que han supuesto un antes y un después en la historia y en el cine rumano; y, posteriormente, repasamos la época dictatorial, durante la cual el arte dependía más de los deseos del dictador que de las exigencias e intereses del público. Finalmente, presentamos la época actual, en que la tecnología conoce sus máximos avances, a pesar de que esta siga teniendo altibajos por la falta de presupuesto y la crisis económica.

Este viaje en el tiempo nos ayudará a conocer las etapas y los progresos de la técnica cinematográfica rumana, gracias al esfuerzo y al talento de un gran número de personas que se han quedado en el anonimato o han escrito sus nombres en la historia de este arte.

\subsection{Un breve recorrido por la historia de Rumanía}

"El destino es la excusa de los débiles y la obra de los fuertes", afirmaba el distinguido histórico Nicolae Titulescu. Comenzamos el recorrido por la historia de Rumanía con esta afirmación, ya que consideramos que es el destino del pueblo rumano desde su creación hasta la actualidad, dado que su historia ha constituido un largo camino de luchas para conservar su independencia, su integridad y sus valores.

Rumanía es un país de origen daco-romano, cuya lengua oficial (el rumano) proviene del latín. Situada en la parte del este de Europa, a lo largo del tiempo ha visto cómo la influencia de países vecinos y de parte de los países que en su día conquistaron el país ha modelado su lengua y su política. Estas circunstancias históricas han servido, tanto a los escritores como a los directores de filmes, para plasmar verdaderas obras de arte literarias y cinematográficas. Una de ellas, la más popular, es la del escritor irlandés Bram Stoker, que presenta al príncipe rumano Vlad Țepeș (1431-1476), muy querido por su pueblo gracias a su espíritu justiciero, como el conde Drácula, el temido vampiro de Transilvania. 
Situado al lado del mar Negro, y con la cordillera de los Cárpatos en el centro, Rumanía es el país de los contrastes, donde el tradicionalismo se funde con el modernismo, y las leyendas con la realidad. Si en las grandes ciudades la arquitectura es moderna, en los pueblos se conservan aún monasterios y castillos construidos hace siglos por los príncipes que han gobernado a lo largo de su historia.

La riqueza más grande de Rumanía consiste en su naturaleza. Las montañas cubiertas de bosques misteriosos e interminables esconden en sus profundidades multitud de lagos glaciales formados siglos atrás. Por otra parte, el mar Negro y el delta del Danubio constituyen las dos perlas del paisaje rumano, que durante todo el año encandilan a los turistas. Cada rincón, cada parte de este maravilloso país, respira historia y leyendas.

Rumanía es el país que, a pesar de las dificultades económicas o políticas que ha atravesado, ha contribuido al enriquecimiento cultural europeo con valores culturales como Cioran, Eliade, Eminescu, Brancusi, Luchian, etc.

La época dictatorial de Ceauşescu (1965-1989) es la que deja una huella trágica en la historia de Rumanía. Querido por unos, odiado o temido por otros, el dictador mantuvo el país en un completo aislamiento. Durante los 24 años de régimen comunista, las fronteras permanecieron cerradas y la única cadena de televisión rumana que existía, emitía programas controlados exhaustivamente por los miembros de su partido.

En el año 1989 el pueblo rumano logró librarse del régimen dictatorial pagando su victoria con mucho sacrificio humano. Todo esto supone un cambio radical en la sociedad rumana tanto desde el punto de vista cultural como desde el socio-político. Es el momento en el que los rumanos pueden ampliar su visión hacia el mundo sin temor y sin restricciones.

A pesar de las dificultades que ha atravesado a lo largo del tiempo, el pueblo rumano se caracteriza por su alegría, su hospitalidad y su respeto hacia las tradiciones.

\subsection{El nacimiento del cine en Rumanía}

La aparición del cine fue una novedad mundial. En el año 1895 los hermanos Lumière son los pioneros de este arte y presentan en París lo que constituiría la primera película de la historia del cine. Pese a que se trataba de una sola toma de trabajadores saliendo de la fábrica, una escena cotidiana, conquistó por sus elementos novedosos: la ausencia de los actores en un escenario como en el teatro, en escenarios naturales. Fue el 
inicio de un gran descubrimiento que paulatinamente se convertiría en una gran industria de entretenimiento presente diariamente en nuestras vidas.

Rumanía tardó solo un año en experimentar este considerable descubrimiento. En el año 1896, en la sede del periódico L'Independence Roumaine, se presenta por primera vez, tal como en el mismo periódico se describe el día 4 de junio de 1896, "la maravilla del siglo", que proporcionaría al público "una experiencia feérica". Sin embargo, tanto el periódico, que estaba redactado en francés (idioma no accesible a la gente con pocos recursos económicos), como el espectáculo, se dirigían al público de la alta sociedad. El documental que se presentaba era el mismo presentado en Francia, L'arrivée d'un train à La Ciotat (en español, La llegada del tren). A este le sucedieron, a partir del siguiente año, películas rumanas realizadas por Paul Menu, un joven de origen rumano formado por los hermanos Lumière.

La temática de las grabaciones realizadas por Menu era variada y de actualidad. Utilizando los sucesos de ese periodo, como por ejemplo la inundación del Danubio, el desfile militar que se realizaba el 10 de mayo, o el hipódromo y las carreras de caballos, realiza un total de 17 reportajes entre los cuales se encuentran Las inundaciones de Galati, El desfile o La terraza del café Capșa (Cantacuzino, 1965: 6).

Durante el año 1897 se proyecta en Rumanía material de origen rumano. Por ello, tal como afirma Cantacuzino (1965: 8), las “actualidades cinematográficas” pueden estar orgullosas de tener una antigua tradición.

Sin embargo, la curiosidad hacia este tipo de arte disminuyó a finales del mismo año, de tal modo que en el periódico L'Independence Roumaine del 16 de marzo de 1898 se publicaba el anuncio de venta de un aparato Lumière, tal como recoge Cantacuzino (1965: 9). A partir de entonces, durante varios años en Rumanía no se proyecta ningún espectáculo cinematográfico hasta el año 1905, cuando reaparecen algunos espectáculos realizados por diferentes personas como Oeser, Kuperman, Bottez y muchas otras que han quedado en el anonimato. Estos espectáculos se emitían en distintos sitios de Bucarest (El teatro lírico, el Circo Sidoli, etc), dado que no existía una sala específica para las proyecciones, esencialmente por falta de inversores, lo que nos deja entrever las carencias económicas que sufría el cine desde sus inicios.

La primera sala que se construye especialmente para este tipo de espectáculo se inaugura en el año 1909 - el cinematógrafo Volta - y paulatinamente en los años siguientes aparecen otras como Blériot, Bristol, Apollo y Venus. 
Con mucho trabajo y mucha pasión, los pioneros de este arte lograron superar las carencias económicas y, empleando materiales rudimentarios, consiguieron producir la primera película rumana (Amor Fatal), realizada por Grigore Brezeanu en el año 1911. Esta película cuenta con la participación de actores rumanos (Lucia Sturza, Tony Bulandra, Aurel Barbelian) y se proyecta en la sala Apollo. No obstante, su estreno no causa una buena impresión ni al público ni a los periódicos, dado que en un artículo del 20 de octubre en L'Independence Roumaine se publicaba la siguiente noticia, tal y como recoge Rîpeanu (2004: 21):

\begin{abstract}
Algunos de nuestros mejores actores han interpretado para el cinematógrafo una película donde ellos figuran y se representan. Esta película es interesante solamente porque figuran en ella nuestros actores, y no por su forma de interpretar. Si estos artistas — he dicho que son algunos de los mejores de los que tenemos - siempre tienen éxito cuando suben al escenario, no ocurre lo mismo cuando se trata de sus actuaciones cinematográficas. Esto significa que incluso para los actores más talentosos, actuar para el público no es lo mismo que actuar para el aparato cinematográfico [...]. Además, es necesario que la persona que maneja el aparato sea un artista. Los diversos movimientos que realizan los actores en sus interpretaciones se tienen que ajustar al aparato, acercándose o alejándose, y eso hace que los actores parezcan unas veces muy grandes, otras muy pequeños. [La traducción es nuestra].
\end{abstract}

Como podemos observar, la novedad "del aparato" recibe pocos elogios y muchas críticas, es una innovación a la que se tienen que adaptar tanto los actores como los técnicos. El resultado no siempre es el esperado, a pesar de la trayectoria profesional y el talento de los actores.

Sin embargo, la aventura cinematográfica continúa y el día 7 de noviembre del mismo año en el Teatro Nacional se estrena una nueva "película": Înșiră-te mărgărite, adaptación de una pieza de teatro del conocido escritor rumano Victor Eftimiu, bajo la dirección de Aristide Demetriade y Grigore Brezeanu. En realidad la película se emitía durante las pausas entre los actos de la pieza e intentaba entrelazar y completar la interpretación de los actores entre una escena y otra. Las reacciones de los críticos de teatro y filme fueron diversas; la principal causa de la controversia la representaba la posibilidad de integrar un espectáculo cinematográfico en una pieza de teatro.

En el año 1912 se proyecta en la sala Eforie, uno de los mayores cinematógrafos de Bucarest, la película Independența României -Răsboiul Româno-Ruso-Turc, bajo la dirección de Grigore Brezeanu. Sin embargo, al tratarse de una película que suponía un 
coste mucho más elevado que la primera, Brezeanu se ve obligado a solicitar la colaboración de Leon Popescu, persona adinerada y propietario del teatro Liric.

Esta película tiene como tema central la guerra de la independencia de 1877, cuando Rumanía logra ser un estado independiente y librarse, con la ayuda de Rusia, del poder otomano que la mantenía bajo su autoridad absoluta. Los personajes principales se inspiran en los poemas del conocido poeta rumano Vasile Alecsandri, que había creado en sus poesías verdaderas figuras de leyenda, como por ejemplo Cobuz o Peneș Curcanul.

El tema y la fecha de este proyecto cinematográfico coinciden con la conmemoración de los 35 años de la liberación de Rumanía, por lo que recibe apoyo económico tanto por parte de la Casa Real, como por parte del Ministerio de Defensa, que aporta para la puesta en escena tropas, uniformes, caballos y cañones; un apoyo que nunca se había visto y nunca se repetirá. En cuanto a los actores, el director había reunido a un grupo de los más prestigiosos de esos tiempos, como por ejemplo: Constantin Nottara, Aristide Demetriade, Constanta Demetriade, Aurel Athanasescu, Ion Niculescu, Aristizza Romanescu, Maria Ciucurescu, Elvira Popescu, Ecaterina Zimniceanu, Olimpia Birsan, Nelly Santa, Lulu Cruceanu y muchos más, que gracias al magnífico trabajo de Pepi Machauer, el encargado de maquillaje y peluquería, difícilmente podrían ser identificados.

Para transmitir la verosimilitud histórica en la pantalla era imprescindible realizar grabaciones en diferentes lugares del país. Por tanto, el equipo de actores y figurantes se desplaza a Băneasa, Măcin y Severin, ciudades que según pensaba Brezeanu le ayudarían a trasladar al espectador al campo de batalla. Dadas las carencias económicas y técnicas, al finalizar la grabación el revelado del filme con sus tres copias se realiza en París en el laboratorio Pathè-Frères (Mihail, 1967: 14).

La película se proyecta durante varias semanas y recibe muy buenas críticas en los periódicos, que alaban su valor educativo, la dura labor y los enormes sacrificios, pero también critican la interpretación de algunos actores y la inexperiencia de los figurantes, que a veces daban un toque cómico a escenas que trataban de ser trágicas.

En el periódico Viitorul del 7 de septiembre de 1912, Gr. Taușan realizaba el análisis de la película elogiando el tema puesto en escena, pero criticando duramente a los figurantes, tal como veremos a continuación (Mihail, 1967: 14):

¿Cómo no vamos a saludar con mucha satisfacción una película que nos presenta las escenas duras de la guerra, que nos ha transformado en lo que somos hoy, un país independiente? Y, ¿qué puede 
ser mejor y más noble que la reproducción evocadora de las luchas en las que los héroes que nos han hecho un país independiente mueren y vencen...? ¡Pero qué pena que tengamos que hacer algunas reservas cuando el corazón nos dice qué tenemos que elogiar! No nos podemos contener así. Creemos que la caballería compuesta de 10-20 caballos, los asaltos realizados por unos cuantos soldados, las poses muy teatreras, los muertos que ríen y los oficiales que miran como en un desfile los ataques, cuando sus vidas podrían estar en peligro, todo este humilde decorado y con una figuración inexperta, produce un efecto que golpea nuestras concepciones sobre la lucha que nos ha dado la independencia. [La traducción es nuestra].

Sin embargo, a pesar de sus debilidades o carencias, podemos afirmar que esta película tiene un valor incontestable y, por tanto, tenemos que considerarla como nuestro primer paso efectivo en el mundo del cine (Cantacuzino, 1965: 13-15).

En la actualidad, la película Independența României (1912) representa una de las únicas producciones rumanas de ese periodo que han perdurado en el tiempo ${ }^{1}$. Considerada una auténtica joya de la cinematografía rumana, sigue siendo una fuente de inspiración para los directores actuales. De hecho, en el año 2009, Nae Caranfil, prestigioso director de filme rumano, se inspiró en su tema central para realizar la película Restul e tăcere, ganadora de nueve premios Gopo ${ }^{2}$.

Después de este gran proyecto, Leon Popescu continúa grabando películas que cuentan con la colaboración de un elenco de grandes actores, dirigidos por Marioara Voiculescu, tal como afirma él mismo en una entrevista realizada para el periódico Rampa de 19 de abril de 1913 y que recopila en su libro Cantacuzino (1965: 15):

Tengo listo para lanzar en el mercado cinematográfico un total de diez mil metros de película, con eso espero emitir cada diez días un programa en que solo se emitan películas. Trabajamos sin parar, así que la cantidad de material crece considerablemente. El primer programa probablemente estará compuesto por un gran drama, Pacostea, con el guion del señor H.G. Lecca, y por una comedia llena de humor, Ghinionul, con el guion del señor Liviu Rebreanu. Luego se emitirán Amorul unei printese, Iancu Jianu, Cetatea Neamtului y otras muchas. [La traducción es nuestra].

Todas estas declaraciones nunca se harían realidad porque, desgraciadamente, en los cines la única película suya que se proyecta en la sala Clasic en el año 1913 es Urgia Cerească, película que no había anunciado en su entrevista, realizada en colaboración con C. Radovici.

\footnotetext{
${ }^{1}$ En la Archiva Nacional de Filme se pueden visionar algunas escenas que aún se conservan de esta película. Véase: http://www.anfcinemateca.ro/independenta-romaniei-1912 [consulta realizada 25/08/2016].

${ }^{2}$ El premio Gopo es un premio cinematográfico rumano otorgado por la Asociación para la Promoción del Filme Rumano.
} 
El año 1913 finaliza con la presentación de otra película, Oțelul Răzbună, que tiene como director y actor a Aristide Demetriade, que logra reunir, para realizar este filme, a algunos de los mejores actores de la época: Cinski, Grigorescu, Cosmin, Romano y Bulfinsky. El tema de la película fusiona el amor y la aventura, y recibe críticas favorables; tanto la pieza como la interpretación de los actores agradan al público y se considera que es el estímulo necesario para animarlos a ofrecer cosas nuevas.

Como hemos podido observar, los proyectos de los pioneros del filme rumano dependían siempre de una persona de la clase alta dispuesta a arriesgar capital en una empresa inestable. En esta relación de desigualdad, la decisión en la parte artística la tenía el inversor, que muchas veces carecía de dotes artísticas. A todo esto se le suma la inexperiencia de algunos actores y también la precariedad técnica; todos estos factores influyen en el resultado final: la película.

Pero a pesar de todas estas dificultades, paulatinamente la cinematografía o "proyecciones eléctricas", como la describían algunos periódicos, logró cautivar al público. Todo esto fue posible gracias a personas que consideraron desde un principio que el cine sería un gran descubrimiento.

\subsection{El cine rumano durante la Primera Guerra Mundial}

La Primera Guerra Mundial comenzó en el año 1914, pero durante los primeros dos años Rumanía fue un país neutral. Sin embargo, en 1916 el príncipe Ferdinand y el gobierno liderado por Ion Brătianu se unen al acuerdo de Antanta para apoyar la guerra de Francia, Rusia y Gran Bretaña. El objetivo de esta elección era la liberación de los territorios rumanos (Transilvania, Crișana, Maramureșul, Banatul y Bucovina) que en esos tiempos estaban bajo la dominación austro-húngara.

Fueron años cruciales en la historia de Rumanía, así como también en la historia del cine. En este periodo se proyectan películas con una técnica más avanzada, debutan nuevos actores, y la práctica de presentar y difundir los estrenos es cada día más innovadora, según afirma Cantacuzino (1965: 19).

Sin embargo, el desinterés de los inversores nacionales hacia el cine, dado que no les aportaba un beneficio rápido, influye disminuyendo la calidad de las películas rumanas en comparación con la de otros países.

Debido a estas circunstancias económicas y políticas, en este periodo se realiza un número reducido de películas y la producción se centra más en documentales y reportajes 
de actualidad. Uno de ellos es una filmación donde aparece el príncipe Ferdinand I y sus generales en el campo de batalla, y la reina María en los hospitales al lado de los heridos; secuencias que años más tarde servirán para la realización de la película Ecaterina Teodoroiu (1930).

A pesar de las condiciones poco favorables, la pasión por el cine permanece, y entre los años 1914-1916 se estrena un total de nueve películas. El género que predomina es la aventura o el drama, acorde a las circunstancias de esa época: Eminescu, Veronica, Creangă (O. Minar, 1914), Cetatea Neamţului (E. Garlenu, 1914), Dragoste la mănastire (G. Georgescu, 1914), Spionul (M. Voiculescu y C. Radovici, 1914), Șiretenie de fată (J. Jnovics, 1915), Intâlnire nocturnă (M. Garas, 1915), Detectivul (M. Voiculescu y C. Radovici, 1915), Viorica (M. Voiculescu y C. Radovici, 1915) y Fistic amorezat (M. Cassvan, 1916). Cabe destacar que las dos películas Șiretenie de fată (J. Jnovics, 1915) e Întâlnire nocturnă (M. Garas, 1915) son una coproducción rumano-húngara, las grabaciones se realizaron en Cluj (Rumanía) y la cinta de ambas se reveló en los laboratorios de Budapest (Hungría). El estreno de la segunda película se realizó simultáneamente el día 29 de noviembre del 1915 en Cluj y Budapest ${ }^{3}$. Es el inicio de las coproducciones internacionales, la colaboración con otros países que pueden aportar al cine rumano nuevos avances en técnica e interpretación.

Dado que las noticias sobre la guerra eran primordiales, se constituye el Servicio foto-cinematográfico de las fuerzas armadas. Sin embargo, este servicio no disponía de ningún tipo de dispositivo para realizar las filmaciones, tal como comentaba Jean Mihail (1967: 24) en su libro Filmul Românesc de Altădată:

\footnotetext{
Este servicio no tenía ningún tipo de aparato, así que hubiera sido difícil trabajar algo. Afortunadamente, existía en Braila el laboratorio "Lumina", inaugurado por Tudor Posmantir en el año 1914, y que tenía dos aparatos para filmar. Cuando Bucarest fue ocupado por los alemanes, Posmantir envió todos los aparatos a Barlad y luego a Iasi porque lo reclutaron para la dirección general de aviación. Cuando lo transfirieron al Gran Cartier General puso los aparatos a disposición de la armada y de este modo se pudo organizar un servicio cinematográfico efectivo. En el mismo sitio se encontraba también el operario Constantin Ivanovici. Los dos operarios grabaron durante la guerra, mostrando en imágenes los momentos más importantes y difíciles de la misma. De los miles de metros grabados se han conservado pocos fragmentos [...]. Es este el resultado del desinterés que manifestaba la actividad cinematográfica en esos tiempos... [La traducción es nuestra].
}

\footnotetext{
${ }^{3}$ http://www.istoriafilmuluiromanesc.ro/filme-romanesti $\sim 6$ [consulta realizada el 17/08/2016].
} 
A pesar de las coyunturas se filmaba mucho, aunque las grabaciones consistían en escenas bélicas, y constantemente los técnicos estaban expuestos al peligro, pero estas circunstancias contribuyeron al progreso profesional de tal forma que entre 1916-1919 las grabaciones mejoraron su calidad, a pesar de las necesidades técnicas que seguían afrontando los profesionales.

La Primera Guerra Mundial no detiene el interés por este arte; más bien al contrario, ya que este demuestra el lugar importante que había empezado a ocupar en la sociedad y los sacrificios que se realizan con el fin de hacer perdurar su existencia. Por otra parte, como veremos en los siguientes capítulos, la aparición del cine contribuye a la creación de nuevas profesiones afines al ámbito cinematográfico, que aportaron también beneficios económicos a un país que había sufrido pérdidas considerables durante ese periodo.

\subsection{El cine rumano entre las dos guerras mundiales}

La época de entreguerras designa el intervalo de 21 años entre las dos guerras mundiales (1918-1939). Se trata de un periodo preocupante, en que a pesar de la situación aparentemente pacífica, los conflictos estaban en estado latente. Las consecuencias de la Primera Guerra Mundial habían afectado al orden político, social y cultural del mundo entero, incluso en los países que no habían participado directamente en este conflicto. Se forman nuevos estados, otros antiguos desaparecen o se modifican las fronteras, aparecen nuevas organizaciones internacionales, nuevas ideas políticas y económicas.

Todos esos cambios afectan también al mundo del cine, que durante este periodo experimentará nuevas técnicas y avances inimaginables. No obstante, este progreso es diferente de un país a otro.

En el caso de Rumanía, la recuperación posbélica fue lenta, y su situación económica y política influyó también en el desarrollo del cine. La falta de capital y los pocos inversores que percibían beneficios en este tipo de proyectos transciende en la calidad técnica y profesional de este arte. La producción de una película implicaba un proceso lento, con una rentabilidad inestable. Por tanto, "los nuevos ricos de posguerra", como los describe Mihail (1967: 27), artista y apasionado cinéfilo de esa época, no estaban dispuestos a arriesgar capital:

En todos estos negocios, la primera condición era ganar dinero cuanto antes y de forma fácil. Con inversiones pequeñas y pocos riesgos. 
Por supuesto, la creación de una industria de películas rumanas no era un negocio que pudiera satisfacer tales criterios.

Primero se necesitaba construir y equipar estudios y laboratorios modernos al mismo nivel que los del extranjero. Luego, sería necesario formar especialistas en todos los ámbitos técnicos cinematográficos. Por lo que también sería necesario contratar desde el extranjero a personas capaces de instruir a nuestros jóvenes. [...] Inversiones, inversiones, espera... ¿A quién le podían interesar estas perspectivas? [La traducción es nuestra].

Por otra parte, el Estado ignoraba el valor educativo y la capacidad del cine de promocionar la cultura y la belleza de Rumanía; lo consideraba una mercancía y le aplicaba más impuestos (Mihail, 1967: 29). En estas circunstancias, con pocas inversiones privadas y nulas por parte del estado, el cine logra sostenerse y progresar gracias a los pocos entusiastas y artistas que, en muchas ocasiones, como en el caso de los actores, participaban en las películas sin percibir ningún tipo de remuneración; solamente lo hacían, y nunca mejor dicho, por amor al arte. En cuanto a la parte técnica, con medios rudimentarios, amigos y compañeros de Mihail (1967: 35), como por ejemplo T. Posmantir, C. Ivanovici, E. Vasilescu, I. Cosma, Gh. Ionescu-Cioc, N. Berbelian, V. Gociu, A. Petrescu, etc. realizarán la mayoría de las películas artísticas, documentales e incluso algunos dibujos animados en ese periodo de entreguerras:

Todas estas personas han luchado y han sufrido con perseverancia, con amor y con pasión para crear el cine rumano. Y, a pesar de las dificultades, se puede decir que lo han conseguido. El número bastante importante de filmaciones de esos años es la prueba de la existencia en nuestro país de un verdadero movimiento cinematográfico. Sus resultados han tenido eco en el extranjero sobre el arte y la belleza de nuestro país. ¡Y, por tanto, sus sacrificios no tienen que caer en el olvido! [La traducción es nuestra].

Con pocos recursos materiales, pero cargados de energía e ilusiones, los profesionales del cine lograron filmar en el periodo comprendido entre 1920 y 1930 un número considerable de películas $(53)^{4}$, que presentamos a continuación:

\begin{tabular}{|c|c|c|c|}
\hline AÑO & GÉNERO & TÍTULO & DIRECTOR \\
\hline 1920 & Aventura, Drama & Pe valurile fericirii & Dolly A. Sigetti \\
\hline
\end{tabular}

${ }^{4}$ Véase:https://ro.wikipedia.org/wiki/Lista_filmelor_artistice_rom\%C3\%A2ne\%C8\%99ti_din_perioada_1911\%E2\%80\%931947 [consulta realizada el 28/08/2016]. 
Capítulo 1: Historia del cine rumano

\begin{tabular}{|c|c|c|c|}
\hline 1920 & Drama, Aventura & Din grozaviile lumii & Eugen Jancovics \\
\hline 1920 & Drama & Cele două orfeline & Eugen Jancovics \\
\hline 1921 & Animación & Păcală pe Lună & Aurel Petrescu \\
\hline 1922 & Comedia, Musical & Vanatorul de dolari & Coloman Perenyi \\
\hline 1923 & $\begin{array}{c}\text { Aventura, Comedia, } \\
\text { Drama }\end{array}$ & Țigăncușa de la iatac & $\begin{array}{l}\text { Alfred Halm (asistente } \\
\text { técnico Jean Mihail) }\end{array}$ \\
\hline 1923 & $\begin{array}{l}\text { Documentario, } \\
\text { Corto metraje }\end{array}$ & D-ale zilei I & Aurel Petrescu \\
\hline 1923 & $\begin{array}{l}\text { Documentario, } \\
\text { Corto metraje }\end{array}$ & D-ale zilei II & Aurel Petrescu \\
\hline 1923 & Comedia & Bărbosul & Geza Salgo \\
\hline 1924 & Drama & Păcat & Jean Mihail \\
\hline 1924 & Drama, Histórico & Manasse & Jean Mihail \\
\hline 1924 & Comedia & $\begin{array}{c}\text { Peripețiile călătoriei lui Rigadin } \\
\text { de la Paris la București }\end{array}$ & Eftimie Vasilescu \\
\hline 1924 & Comedia & Milionar pentru o zi & Jean Georgescu \\
\hline 1925 & Comedia, Aventura & Năbădăile Cleopatrei & Ion Șahighian \\
\hline 1925 & $\begin{array}{l}\text { Dibujos animados } \\
\text { humorísticos }\end{array}$ & Păcală amorezat & Aurel Petrescu \\
\hline 1925 & $\begin{array}{c}\text { Documentario, } \\
\text { Histórico, Aventura }\end{array}$ & Datorie și sacrificiu & Ion Şahighian \\
\hline 1925 & Drama, Romántico & Legenda celor două cruci & Ghiță Popescu \\
\hline 1925 & Comedia & $\begin{array}{c}\text { Coana Sița a lui Nea Nae } \\
\text { parlagiul }\end{array}$ & Ghiță Popescu \\
\hline 1926 & Comedia & Motanul în lună & Aurel Petrescu \\
\hline 1926 & $\begin{array}{l}\text { Dibujos animados } \\
\text { humorísticos }\end{array}$ & Păcală şi Tândală la București & Aurel Petrescu \\
\hline 1926 & $\begin{array}{l}\text { Dibujos animados } \\
\text { humorísticos }\end{array}$ & $\begin{array}{l}\text { D-ale zilei III: Politică-Modă- } \\
\quad \text { Finanțe-Import-Export }\end{array}$ & Aurel Petrescu \\
\hline 1926 & Drama, Aventura & Cererea în căsătorie & Jean Mihail \\
\hline 1926 & Drama & Dinu şi Rodica & Aurel Petrescu \\
\hline 1926 & Acción & Jandarmii & Aurel Petrescu \\
\hline
\end{tabular}


Capítulo 1: Historia del cine rumano

\begin{tabular}{|c|c|c|c|}
\hline 1927 & $\begin{array}{c}\text { Comedia, Aventura, } \\
\text { Drama }\end{array}$ & Iadeș & Horia Igiroșanu \\
\hline 1927 & Drama & Vitejii neamului & Ghiță Popescu \\
\hline 1927 & Drama, Aventura & Lia & Jean Mihail \\
\hline 1927 & Drama & Năpasta & Ghiță Popescu \\
\hline 1927 & Comedia & Ginere fără voie & $\begin{array}{c}\text { George Theodorescu y Jean } \\
\text { Vulpescu }\end{array}$ \\
\hline 1927 & Comedia & Nea Ghiță Cocoloș la Moși & Horia Igiroșanu \\
\hline 1927 & $\begin{array}{l}\text { Dibujos animados } \\
\text { humorísticos }\end{array}$ & D-ale zilei $I V$ & Aurel Petrescu \\
\hline 1927 & $\begin{array}{l}\text { Dibujos animados } \\
\text { humorísticos }\end{array}$ & Proverbe ilustrate & Aurel Petrescu \\
\hline 1927 & $\begin{array}{l}\text { Dibujos animados } \\
\text { humorísticos }\end{array}$ & Capete, figuri, politice & Aurel Petrescu \\
\hline 1927 & $\begin{array}{l}\text { Dibujos animados } \\
\text { humorísticos }\end{array}$ & Bărbatul de la Adam până astăzi & Aurel Petrescu \\
\hline 1927 & $\begin{array}{l}\text { Dibujos animados } \\
\text { humorísticos }\end{array}$ & $\begin{array}{c}\text { Femeia de la Eva până în zilele } \\
\text { noastre }\end{array}$ & Aurel Petrescu \\
\hline 1927 & $\begin{array}{c}\text { Animación, } \\
\text { Aventura, Comedia }\end{array}$ & Haplea & Marin Iorda \\
\hline 1927 & Drama, Acción & Drumul iertării & Fernand Gabriel Roșca \\
\hline 1927 & Terror & Strigoii & Dimitrie Mărculescu \\
\hline 1928 & Comedia, Aventura & Lache în harem & $\begin{array}{l}\text { Marcel Blossoms și Micu } \\
\text { Kellerman }\end{array}$ \\
\hline 1928 & Comedia & Vagabonzii de la Cărăbuș & Eftimie Vasilescu și Ion Cosma \\
\hline 1928 & Aventura, Drama & Iancu Jianu & Horia Igiroșanu \\
\hline 1928 & Drama & Povara & Jean Mihail \\
\hline 1928 & Drama, Romántico & Simfonia Dragostei & Ion Șahighian \\
\hline 1928 & Aventura, Comedia & Maiorul Mura & Ion Timuș \\
\hline 1928 & $\begin{array}{c}\text { Comedia, Musical, } \\
\text { Aventura }\end{array}$ & Așa e viata & Marin Iorda \\
\hline 1929 & $\begin{array}{l}\text { Cortometraje- } \\
\text { película publicitaria }\end{array}$ & Poveste de iubire & Jean Georgescu \\
\hline
\end{tabular}


Capítulo 1: Historia del cine rumano

\begin{tabular}{|c|c|c|c|}
\hline 1929 & Aventura & Război fără arme & Jean Georgescu \\
\hline 1929 & $\begin{array}{c}\text { Aventura, Histórico, } \\
\text { Drama }\end{array}$ & Haiducii & Horia Igiroșanu \\
\hline 1929 & Aventura, Drama & Venea o moară pe Siret & Martin Berger \\
\hline 1929 & Drama, Histórico & Piatra lui Osman (sin acabar) & $\begin{array}{c}\text { Los actores mismos han dirigido } \\
\text { la película }\end{array}$ \\
\hline 1929 & Comedia, Aventura & Guguță la Ștrand & Marcel Blossoms \\
\hline 1929 & Comedia & Gogulică C.F.R. (sin acabar) & Cornel Dumitrescu \\
\hline 1930 & Drama & Viața începe mâine & Jean Mihail \\
\hline
\end{tabular}

Tabla 1. Lista de películas rumanas realizadas entre los años 1920-1930

El año 1921 fue un año representativo en la historia del cine rumano, ya que este marcó el inicio del dibujo animado concebido por Aurel Petrescu, y se proyectó la primera animación rumana (Păcală pe lună), plasmada en forma de película. Pionero en este género, Petrescu realizó un número considerable de dibujos animados, de los cuales la Archiva Nacional de Filme (ANF) conserva un álbum con 80 fotogramas, dado que las películas se perdieron.

Otro pilar importante de esta época es Jean Mihail, uno de los precursores del cinematógrafo rumano, instruido profesionalmente en Viena por Max Neufeld y Eduard Seckler hasta el año 1923, cuando regresó a Rumanía. Varios años atrás el mismo Mihail (1967: 27) contó cómo inició "la aventura cinematográfica” en su propio país:

\footnotetext{
Y cuando volví a mi país, en la primavera del año 1923, pensé que era natural continuar esta realidad, que tenía que hacer filmes en Bucarest en un estudio parecido al de Viena.

Qué joven, qué entusiasta y qué ingenuo era...

No me imaginaba que pasaría un cuarto de siglo para poder cumplir mis sueños de entonces... [La traducción es nuestra].
}

En el año 1927, bajo la dirección de Mircea Filloti y con la financiación de un empresario alemán, que quería complacer a su esposa actriz y convertirla en estrella de cine, Mihail logra realizar la película Lia. Un año más tarde y con los mismos patrones de financiación graba la película Povara. 
Otros directores, como Marcel Blossoms y Micu Kellerman, realizaron a petición de una empresa comercial la película Lache în harem (1927).

En varias ocasiones, los técnicos se asociaban en una cooperativa, de modo que cada uno aportaba algo de lo que disponía: laboratorio, guion, cámara para filmar, etc. Por otra parte, los actores participaban gratuitamente, impulsados por el deseo de convertirse en estrellas de cine. De este modo se graban películas como: Păcat (J. Mihail, 1924), Manasse (J. Mihail, 1925), Legenda celor două cruci (G. Popescu, 1925), Vitejii neamului (G. Popescu, 1926), Năpasta (G. Popescu, 1927), Maiorul Mura (I. Timus, 1928).

Vistas las coyunturas socio-económicas, son de agradecer y respetar los esfuerzos y la capacidad creativa de todos estos profesionales, que a pesar de las dificultades no renunciaron a su pasión y al deseo de posicionar el cine rumano al mismo nivel que el de otros países europeos, y lograron escribir en la historia del cinematógrafo rumano una página memorable.

Los años 1930-1939 marcaron otra etapa en la evolución del cine rumano; lo que se consideraba un avance mundial inimaginable - la aparición del cine sonoro- para los profesionales rumanos representaba una dificultad añadida al proceso de grabación, bastante limitado por las restricciones técnicas. A todo esto se le asocia el tema artístico, dado que el estilo interpretativo de los actores sufrió también alteraciones evaluativas a nivel de expresión artística; muchos de los que actuaban en el cine mudo dejaron de actuar debido a una mala dicción o a una voz estridente.

Las nuevas condiciones de trabajo exigen nuevas técnicas y dispositivos más silenciosos para proporcionar un resultado impecable, materiales de los que, según Mihail (1967: 149), carecían los profesionales del cine rumano:

Por falta de un estudio habíamos encontrado una solución alternativa: grabar en casas con mucho espacio o en el teatro. Ahora había aparecido una nueva condición: este espacio tenía que estar insonorizado, o sea, perfectamente aislado de todos los ruidos exteriores, que arriesgaban devenir, en la banda sonora, parásitos sonoros del diálogo del filme. Tal exigencia eliminaba, por supuesto, todas las soluciones improvisadas hasta entonces, porque nos obligaba a adecuar el sitio de grabación de un modo especial, con un gasto que — en las nuevas condiciones - era mucho más elevado que construir un estudio "mudo". Al mismo tiempo, nuestros aparatos pasados de moda y rudimentarios no nos servían. La película sonora no se podía realizar con los aparatos que nos habían servido para realizar nuestras pobres "películas artísticas”, porque hacían un ruido de molinillo 
estropeado. Para la película sonora nos hacían falta aparatos insonoros. Pero su coste era exorbitante, sobrepasaba él solo el presupuesto de la película más cara realizada hasta entonces en Rumanía. ¿En estas condiciones podías proponerle a alguien la realización de una película? Habría pensado que estabas loco. [La traducción es nuestra].

Por tanto, después del año 1930 se percibió un gran descenso en la producción de películas rumanas, de modo que hasta el año 1939 se realizaron solamente 16 películas. La mayoría son "versiones rumanas" de películas extranjeras realizadas en los estudios de París, Praga o Budapest, en las que se empleaba un número reducido de técnicos y actores rumanos para traducir, representar y grabar los diálogos. De este modo, se realizaron películas como Parada Paramont (Charles de Rochefort, 1931) y Televiziune (J. Salvadori, 1931) en París, o como Fum (desconocido, 1931), Trenul fantomă (J. Mihail, 1933), Prima dragoste (J. Mihail, 1934) y Suflete în furtună (desconocido,1934) en Budapest ${ }^{5}$.

Otra solución para este tipo de películas podría haber sido la subtitulación en la parte baja de la imagen de las películas, pero esta técnica habría podido distraer al espectador, dado que su atención se habría distribuido simultáneamente en más direcciones (Mihail, 1967: 155). Sin embargo, los temores de los productores se disiparon rápidamente, puesto que el espectador se adaptó fácilmente a este tipo de técnica. Con la aparición del cine sonoro, aparece también la necesidad de la traducción de las películas extranjeras y, por tanto, la necesidad de la traducción audiovisual.

No obstante, a pesar del pesimismo y la preocupación de los profesionales, el cine sonoro sustituía paulatinamente al cine mudo. Los espectadores se habituaban a este nuevo invento y los cinematógrafos atraían a nuevos admiradores.

La primera película sonora integral autóctona, realizada por rumanos, que ejercían múltiples funciones en ese proyecto, es Bing Bang (1935). Los aparatos de sonido que se habían utilizado para la grabación habían sido construidos por el ingeniero Iulian Gartenberg-Argani, que también era el productor ejecutivo. Stroe y Vasilescu eran los actores, pero también directores y guionistas. Con una historia simple, humana y muy cercana a la realidad (trataba sobre dos desempleados que acababan siendo millonarios), la película tuvo un gran éxito y logró permanecer en los cines varios meses. Por tanto, a pesar de las limitaciones técnicas, la falta de presupuesto y de interés por parte del

\footnotetext{
${ }^{5}$ Véase: https://ro.wikipedia.org/wiki/Filmul_rom\%C3\%A2nesc_p\%C3\%A2n\%C4\%83_\%C3\%AEn_1948 [consulta realizada el 28/08/2016].
} 
gobierno para el arte cinematográfico, gracias a las personas que creían realmente en su perpetuidad, el cine rumano había conseguido mantener el ritmo del avance europeo.

El año 1935 marca un avance en la historia del cine rumano, pero además aporta el sustento de la clase política en los proyectos cinematográficos. La influencia que había adquirido el cine en los medios de comunicación y en el público fue vista por los políticos como una modalidad discreta pero efectiva para el adoctrinamiento de las masas ${ }^{6}$. Por tanto, se publicó la ley para la constitución del Fondo Nacional de la Cinematografía, que suponía la percepción de una tasa para poder crear posteriormente una base material para la producción cinematográfica rumana (estudios cinematográficos, laboratorios, aparatos, etc.) o la financiación de futuros proyectos de este ámbito. De este modo, entre los años 1936-1937 se construyó un laboratorio dotado con aparatos modernos, un estudio, y empezaron a emitirse los diarios de actualidades. Eran progresos considerables para ese ámbito, que se había conformado y había perdurado varios años gracias a los pioneros animados por la pasión y la ilusión. Al mismo tiempo se constituyó el Oficio Nacional Cinematográfico bajo la dirección del crítico de cine D. I. Suchianu, que se inició con la realización de documentales y un diario de actualidades periódico. Uno de estos documentales, Țara Moților, fue galardonado con un premio del Festival de Venecia en el año 1938.

Lentamente, el cinematógrafo rumano alcanza el reconocimiento social y político que tanto había anhelado y los profesionales finalmente se benefician de una organización administrativa y de un respaldo político pese a sus intereses ocultos.

\subsection{El cine rumano durante la Segunda Guerra Mundial}

De forma activa o pasiva, casi todos los países se habían visto implicados o afectados por la Segunda Guerra Mundial, que había supuesto un enfrentamiento en una escala destructiva sin precedentes. La capacidad ofensiva de las nuevas armas y tácticas de guerra había dejado un balance inimaginable de pérdidas humanas y materiales. Este contexto mundial dificultó la realización de muchas películas, pero marcó un nuevo progreso en la técnica del cinematógrafo rumano. En este periodo los fondos del estado se designaban a la guerra y las únicas que recibían subvenciones eran las películas con tema propagandístico sobre la guerra. Con influencias alemanas, pero realizadas en rumano, películas documentales como România în lupta contra bolșevismului (P.

${ }^{6}$ Ibíd. 5. 
Călinescu, 1941), Imprumutul Reîntregirii (A. Morrin, 1941) y Escadrila Albă (A. Morrin, 1942) informaban a la población sobre el inicio de la guerra en el frente del Este. Las imágenes que se filmaban del frente se emitían posteriormente en los diarios de guerra que se iniciaron durante la conflagración. Por otra parte, a finales de los años 1940 se presentó otra limitación para los cineastas rumanos: la implicación política en todas las artes, implícitamente en el cine, y la obligación de exponer solamente temas favorables al régimen comunista. La clase política se apoderó lentamente de ese ámbito, cuya continuidad durante muchas décadas lograron mantener los profesionales a base de inmensos sacrificios.

El número de películas que se materializa en este periodo es reducido, dado que tanto en el plano social como económico la atención se centraba en los sucesos bélicos. Algunas de las películas artísticas que se grabaron durante el periodo comprendido entre 1939 y 1945 son:

- Ziua cumpătării (T. Râpeanu, 1942), documental cinematográfico realizado a petición del Ministerio de Propaganda Nacional y basado en una campaña de sensibilización a la población sin iniciativa gubernamental para inculcar la austeridad e instaurar el 22 de febrero de 1942 como el Día de la Sensatez.

- Odessa în flăcări (coproducción rumano-italiana, 1942), película encontrada por casualidad en el año 2005 en la Archiva Cinecitta de Roma. Se filmó en Rumanía con actores rumanos, pero el idioma utilizado era el italiano, tal como los nombres de los personajes. El tema era simple, pero al no concordar con los criterios de la clase política comunista, varios años más tarde se prohíbe su proyección ${ }^{7}$.

- Cetatea Fermecată (I. Sava, 1945), película que abordaba un tema fantástico y de aventura sobre dos hermanos que iban a la búsqueda de una ciudad ilusoria.

Indudablemente, la película más importante de este periodo es $O$ noapte furtunoasă (J. Georgescu, 1942), adaptación de una pieza de teatro de uno de los clásicos más distinguidos de la literatura rumana, I. L. Caragiale. La razón por la que destaca entre las demás no es principalmente por el tema que trata, sino por el esfuerzo que supuso su realización por parte de los profesionales en las difíciles coyunturas para filmar (muchas

\footnotetext{
${ }^{7}$ Véase: http://www.evz.ro/odessa-in-flacari-propaganda-pana-in-panzele-albe-933164.html [consulta realizada el 01/09/20016].
} 
veces grababan camuflados) y el resultado, que marca un antes y un después en la historia del cine rumano.

La película se filmó en un pequeño estudio de la Organización Nacional Cinematográfica (ONC), que puso a disposición del director todos los medios necesarios para una buena realización artística: reflectores, cables, paneles de decorado, etc. El equipo de profesionales estaba formado también por algunos de los mejores expertos nacionales e internacionales. De la música se encargaba el conocido compositor Paul Constantinescu, el decorado y el vestuario eran obra del caricaturista Aurel Jiquidi, los actores eran algunos de los mejores de aquellos tiempos. Del extranjero se habían contratado varios técnicos como, por ejemplo, para la imagen el técnico francés Gérard Perrin, para montar el decorado el arquitecto Stefan Norris, y para el maquillaje el matrimonio alemán Stuhr. Bajo la dirección de Jean Georgescu, el objetivo del filme era el de realizar una combinación perfecta entre la fantasía y la realidad, y por ese motivo el director supervisaba cualquier detalle interpretativo de los actores para reconstruir íntegramente la atmósfera que presentaba Caragiale en su pieza (Mihail, 1967: 120-122).

El patrocinio de la ONC en ese proyecto aportó al equipo rumano sustento internacional para perfeccionar las secciones que aún carecían de profesionales. Se puede decir que es la primera vez, después de tantos años de experimentos y sacrificios, que a un equipo rumano se le brinda la posibilidad de ejercer su profesión en condiciones habituales para la grabación de una película (un estudio, decorados, etc.) y con técnica moderna. La película se estrenó el 22 de marzo de 1943 en el cinematógrafo Aro (Bucarest), y se presentó una vez más en el año 1953 para conmemorar el centenario de Caragiale. Posteriormente, el régimen comunista censuró gran parte de las escenas, que estimó como no recomendables para el público rumano.

Varios años más tarde, en su artículo De la teatru la film, publicado en el libro Contribuții la istoria cinematografiei în România 1896-1848 (1971), Racoviceanu (1971: 144-145) analizaba el estilo y la contribución de esta película al avance de la historia del cine rumano:

El autor había demostrado una gran iniciativa; no había copiado simplemente las escenas en la película, o los actos de la pieza, sino que cogió la pieza de Caragiale como punta de partida y logró con libertad creativa transformarla en un nuevo producto, una película llena de frescura y resplandor cinematográfico. 
El espectáculo O noapte furtunoasă estimula al público en la misma medida, en todos los elementos cinematográficos específicos: imagen, sonido, música y diálogo. [...] En opinión de Georgescu, $O$ noapte furtunoasă no es solamente una comedia, sino una tragicomedia, porque bajo los aspectos cómicos existe un subtexto trágico, generado por la mentalidad de los personajes satirizados, contextualizado en su lugar en sociedad. [...] En cuanto a la interpretación de los actores de esta película, esta constituye una demonstración de cómo se puede realizar una buena distribución. La adherencia tipológica es perfecta, la réplica de Caragiale con todo su sabor, con toda la sátira realizada mediante el lenguaje pedante de los personajes, encuentra - gracias a los intérpretesuna feliz cita con el cinematógrafo. [La traducción es nuestra].

A pesar de los momentos difíciles de esta época y del escaso número de películas que se realizaron, el cine rumano logró marcar un progreso significativo en la ejecución técnica y artística del filme, que constituiría una referencia para las futuras generaciones de cinéfilos. Gracias a todos estos profesionales hemos podido observar que la escasez económica se complementaba siempre con la pasión y el sacrificio; como característica general podríamos decir que todas las películas realizadas hasta esta fecha tenían como base un denominador común e imprescindible: la improvisación técnica y la perseverancia.

\subsection{El cine rumano después de la Segunda Guerra Mundial}

La Segunda Guerra Mundial tuvo grandes y nefastas consecuencias para Rumanía. A los perjuicios materiales y humanos se les añadió la pérdida de territorio; en consecuencia, a finales de esta guerra, Rusia se apoderó definitivamente de dos partes importantes pertenecientes a nuestro país: Basarabia y Bucovina. En el plano político, en un tiempo relativamente corto, Rumanía experimentó también varias formas de gobierno, pasó de la monarquía a la dictadura militar, y en el año 1948 se instauró el comunismo, que duró hasta el año 1989. Todos estos factores trascendieron también en el área cinematográfica - tanto en los temas que se van a proyectar en el futuro, como en los trámites administrativos-.

La instauración del comunismo en 1948 supuso la nacionalización de todas las empresas industriales, bancarias, de seguros, mineras y de transporte, etc. Tras la publicación de la ley número 119 de 11 de junio de 1948, se pasaba de la economía capitalista a la economía centralizada. La ley estipulaba también algunas condiciones de indemnización para los anteriores propietarios que nunca se concretaron, dado que no se 
trataba de una ley de "nacionalización”, sino más bien de una ley de "expropiación" de la propiedad $\operatorname{privada}^{8}$.

Por su parte, la cinematografía rumana no aportaba grandes dotes al Estado. $\mathrm{Su}$ situación de precariedad, como hemos podido ver en los capítulos anteriores, no la posicionaba entre los ámbitos más prósperos económicamente. En ese periodo existía solamente un estudio cinematográfico, dotado con un plató de $200 \mathrm{~m}^{2}$, unas cuantas cabinas de montaje, una instalación de grabación y se conservaba también un modesto laboratorio que se encargaba de la producción nacional e internacional.

Considerando la escasez de estos suministros técnicos y materiales, el Estado consideró pertinente construir un nuevo complejo cinematográfico correspondiente a la nueva coyuntura histórica. En 1949 el Estado anunciaba y disponía la construcción de un nuevo y amplio Centro Cinematográfico, cuya construcción se iniciaría el siguiente año en Buftea (Bucarest); y como solución transitoria se construiría uno más pequeño en el Complejo Floreasca (Bucarest), seguido por otro, Tomis (Bucarest), para poder asegurar provisionalmente las condiciones necesarias mínimas para la producción del cine rumano.

Los estudios precisaban también de dispositivos adecuados y modernos y, en consecuencia, se dispuso su realización en I. S. Tehnochin, una fábrica especializada en la producción de aparatos de proyección, amplificadores, paneles de mando, altavoces, reflectores, etc. Diez años más tarde, en 1959, el estudio Buftea finalizaba su construcción y sería uno de los estudios más importantes y modernos de Rumanía (M. Gheorghiu, C. Pătrăscoiu, 1976: 32). Por otra parte, según afirmaba Mihai Duță (1976: 38), entre los años 1949 y 1950 se habían importado 1000 aparatos de proyección y 100 caravanas cinematográficas, que constituirán el principio de un amplio e importante despliegue para llevar el filme también al medio rural.

Paulatinamente, el cinematógrafo rumano se iba adaptando y se acondicionaba con tecnología adecuada a la demanda de los profesionales, y se apreciaba un progreso en este sector similar a los demás países europeos. El sueño y el sacrificio de muchos profesionales a lo largo de la historia cinematográfica quedarán reflejados en la realidad en este periodo.

No obstante, esta evolución tecnológica basada en las subvenciones del Estado supondrá un valioso coste para los cineastas: la libertad ideológica. El socialismo utilizará el cine no como una modalidad amena para proporcionar entretenimiento al público, sino

\footnotetext{
${ }^{8}$ Véase: http://enciclopediaromaniei.ro/wiki/Legea_Na\%C5\%A3ionaliz\%C4\%83rii_din_1948 [consulta realizada el 28/08/2016].
} 
como una nueva forma de controlar y exponer a las masas sus grandiosos avances históricos, económicos y sociales, tal como afirmaba Caterina Oproiu (1976: 11):

\footnotetext{
"El filme es un arma" era uno de los eslóganes de aquel tiempo, y no se trataba de un simple dicho. La nueva sociedad que se construía, las nuevas clases que tenían el poder, veían en el filme, como en cualquier otro arte, un instrumento de influencia ideológica. Sin disimular, declarado como una necesidad, como un imperativo, el filme hacía propaganda. No siempre la hacía con sutileza, no siempre la hacía con convicción, pero el filme autóctono, evidentemente, estaba predestinado a otro propósito, diferente al que había tenido hasta ahora. En una época donde "si no estás con nosotros, estás en nuestra contra", el filme "tenía que militar", tenía que enseñar cómo se prepara la lucha de clases, cómo las clases desposeídas intentaban inútilmente pararlos. [La traducción es nuestra].
}

Por tanto, el progreso tecnológico traerá muchas películas autóctonas, pero sus temas estarán estrictamente vinculados al progreso del socialismo, a la lucha para consolidar el proletariado; los personajes simbolizarán la perpetua lucha entre la nueva clase proletaria y la antigua burguesía. El intelectual arcaico ejercía de espía para el enemigo y estaba totalmente opuesto al nuevo tipo de intelectual que brotaba del socialismo, tal como se mostraba en la película Viața învinge (D. Negreanu, 1951); los antiguos explotadores sembraban la desconfianza o creaban nuevas redes de espionaje, como por ejemplo en las películas Alarmă în munţi (D. Negreanu, 1955) y Vultur 101 (A. Călărașu, 1957).

Cautelosamente, se presentaban también comedias, en las que a través del sarcasmo y la hilaridad se acentuaban las críticas hacia la burguesía y se remarcaba su discrepancia con el proletariado. En este contexto se proyectaba la película Directorul nostru (J. Georgescu, 1955), que reflejaba el burocratismo representado por un director con una actitud despectiva hacia sus subordinados, que ponía de manifiesto una vez más el paralelismo entre las dos clases sociales empleando el humor. Sin embargo, las críticas que recibió fueron intransigentes, ya que se objetaba que no se ilustraba la esencia general positiva del modo en que la burguesía había perdido el poder (Caterina Oproiu, 1976: 13). Posteriormente, le seguirán otras del mismo género, como Pe răspunderea mea (Paul Călinescu, 1956) o Alo?... Ați greșit numărul (A. Călăraşu, 1958), pero se abstendrán de presentar implicaciones sociales profundas. El público se mostraba entusiasmado con el cambio, dado que estaba saturado de un repertorio cinematográfico excesivamente severo, repleto de temas de guerra y de lucha de clases que desestimaban el entretenimiento. 
Otro tema reflejado en las películas de esta época era la historia del pueblo rumano, su lucha por la libertad y dignidad social. Insuficiente en el filme de actualidad (sea por falta de temas, sea por falta de exención) la cinematografía rumana descubrirá el filón histórico como medio indirecto para contemplar un problema mayor, indagando en el pasado las correspondencias de una actualidad doctrinaria. El filme histórico se concibió como un acto de cultura y una escuela de patriotismo basado en una rigurosa documentación para describir los sucesos de un pueblo que se había visto obligado a vivir y sobrevivir a muchas dificultades. Sobre este tema versaban películas como Lupeni'29 (M. Drăgan, 1963) y Tudor (L. Bratu, 1963), que personificaban la historia para intentar afrontar el presente. Para ser más específicos y exhaustivos, hemos elaborado la siguiente lista las películas (58) que se proyectaron en esa etapa:

\begin{tabular}{|c|c|c|c|}
\hline AÑO & GÉNERO & TÍTULO & DIRECTOR \\
\hline 1946 & $\begin{array}{l}\text { Comedia, } \\
\text { Romántico }\end{array}$ & Visul unei nopți de iarnă & Jean Georgescu \\
\hline 1946 & Musical & Allo București & Mircea Botez \\
\hline 1946 & Aventura & Furtul din Arizona & Mircea Botez \\
\hline 1946 & Romántico & Două lumi și o dragoste & Victor Gertler \\
\hline 1946 & $\begin{array}{l}\text { Comedia, } \\
\text { Romántico }\end{array}$ & Pădurea îndrăgostiților & Cornel Dumitrescu \\
\hline 1946 & Dibujos animados & $\begin{array}{c}\text { Pățania lui Ion (poveste tristă dar } \\
\text { adevărată) }\end{array}$ & Jean Moraru \\
\hline 1949 & Drama, Aventura & Răsună valea & Paul Călinescu \\
\hline 1949 & Drama, Documental & $\begin{array}{c}\text { Scrisoarea lui Ion Marin către } \\
\text {, Scânteia” }\end{array}$ & Victor Iliu \\
\hline 1950 & Comedia, Aventura & Bulevardul 'Fluiera Vântu' & Jean Mihail \\
\hline 1951 & Drama, Histórico & In sat la noi & Jean Georgescu, Victor Iliu \\
\hline 1951 & Drama, Aventura & Viața învinge & Dinu Negreanu \\
\hline 1952 & Comedia & Arendaşul român & Jean Georgescu \\
\hline 1952 & Drama, Histórico & Mitrea Cocor & Marietta Sadova, Victor Iliu \\
\hline 1952 & Comedia & Vizită & Jean Georgescu \\
\hline 1953 & Drama, Histórico & Nepoții gornistului & Dinu Negreanu \\
\hline
\end{tabular}


Capítulo 1: Historia del cine rumano

\begin{tabular}{|c|c|c|c|}
\hline 1953 & Comedia, Aventura & O scrisoare pierdută & Sică Alexandrescu, Victor Iliu \\
\hline 1954 & Drama, Histórico & Desfăşurarea & Paul Călinescu \\
\hline 1954 & Drama, Histórico & Viața învinge & Dinu Negreanu \\
\hline 1955 & Guerra, Drama & Alarmă în munţi & Dinu Negreanu \\
\hline 1955 & Comedia, Acción & Directorul nostru & Jean Georgescu \\
\hline 1956 & Comedia, Aventura & Afacerea Protar & Haralambie Boroș \\
\hline 1956 & Drama & Citadela sfărâmată & $\begin{array}{c}\text { Marc Maurette, Haralambie } \\
\text { Boroş }\end{array}$ \\
\hline 1956 & Drama & Mândrie & Marius Teodorescu \\
\hline 1956 & Aventura,Comedia & Nufărul roșu & Gheorghe Tobias \\
\hline 1956 & Aventura,Comedia & ORA $H$ & Andrei Blaier,Sinișa Ivetici \\
\hline 1956 & $\begin{array}{l}\text { Comedia, } \\
\text { Romántico }\end{array}$ & Pe răspunderea mea & Paul Călinescu \\
\hline 1957 & Acción, Drama & Dincolo de brazi & Mircea Drăgan, Mihai Iacob \\
\hline 1957 & $\begin{array}{l}\text { Drama, Aventura, } \\
\text { Histórico }\end{array}$ & Erupția & Liviu Ciulei \\
\hline 1957 & Drama, Histórico & La Moara cu noroc & Victor Iliu \\
\hline 1957 & $\begin{array}{l}\text { Animación, } \\
\text { Histórico }\end{array}$ & Scurtă istorie & Ion Popescu Gopo \\
\hline 1957 & Drama, Aventura & Vultur 101 & Andrei Călărașu \\
\hline 1958 & $\begin{array}{l}\text { Comedia, } \\
\text { Romántico }\end{array}$ & Alo?... Ați greșit numărul & Andrei Călăraşu \\
\hline 1958 & Drama, Histórico & Ciulinii Bărăganului & Louis Daquin \\
\hline 1959 & $\begin{array}{l}\text { Drama, Histórico, } \\
\text { Aventura }\end{array}$ & Viața nu iartă & Iulian Mihu, Manole Marcus \\
\hline 1960 & Comedia, Aventura & Bădăranii & $\begin{array}{c}\text { Sică Alexandrescu, Gheorghe } \\
\text { Nagy }\end{array}$ \\
\hline 1960 & Comedia, Aventura & Băieții noștri & $\begin{array}{c}\text { Gheorghe Vitanidis, Anastasia } \\
\text { Anghel }\end{array}$ \\
\hline 1960 & Drama & Când primăvara e fierbinte & Mircea Săucan \\
\hline 1960 & Comedia & O zi pierdută & Constantin Neahu, Mircea Iva \\
\hline 1960 & Comedia, Histórico & Telegrame & Gheorghe Naghi, Aurel Miheleș \\
\hline
\end{tabular}


Capítulo 1: Historia del cine rumano

\begin{tabular}{|c|c|c|c|}
\hline 1960 & Drama, Histórico & Valurile Dunării & Liviu Ciulei \\
\hline 1961 & Musical, Aventura & Nu vreau să mă însor & Manole Marcus \\
\hline 1961 & Drama, Aventura & Porto-Franco & Paul Călinescu \\
\hline 1961 & Comedia & Post Restant & Gheorghe Vitanidis \\
\hline 1961 & $\begin{array}{l}\text { Guerra, Drama, } \\
\text { Acción }\end{array}$ & Soldați fără uniformă & Francisc Munteanu \\
\hline 1961 & Comedia & Vara romantică & Sinisa Ivetici \\
\hline 1962 & Comedia & Inbirea e un lucru foarte mare & Titi Acs, Cornel Popa \\
\hline 1962 & Drama, Romántico & Poveste sentimentală & Iulian Mihu \\
\hline 1962 & $\begin{array}{c}\text { Comedia, Aventura, } \\
\text { Fantástico }\end{array}$ & S-a furat o bombă & Ion Popescu Gopo \\
\hline 1962 & Documental, Drama & Trei strigăte pe Bistrița & Mirel Ilieșiu \\
\hline 1963 & Drama & Anotimpuri & Savel Stiopul \\
\hline 1963 & Drama, Aventura & Codin & Henri Colpi \\
\hline 1963 & Acción, Drama & Secretul cifrului & Lucian Bratu \\
\hline 1963 & Drama, Histórico & Lupeni'29 & Mircea Drăgan \\
\hline 1963 & $\begin{array}{c}\text { Drama, Histórico, } \\
\text { Aventura }\end{array}$ & Tudor & Lucian Bratu \\
\hline 1964 & Drama, Histórico & Comoara din Vadul Vechi & Victor Iliu \\
\hline 1964 & Musical, Comedia & Dragoste la zero grade & Geo Saizescu, Cezar Grigoriu \\
\hline 1964 & $\begin{array}{c}\text { Drama, Aventura, } \\
\text { Acción }\end{array}$ & La patru paşi de infinit & Francisc Munteanu \\
\hline 1964 & $\begin{array}{l}\text { Drama, Guerra, } \\
\text { Histórico }\end{array}$ & Pădurea spânzuratilor & Liviu Ciulei \\
\hline
\end{tabular}

Tabla 2. Lista de películas rumanas realizadas entre los años 1946-1964

Como hemos expuesto anteriormente, la cantidad de películas que se filmaron en este periodo es elevada, comparada con la época del nacimiento de este arte. Sin embargo, en estos tiempos muchas representaban más una reivindicación de la libertad de expresión que del talento cinematográfico. Profesionalmente, se puede considerar que el avance tecnológico no compensaba las restricciones impuestas por la clase política, no obstante, los cineastas habían encontrado diversas formas de transmitir su arte a través del filme; 
no era la primera vez que tenían que recurrir a la improvisación y a la perseverancia. Sin embargo, el perfil de los directores de esta época destaca por su formación profesional, dado que se trata de la primera promoción de directores, técnicos y actores que se había instruido en el Instituto de Arte Cinematográfico — en esos momentos uno de los pocos institutos de enseñanza cinematográfica superior de Europa-. Entre ellos se distinguirán figuras de nuevos y talentosos directores como Victor Iliu, Ion Popescu Gopo o Liviu Ciulei, que lograrán llevar al cine rumano (durante varios años) a las cumbres más altas de este arte.

\subsection{El cine rumano durante la dictadura}

En el año 1965, tras la muerte del presidente Gheorghe Gheorghiu Dej, se instauró en el poder del Estado el secretario del partido comunista Nicolae Ceaușescu.

La Época de Oro, como le gustaba denominar al periodo histórico que estuvo bajo su mandato, duró desde el año 1965 hasta el año 1989, cuando el pueblo rumano se rebeló contra su tiranía. En ese periodo todas las informaciones estaban controladas por dos departamentos que centralizaban los mensajes: la Sección de Propaganda y Prensa del Comité Central del Partido Comunista Rumano (PCR) y la Agencia Nacional de Prensa (Agerpres). El primero se dedicaba a la elaboración de los documentos de los congresos y las conferencias del partido, y la segunda, Agerpres, seleccionaba los eventos que confirmaban la doctrina del partido y difundía noticias u otros materiales con carácter movilizador comunista, que se distribuían a todas las instituciones de prensa. Ambas agencias funcionaban conforme a unas lógicas propagandísticas basadas en la eliminación de la información innecesaria y la prefabricación del mensaje, con el rol de movilizar a las masas para realizar el objetivo de la autoridad comunista. La información se sustituía por una pseudoinformación, desactualizada y profundamente ideologizada; y el lenguaje periodístico por un lenguaje indoctrinado, o "lenguaje de madera" como se llamaba en esa época. La instauración del régimen de Ceaușescu dio lugar a una dictadura que controlaba y limitaba la prensa, atribuyéndole una simple pero primordial función: sustentar el culto de su grandiosa personalidad como presidente ${ }^{9}$.

Ceaușescu había encontrado en el cine y la televisión un modo incauto de prorratear la magnanimidad del comunismo, de su admirable rol de presidente que velaba por el

\footnotetext{
${ }^{9}$ Véase: https://ro.wikipedia.org/wiki/Republica_Socialist\%C4\%83_Rom\%C3\%A2nia [consulta realizada el 8/08/2015].
} 
bienestar de su pueblo y de su futuro. Por tanto, el inicio de su dictadura conllevó una considerable inversión en el arte cinematográfico y una disminución del coste de las entradas para que toda la población, independientemente de sus ingresos, pudiera disfrutar de las películas que elogiaban sus ideales comunistas y despreciaban la conducta occidental. Sin embargo, se trataba de una situación absurda, puesto que había muchos cinematógrafos, pero pocas películas que proyectar debido a la censura que aplicaban los mecanismos del partido.

En esas circunstancias, cuando todo giraba alrededor del dictador y cuando la creación cinematográfica nacional se examinaba exhaustivamente, los cineastas empleaban el ingenio para crear películas conformes con las peticiones del régimen, y lograron en algunas ocasiones filtrar matices sutiles sobre la situación política real del país. El registro absoluto de los productos cinematográficos generó frecuentemente la prohibición de películas, que incumplían las directivas impuestas por los medios de control. En consecuencia, películas como Faleze de nisip (Dan Piţa, 1983), Fructe de pădure (Alexandru Tatos, 1983) o Râdeţi ca-n viaţă (Andrei Blaier, 1983), con temas cotidianos, pero que representaban personajes que eludían los patrones de integridad moral comunista (delincuentes, presidiarios, informales), se prohibieron en los cines.

Por consiguiente, para evitar situaciones similares, la mayoría de los cineastas centraron sus temas en la historia y recrearon sucesos históricos que agradaban tanto al público, como a las comisiones supervisoras. En la siguiente lista de películas (63), que se estrenaron en este periodo, podemos observar que los géneros que destacan son el drama y el histórico:

\begin{tabular}{|c|c|c|c|}
\hline AÑO & GÉNERO & TÍTULO & DIRECTOR \\
\hline 1965 & $\begin{array}{c}\text { Histórico, Drama, } \\
\text { Aventura }\end{array}$ & Neamul Șoimăreștilor & Mircea Drăgan \\
\hline 1965 & Comedia, Guerra & Serbările galante & René Claire \\
\hline 1965 & Comedia & Titanic Vals & Paul Călinescu \\
\hline 1966 & Aventura, Comedia & Faust XX & Ion Popescu Gopo \\
\hline 1966 & Drama, Histórico & Golgota & Mircea Drăgan \\
\hline 1966 & Drama, Histórico & Procesul alb & Bernard Bordérie \\
\hline 1967 & Comedia, Aventura & Șapte băieți și o ștrengăriţă & Sula \\
\hline
\end{tabular}


Capítulo 1: Historia del cine rumano

\begin{tabular}{|c|c|c|c|}
\hline 1967 & $\begin{array}{l}\text { Comedia, } \\
\text { Romántico }\end{array}$ & Şeful sectorului suflete & Gheorghe Vitanidis \\
\hline 1967 & Comedia & Balul de sâmbătă seara & Geo Saizescu \\
\hline 1967 & Drama & Cerul începe la etajul III & Francisc Munteanu \\
\hline 1967 & Drama, Romántico & Diminețile unui băiat cuminte & Andrei Blaier \\
\hline 1967 & Drama, Aventura & Meandre & Mircea Săucan \\
\hline 1967 & Romántico & Un film cu o fată fermecătoare & Lucian Bratu \\
\hline 1968 & $\begin{array}{l}\text { Drama, Aventura, } \\
\text { Histórico }\end{array}$ & Columna & Mircea Drăgan \\
\hline 1968 & Drama, Romántico & Gioconda fără surâs & Malvina Urşianu \\
\hline 1968 & Aventura, Histórico & Răpirea fecioarelor & Dinu Cocea \\
\hline 1969 & Drama, Aventura & Căldura & Şerban Creangă \\
\hline 1970 & $\begin{array}{l}\text { Documental, } \\
\text { Histórico, Drama }\end{array}$ & Apa ca un bivol negru & $\begin{array}{c}\text { Andrei Cătălin Băleanu, Pierre } \\
\text { Bokor, Dan Pița, Mircea Veroiu, } \\
\text { Youssouff Aidaby }\end{array}$ \\
\hline 1970 & Drama, Histórico & $\begin{array}{c}\text { Prea mic pentru un război atât de } \\
\text { mare }\end{array}$ & Radu Gabrea \\
\hline 1970 & Drama & Reconstituirea & Lucian Pintilie \\
\hline 1971 & Comedia, Aventura & Brigada Diverse în alertă & Mircea Drăgan \\
\hline 1971 & $\begin{array}{l}\text { Acción, Aventura, } \\
\text { Histórico }\end{array}$ & Haiducii lui Șaptecai cai & Dinu Cocea \\
\hline 1971 & Histórico & Mihai Viteazul & Sergiu Nicolaescu \\
\hline 1971 & Drama, Aventura & Printre colinele verzi & Nicolae Breban \\
\hline 1971 & Acción, Histórico & Săptămîna nebunilor & Dinu Cocea \\
\hline 1972 & Acción , Histórico & Conspiraţia & Manole Marcus \\
\hline 1972 & Drama, Aventura & Felix și Otilia & Iulian Mihu \\
\hline 1972 & Drama, Guerra & Pădurea pierdută & Andrei Blaier \\
\hline 1972 & Drama, Histórico & Săgeata căpitanului Ion & Aurel Miheleș \\
\hline 1973 & Drama & 100 lei & Mircea Săucan \\
\hline 1973 & Drama, Histórico & Departe de Tipperary & Manole Marcus \\
\hline 1973 & Drama, Aventura & Dragostea începe vineri & Virgil Calotescu \\
\hline 1973 & Drama, Histórico & Nunta de piatră & Mircea Veroiu, Dan Pița \\
\hline
\end{tabular}


Capítulo 1: Historia del cine rumano

\begin{tabular}{|c|c|c|c|}
\hline 1974 & Drama, Aventura & Capcana & Manole Marcus \\
\hline 1974 & Drama, Aventura & Duhul aurului & Mircea Veroiu, Dan Pița \\
\hline 1974 & Drama & Proprietarii & Șerban Creangă \\
\hline 1974 & Drama, Histórico & Stejar, extremă urgență & Dinu Cocea \\
\hline 1975 & Comedia, Fantástico & Comedie fantastică & Ion Popescu Gopo \\
\hline 1975 & $\begin{array}{l}\text { Aventura, Drama, } \\
\text { Romántico }\end{array}$ & Cursa & Mircea Daneliuc \\
\hline 1975 & Drama, Histórico & Mastodontul & Virgil Calotescu \\
\hline 1976 & Drama, Comedia & Mere roșii & Alexandru Tatos \\
\hline 1977 & $\begin{array}{c}\text { Comedia, Musical, } \\
\text { Aventura }\end{array}$ & Gloria nu cântă & Alexandru Bocăneț \\
\hline 1977 & Drama, Histórico & Marele singuratic & Iulian Mihu \\
\hline 1980 & Drama, Aventura & Bietul Ioanide & Dan Pița \\
\hline 1980 & Drama, Histórico & Duios Anastasia trecea & Alexandru Tatos \\
\hline 1980 & Drama, Histórico & La răscrucea marilor furtuni & Mircea Moldovan \\
\hline 1980 & Aventura & Mireasa din tren & Lucian Bratu \\
\hline 1980 & Drama, Acción & O lacrimă de fată & Iosif Demian \\
\hline 1980 & Drama, Romántico & Stop-cadru la masă & Ada Pistiner \\
\hline 1981 & Drama & Ștefan Luchian & Nicolae Mărgineanu \\
\hline 1981 & Drama & Angela merge mai departe & Lucian Bratu \\
\hline 1982 & Drama & Orgolii & Manole Marcus \\
\hline 1982 & Drama, Aventura & Un echipaj pentru Singapore & Nicu Stan \\
\hline 1983 & Drama, Aventura & Tapinarii & Ioan Cărmăzan \\
\hline 1983 & Aventura, Drama & Căruţa cu mere & George Cornea \\
\hline 1984 & Drama & Lişca & Ioan Cărmăzan \\
\hline 1984 & Comedia, Aventura & Secretul lui Bachus & Geo Saizescu \\
\hline 1985 & Aventura, Drama & Pas în doi & Dan Pița \\
\hline 1987 & Drama, Guerra & Figuranţii & Malvina Urşianu \\
\hline 1988 & Drama, Histórico & Moromeții & Stere Gulea \\
\hline 1988 & Drama & Drumeț în calea lupilor & Constantin Vaeni \\
\hline
\end{tabular}




\begin{tabular}{|c|c|c|c|}
\hline 1988 & Drama, Acción & Iacob & Mircea Daneliuc \\
\hline 1988 & Drama, Romántico & Liliacul înflorește a doua oară & Cristina Nichituș \\
\hline
\end{tabular}

Tabla 3. Lista de películas rumanas realizadas entre los años 1965-1989

El exhaustivo control de los filmes aplicado a los productos nacionales se centraba en tres temas fundamentales para los comunistas: el religioso, el político y el social. El prestigioso director de filme Mircea Daneliuc exponía en una entrevista al periódico Adevărul (Remus Florescu, 2015) las pautas que les obligaban a seguir las comisiones de control, pautas que le exigieron adaptar tanto el título de una de sus películas, como la trama completa:

\begin{abstract}
La segunda película que hice se titulaba Foc în iarbă (Fuego en la hierba), pero se proyectó en los cines como Ediție specială (Edición especial). En otra película, dirigida también por Dumitru Popescu, el responsable de registrar las películas me preguntaba dónde estaban los comunistas en mi filme. Habían empezado a amenazarme con que no iba a tocar nunca más una cámara, que nunca iría a ningún plató. En realidad, me asusté un poco, porque existía el precedente del director de filme Mircea Săucan, que había desaparecido del mundo cinematográfico después de unas cuantas películas de actualidad que había realizado. A mí me hubiera podido pasar lo mismo. Para seguir haciendo mi trabajo me vi obligado a llegar a un compromiso con ellos, realizar una película con comunistas, pero utilizando una cara más humana y una psicología creíble para el público. Tuvimos que empezar de nuevo el rodaje, y se necesitaba más dinero, pero ellos me dijeron que el dinero no era un problema. Cuando acabé la película la presentaron a varios festivales. [La traducción es nuestra].
\end{abstract}

Las películas rumanas que se realizaban en la época dictatorial tenían que representar la pureza del pueblo rumano continuamente sonriente y trabajador, sin distinciones políticas o religiosas, representaciones que se desvinculaban muchísimo de la cruda realidad. Laurenţiu Damian, otro regidor que ejerció sus funciones en los años del comunismo, contaba también al canal Digi24.ro (2013) sus peripecias cinematográficas en las etapas de recortes y prohibiciones que experimentaban los filmes:

¡Entre 1985 y 1986 las alusiones políticas eran algo muy grave! ¡No podías, por ejemplo, filmar campanarios de iglesias! Aunque el tema tratara sobre una iglesia, sobre la pintura religiosa, tú grababas en el interior de la iglesia y en el exterior una iglesia, sin campanario, sin techo. No podías grabar cruces, polvo o zonas donde aparecían perros vagabundos o zonas grises de la ciudad. No podías grabar personas feas. ¡No podías mostrar trabajadores sudorosos que trabajaban el acero! 
Venía esa comisión y existían diferentes etapas. La primera, cuando algunas personas no miraban la imagen, pero escuchaban el sonido, e indicaban lo que era necesario eliminar. La segunda, cuando después de escuchar el sonido, examinaban la imagen y decían lo que se tenía que eliminar. Eran personas... ¡Posiblemente podría contrariar a mucha gente: extremadamente inteligente! ¡No se les podría acusar de estupidez! ¡Sabían muy bien lo que hacían! Tenían una escuela de corte extraordinaria. [La traducción es nuestra].

Todo el producto cinematográfico o televisivo que se emitió en ese tiempo, incluyendo los cortometrajes que se realizaban, pasaba por el mismo esquema - filtro de control y de directivas - según afirmaba el director Copel Moscu en el mismo medio informativo Digi24.ro (2013):

Si ibas a realizar un filme sobre la agricultura comunista, los directores comprábamos algunos botes de champú para lavar las vacas antes de la grabación. Luego a las vacas se les paseaba por todos los lados. Eran unas vacas “top model”. Eran Miss Cow 1980. Porque eran las más guapas, tenían las ubres más grandes y las más relucientes cornamentas. [La traducción es nuestra].

Podemos observar que la producción televisiva y cinematográfica implicaba un ingenioso mecanismo de control de contenido por parte de las comisiones comunistas. El arte cinematográfico se veía obligado a seguir las indicaciones totalitarias del régimen y su incumplimiento suponía para los directores la derogación profesional.

Por tanto, el arte cinematográfico que se exponía en ese periodo era un arte realizado según las directrices políticas, dado que la libertad de expresión era nula. Las amenazas y las represalias comunistas estaban presentes en todas las grabaciones que se realizaban, y en consecuencia el resultado era una mera pantomima comunista, exceptuando las películas históricas, que presentaban temas del agrado del dictador.

\subsection{La censura sobre la producción y traducción de obras cinematográficas durante la dictadura comunista}

Dada la intensidad y la transcendencia cinematográfica y social que tuvo la dictadura comunista, hemos considerado imprescindible presentar en este subepígrafe cómo la censura aplicada en esta época incide también en la traducción de los textos audiovisuales extranjeros, en la actividad de los profesionales de esta disciplina y constituye una potente red ideológica que, más allá de prohibir la exhibición de programas con tema tabú, intenta, y casi siempre logra, adoctrinar a la población rumana. 
La censura se ha utilizado en diversos países y épocas históricas para dominar y, al mismo tiempo, inculcar a las masas diversos intereses, tal como afirman teóricos como Manvell (1944), Robyns (1994) o Merino (2006), que han analizado en sus estudios esta herramienta de manipulación.

De todos los tipos de censura, la censura audiovisual tiene una enorme repercusión, dada la ingente cantidad de espectadores potenciales que tienen los textos audiovisuales, tanto originales como traducidos, y aún más cuando el país tiene solamente una cadena de televisión manipulada por el poder político, como pasó en Rumanía. Por ello, la podemos considerar una potente herramienta para llegar a la meta que se proponen las instituciones y agentes que adoptan el papel de censores.

Uno de los primeros teóricos que estudió este tipo de manipulación social, en general, ejercida a través de las películas es Roger Manvell. En su libro Film (1944), el autor apunta tres tipos de censura en las películas (Manvell, 1944: 143), en los que quedan catalogadas las causas más relevantes de la censura en su época:

- La religiosa: en algunos filmes se prohíben las escenas que muestren la figura de Cristo o que hagan alusiones irreverentes a la Biblia, a alusiones bíblicas o a prácticas y ritos religiosos.

- La política: se prohíbe mostrar todo lo que pueda herir susceptibilidades extranjeras o fomentar inquietud y descontento social.

- Y la última, pero no por ello menos importante, la social: se prohíbe la desnudez (salvo en los negros), blasfemar, el alcohol, etc.

Por su parte Robyns (1994: 408-409) estudió las diferentes posturas de una cultura meta frente a la cultura original, tal como lo describe Richart (2016: 246) en su investigación sobre la censura audiovisual en España:

a) la imperialista, que niega "lo otro" y lo transforma

b) la defensiva, que reconoce "lo otro" y también lo transforma

c) la transdiscursiva, que no se opone de forma radical y no lo transforma

d) la defectiva, que demanda "lo otro" y no lo transforma

Se puede observar que la censura se aplica de diferentes formas, aunque con un mismo objetivo, y que a pesar del tiempo trascurrido desde su primera exposición, estos 
elementos perduraran muchos años después, tal y como afirma Merino (2006: 4), tanto en el cine como en la traducción:

Este espejismo sigue vigente y si no, consultemos cualquier monografía que no ponga el acento en el estudio de la traducción. Hoy aún seguimos clamando en el desierto y se sigue tendiendo a ignorar u obviar que existe un proceso indispensable que hace posible que estos espectáculos dramáticos lleguen al público.

La censura se puede analizar bajo dos puntos de vista: en primer lugar, como un elemento nocivo, que plantea la prohibición de visionar un producto audiovisual en una cultura y tiempo determinados. Y en segundo, como una forma de proteger al público de ciertas edades, que se considera que no está preparado para visualizar escenas con un alto contenido sexual o de violencia.

Aunque pueda parecer que la primera clase de censura es cosa del pasado, su permanencia en las pantallas de televisión de todo el mundo nos acompaña en la actualidad y es una poderosa herramienta de control, casi siempre ejecutada por el poder político, económico o religioso de cada país o comunidad. ${ }^{10}$

Rumanía es un país que utiliza la subtitulación para la traducción de las películas extranjeras. En esta modalidad de traducción audiovisual la censura afecta aún más a la calidad y a la verosimilitud del texto meta y del trabajo del traductor, frente al espectador que conoce la lengua origen. Además, por ignorancia del espectador, que desconoce el proceso y las normas de la traducción, la "culpabilidad" de todo aquello que difiere entre el texto origen y la traducción se le atribuye al traductor.

Bajo la dictadura de Nicolae Ceaușescu, Rumanía vivió dos etapas económicas: la primera entre las décadas de los años 60 y 70, cuando el país experimentó un gran crecimiento económico, y la segunda a partir de mediados de la década de los 70, cuando la crisis económica, junto a la megalomanía del dictador, llevaron al empobrecimiento extremo de la población. Estas dos etapas económicas incidieron directamente en los productos audiovisuales emitidos en el cine y en la televisión.

La primera etapa se puede definir como una etapa gloriosa, en la que el espectador podía disfrutar de los estrenos de las películas de Hollywood; sin embargo, la etapa de pobreza fue la época del declive cinematográfico y televisivo. El régimen recortó las

${ }^{10}$ Véase la polémica suscitada en estos últimos meses sobre el filme The Interview, bajo la dirección de Evan Goldberg y Seth Rogen, 2014. 
inversiones en el ámbito cultural e instaló un sistema de trueque entre Rusia y Rumanía basado en el intercambio de películas rumanas y rusas (Liv Anna, 2012). Así pues, en Rumanía solo se emitían filmes del bloque ruso. Por otra parte, la única cadena de televisión que existía en el país (Televiziunea Română) pasó a tener una emisión diaria de solo dos horas de duración. Por tanto, no solo se trató de un caso de censura fílmica, tanto en versión original como traducida, sino también de un aislamiento cultural del pueblo rumano.

Durante esta etapa, aquellas películas, tanto rumanas como provenientes de Occidente, que se consideraban más permisivas y con un contenido que superaba los estándares impuestos por el régimen comunista, se prohibían directamente. De esta forma, películas como: Reconstituirea (Lucian Pintilie, 1968), La dolce vita (Federico Fellini, 1960), Mayerling (Terence Young, 1968), ¡Hello Dolly! (Gene Kelly, 1969) o Anonimo Veneziano (Enrico Maria Salerno, 1970) no llegaron a ver la luz en Rumanía durante este periodo (Liv Anna, 2012). El público infantil y juvenil tampoco se libró de la censura, y toda una generación se crío y educó con tan solo 10-15 minutos de dibujos animados al día, y de vez en cuando con una película de Occidente, en las dos horas de emisión de la única cadena que existía.

En cuanto al contenido de las películas que se decidía televisar o proyectar en el cine, existían directrices específicas y se ejercía un control exhaustivo sobre ellas. Según afirma la traductora y crítica de filme Irina Margareta Nistor para el periódico Adevărul (Iulia Roșu, 2013):

Desaparecía todo lo que significaba opulencia. Por ejemplo, en la serie Dallas se hacían más cortas las escenas con piscina y se acentuaban los conflictos familiares. [La traducción es nuestra].

De esta forma, desvirtuando la historia de la película mediante la omisión o la reducción de escenas y la tergiversación de la traducción, se le enseñaba al espectador la negatividad y las posibles malas influencias de otros sistemas de valores y de otros lugares, en este caso la vida y valores estadounidenses, cambiando en su totalidad el mensaje del filme. Asimismo, dada la pobreza alimentaria de esa época, se censuraban de las películas las escenas que contenían mesas con mucha comida. Esto incluía también las escenas de dibujos animados, como por ejemplo Tom y Jerry, en las que aparecían banquetes con abundantes alimentos. De este modo, el público no podía comparar los manjares occidentales con la escasez y penurias del mercado comunista. De igual manera, 
también se consideraba que las escenas de amor podían alterar la pureza de las masas. Según Irina Margareta Nistor (2013), traductora de Romance on the Orient Express (Lawrence Gordon Clark, 1985), durante la emisión de esta película se censuró el encuentro amoroso de los dos protagonistas en la litera del tren, de modo que el espectador tenía que utilizar su imaginación para suponer lo que allí ocurría.

Como vemos, mediante la censura el sistema comunista intentaba aislar al pueblo rumano de los demás países y hacerle creer que el sistema político comunista era la forma idónea de cuidar a la población y de velar por su futuro. Este objetivo también se perseguía con la programación infantil y juvenil, ya que el régimen intentaba instaurar sus doctrinas desde una edad temprana.

Como se ha señalado, los telespectadores rumanos podían disfrutar de dos horas de emisión televisiva en la única cadena que existía antes de 1989, y de estas, diez minutos se dedicaban a emitir películas infantiles y juveniles; pero esto fue así hasta el año 1974, cuando los niños de Rumanía empezaron a disfrutar de una hora más de dibujos una vez a la semana, con una nueva programación llamada Gala desenului animat (La gala de los dibujos animados). Su emisión se realizaba inicialmente los domingos, pero se cambió definitivamente a los sábados por la tarde, días en que los niños podían disfrutar de una hora con los personajes de Disney, principalmente.

Gala desenului animat se inaugura en el segundo periodo de la dictadura, cuando la crisis económica reina en Rumanía, y Ceaușescu y su gobierno se niegan a invertir dinero en el disfrute y el entretenimiento de la población. Por tanto, la nueva programación infantil consistía en material existente en el archivo de la televisión nacional comprada en la primera época de la dictadura, entre los años 1965 y 1968, cuando el dictador se encontraba aún al principio de su mandato y el régimen era más permisivo. Así lo cuenta la realizadora Viorica Bucur al periódico Historia.ro (Florentina Tone, 2011):

En el Archivo Nacional de Filmes había mucho Disney, muchas copias de películas de corto o largo metraje, como el ciclo Mickey o Blancanieves, El libro de la selva, 101 dálmatas, Bambi, Tom y Jerry, etc., que se habían emitido anteriormente en las pantallas. Existían todas las películas importantes de Disney, dado que en el periodo comprendido entre 1965 y 1968, Rumanía era un país más abierto, comparado con los demás países socialistas, y se emitían películas americanas. [La traducción es nuestra]. 
Como vemos, en la primera etapa de la dictadura, Rumanía adquirió los derechos de emisión de una buena cantidad de películas extranjeras, y el público pudo ver películas que otros países bajo el mismo régimen comunista tenían prohibidas. Sin embargo, estos productos audiovisuales adquiridos con licencia en los años anteriores se emitieron años más tarde de forma ilícita, tal como explica Bucur en el mismo medio informativo (Florentina Tone, 2011):

Cuando se compra la licencia de emisión de una película para la gran pantalla, se compra también un número de copias que se pueden distribuir un cierto tiempo. Después las copias se tienen que destruir, y si quieres emitirlas en las cadenas, tienes que comprar otra licencia con otro número de copias para la televisión. Pero en esos tiempos, en nuestro país no se respetaba ningún derecho, ni de autores, ni humanos, y las copias, bastante desgastadas, se guardaban en el Archivo Nacional de Filmes. [La traducción es nuestra].

Por otra parte, podemos afirmar que la censura aplicada a los productos extranjeros para el público infantil era aleatoria y caprichosa, según los deseos del régimen del dictador. Por ejemplo, se prohibió emitir Popeye por el mero hecho de que Olivia se parecía a la mujer del dictador. También se prohibió Tom y Jerry, ya que se consideraba que este tipo de dibujos instigaba a la violencia, aunque el argumento decisivo para suprimir su emisión, según Bucur (2011), tal como afirmaba para el periódico digital Historia, es que los niños de algunos políticos se horrorizaban al verlos.

En cuanto a las órdenes del régimen para censurar ciertos productos extranjeros, estas llegaban por diversas vías; la más utilizada era la vía telefónica. En ocasiones, si había "errores" graves en la traducción (es decir, si no se habían realizado los cortes en las escenas especificadas) se citaba a los traductores a una reunión urgente donde participaban los realizadores del programa y el jefe de la televisión rumana en esa época y miembro del Comité Central del Partido Comunista Rumano, Dumitru Popescu, de apodo "Dios", que se encargaba directamente de transmitir los deseos y las directrices del dictador (Bucur, 2011).

En estas condiciones la traducción de una película extranjera supone doble trabajo, pero el objetivo no es obtener un resultado mejor, sino acatar la prohibición de la censura.

En general esta manipulación es casi siempre visible especialmente en el caso de la subtitulación, dado que es una modalidad de traducción audiovisual más vulnerable que el doblaje (Díaz Cintas, 2003: 43-44), ya que el espectador se encuentra frente a la versión original y al texto traducido. 
No obstante, en Rumanía, en la época dictatorial, la censura audiovisual se empleó como un instrumento de prohibición y de manipulación de masas, y se erigió en una herramienta poderosa del dictador para aislar al pueblo rumano del mundo que le rodeaba. El tipo de censura que se aplicó a las películas extranjeras era totalitario y abusivo: el régimen dificultaba el trabajo de los traductores, y muchas veces se les obligaba a alterar o cambiar por completo el argumento del producto original. Se ejercía un control exhaustivo tanto de las escenas del producto original, como de la traducción, pero esta "supervisión" no la realizaban profesionales del medio audiovisual ni de la traducción, de modo que el resultado final acababa siendo una adaptación manipulada de la película original, y el espectador se veía obligado a visionar un producto distorsionado, tal como veremos en el siguiente capítulo.

Por tanto, las restricciones impuestas por la dictadura alteran el trasvase del texto original al texto meta, con el propósito de educar al pueblo según las doctrinas del Partido Comunista y presentar a los otros países, que no compartían las mismas ideas políticas que la parte del Este de Europa, como algo nocivo para "la pureza" del pueblo rumano. Tal como afirmaba Bordieu (2008: 29), "las palabras expresan perfectamente la gimnasia política de la dominación o de la sumisión porque son, con el cuerpo, el soporte de montajes profundamente ocultos en los cuales un orden social se inscribe duraderamente".

Para finalizar, consideramos que la siguiente afirmación de Mayoral (1999: 91) refleja y describe perfectamente la situación particular del traductor audiovisual durante el régimen comunista, que hemos analizado en este capítulo:

En los antiguos países del Este de Europa se produjo por parte del poder una manipulación de la traducción y de interpretación por la cual se desvirtuaban los contenidos originales y las intenciones de los autores originales cuando éstos no se consideraban favorables a los intereses de la causa (...). La ideología que se construyó para justificar esta práctica fue que, al no darse una equivalencia entre las culturas correspondientes a clases sociales diferentes, al ver la realidad con ópticas diferentes las diferentes clases/ideologías, una traducción fiel había de producir interpretaciones diferentes de los mismos hechos; se imponía por tanto, cierta modulación de clase social que ayudara a evitar la distorsión producida por las diferencias ideológicas. Esta situación colocaba a los profesionales de la traducción en estos países en una situación ciertamente peculiar en relación con otros compatriotas de otros países. 


\subsection{El cine rumano después de la revolución del año 1989 y en la actualidad}

La revolución del año 1989 consistió en una serie de protestas y manifestaciones realizadas entre el 16 y el 25 de diciembre, que llevaron a la caída del régimen comunista y a la muerte del dictador y de su esposa. A las manifestaciones pacíficas se respondió con violencia y muchos ciudadanos rumanos perdieron su vida en la lucha por la libertad. Como una paradoja, la televisión rumana emitió sin interrupción, después de tantos años de prohibiciones, los trágicos sucesos en el camino hacia la democracia mostrando detalladamente la cruda realidad disimulada durante 26 años.

A partir de esa fecha las reacciones de los cineastas fueron diversas. No obstante, coincidían en un mismo tema que consideraban necesario ilustrar: la verdad sobre el régimen comunista y sus atributos, como temor, hambre, humillación y corrupción. Por tanto, se manifestó un itinerario cinematográfico, donde los temas con aspecto socialpolítico alternaban con películas comerciales o de arte al estilo occidental o americano, con problemáticas específicas del mundo contemporáneo. La época de oro constituía una importante fuente de inspiración para los directores del cine rumano, que consideraban necesario mostrar, tanto a nivel nacional como internacional, las atrocidades del dictador y de su partido.

A los directores consagrados en la época comunista, como por ejemplo Sergiu Nicolescu, Liviu Ciulei, Nicolae Mărgineanu o Mircea Danieliuc, se les incorporan nuevos jóvenes talentos que pertenecen a la generación actual de directores de filmes; sus producciones aportarán al cine rumano nuevas visiones y alcanzarán el reconocimiento internacional tras ser galardonadas con varios premios.

Entre ellos cabe destacar al director Cristi Puiu, cuyas producciones de cinematografía rumana han iniciado "la nueva ola rumana" de filmes. Sus películas Marfa si banii (2001), Un cartus de Kent si un pachet de cafea (2004) y Aurora (2010), inspiradas en la realidad cotidiana rumana, han sido premiadas a nivel nacional e internacional. La película Moartea domnului Lăzărescu (2005), donde Cristi Puiu presentaba la cruda realidad del sistema de sanidad, contribuyó a su reconocimiento profesional y fue premiada en el festival de Cannes en la sección "Un Certain Regard"11.

El director que logró llevar a Rumanía el premio Palme D'Or con la producción 4 luni, 3 saptamani si 2 zile (2007) es Cristian Mungiu, un profesional que destaca por su

\footnotetext{
${ }^{11}$ Véase: https://es.wikipedia.org/wiki/Un_certain_regard [consulta realizada el 3/11/2016].
} 
modo sugerente de elegir y combinar temas sobre el pasado y el presente de la sociedad rumana. El comunismo, una realidad histórica en el pasado de nuestro país y presentada en sus películas, sorprendió positivamente a los críticos de filme y reincorporó a Rumanía al mapa cinematográfico europeo, otorgándole el premio al mejor director europeo de la Academia Europea de Cine del año 2007.

Radu Munteanu es un director cuyos temas predilectos son las escenas de la vida cotidiana, con sus dramas o sus diversiones específicas de la sociedad rumana. Este tipo de trama simple y actual, que ilustraba en películas como, por ejemplo, Furia (2002), Hârtia va fi albastră (2006), Boogie (2008) y Marți, după Crăciun (2010), era necesario para entretener al espectador rumano hastiado de la época dictatorial.

Otro director importante para la cinematografía rumana actual es Cătălin Mitulescu, que captó la atención de los cinéfilos con el cortometraje Trafic (2004), premiado con el Palme D'Or en el mismo año. También es el director de películas como Bucuresti-Wien ora 8:15 (2000), 17 minute întârziere (2002), Cum mi-am petrecut sfârșitul lumii (2006), Loverboy (2011) o Dincolo de calea ferată (2016), entre muchas otras. Presentando la realidad social, Mitulescu realiza mediante sus películas un análisis psicológico-social trasladando a sus personajes a una actualidad cotidiana, presentando el filme como una experiencia artística y empresarial, como él mismo lo define en una entrevista conferida al medio de comunicación Mediafax.ro (Katy Marinescu, 2016):

Todas las películas de autor se dirigen a un patrón, pero son muchas las personas que descubren este género de filme y después permanecen fieles a un filme de autor. Son muchísimos... seguramente que en nuestro país son menos, pero son cinéfilos. Estos ven la película como una experiencia propia, una experiencia artística. No la ven como un entretenimiento. Son diferentes a las películas americanas. Es otro tipo de película. Descubres mundos, descubres una historia, descubres unos actores. Es como un viaje, no es una máquina para hacer dinero, un entretenimiento americano. Esto no significa que esas películas no estén bien. Están bien, pero son diferentes. [...] Ahora no tenemos muchas películas de público, pero es muy difícil financiar una película de este tipo, ya que el mercado rumano es muy restringido. Me refiero al sistema de distribución. Y a pesar de tener éxito, eso no te aporta los ingresos necesarios para financiar una nueva película. No somos el mercado de Francia o de Chequia, donde, en sí, el mercado local puede sostener la producción de un filme. Por ejemplo, si tienes éxito en Chequia y tienes un millón de espectadores, no tienes que soñar con llegar a un gran festival. Simplemente, es suficiente. Es suficiente tener éxito allí. Aquí no es suficiente. A pesar de tener un gran éxito, el beneficio es... pequeño. No te llega. Y todos han empezado con filmes personales y continúan con filmes personales. Es un cine de calidad. Pero tiene una realidad de la cinematografía rumana. [La traducción es nuestra]. 
Por su parte, Nae Caranfil, el director de varias películas referentes en la cinematografía rumana después de 1989 y galardonadas con varios premios internacionales, como por ejemplo E pericoloso sporgersi (1993), Asfalt Tango (1995), Dolce far niente (1998), Filantropica (2002) o Restul e tăcere (2007), evidenciaba las dificultades presupuestarias que implica la creación de una película rumana. Según Caranfil, la única plataforma para un director y su película hacia el éxito son los festivales, dado que actualmente la cinematografía tiene un potente competidor, la piratería, a la que se añade el desinterés de los inversores, tal como lo explicaba en una entrevista para la revista Iaşul Cultural (Francesca Stoian, 2009):

\footnotetext{
En este momento, un filme no se puede amortizar económicamente, porque la gente ya no va al cine. Pero la película no trae ningún beneficio si se vende a nivel internacional. Indudablemente ningún filme rumano será visionado en el mercado internacional "mainstream", donde solamente las películas americanas o de unos cuantos países europeos pueden llegar. Esto se debe a que es una cinematografía demasiado pequeña y un idioma que no es de circulación internacional. Existe un mercado de festivales que es muy importante para este tipo de películas. Si la película de autor es muy personal, pero al mismo tiempo popular, abierta hacía el público, el jurado del festival siente que tu película no le pertenece, porque el jurado está allí para ayudar a las películas que de otra forma no llegarían al público. [La traducción es nuestra].
}

Conforme a las declaraciones de los directores rumanos que constituyen la nueva generación, podemos afirmar que la situación cinematográfica es circular, y a pesar del paso del tiempo, la falta de presupuesto sigue presente entre los profesionales del cine, acordándonos de Menu, Mihail o Brezeanu, que en el año 1911 atravesaban las mismas circunstancias. De modo que, llegados al año 2016, la condición del cinematógrafo se basa en los mismos pilares: la pasión y la improvisación económica, elementos inherentes para la realización del cine rumano en la actualidad. Sin embargo, las limitaciones presupuestarias no influyen en la calidad de las películas y tampoco en el entusiasmo que caracteriza a los profesionales; el número considerable de películas premiadas $(47)^{12} \mathrm{y}$ de películas realizadas entre los años 1990 y 2016 (105), que expondremos en la siguiente lista, acreditan su valor:

\footnotetext{
${ }^{12}$ Véase:https://ro.wikipedia.org/wiki/List\%C4\%83_de_filme_rom\%C3\%A2ne\%C8\%99ti_cu_distinc\%C8\%9Bii_interna\%C8\%9Bi onale [consulta realizada el 27/07/2017].
} 


\begin{tabular}{|c|c|c|c|}
\hline AÑO & GÉNERO & TÍTULO & DIRECTOR \\
\hline 1990 & Aventura & Coroana de foc & Sergiu Nicolaescu \\
\hline 1990 & Drama & Cine are dreptate? & Alexandru Tatos \\
\hline 1990 & $\begin{array}{l}\text { Drama, Histórico, } \\
\text { Fantástico }\end{array}$ & A unsprezecea poruncă & Mircea Daneliuc \\
\hline 1990 & Drama, Aventura & Şobolanii roşii & Forin Codre \\
\hline 1991 & Comedia & Miss Litoral & Mircea Mureșan \\
\hline 1991 & Drama & Vânătoarea de lilieci & Daniel Bărbulescu \\
\hline 1991 & Comedia, Amor & Liceenii Rock'n'Roll & Nicolae Corjos \\
\hline 1992 & Drama, Aventura & Hotel de lux & Dan Pița \\
\hline 1992 & Drama & Privește inainte cu mânie & Nicolae Mărgineanu \\
\hline 1992 & Drama & Divorț... din dragoste & Andrei Blaier \\
\hline 1992 & Amor & Telefonul & Elisabeta Bostan \\
\hline 1993 & Drama & Vulpe - vânător & Stere Gulea \\
\hline 1993 & Drama & Doi haiduci și o crâșmăriță & George Cornea \\
\hline 1993 & Drama & Patul Conjugal & Mircea Daneliuc \\
\hline 1993 & $\begin{array}{c}\text { Comedia, Drama, } \\
\text { Aventura }\end{array}$ & E pericoloso sporgersi & Nae Caranfil \\
\hline 1994 & Comedia & Şoapte de amor & Mircea Danelic \\
\hline 1994 & Drama & O vară de neuitat & Lucian Pintilie \\
\hline 1994 & Drama & Somnul insulei & Mircea Veroiu \\
\hline 1994 & Comedia & $\begin{array}{c}\text { A doua cădere a } \\
\text { Constantinopolului }\end{array}$ & Mircea Mureșan \\
\hline 1995 & Drama & Senatorul melcilor & Mircea Danelic \\
\hline 1995 & $\begin{array}{c}\text { Fantástico, Drama, } \\
\text { Aventura }\end{array}$ & Craii de Curtea Veche & Mircea Veroiu \\
\hline 1995 & Acción & Terente - regele bălților & Andrei Blaier \\
\hline 1996 & Acción & Punctul zero & Sergiu Nicolaescu \\
\hline 1996 & Drama & Eu sunt Adam! & Dan Pița \\
\hline 1996 & Comedia, Aventura & Asfalt Tango & Nae Caranfil \\
\hline 1996 & Drama & Prea târziu & Lucian Pintilie \\
\hline
\end{tabular}


Capítulo 1: Historia del cine rumano

\begin{tabular}{|c|c|c|c|}
\hline 1996 & Drama & Stare de fapt & Stere Gulea \\
\hline 1997 & Político & Omul zilei & Dan Pița \\
\hline 1997 & Drama & Femeia în roșu & Mircea Veroiu \\
\hline 1997 & Comedia & Paradisul in direct & Cornel Diaconu \\
\hline 1998 & Drama & Dublu Extaz & Iulian Mihu \\
\hline 1998 & Drama & Terminus Paradis & Lucian Pintilie \\
\hline 1998 & Comedia & Dolce far niente & Nae Caranfil \\
\hline 1998 & Drama & Martori dispăruți & Szabolcs Cseh, Dan Mironescu \\
\hline 1999 & Guerra & Triunghiul morții & Sergiu Nicolaescu \\
\hline 1999 & Drama, Acción & Faimosul paparazzo & Nicolae Margineanu \\
\hline 1999 & Drama & Fii cu ochii pe fericire & Alexandru Maftei \\
\hline 1999 & Drama & Față în față & Marius Barna \\
\hline 2000 & Drama & Manipularea & Nicolae Oprițescu \\
\hline 2000 & Drama & București-Viena, 8-15 & Cătălin Mitulescu \\
\hline 2000 & Drama & La bloc oamenii mor după muzică & Cristian Nemescu \\
\hline 2001 & Comedia & Sexy Harem Ada-Kaleh & Mircea Mureșan \\
\hline 2001 & Drama, Histórico & După-amiaza unui torționar & Lucian Pintilie \\
\hline 2001 & Drama & Marfa şi banii & Cristi Puiu \\
\hline 2001 & Drama & Război în bucătărie & Marius Theodor Barna \\
\hline 2002 & Comedia & Occident & Cristian Mungiu \\
\hline 2002 & Drama, Musical & Turnul din Pisa & Şerban Marinescu \\
\hline 2002 & Drama & Binecuvântată fii, închisoare & Nicolae Margineanu \\
\hline 2002 & Comedia & Filantropica & Nae Caranfil \\
\hline 2003 & Comedia & Ambasadori, căutăm patrie & Mircea Danieluc \\
\hline 2003 & Drama & Examen & Titus Muntean \\
\hline 2003 & Drama & Niki Ardelean, colonel în rezervă & Lucian Pintilie \\
\hline 2004 & Comedia, Aventura & Milionari de weekend & Cătălin Saizescu \\
\hline 2004 & Drama, Amor & Orient Express & Sergiu Nicolaescu \\
\hline 2004 & Drama & Raport despre starea națiunii & Ioan Cărmăzan \\
\hline
\end{tabular}


Capítulo 1: Historia del cine rumano

\begin{tabular}{|c|c|c|c|}
\hline 2004 & Drama & Lotus & Ioan Cărmăzan \\
\hline 2005 & Comedia & Eminescu versus Eminem & Florin Piersic Jr \\
\hline 2005 & Drama & Moartea domnului Lăzărescu & Cristi Puiu \\
\hline 2005 & Drama & Second Hand & Dan Pița \\
\hline 2005 & Drama & Femeia visurilor & Dan Pița \\
\hline 2005 & Drama & 15 & Sergiu Nicolaescu \\
\hline 2006 & $\begin{array}{l}\text { Drama, Aventura, } \\
\text { Romántico }\end{array}$ & Azucena - Ingerul de abanos & Mircea Mureșan \\
\hline 2006 & Drama & Cum mi-am petrecut sfârșitul lumi & Cătălin Mitulescu \\
\hline 2006 & Drama satírica & A fost sau $n$-a fost? & Corneliu Porumboiu \\
\hline 2006 & Drama & Hîrtia va fi albastră & Radu Muntean \\
\hline 2007 & $\begin{array}{c}\text { Comedia, Drama, } \\
\text { Aventura }\end{array}$ & California Dreamin' (Nesfârșit) & Cristian Nemescu \\
\hline 2007 & $\begin{array}{c}\text { Histórico, Drama, } \\
\text { Aventura }\end{array}$ & Restul e tăcere & Nae Caranfil \\
\hline 2007 & Drama & 4 luni, 3 săptămâni și 2 zile & Cristian Mungiu \\
\hline 2007 & Drama & Logodnicii din America & Nicolae Mărgineanu \\
\hline 2008 & Drama & Boogie & Radu Muntean \\
\hline 2008 & Acción & Supraviețitorul & Sergiu Nicolaescu \\
\hline 2008 & Drama & Marilena & Mircea Danieliuc \\
\hline 2008 & Acción & Legiunea străină & Mircea Danieliuc \\
\hline 2009 & Drama & Polițist, adjectiv & Corneliu Porumboiu \\
\hline 2009 & Histórico & $\begin{array}{c}\text { Carol I - Un destin pentru } \\
\text { România }\end{array}$ & Sergiu Nicolaescu \\
\hline 2009 & Comedia & $\begin{array}{l}\text { Amintiri din Epoca de Aur 1: } \\
\text { Tovarăși, frumoasă e viața! }\end{array}$ & Cristian Mungiu \\
\hline 2010 & Drama & Eu când vreau să fluier, fluier & Florin Șerban \\
\hline 2010 & Comedia & Poker & Sergiu Nicolaescu \\
\hline 2010 & Drama, Histórico & Portretul luptătorului la tinerețe & Constantin Popescu \\
\hline 2010 & Drama & Principii de viață & Constantin Popescu \\
\hline 2011 & Drama & Loverboy & Cătălin Mitulescu \\
\hline
\end{tabular}


Capítulo 1: Historia del cine rumano

\begin{tabular}{|c|c|c|c|}
\hline 2011 & Comedia & Ceva Bun de la Viață & Dan Pița \\
\hline 2011 & Amor & $\begin{array}{c}\text { Din dragoste cu cele mai bune } \\
\text { intenții }\end{array}$ & Adrian Sitaru \\
\hline 2011 & Comedia & Ursul & Dan Chișu \\
\hline 2012 & Comedia & Ultimul corupt din România & Sergiu Nicolaescu \\
\hline 2012 & Drama & După dealuri & Cristian Mungiu \\
\hline 2012 & Drama & Trei zile până la Crăciun & Radu Gabrea \\
\hline 2012 & Drama & Toată lumea din familia noastră & Radu Jude \\
\hline 2013 & Drama, Terror & Domnişoara Christina & Alexandru Maftei \\
\hline 2013 & Drama & $\begin{array}{c}\text { Când se lasã seara peste București } \\
\text { sau metabolism }\end{array}$ & Corneliu Porumboiu \\
\hline 2013 & Comedia & Sunt o babă comunistă & Stere Gulea \\
\hline 2014 & Drama & Quod erat demonstrandum & Andrei Gruzsniczki \\
\hline 2014 & Comedia & America, venim! & Răzvan Săvescu \\
\hline 2014 & Comedia & Selfie & Cristina Iacob \\
\hline 2014 & Drama & Cel Ales & Cristian Comeaga \\
\hline 2014 & Aventura, Comedia & Usturoi & Lucian Alexandrescu \\
\hline 2015 & Drama, Histórico & Aferim & Radu Jude \\
\hline 2015 & Drama, Comedia & București NonStop & Dan Chișu \\
\hline 2015 & Comedia, Drama & Acasă la tata & Andrei Cohn \\
\hline 2015 & Drama & Lumea e a mea & Nicolae Constantin Tănase \\
\hline 2015 & Drama & Comoara & Corneliu Porumboiu \\
\hline 2016 & Comedia romántica & \#Selfie 69 & Cristina Iacob \\
\hline 2016 & Drama & Sieranevada & Cristi Puiu \\
\hline 2016 & Drama, Terror & Câini & Bogdan Mirică \\
\hline 2016 & Drama & Bacalaureat & Cristian Mungiu \\
\hline 2016 & Drama & Ilegitim & Adrian Sitaru \\
\hline
\end{tabular}

Tabla 4. Lista de películas rumanas relevantes realizadas entre los años 1990-2016

El talento de la nueva generación de directores es indiscutible: ellos han logrado fascinar no solamente al público rumano, sino también al europeo. Los numerosos 
premios (47) recibidos por sus producciones cinematográficas demuestran sus habilidades directivas; presentando el pasado o el presente con humor o con dramatismo, han creado una filmografía rumana admirable.

\subsection{Síntesis y conclusiones}

En el presente capítulo hemos realizado una inmersión en la cinematografía rumana, desde su inicio hasta la actualidad. Hemos podido observar la fase incipiente de este arte, basada en la pasión y la improvisación de los primeros profesionales, que promovieron "la maravilla del siglo" en Rumanía; a pesar de sus dificultades, paulatinamente "las proyecciones eléctricas", como la describían algunos periódicos, lograron cautivar al público. Todo esto fue posible gracias a personas que consideraron desde un principio que el cine sería un gran descubrimiento.

Las dos guerras mundiales que sufrieron Rumanía y el resto de los países europeos dificultaron el progreso cinematográfico, pero no lograron detener el interés por este arte, que había fascinado desde su comienzo al público rumano. Fueron años cruciales en la historia de Rumanía, así como también en la historia del cine. En este periodo se proyectan películas con una técnica más avanzada, debutan nuevos actores, y la práctica de presentar y difundir los estrenos es cada día más innovadora.

Después de la segunda guerra mundial, y de forma paulatina, el perfil amateur de los profesionales se perfecciona y destaca por su formación profesional, dado que los directores, técnicos y actores tienen la posibilidad de formarse académicamente en el Instituto de Arte Cinematográfico, en esos momentos uno de los pocos institutos de enseñanza cinematográfica superior de Europa. En el plano político, en un tiempo relativamente corto, Rumanía experimentó también varias formas de gobierno, pasó de la monarquía, a la dictadura militar y en el año 1948 se instauró el comunismo, que duró hasta el año 1989. Todos estos factores trascendieron también en el área cinematográfica, tanto en los temas que se van a proyectar en el futuro, como en los trámites administrativos.

Por consiguiente, en la época dictatorial, que duró casi 25 años, todo el producto cinematográfico o televisivo que se emitió, incluyendo los cortometrajes que se realizaban, pasaba por el mismo esquema — filtro de control y de directivas - según afirman los directores de ese período. Las películas rumanas que se realizan en la época dictatorial tienen que representar la pureza del pueblo rumano continuamente sonriente y 
trabajador, sin distinciones políticas o religiosas, representaciones que se desvinculan muchísimo de la cruda realidad. Asimismo, los cineastas emplean el ingenio para crear películas conformes con las peticiones del régimen y logran en algunas ocasiones filtrar matices sutiles sobre la situación política real del país.

Los productos audiovisuales extranjeros, especialmente los que se importan del occidente son otro objetivo, minuciosamente analizado por la censura comunista. De esta forma, desvirtuando la historia de la película mediante la omisión o la reducción de escenas y la tergiversación de la traducción, se le enseñaba al espectador la negatividad y las posibles malas influencias de otros sistemas de valores y de otros lugares, en este caso la vida y valores estadounidenses, cambiando en su totalidad el mensaje del filme. Esta práctica se le aplica también a los dibujos animados, o simplemente se prohíbe su emisión.

A modo de conclusión podemos afirmar que, a pesar de las duras coyunturas socio-económicas y políticas que atravesó Rumanía, los profesionales que se dedicaron al cine lograron posicionarlo al mismo nivel de otros países europeos. Por ello, es necesario agradecer y respetar los esfuerzos y la capacidad creativa de todos aquellos que, a pesar de las dificultades, no renunciaron a su pasión y al deseo de situar a Rumanía entre los primeros países que desarrollaron la invención de los hermanos Lumière. 


\section{Capítulo 2: La traducción audiovisual en Rumanía}

En el presente capítulo describimos y definimos las modalidades de traducción audiovisual que se utilizan en Rumanía. Nuestra intención no es realizar un amplio repaso sobre los estudios de traducción audiovisual, dado que hasta la fecha esta disciplina reúne una abundante bibliografía en este sentido ${ }^{13}$. No obstante, expondremos sus características básicas y presentaremos brevemente algunas de sus modalidades (concretamente, la subtitulación, el doblaje y el voice-over), dado que son los tipos de traducción audiovisual más empleados en la actualidad en Rumania. Para ello, indagaremos en los aspectos históricos de la traducción audiovisual en Rumanía describiendo los orígenes de las dos modalidades de traducción audiovisual más utilizadas (la subtitulación y el doblaje) e intentaremos esclarecer las razones del triunfo del subtitulado en Rumanía.

\subsection{Las modalidades de la traducción audiovisual en Rumanía}

La traducción se caracteriza por su interdisciplinaridad interna (Mayoral, 2001: 65), no obstante, esta particularidad ha constituido a lo largo del tiempo el tema de estudio de numerosos teóricos, que han tratado de definir y esclarecer la importancia de estos elementos en el desarrollo de la traducción audiovisual.

En este sentido, Gambier (2003: 172) definía que la especificidad de la traducción audiovisual se sustentaba en tres pilares fundamentales:

There are three fundamental issues in the AV filed, namely, the relationship between verbal output and pictures and soundtrack, between a foreign language/culture and the target language/culture, and finally between the spoken code and the written code.

Por su parte, Chaume (2001: 45), ponía de manifiesto la especificidad de la traducción audiovisual como objeto de estudio, definiéndola de la siguiente manera:

La traducción audiovisual es una modalidad de traducción que refleja con suma nitidez la necesidad de utilizar enfoques pluridisciplinares para acercarse con rigor a su objeto de estudio. En efecto, los

${ }^{13}$ Véanse, por ejemplo, Martínez Sierra (2004, 2009), Martí Ferriol (2006) y Bartoll (2008), que ofrecen una amplia revisión teórica en sus tesis. 
textos audiovisuales, por su carácter híbrido, tanto desde el punto de vista textual y genérico — es difícil delimitar dónde acaba un género y empieza otro-, como desde el punto de vista de sus variadísimos contenidos, así como, especialmente, desde el punto de vista de los múltiples códigos de significación que operan simultáneamente en la producción de sentido, incitan al analista a emplear enfoques diversos para intentar comprender mejor tanto la RELACIÓN entre los elementos que configuran su objeto de estudio, como las claves textuales y contextuales para la transferencia de estos elementos a otra lengua y cultura.

Por consiguiente, el conjunto de códigos de significación transmitidos a través del canal acústico y del canal visual interaccionan en este proceso y construyen el significado que llega al espectador. En cuanto a estos códigos, Chaume (2004: 305) enumera los más frecuentes: el código linguiístico, los códigos paralingüísticos, el código musical y de efectos especiales, el código de colocación del sonido, el código iconográfico, el código fotográfico, el código de planificación, el código de movilidad, los códigos gráficos y los códigos sintácticos o montaje.

Estas particularidades de la traducción audiovisual la distinguen de otros tipos de traducción, puesto que gobiernan el proceso de traducción y, por ende, la labor del profesional de este ámbito. Además, todos estos códigos han de estar en perfecta sincronización con la traducción, sea subtitulación o doblaje, para obtener un resultado similar del texto original al texto meta, tal como afirma Martínez Sierra (2004: 22):

Se trata de una variedad de traducción que presenta una serie de características propias que la definen frente a la traducción escrita y a la interpretación, y que tienen que ver principalmente con los condicionantes (internos y externos) que dicha modalidad presenta y las estrategias que requiere.

Tal como presentaremos a continuación, "esta variedad de traducción" como la define Martínez Sierra (2004: 22) se estructura en diferentes modalidades de traducción audiovisual (doblaje, subtitulación, voice-over, etc.) que han dividido los países en dobladores o subtituladores, según el tipo de traducción audiovisual que emplean mayoritariamente.

Si intentamos ahora aplicar todas estas consideraciones teóricas generales al objeto específico de nuestro estudio, cabe destacar que el cambio de sistema económico-político del año 1989 en Rumanía influye en el ámbito audiovisual rumano, de modo que, en los primeros años que transcurren a partir de esta fecha, los medios audiovisuales sufren su propia revolución y evolución. El gran número de cadenas de televisión que aparece, 
cambia y amplía la cantidad del producto extranjero que se emite, lo que conlleva un incremento del número de traductores necesarios en el país, así como la aparición de idiomas desde y hacia los que traducir.

Los programas y las películas que se emiten son variados, y mayoritariamente son importados de occidente, copiando el formato y la estructura bajo licencias.

Los formatos televisivos y los programas son supervisados por el Consejo Nacional Audiovisual (CNA), que actualmente es la única autoridad de reglamentación del dominio audiovisual en Rumanía. Creado en 1992, el CNA es una autoridad pública autónoma que protege y controla el interés público de este ámbito. Sus actividades están reguladas por leyes que amparan la monitorización del mercado audiovisual y que incluyen las siguientes obligaciones ${ }^{14}$ :

- Respetar la expresión de ideas pluralistas y de opiniones que se emiten en los programas bajo la jurisdicción de Rumanía.

- Asegurar el pluralismo de las fuentes de información del público y fomentar la libre competencia.

- Proteger la cultura y la lengua rumana, así como la cultura y la lengua de las minorías nacionales.

- Proteger la dignidad humana y a los menores.

- Asegurar la transparencia de los medios de comunicación del medio audiovisual.

- Establecer las condiciones, los criterios y el procedimiento para acordar las licencias audiovisuales.

- Elaborar instrucciones y emitir recomendaciones para el buen desarrollo de las actividades del dominio audiovisual.

- Observar e intentar mejorar, si es el caso, el contenido de los materiales audiovisuales que se emiten, supervisando de forma continua y atenta los programas de televisión y radio.

Podemos observar que el CNA controla el medio audiovisual y no pocas veces ha impuesto sanciones, como por ejemplo en el año 2003, cuando aplicó 35 multas y 125 sanciones ${ }^{15}$. O, cuando en el mismo año, criticó duramente en su informe de actividad el

${ }^{14}$ Véase: http://legislatie.resurse-pentru-democratie.org/legea/504-2002.php [consulta realizada 04/01/2016].
${ }^{15}$ Ibíd. 14. 
contenido y el tipo de noticias que se transmitieron en las cadenas de televisión, tal como se expone en el informe de actividad de esta institución (CNA-Informe de actividad, 2003: 14):

La monitorización de los programas informativos revela un preocupante aumento del número de emisiones que hacen referencia excesiva a la violencia gratuita y cuya presentación excede los límites de la decencia y del sentido común. [La traducción es nuestra].

Esta opinión define la situación audiovisual en Rumanía y nos ayuda a situar la posición del traductor audiovisual, que es el objetivo de nuestra investigación.

En Rumanía, las modalidades más habituales que se utilizan en la traducción audiovisual son la subtitulación, el doblaje y el voice-over. Entre los tres tipos destaca la subtitulación, aunque, tal y como veremos más adelante, el doblaje está adquiriendo una importancia creciente en la actualidad, especialmente en la traducción de productos audiovisuales para el público infantil.

\subsubsection{El subtitulado}

La elección del tipo de modalidad de traducción audiovisual empleada en cada país depende de su coste, pero también puede depender del habitus, que Bourdieu (1972: 178) define como la interacción entre personas, que no puede considerarse independiente de las propias estructuras sociales. Estas estructuras producen una predisposición (habitus) de los agentes que intervienen en la comunicación. De modo que el hábito, tal como lo describe el autor, es el conjunto de esquemas generativos a partir de los cuales los sujetos perciben el mundo y actúan en él:

\footnotetext{
Un systèm de dispositions durables et transposables, structures structurées prédisposées à fonctionner comme structures structurantes, c'est-à-dire en tant que príncipes générateurs et organisateurs de prectiques es de représentations que peuvent être objectivement adaptées à leur but sans supposer la visée consciente des fins et la maitrise expresse des opérations nécessaires pour les atteindre.
}

Rumanía es uno de los países de la antigua Europa del Este que emplea mayoritariamente como modalidad de traducción audiovisual la subtitulación, tanto para cine como para televisión. Sea por motivos políticos, económicos o de hábito, este tipo 
de traducción lleva mucho tiempo siendo la modalidad más empleada para traducir la avalancha de programas y películas que se han producido en el campo audiovisual desde de la revolución del año 1989.

La subtitulación es un proceso que consiste en la incorporación del texto traducido escrito generalmente en la parte inferior de la pantalla, manteniendo inalterada la banda sonora original. Díaz Cintas y Remael (2007: 8) la definen del siguiente modo:

Subtitling may be defined as a translation practice that consists of presenting a written text, generally on the lower part of the screen, that endeavors to recount the original dialogue of the speakers, as well as the discursive elements that appear in the image (letters, inserts, graffiti, inscriptions, placards, and the like), and the information that is contained on the soundtrack (songs, voices off).

Por su parte, Georgakopoulou (2009: 21) añade algunos requisitos y características de los subtítulos, tales como la necesidad de que se encuentren en sincronía con los diálogos que traducen o la importancia de su legibilidad:

Interlingual subtitling is a type of language transfer in which the translation, that is the subtitles, do not replace the original Source Text (ST), but rather, both are present in synchrony in the subtitled version. Subtitles are said to be most successful when not noticed by the viewer. For this to be achieved, they need to comply with certain levels of readability and be as concise as necessary in order not to distract the viewer's attention from the programme.

En la subtitulación es necesaria la perfecta coordinación de tres elementos fundamentales que caracterizan esta modalidad: los diálogos en la lengua original, las imágenes y los subtítulos en lengua meta. El conjunto de estos tres elementos, la capacidad de lectura del espectador y las dimensiones de la pantalla definen las características básicas de este tipo de traducción. Todo esto conlleva, a su vez, la necesidad de síntesis de información y de segmentación en unidades de sentido completo de los subtítulos para garantizar y favorecer su legibilidad por parte de los espectadores.

Otra de las características fundamentales de esta modalidad de traducción audiovisual que repercute en gran medida en la traducción es el cambio de modo que supone (de oral a escrito). Tal y como afirman Díaz Cintas y Remael (2007: 61):

Not only is subtitling an unusual form of translation because it is added to the ST, it also stands out as a unique translational genre because it renders speech in writing. This feature too determines the shape subtitles eventually take. 
Considerando todas estas particularidades que definen la subtitulación, la habilidad del traductor es esencial en este proceso. Tal como afirman Ivarsson y Carrol (1998: 1), para lograr crear unos subtítulos que conserven y transmitan la misma información del texto original al texto meta es necesario lo siguiente:

Subtitlers not only require outstanding language ability and journalistic talent, they must also have good visual sense, a thorough understanding of film and reading rhythms and a wide range of other skills.

Al verse limitada por factores espacio-temporales, la traducción en esta modalidad está sometida a restricciones de varios tipos (número de caracteres, duración mínima y máxima del subtítulo, velocidad de lectura, sincronía con imagen y sonido, etc.). Además, como hemos mencionado, la subtitulación implica un cambio de modo del discurso de oral a escrito, lo que en muchas ocasiones también lleva al traductor a omitir elementos del mensaje original. Todo esto conlleva que algunos teóricos, como Darbelnet (1970), Newmark (1981) o Garcia Yebra (1982), entiendan la subtitulación como una adaptación y no como una traducción del texto original al texto meta.

Las características anteriormente mencionadas han hecho que la subtitulación reciba muchas críticas, ya que es un tipo de traducción vulnerable (Díaz Cintas, 2003: 4344). Esto supone un reto para el traductor, dado que la yuxtaposición del texto original con el texto traducido puede permitir al espectador realizar la comparación de ambos mensajes (Mayoral, 1993: 49).

La subtitulación se empleaba en Rumanía antes de 1989 por motivos sociopolíticos y económicos. La dictadura del régimen prosoviético y su situación de aislamiento político respecto al mercado europeo impedían la llegada masiva de productos audiovisuales foráneos, y los pocos que penetraban el mercado rumano se consumían subtitulados. En la actualidad, aunque el mercado audiovisual rumano se ha abierto considerablemente, los hábitos adquiridos por el público y la precariedad económica de algunas cadenas de televisión han determinado la pervivencia de la subtitulación como modalidad habitual. Aunque existen algunos grupos profesionales y sociales que apuestan por el doblaje, la subtitulación es la modalidad de traducción audiovisual que prevalece en este país. 


\subsubsection{El doblaje}

El doblaje es otra de las principales modalidades de traducción audiovisual, que Chaume (2012: 1) define del siguiente modo:

[... ] it consists of replacing the original track of a film's (or any audiovisual text) source language dialogues with another track on which translated dialogues have been recorded in the target language.

Es un proceso complejo que implica en su realización un mayor número de participantes, y que supone costes más elevados en comparación con la subtitulación dadas sus características (Luyken et al., 1991: 112). La sincronía es una de ellas y corresponde a diversas fases del proceso, de las cuales se hacen cargo diferentes participantes: fase de contenido (el traductor), fase visual (el ajustador), fase acústica (el director), tal como determina Chaume (2004: 61-79). Uno de los objetivos fundamentales que se pretende en las traducciones para el doblaje es que el enunciado en la lengua meta suene lo más natural posible (Chaves, 2000: 20). Y, por esa razón, redactar diálogos que no sean ficticios, que suenen verosímiles, puede ser el mayor reto para un traductor, especialmente en el doblaje. El resultado final del doblaje es que los espectadores perciben, a través del canal acústico, información en su idioma, pero a través del canal visual visualizan actores extranjeros. Esto se puede calificar como una situación sorprendente, pero ha sido aceptada con bastante naturalidad en los países que utilizan como modalidad de traducción audiovisual el doblaje, si el proceso implicado se ha completado con éxito y calidad.

Otro elemento fundamental, que puede repercutir en el resultado final del doblaje, es el género del producto audiovisual. En este caso, Chaume (2012: 159) apunta tres tipos como los más comunes: dibujos animados, series y películas. Los dibujos animados son los que requieren una menor sincronización labial o fonética desde el punto de vista técnico. Sin embargo, como afirma Chaume (2012: 76), este tipo de género requiere una sincronización cinésica especial:

In contrast, kinesic synchrony is important to children's cartoons, as the cartoon characters tend to use exaggerated gestures to capture the attention of their young viewers. These gestures should be accompanied by a coherent translation. 
A diferencia de los dibujos animados, que son productos que se dirigen mayoritariamente al público infantil, las películas, principalmente destinadas al público adulto, son un género que necesita una sincronización perfecta a todos los niveles. Por lo tanto, los productores y distribuidores son muy exigentes con el doblaje, dado que el éxito comercial de la película depende en gran parte de la calidad de esta modalidad de traducción audiovisual.

Aunque en Rumanía la modalidad más empleada tanto para cine como para TV y DVD es la subtitulación, el doblaje también se utiliza para traducir los programas de animación y algunas películas dirigidas a los jóvenes. En otros países (como Francia, España, Alemania o Italia), el doblaje es la forma de traducción más extendida para la producción ajena de distribuidoras y cadenas de televisión.

En cambio, en Rumanía, los primeros experimentos con el doblaje se realizaron en la década de 1990. La primera película doblada emitida en los cines rumanos fue un filme dirigido al público joven: Babe, el cerdito valiente (Chris Noonan, 1995). Pero al tratarse de un campo bastante nuevo para Rumanía, las grabaciones de voz del proceso de doblaje se realizaron en Londres ${ }^{16}$. Posteriormente se ha empleado la misma modalidad (el doblaje) para realizar la primera y la única traducción para doblaje de otro género: la telenovela mejicana Alma de mujer (Roberto Hernández Vásquez, 1997). Aunque, en este caso, el proceso de doblaje se realizó en los estudios Mediavision de Bucarest, en el periodo de agosto de 1998 a enero de $1999{ }^{17}$.

De este modo, el doblaje empieza a ser una modalidad de traducción más usual en Rumanía durante la década del 2000, pero al no tener gran éxito en el mercado nacional, actualmente su empleo se limita a las grandes producciones animadas o a películas destinadas al público juvenil, que se presentan en el cine en las dos modalidades: doblaje o subtitulación, como por ejemplo Despicable Me (Pierre Coffin y Chris Renaud, 2010), Minions (Kyle Balda, Pierre Coffin, 2015) o Kubo and the Two Strings (Travis Knight, 2016).

Como hemos dicho, en Rumanía el doblaje se utiliza mayoritariamente para traducir los programas infantiles, al parecer desde diciembre del año 1989. Al principio se utilizaba un tipo de sonorización con un solo locutor, procedimiento que consiste en la grabación de todas las voces que aparecen en el filme por parte de un solo actor, como ocurre en el caso del voice-over polaco, por ejemplo (Franco, Matamala y Orero, 2010).

\footnotetext{
16 Véase: http://ro.wikipedia.org/wiki/Dublaj [consulta realizada 20/09/2013].

${ }^{17}$ Ibíd. 16.
} 
Pero paulatinamente, las cadenas privadas empezaron a utilizar el doblaje profesional para traducir las series infantiles extranjeras, que han invadido el mercado rumano después de la revolución. Como resultado del desarrollo de esta modalidad de traducción audiovisual y del crecimiento de los productos extranjeros destinados al público infantil, en el año 1999 lanza sus emisiones la primera cadena de televisión exclusivamente con doblajes al rumano, Fox Kids, cadena que cambió posteriormente su nombre por Jetix y Disney Channel. En el año 2004 aparece otra cadena de las mismas características, Cartoon Network, que contribuye todavía más al hecho de que esta modalidad de traducción sea más conocida y más empleada.

El doblaje en Rumanía, como decimos, se utiliza para traducir los dibujos animados, y en este ámbito destaca el estudio de doblaje Ager Film, encargado de esta modalidad de traducción en el país desde 1991 en colaboración con distribuidoras como Paramount, Dreamworks o Sony Pictures.

En cuanto al coste, como hemos mencionado previamente, el doblaje tiene un precio más elevado que la subtitulación (Luyken et al., 1991: 112), aunque generalmente en Rumanía, las empresas que prestan este tipo de servicios son muy reservadas a la hora de hacer públicos los precios que emplean para el doblaje. Habitualmente se cobra por cada episodio, en el caso de las series, y el precio sube si se trata de un largometraje. Todo se negocia de forma diferente en cada caso, en función del periodo del contrato o de sus características (si la película o los dibujos animados contienen canciones, o si las voces que se van a emplear son célebres ${ }^{18}$. Como ya hemos mencionado, el doblaje es una modalidad de traducción audiovisual poco empleada en el mercado rumano, sin embargo, a causa de los costes elevados que conlleva, las empresas especializadas en este ámbito pueden llegar a obtener pingües beneficios. En algunos casos, el coste aumenta por realizar la banda sonora en rumano para las películas o los dibujos animados. Las empresas más conocidas que actualmente utilizan el doblaje como modalidad de traducción en el mercado rumano, según los datos aportados por Consiliul Concurentei ${ }^{19}$, son: Audio Design Digital Art, Ager Film, Fast Production Film, MediaVision, Empire Video Production, Nord Media Studio, Ines Sunet y Video SRL și Broadcast Text International (que acaba de cambiar el nombre por Zone Studio Oradea), aunque entre todas destacan las tres mencionadas en la Tabla 5.

\footnotetext{
18 Véase:http://www.capital.ro/detalii-articole/stiri/de-unde-au-invatat-romaneste-filmele-straine-157531.html [consulta realizada 25/10/2013].

${ }^{19}$ Ibíd 18.
} 
Para ejemplificar el volumen de producción doblada, observemos los beneficios declarados ${ }^{20}$ por las tres empresas en Rumanía en el sector del doblaje durante los años 2009 y 2010.

\begin{tabular}{|c|c|c|}
\hline Empresa & Año 2009 & Año 2010 \\
\hline Zone Studio Oradea & $1556412,54 €$ & $1778750,83 €$ \\
\hline Empire Video Production & $889397,65 €$ & $1111847,12 €$ \\
\hline Ager Film & $667192,76 €$ & $889486,59 €$ \\
\hline
\end{tabular}

Tabla 5. Ingresos de las empresas de doblaje

Asimismo, las empresas de doblaje incrementan sus beneficios debido al importante crecimiento de cadenas con programas de animación dirigidos especialmente al público infantil ${ }^{21}$.

\subsubsection{El voice-over}

El voice-over o voces superpuestas es una modalidad de doblaje que se utiliza especialmente en documentales, así como en entrevistas en televisión o en realities. Los orígenes de esta modalidad se remontan a los inicios del cine, cuando en 1893 las películas mudas necesitaban un "lector" para proporcionar los comentarios al público. Se trababa entonces de un tipo de interpretación simultánea en la que la función del lector consistía en realizar la traducción respetando la sincronía temporal, espacial y narrativa del filme (Kozloff, 1988: 5).

Autores como Díaz Cintas y Orero (2010: 441) consideran que esta modalidad de traducción audiovisual se podría definir como:

From a translational perspective, voiceover consists in presenting orally a translation in a TL, which can be heard simultaneously over the SL voice.

From a technical perspective, there are many possibilities of synchronising the ST and the TT in the case of voiceover. The standard approach is to reduce the volume of the original soundtrack to a faint auditory level that can still be heard in the background, whilst the translation is being read. Usually, the viewer is allowed to hear the foreign language for a few seconds at the onset of the speech, before the volume of the original is subsequently reduced so that the translated speech can be superimposed. The translation typically finishes a couple of seconds before the foreign language

${ }^{20}$ Véase: http://www.capital.ro/detalii-articole/stiri/de-unde-au-invatat-romaneste-filmele-straine-157531.html [consulta realizada 25/10/2015].

${ }^{21}$ Véase: http://eacea.ec.europa.eu/llp/studies/documents/study_on_the_use_of_subtitling/rapport_final-en.pdf [consulta realizada 10/08/2016]. 
speech does, the sound of the original is raised again to a normal volume level and the viewer can hear once more the original speech.

Como vemos, esta modalidad de traducción audiovisual consiste en superponer la versión oral traducida sobre la versión original. Las voces superpuestas traducen el diálogo al igual que el doblaje, pero sin reemplazarlo por completo, ya que se escucha simultáneamente la versión original y la traducción, y normalmente con solo una voz.

No existe una norma sobre la superposición de voces y su sincronía, pero normalmente la traducción comienza después y termina antes, lo que permite escuchar el diálogo original. Las exigencias de sincronismo son menores que en otros tipos de traducción, y esto ofrece al traductor más libertad en el estilo y la reformulación. Sin embargo, es necesario formular una versión traducida que garantice una velocidad de lectura normal por los locutores (o actores de doblaje). Otra característica de este tipo de traducción audiovisual consiste en que tampoco es necesario ajustar en boca (sincronía fonética), con lo cual se puede añadir más información (sin caer en la sobretraducción o “traducción excesiva"), tal como afirma Mayoral (2001: 38).

No obstante, algunos teóricos, como por ejemplo Belton (1985: 65), desacreditan este tipo de traducción por proporcionar poca credibilidad al público:

By the same token, dubbing, and especially the dubbing of foreign films in which one language is seen spoken but another heard, is "read" by audiences as false. [...] The rather obvious intervention of technology involved with dubbing severely circumscribes our faith in both sound and image, provoking a crisis in their credibility.

A pesar de sus particularidades, la traducción para el voice-over se asemeja a la traducción del doblaje, tal como menciona Lukić (2012: 195-196) en su estudio:

En la mayoría de los casos, el traductor que traduce para el voice-over realiza el trasvase del texto con la ayuda del guión original, y a menudo dispone de un libro de estilo. El traductor introduce los códigos de tiempo delante de las entradas de las intervenciones del narrador y de otros interlocutores. (...) Estos códigos se separan con dos puntos en la mayoría de los estudios que doblan películas o documentales (00:00:00), contienen el código de la entrada de los takes (unidades de doblaje), y corresponden a los inicios de las intervenciones de los actores de doblaje. 
Autores como Franco, Matamala y Orero (2010) o como Chaume (2013) describen este tipo de traducción audiovisual presentando sus características y los tipos de voice-over.

Desde nuestro punto de vista particular, el objeto de esta investigación, cabe destacar que el voice-over es la otra modalidad de traducción audiovisual presente en el mercado rumano, aunque menos empleada que la subtitulación o el doblaje. Sus características profesionales son similares a las otras modalidades de traducción audiovisual, como por ejemplo, un tiempo de entrega muy ajustado y una calidad de imagen y sonido que no son siempre las óptimas. En cuanto a las características textuales del material que se recibe para traducir, Díaz Cintas (2003: 32) asegura que es necesario tener en cuenta diversos aspectos de esta modalidad de traducción como: los elementos prosódicos que pueden determinar la velocidad de la locución, el acento, la competencia lingüística, los elementos paralingüísticos que determinan la voz, la dicción y el lenguaje corporal de los participantes; $y$, por consiguiente, las competencias que se exigen en este caso son una combinación entre las de un traductor y las de un intérprete.

Esta práctica se utiliza en Rumanía en la emisión de los documentales de producción ajena o de entrevistas a personas extranjeras.

\subsection{Las razones del triunfo del subtitulado en Rumanía}

La subtitulación es la modalidad de traducción audiovisual más antigua y más utilizada en Rumanía, tanto en el cine como en la televisión. Sea por motivos económicos, políticos (especialmente en la época de la dictadura, cuando la censura se aplicaba de modo irregular, tal como presentamos en el capítulo anterior) o de hábito, en la actualidad la subtitulación conserva aún su supremacía en este país.

En el año 2011 el diputado Victor Socaciu propuso en el parlamento cambiar la subtitulación por el doblaje, sosteniendo que de este modo se protegía la identidad nacional $^{22}$, pero su propuesta fue rechazada por una gran mayoría de votos. Los adeptos a la subtitulación insisten en afirmar que una película está concebida para visionarla en su idioma original. Sostienen que, a través de la voz y de la entonación, se transmiten al espectador emociones que no se pueden transferir del mismo modo a través del doblaje.

${ }^{22}$ Véase: http://194.88.148.105/fb/bf/4e/41/em237.pdf?c=705d98dc7668785913f670a99c49e883 [consulta realizada 19/10/2015]. 
Por otra parte, las asociaciones de sordos del país también muestran su interés a favor del subtitulado. En este sentido, Mihail Grecu (2011), presidente de la Asociación de Sordos en Rumanía ${ }^{23}$, apunta lo siguiente:

Si no existe la subtitulación en Rumanía, las personas sordas van a visionar la película como una pantomima, no entenderán nada. Desde nuestro punto de vista, es una discriminación. A nivel europeo y, podemos decir, global, existen subtítulos especiales para las personas sordas. En nuestro país no existe nada así, por lo que las películas y la banda con las informaciones que aparecen en la pantalla (subtítulos) son nuestros únicos medios de información. [La traducción es nuestra].

En esta coyuntura, dado que ni la situación económica ni el panorama profesional permiten un cambio drástico en este sector, la subtitulación convencional sería momentáneamente la modalidad que puede ser más accesible a los espectadores con discapacidades auditivas en este país.

Por otra parte, los profesionales de este ámbito, como Irina Margareta Nistor (2011), afirman que este cambio (pasar de la subtitulación al doblaje) no puede realizarse repentinamente, porque el público ya está habituado a la subtitulación. Otro factor que influye es el hecho de que las cadenas de televisión no están preparadas para afrontar esta transformación, que implica unos costes elevados sobre todo por la necesidad de formación específica de los profesionales del doblaje ${ }^{24}$ :

Yo considero que este cambio sería un claro inconveniente para el público, dado que se trata de grandes actores que no pueden ser reemplazados con cualquier voz de Rumanía. Simplemente, es un crimen. Por eso, no veo por qué, de repente, tenemos que empezar a doblar. De todas formas, todo esto tiene un gran coste, y creo que este será el argumento final para no cambiar. [La traducción es nuestra].

A todo esto, se le añade el hábito del entorno social, tal como confirmaba para la prensa Irina Catanchin (experta en marketing y mánager de HBO Rumanía) en el año 2011:

Creemos que existe una fuerte tradición en la subtitulación de las películas extranjeras. El público está acostumbrado a oír la pista sonora original, no doblada, no alterada. Ni en la época comunista

\footnotetext{
23 Véase: http://www.cinemarx.ro/stiri-cinema/dublarea-filmelor-in-limba-romana-e-cea-mai-respinsa-propunere-legislativa-dinultima-vreme/ [consulta realizada 15/02/2016].

${ }^{24}$ Véase: http://www.ziare.com/media/televiziune/vreti-filme-dublate-sau-subtitrate-sondaj-ziare-com-1092879 [consulta realizada 19/08/2016].
} 
se han doblado las películas. Se trata de una cultura y una educación en este sentido en nuestro país. El filme es un arte, y HBO considera que las películas significan mucho más que un producto. [La traducción es nuestra].

Podemos observar que la simple propuesta de cambiar la modalidad de traducción audiovisual de los productos extranjeros causa rechazo por parte de la mayoría de los implicados en este proceso, especialmente profesionales y cadenas, pero también público. La subtitulación es una modalidad de traducción que se utiliza desde el año 1956, cuando emitió por primera vez la cadena nacional (TVR) en Rumanía, y consideramos que un cambio repentino supondría, además de unos gastos más elevados en lo que concierne el proceso de traducción audiovisual, también una alteración de los hábitos del público.

La crisis económica y política llevó a la elección de una modalidad de traducción audiovisual (el subtitulado), que es la modalidad imperante en el país a día de hoy. La exposición a productos subtitulados durante años es lo que crea un hábito de consumo entre la audiencia que difícilmente puede cambiar, tal como afirma Chaume (2004: 60).

Mientras el doblaje avanza paulatinamente, principalmente para traducir productos destinados al público infantil, la subtitulación sigue siendo, indudablemente, la modalidad más habitual de la traducción audiovisual en Rumanía.

\subsection{Los medios que utilizan la traducción audiovisual en Rumanía}

\subsubsection{Las cadenas de TV}

El cambio del sistema económico-político que sufre Rumanía en 1989, año en que el pueblo rumano consigue poner fin a la dictadura de Nicolae Ceaușescu, repercute también en el panorama audiovisual de este país. Hasta esa fecha, en Rumanía solamente emitía una cadena de televisión, la Televisión Rumana (Televiziunea Româna), con dos horas diarias de programas que elogiaban las gestas y las salomónicas decisiones del dictador. Gracias a esta cadena, se pudo ver también, en directo, la revolución que libró al país de la antigua dictadura prosoviética.

Al ser un campo inexplorado hasta esa fecha, el sistema audiovisual sufre cambios importantes a partir de la liberación de la dictadura y paulatinamente van apareciendo cadenas privadas que hacen cambiar el modelo de televisión, los programas y los tiempos de emisión. En la siguiente tabla se observan los años de aparición de distintas cadenas privadas en Rumanía: 


\begin{tabular}{|l|l|}
\hline \multicolumn{1}{|c|}{ Año de aparición } & \multicolumn{1}{|c|}{ Cadena } \\
\hline 1991 & $\begin{array}{l}\text { Sociedad para una televisión } \\
\text { independiente (SOTI) }\end{array}$ \\
\hline 1993 & Antena 1 \\
\hline 1994 & Tele 7 ABC \\
\hline 1995 & Pro TV \\
\hline 1997 & Prima TV \\
\hline
\end{tabular}

Tabla 6. Año de aparición de diversas cadenas de TV privadas en Rumanía

Según los datos presentados por el CNA en la última estadística realizada a finales del año 2013, la situación audiovisual en Rumanía es la siguiente: 185 cadenas con emisión digital terrestre y 22 cadenas que emiten vía satélite ${ }^{25}$. Los grandes índices de audiencia, sin embargo, los tienen TVR1, que ocupa el primer puesto, ProTV, situada en segundo puesto, y Antena 1, en el tercero.

Actualmente existen cadenas generalistas como, por ejemplo, Antena 1, Pro TV, Prima TV, Nacional TV, pero también cadenas con programas específicos de noticias (Antena 3, Realitatea TV y N 24), cadenas con contenido dirigido a las mujeres (Acasa y Euforia TV), centradas en el deporte (Telesport sport.ro) o en la música (como MTV Rumanía o KISS TV).

Con el fin de realizar un análisis preliminar entre dos tipos de cadenas y sus respectivas programaciones diarias, y para comprobar qué porcentaje de producción ajena se traduce en las mismas, en el año 2013 realizamos un estudio ${ }^{26}$ en el que elegimos una cadena pública nacional, TVR 1; y otra privada, ProTV.

De esta forma, los porcentajes semanales de producción ajena traducida en TVR1 y ProTV en la segunda semana del mes de septiembre de 2013 eran los siguientes:

TVR1 168 horas de emisión semanal (24 horas diarias)

62 horas de producción ajena $=36,90 \%$ de la emisión global

ProTV 168 horas de emisión semanal (24 horas diarias)

\footnotetext{
${ }^{25}$ Véase: http://www.cdep.ro/caseta/2014/05/22/hp14011_CNA13.pdf [consulta realizada 20/01/2017].

${ }^{26}$ Véase el Trabajo de Fin de Máster, La Traducción Audiovisual en Rumania: Análisis de la subtitulación Pirates of the Caribbean: On Stranger Tides Inglés-Rumano (Vulpoiu, 2013).
} 
92 horas de producción ajena $=54,76 \%$ de la emisión global

Los porcentajes semanales de estas dos televisiones nos dan una idea preliminar del volumen de producción ajena que se emite en Rumanía al cabo del año. Según podemos comprobar, la cadena TVR1 emite menos programas extranjeros. Como ocurre en otros países europeos, el principal motivo puede ser el hecho de que se trata de una cadena pública, pero en el caso rumano, también podría ser por tener menos poder adquisitivo para comprar licencias de emisión de películas u otros programas extranjeros, a diferencia de la cadena privada ProTV.

En una entrevista concedida a Mediafax.ro (2014), el director de la televisión nacional (TVR1), Stelian Tănase, corrobora esta hipótesis:

La cadena de televisión TVR1 está en una situación financiera bastante crítica. En este período tan difícil, los directivos de la TVR se ven obligados a priorizar los gastos en función del interés del público, conforme a la misión pública de la Televisión Rumana. Dado el grave contexto en el que se encuentra TVR, la actual dirección decide rescindir los contratos de los programas con precio más elevado para reducir los gastos de producción. En este período, esta cadena funciona emitiendo programas mucho más económicos que en los años anteriores. [La traducción es nuestra].

Por tanto, la grave situación económica que atraviesa esta cadena influye de tal modo en la variedad y la calidad de los programas que emite, que desemboca en su exclusión de la competición musical Eurovision del año 2016. Una situación sin precedentes en la historia del European Broadcasting Union (EBU), dado que es la primera vez que se retiran los servicios de asociado a una cadena por motivos económicos.

\subsubsection{El cine}

La situación del cine en Rumanía es totalmente contraria a la situación de la televisión. A partir del año 1989 se produce un gran descenso, tanto de público como de número de salas de exhibición. Los datos estadísticos publicados por el Centro Nacional de Cinematografía (Centrul Naţional de Cinematografie) ${ }^{27}$ reflejan las pérdidas que ha sufrido este negocio en los últimos años:

\footnotetext{
${ }^{27}$ Véase: http://cnc.gov.ro/[consulta realizada 12/01/2017].
} 
Capítulo 2: La traducción audiovisual en Rumanía

\begin{tabular}{|l|l|}
\hline Año & Número de salas de cine \\
\hline 1997 & 432 \\
\hline 2005 & 85 \\
\hline
\end{tabular}

Tabla 7. Evolución del número de salas de cine en Rumanía (fuente: CNC)

El número de usuarios o espectadores en las salas de cine ha descendido notablemente de 9456234 espectadores en 1997, a tan solo 2829563 en $2005^{28}$.

Esta situación se debe, sobre todo, al cambio social y al gran número de cadenas de televisión que han aparecido en poco tiempo en el panorama audiovisual rumano. La situación económica y los hábitos de la audiencia, según afirmaba el director de cine Nae Caranfil en una entrevista para la revista Iașul Cultural (Francesca Stoian, 2009), también influyen en este descenso de público que sufren los cinematógrafos rumanos actualmente:

En Rumanía existen dos tipos de salas de cine: una tradicional, con dispositivos muy obsoletos, y donde la película no se ve y no se oye; y el multiplex, donde la película se ve perfectamente, pero es una sala para comer palomitas. Entras en la sala y se habla por el móvil, se oye el ruido de las bolsas de palomitas y algunos no tienen el más mínimo respeto por el que ha pagado bastante dinero y quiere visionar la película desde el principio hasta el final, si es posible. Entiendo de algún modo la reticencia a ir al cine del público, que tiene que elegir entre estos dos tipos de salas. No sé cuál sería la solución. [La traducción es nuestra].

Las nuevas tecnologías, que actúan como nuevas ventanas, y la piratería de los productos audiovisuales, pueden ser otro gran motivo por el cual muchas salas de cine que antes de la revolución recibían un número impresionante de espectadores, hoy en día están casi en la ruina. Pero a pesar de todo este panorama de descuido y dejadez, en Rumanía afortunadamente aún existen salas de cine que ofrecen al público las películas extranjeras y nacionales más actuales, y que en los últimos años algunos se han equipado con tecnología de última generación.

En 2014 la Asociación para Promover el Filme Rumano (APFR) ${ }^{29}$, patrocinada por el Festival Internacional de Filme Transilvania (TIFF), inició una amplia campaña para detener la desaparición de los cinematógrafos bajo el lema Salvaţi Marele Ecran! (¡Salvemos la gran pantalla!); asimismo, inauguró una página web interactiva

\footnotetext{
${ }^{28}$ Ibíd. 24.

${ }^{29}$ Véase: http://www.creative-europe-media.eu/festivals/organisers/item/938-transilvania-international-film-festival-14th-edition [consulta realizada 9/01/2017].
} 
(www.salvatimareleecran.ro) y organizó seminarios y congresos para debatir este problema.

El número de películas que se han estrenado en el periodo 2011-2015, según los datos recopilados por el Centro Nacional de Cinematografía $(\mathrm{CNC})^{30}$, es el siguiente:

\begin{tabular}{|l|c|c|c|c|c|}
\hline \multirow{2}{*}{ Nacionalidad de los filmes } & $\mathbf{2 0 1 1}$ & $\mathbf{2 0 1 2}$ & $\mathbf{2 0 1 3}$ & $\mathbf{2 0 1 4}$ & $\mathbf{2 0 1 5}$ \\
& $\mathbf{N}^{\mathbf{o}}$ & $\mathbf{N}^{\mathbf{o}}$ & $\mathbf{N}^{\mathbf{0}}$ & $\mathbf{N}^{\mathbf{0}}$ & $\mathbf{N}^{\mathbf{0}}$ \\
& $\mathbf{\%}$ & $\mathbf{\%}$ & $\mathbf{\%}$ & $\mathbf{\%}$ & $\mathbf{\%}$ \\
\hline \multirow{2}{*}{ Rumanos } & 24 & 23 & 27 & 23 & 22 \\
& 12,50 & 12,37 & 13,64 & 11,98 & 10,14 \\
\hline \multirow{2}{*}{ Europeos } & 49 & 48 & 38 & 47 & 80 \\
\hline \multirow{2}{*}{ Estados Unidos } & 25,52 & 25,81 & 19,19 & 24,48 & 36,87 \\
\hline \multirow{2}{*}{ Otros países } & 114 & 131 & 123 & 113 & 104 \\
& 59,38 & 60,75 & 62,12 & 58,85 & 60,7 \\
\hline \multirow{2}{*}{ Total } & 5 & 2 & 10 & 9 & 11 \\
& 2,60 & 1,08 & 5,05 & 4,69 & 5,07 \\
\hline
\end{tabular}

Tabla 8. Procedencia de los filmes exhibidos en Rumanía entre 2011 y 2015 (fuente: CNC)

Las empresas que se encargan de distribuir y, a veces, de realizar la traducción audiovisual de las películas que se van a exhibir en los cinematógrafos, se clasifican de la siguiente forma, según el número de películas que han estrenado durante los últimos cinco años en el mercado cinematográfico rumano:

\begin{tabular}{|l|c|c|c|c|c|}
\hline & $\mathbf{2 0 1 1}$ & $\mathbf{2 0 1 2}$ & $\mathbf{2 0 1 3}$ & $\mathbf{2 0 1 4}$ & $\mathbf{2 0 1 5}$ \\
& $\mathbf{N}^{\mathbf{0}}$ & $\mathbf{N}^{\mathbf{0}}$ & $\mathbf{N}^{\mathbf{0}}$ & $\mathbf{N}^{\mathbf{0}}$ & $\mathbf{N}^{\mathbf{0}}$ \\
& $\mathbf{\%}$ & $\boldsymbol{\%}$ & $\boldsymbol{\%}$ & $\mathbf{\%}$ & $\mathbf{\%}$ \\
\hline Ro-Image 2000 & 35 & 42 & 35 & 36 & 46 \\
& 18,23 & 22,58 & 17,68 & 18,75 & 21,20 \\
\hline Freeman Entertainement & & & & 10 & 28 \\
& & & & 5,21 & 12,90 \\
\hline
\end{tabular}

${ }^{30}$ Véase: http://cnc.gov.ro/ [consulta realizada 13/01/2017]. 
Capítulo 2: La traducción audiovisual en Rumanía

\begin{tabular}{|c|c|c|c|c|c|}
\hline Intercom Film & $\begin{array}{c}20 \\
10,42\end{array}$ & $\begin{array}{c}14 \\
7,53\end{array}$ & $\begin{array}{c}23 \\
11,62\end{array}$ & $\begin{array}{c}26 \\
13,54\end{array}$ & $\begin{array}{c}24 \\
11,06\end{array}$ \\
\hline \multirow{2}{*}{ Forum Film Romania } & 10 & 21 & 16 & 19 & 21 \\
\hline & 5,21 & 11,29 & 8,08 & 9,90 & 9,68 \\
\hline \multirow{2}{*}{ Independenta Film } & 15 & 13 & 18 & 17 & 17 \\
\hline & 7,81 & 6,99 & 9,09 & 8,85 & 7,83 \\
\hline \multirow{2}{*}{ Odeon Cineplex } & 13 & 12 & 17 & 19 & 15 \\
\hline & 6,77 & 6,45 & 8,59 & 9,90 & 6,91 \\
\hline \multirow{2}{*}{ Clorofilm } & 7 & 2 & 3 & 3 & 12 \\
\hline & 3,65 & 1,08 & 1,52 & 1,56 & 5,53 \\
\hline \multirow{2}{*}{ Cine Europa } & & & & & 10 \\
\hline & & & & & 4,61 \\
\hline \multirow{2}{*}{ Transilvania Film } & 20 & 12 & 9 & 7 & 9 \\
\hline & 10,42 & 6,45 & 4,55 & 3,65 & 4,15 \\
\hline \multirow{2}{*}{ Asociatia Culturala Macondo } & 2 & 2 & 7 & & 5 \\
\hline & 1,04 & 1,08 & 3,54 & & 2,30 \\
\hline \multirow{2}{*}{ Mandragora } & & & & & 4 \\
\hline & & & & & 1,84 \\
\hline \multirow{2}{*}{ Voodoo Film } & & & 2 & & 3 \\
\hline & & & 1,01 & & 1,38 \\
\hline \multirow{2}{*}{ Parlux Entertainement } & & & & & 3 \\
\hline & & & & & 1,38 \\
\hline \multirow{2}{*}{ Parada Film } & & & 3 & & 3 \\
\hline & & & 1,52 & & 1,38 \\
\hline \multirow{2}{*}{ BML Movie Entertainement } & & & & 6 & 2 \\
\hline & & & & 3,13 & 0,92 \\
\hline \multirow{2}{*}{ Otras distribuidoras ${ }^{31}$} & 70 & 68 & 65 & 49 & 15 \\
\hline & 36,45 & 36,55 & 32,82 & 25,52 & 6,91 \\
\hline \multirow{2}{*}{ Total } & 192 & 186 & 198 & 192 & 217 \\
\hline & $100 \%$ & $100 \%$ & $100 \%$ & $100 \%$ & $100 \%$ \\
\hline
\end{tabular}

Tabla 9. Principales distribuidoras de cine en Rumanía entre 2011-2015 (fuente: CNC)

31 "Otras distribuidoras" representa el número de películas que se han exhibido en los festivales de filme durante este periodo. 
Según los datos expuestos, podemos observar que, a pesar del descenso de número de salas de cine, actualmente el mercado en este ámbito está en un continuo ascenso gracias a las distribuidoras que durante estos años han elevado su número y han invertido capital para proyectar estrenos cinematográficos que han logrado atraer de nuevo al público a las salas de cine.

\subsubsection{La industria del DVD}

Para tener una idea de la situación actual del mercado rumano de cintas de video, DVD, CD, UMD (Universal Media Disc) y BD (Blu-ray) utilizamos los datos presentados por el Registro de Cinematografía de Rumanía en el período comprendido entre 2011 y 2015 (vid. Anexo 5). Según podemos comprobar a través de las siguientes tablas, el mercado de estos productos va bajando año tras año, suponemos que, debido a la irrupción de las nuevas tecnologías, a la piratería o al gran número de películas que emiten las cadenas de televisión o las plataformas de vídeo en línea, con cuya oferta parece ser innecesaria la compra de DVD. La situación económica que atraviesa la población del país también influye en una disminución en los gastos que realizan los consumidores. De la traducción de las películas en este formato se encargan las empresas distribuidoras, que contactan con el traductor, situación parecida a la de la traducción de las películas para las salas de cine.

La siguiente tabla muestra la progresión de ediciones de nuevos títulos de películas en el mercado en formato de cintas de video, DVD, CD, UMD y BD:

\begin{tabular}{|l|l|l|l|l|l|}
\hline Año & 2011 & 2012 & 2013 & 2014 & 2015 \\
\hline Número de títulos & 5813 & 3417 & 3365 & 3601 & 3320 \\
\hline
\end{tabular}

Tabla 10. Progresión en el número de títulos de filmes editados en diferentes soportes en Rumanía

Como se aprecia, en tan solo tres años, el número de filmes editados en los soportes mencionados arriba se ha reducido a aproximadamente la mitad.

La tirada en diferentes soportes, como por ejemplo cintas de video, DVD, CD, UMD y BD grabadas por el CNC, ha sufrido la misma progresión descendente: 


\begin{tabular}{|l|c|c|c|c|c|}
\hline Año & $\mathbf{2 0 1 1}$ & $\mathbf{2 0 1 2}$ & $\mathbf{2 0 1 3}$ & $\mathbf{2 0 1 4}$ & $\mathbf{2 0 1 5}$ \\
\hline Número de grabaciones & 1946651 & 945850 & 677150 & 402350 & 330170 \\
\hline
\end{tabular}

Tabla 11. Progresión del número de cintas editadas en diferentes soportes por el CNC

El número de empresas que comercializan las películas en mercado en formato de cintas de video, DVD, CD, UMD y BD no parece haber disminuido, sino más bien al contrario:

\begin{tabular}{|l|c|c|c|c|c|}
\hline Año & $\mathbf{2 0 1 1}$ & $\mathbf{2 0 1 2}$ & $\mathbf{2 0 1 3}$ & $\mathbf{2 0 1 4}$ & $\mathbf{2 0 1 5}$ \\
\hline Número de empresas a fin de año & 545 & 551 & 562 & 581 & 590 \\
Registradas durante el año & 20 & 6 & 11 & 20 & 11 \\
\hline
\end{tabular}

Tabla 12. Número de empresas que comercializan cintas de video, DVD, CD, UMD y BD

Lo mismo ocurre con el número de empresas de alquiler de películas en formato de cintas de video, DVD, CD, UMD y BD existentes en el país:

\begin{tabular}{|l|c|c|c|c|c|}
\hline Año & $\mathbf{2 0 1 1}$ & $\mathbf{2 0 1 2}$ & $\mathbf{2 0 1 3}$ & $\mathbf{2 0 1 4}$ & $\mathbf{2 0 1 5}$ \\
\hline Número de empresas a fin de año & 496 & 503 & 512 & 527 & 540 \\
Registradas durante el año & 14 & 7 & 9 & 16 & 7 \\
\hline
\end{tabular}

Tabla 13. Número de empresas que alquilan cintas de video, DVD, CD, UMD y BD

Finalmente, para completar la visión panorámica de la exhibición y traducción audiovisual en Rumanía, se incluye a continuación un listado de distribuidoras mayoristas en el mercado de alquiler de películas en formato de cintas de video, DVD, CD, UMD y BD, así como el número de filmes editados y distribuidos en este formato entre 2011 y 2015:

\begin{tabular}{|l|c|}
\hline Nombre de la empresa distribuidora & $\begin{array}{c}\text { Número de filmes editados y } \\
\text { distribuidos }\end{array}$ \\
\hline Pro Video & 153500 \\
\hline Empire Film & 87950 \\
\hline Odeon Cineplex & 62500 \\
\hline
\end{tabular}

Tabla 14. Empresas distribuidoras de cintas de video, DVD, etc. y número de títulos editados 
Tal como se refleja en el conjunto de diferentes datos presentados anteriormente, el mercado de la industria de películas en formato de cintas de video, DVD, CD, UMD y BD descendió considerablemente en los años posteriores a la revolución del año 1989.

Uno de los motivos fundamentales de este declive podría ser la eclosión considerable de cadenas privadas, que cambian el modelo de televisión y aportan al espectador rumano una avalancha de nuevos programas, y el aumento de tiempos de emisión, comparado con la época comunista, que a su vez modifica sus hábitos de ocio.

Por otra parte, la evolución tecnológica que experimentó este país en un breve período de tiempo podría constituir otro factor importante, tal como pudimos observar en el apartado anterior dedicado al cine.

A modo de conclusión, podemos afirmar que el cambio político influyó y, al mismo tiempo, transformó íntegramente el mercado audiovisual, implantando nuevos modelos de distribución y explotación, que a su vez repercutieron en las costumbres del usuario.

\subsection{Síntesis y conclusiones}

En este capítulo hemos realizado una breve descripción de las tres modalidades de traducción audiovisual empleadas actualmente en Rumanía (subtitulación, doblaje y voice-over), hemos presentado los medios y soportes a través de los cuales es posible consumir productos audiovisuales traducidos en el país y hemos ofrecido algunas pinceladas del rol que ejerce el traductor en este ámbito en Rumanía.

A continuación presentamos algunas de las cuestiones de mayor interés para el trabajo que hemos abordado en el presente capítulo:

- El cambio del sistema económico-político del año 1989 en Rumanía influye en el ámbito audiovisual rumano de modo que, en los primeros años que transcurren a partir de esta fecha, los medios audiovisuales sufren su propia revolución y evolución. Los nuevos formatos televisivos y programas son supervisados por el Consejo Nacional Audiovisual (CNA), que actualmente es la única autoridad de reglamentación del dominio audiovisual. 
- Rumanía es uno de los países de la antigua Europa del Este que emplea como modalidad de traducción audiovisual la subtitulación, tanto para cine como para televisión. Sea por motivos políticos, económicos o de habitus (Bordieu, 1972: 178), este tipo de traducción lleva mucho tiempo siendo la más empleada para traducir la avalancha de programas y películas de origen extranjero que se ha producido desde 1989 en el campo audiovisual.

- En cuanto al doblaje, los primeros experimentos se realizaron en la década de 1990. La primera película doblada emitida en los cines rumanos fue un filme dirigido al público joven: Babe, el cerdito valiente (Chris Noonan, 1995). Sin embargo, al tratarse de un campo bastante nuevo en Rumanía, las grabaciones de voz del proceso de doblaje se realizaron en Londres. Paulatinamente, la aparición de varias cadenas de televisión privadas, que emiten programas dedicados exclusivamente al público infantil, como por ejemplo Jetix, Minimax, Disney Junior o Nickelodeon, ha contribuido al incremento del doblaje, modalidad poco habitual en Rumanía antes del año 1989.

- El voice-over es la otra modalidad de traducción audiovisual presente en el mercado rumano, aunque menos empleada que la subtitulación o el doblaje. Esta práctica se utiliza en Rumanía en la emisión de los documentales de producción ajena o de entrevistas a personas extranjeras.

- En cuanto al triunfo de la subtitulación en Rumanía, consideramos que existen dos motivos importantes para ello: los económicos y los de hábito. La propuesta de cambiar esta modalidad de traducción audiovisual por la de doblaje causó rechazo en el sector del audiovisual, en el gremio de los traductores y en la principal asociación de personas sordas de Rumanía. A día de hoy, no se contempla como opción cambiar esta modalidad por el doblaje para la traducción películas para el público adulto.

- Desde 1989, el modelo de televisión, los programas y los tiempos de emisión han experimentado una gran transformación. Las diferencias adquisitivas marcan, a su vez, importantes diferencias de programación entre la cadena pública y las cadenas privadas, tal y como hemos ejemplificado anteriormente (véase el apartado 2.3.1.) y como, por otro lado, también ocurre en otros países europeos.

- La situación del cine en Rumanía es totalmente contraria a la situación de la televisión. A partir del año 1989 se produce un gran descenso tanto de público como de salas de exhibición. Las nuevas tecnologías, que actúan como nuevas 
ventanas, y la piratería de los productos audiovisuales, pueden ser el motivo por el cual muchas salas de cine que antes de la revolución recibían un gran número de espectadores, hoy en día están casi en la ruina. No obstante, según los datos presentados, podemos observar que, a pesar del descenso del número de salas de cine, actualmente el mercado en este ámbito está en un continuo ascenso gracias a las distribuidoras, que durante estos años han elevado su número y han invertido capital para proyectar estrenos cinematográficos que han logrado atraer de nuevo al público a las salas de cine.

- Para presentar la situación actual del mercado rumano de cintas de video, DVD, CD, UMD y BD, utilizamos los datos recogidos por el Registro de Cinematografía de Rumanía en el período comprendido entre 2011 y 2015. Según estos datos, el mercado de estos productos ha bajado año tras año, probablemente también debido a la irrupción de las nuevas tecnologías, a la piratería o al gran número de películas que emiten las cadenas de televisión o las plataformas de vídeo en línea, cuya oferta parece hacer innecesaria la compra de DVD. La situación económica que atraviesa la población del país (por ejemplo, en el año 2016 el salario mínimo bruto se situaba en torno a 278,52 euros al mes) $)^{32}$ también puede influir en una disminución en los gastos que realizan los consumidores.

En este contexto, el aumento de producciones audiovisuales que tienen que pasar por un proceso de traducción para ser consumidas en Rumanía ha aumentado considerablemente en las últimas décadas. Consecuentemente, el número de profesionales que se dedican a la traducción audiovisual ha aumentado de forma significativa, y su perfil ha evolucionado en los últimos años, tal y como veremos en los siguientes capítulos.

${ }^{32} \mathrm{http}: / / g o v . r o /$ ro/guvernul/sedinte-guvern/salariul-de-baza-minim-brut-pe-tara-majorat-incepand-cu-1-mai-2016/ [consulta realizada 15/02/2017] 


\section{Capítulo 3: El entorno profesional de la traducción audiovisual en Rumanía}

En este capítulo vamos a describir y presentar el rol que ejerce el traductor en el proceso de traducción audiovisual en Rumanía, perfilando su papel en las dos modalidades de traducción audiovisual más empleadas actualmente en este país: la subtitulación y el doblaje.

Además, trataremos de mostrar el estado y el desarrollo de esta profesión, su evolución y variación en las últimas dos décadas gracias al cambio socio-político, al avance tecnológico y al nuevo plan educativo, que han influido en el perfil actual de este profesional.

Asimismo, expondremos algunas cuestiones que generalmente afectan a este gremio, como por ejemplo el tiempo de elaboración de la traducción, los derechos de autor y las tarifas, cuestiones que, tal como veremos a continuación, persisten en el tiempo y se convierten en características específicas de esta profesión en Rumanía.

También definiremos el perfil profesional del traductor audiovisual, en general, y las habilidades y competencias que requiere esta profesión, para describir y analizar posteriormente las competencias específicas y genéricas que caracterizan este gremio en Rumanía.

\subsection{El proceso de subtitulación y el papel del traductor}

Tal como se ha visto en el capítulo anterior, la subtitulación es una modalidad de traducción audiovisual en la que imperan una serie de restricciones espaciales, temporales, de cambio de modo, etc. que particularizan la labor del traductor y el perfil de este profesional.

De esta manera, más allá de limitarse a traducir, el subtitulador debe editar minuciosamente el texto atendiendo a estas restricciones y conservando al máximo el sentido original del guion. El proceso de subtitulación exige competencias específicas por parte del subtitulador, como por ejemplo: una facilidad extraordinaria para los idiomas, un sentido visual desarrollado, una excelente comprensión de los ritmos tanto de las películas como de lectura o una habilidad especial para condensar y saber excluir tramos 
de conversación no cruciales para la comprensión, entre otras (Ivarsson y Carroll, 1998: 1).

Asimismo, Leboreiro Enríquez y Poza Yagüe (2001: 323) consideran que la labor del subtitulador se puede definir como un arte:

\begin{abstract}
Subtitular no es solamente una técnica, sino también un arte: el arte de reproducir un diálogo de cincuenta caracteres en una frase de quince sin perder información; o el arte de engranar a todas las personas implicadas en el trabajo (localizadores, traductores, simuladores, técnicos de láser) dando cabida a todas las peticiones de subtitulación; o el arte de llegar a tiempo con plazos muy ajustados (¡subtitular en un solo día!); o el arte de dar lo mejor de uno mismo para que el resultado final lo disfruten miles de ojos ávidos de leer y entender lo que tiene que contar un director bosnio, de Hong Kong o de la Colombia más profunda. Eso es subtitular.
\end{abstract}

En nuestro caso, la evolución de la subtitulación en Rumanía y, por ende, el perfil del traductor y su rol en este proceso, se puede estructurar en dos etapas:

- La primera etapa se inicia en el año 1956, cuando empezó a emitir por primera vez la cadena de televisión rumana TVR, hasta el año 1989, cuando el pueblo rumano decidió poner fin a la dictadura comunista.

- La segunda etapa se puede delimitar desde el año 1989 hasta la actualidad, cuando Rumanía atravesó el gran cambio político-social y ha desarrollado una considerable evolución tecnológica.

La primera etapa representa la fase incipiente de la traducción audiovisual, concretamente de la subtitulación, dado que la cantidad de productos extranjeros que se emitía estaba limitada por factores políticos. El programa de emisión restringido de la televisión repercutió también en el número de profesionales que se dedicaban a la traducción audiovisual. Y, por otra parte, también tuvo impacto el aislamiento territorial, dado que las fronteras estaban cerradas, con lo que se obstaculizó la formación académica y profesional de los pocos traductores audiovisuales que había en ese periodo. De este modo lo exponía en una entrevista para el periódico Adevărul (2013) una de las traductoras audiovisuales más distinguidas de esa época, Irina Margareta Nistor, que durante décadas desempeñó esta profesión para la cadena estatal TVR, bajo la presión política o la censura: 
Dado que no tuve la posibilidad de viajar a otros países en esa época, pude enriquecer mi vocabulario gracias a los pocos grupos de estudiantes extranjeros que venían de vez en cuando. De esta forma, también pude mejorar mi dicción, porque durante la conversación se les podía preguntar lo que no entendías, cosa que no podía hacer cuando, por ejemplo, traducía los diálogos de De Niro, ya que el actor no podía contestarme. [La traducción es nuestra].

Por tanto, podemos observar que el contexto social influye en el desarrollo cultural del traductor y limita sus conocimientos de la lengua original del producto audiovisual. La escasez de material de consulta específico sobre este tipo de traducción en ese periodo podía dificultar el trabajo del traductor, a no ser que tuviera una gran imaginación o la capacidad de inferir muchos significados a partir las imágenes de las películas, tal como afirma Irina Margareta Nistor (2013) en la misma entrevista:

Por ejemplo, al encontrar la palabra chopper (helicóptero) en una película me vi obligada a utilizar la intuición y ayudarme de la imagen de la escena de la película que traducía, dado que se trataba de un término que desconocía y existía muy poco material para realizar este tipo de consultas. [La traducción es nuestra].

La autocensura es otro componente de la traducción audiovisual, que algunos traductores aplican en diferentes contextos y con diferentes propósitos. En este sentido, esta misma traductora nos desvela las particularidades de sus interpretaciones del texto original al texto meta que aplicó durante esa época:

La censura de la subtitulación antes del año 1989 me la impuse sola, porque me parecía una falta de educación y partí de la premisa de que, de todas formas, en Rumanía seguramente había otras personas que podían enseñar al extranjero el lenguaje vulgar. Actualmente la subtitulación es mucho más libre, pero en aquella época la censura no se aplicaba a las palabras groseras, sino a términos de tipo religioso como por ejemplo "Dios", "iglesia” o las fiestas religiosas. [La traducción es nuestra].

Por otra parte, el equipo técnico que se empleaba se podía incluir en la categoría más rudimentaria, tal como lo describe Irina Margareta Nistor (2015) en CinemaFrame:

Los subtítulos en la Televisión Rumana se escribían en algo parecido al papiro. Se giraba de forma manual, con la mano, porque no existía aún una modalidad de subtítulos electrónicos. Fue un zurdo quien inventó aquella máquina, así que todo se giraba con la mano izquierda. El traductor giraba el rollo (bobina) en directo. Inicialmente, los ilustradores escribían los subtítulos, no se dactilografiaban... Después se escribieron con una máquina de esas que se utilizaban para redactar 
el discurso de Ceaușescu, que utilizaban caracteres muy grandes, porque él no quería utilizar gafas. [La traducción es nuestra].

Afortunadamente, las revelaciones de los pocos traductores que ejercieron en esa época nos ayudan a evidenciar las dificultades tecnológicas y profesionales que atravesaron desde el inicio de esta actividad.

Entre los años 1956 y 1989, el traductor audiovisual acata las disposiciones comunistas y, por tanto, su rol y sus decisiones en el proceso de traducción son limitados por el régimen político. El intercambio cultural, mediante los pocos productos extranjeros audiovisuales que se emiten, no impera en la actividad comunista y el resultado en el texto meta es muy diferente al texto original por la censura que se le aplica. Si a este contexto añadimos las limitaciones técnicas, el traductor audiovisual de ese periodo se podría definir como un "mago" invisible que está detrás de la pantalla.

La segunda etapa, que arranca a partir del año 1989, marcó una variación en la labor del traductor audiovisual, aunque no en su estatus social. El aumento del número de cadenas de televisión privadas implicó el incremento del número de profesionales de esta área. También el avance tecnológico contribuyó a la renovación técnica de los recursos necesarios para realizar este proceso; la llegada de los ordenadores y del láser industrial permitió el aumento de la calidad y la precisión de esta modalidad de traducción audiovisual.

Sin embargo, la labor del subtitulador sigue siendo compleja y el recorrido hasta el resultado final requiere por su parte un alto nivel de creatividad y perseverancia, tal y como precisaba en una entrevista concedida a LinterNet.ro (2008) Andreea Puticiu, profesional de la traducción audiovisual en Rumanía:

La parte difícil de una traducción, como por ejemplo de la película Horton (Jimmy Hayward y Steve Martino, 2008), puede radicar en los versos de las canciones que contiene el texto original. Por otra parte, para entender mejor lo que traduces, lo mejor sería visionar antes la película, pero esto no pasa con mucha frecuencia últimamente, porque la película está en bobina y no está disponible cuando se realiza la traducción; aun así, se puede corregir algo cuando se realiza la subtitulación. [La traducción es nuestra].

Por su parte, Raluca Cîrcea, otra traductora que trabaja en el área de la traducción audiovisual rumana, desvela en el mismo medio de comunicación, LinterNet.ro (2008), 
algunas dificultades que conlleva el proceso de subtitulación y algunas restricciones impuestas por el cliente:

Pautar una película es la operación más difícil de la subtitulación. Una mano la tienes en la mesa de pautar y la otra, en el ordenador. Es imprescindible tener una buena coordinación entre vista y oído. En Citadel Film (distribuidora y productora de películas) se pueden realizar subtitulaciones con caracteres en todos los idiomas, y los errores de traducción o de lengua se revisan en el momento cuando se realiza la subtitulación. A veces es posible que algunas películas realizadas por estudiantes o cineastas rumanos consagrados lleguen al traductor que realiza la subtitulación con la traducción realizada por el "cliente" y con la anotación expresa de no modificarla. Pero, independientemente de la situación, tanto si nosotros hemos traducido el texto como si lo ha hecho otra persona, intervenimos en el texto si lo consideramos necesario. [La traducción es nuestra].

Por ende, la subtitulación es un proceso que se rige por las restricciones y las convenciones propias de esta modalidad de traducción. Pero, además, se rige por las exigencias impuestas por los clientes, como veremos en las respuestas de los cuestionarios dirigidos a los profesionales de este ámbito que hemos empleado en nuestro estudio.

\subsection{El proceso de doblaje y el papel del traductor}

Como veíamos en la sección anterior 2.1.2, el doblaje consiste en reemplazar la banda de los diálogos originales por otra banda en la que estos diálogos aparecen traducidos a la lengua meta y en sincronía con la imagen (Chaume, 2012: 1). En el capítulo anterior también explicábamos que esta modalidad de traducción comprende un proceso de trabajo mucho más complejo que la subtitulación, que implica un mayor número de profesionales y etapas, tal como lo describe Chaume (2004: 32):

El doblaje consiste en la traducción y ajuste de un guión de un texto audiovisual y la posterior interpretación de esta traducción por parte de los actores, bajo la dirección del director de doblaje y los consejos del asesor lingüístico, cuando esta figura existe.

Según esta definición, podemos observar que no siempre el proceso de doblaje reúne en cada etapa a los profesionales pertinentes en este tipo de traducción audiovisual. Además, el doblaje requiere una serie de sincronías definidas por Chaume (2012: 68-69), según las tres etapas fundamentales que se emplean en este proceso: 
- Lip or phonetic synchrony, consists of adapting the translation to the articulatory movements of the on-screen characters, especially in close-ups and extreme or close-ups, also called big close-ups.

- Kinesic synchrony or body movement synchrony, consists in the synchronization of the translation with the actor's body movements.

- Isochrony or synchrony between utterances and pauses, consists in the synchronization of the duration of the translation with the screen character's utterances.

Por tanto, la labor del traductor se ve condicionada por la complejidad del proceso en sí, tal como expone Chaume (2004: 67). Además, posteriormente, pueden surgir posibles modificaciones de la traducción por parte de los demás profesionales implicados en este proceso:

El traductor es el emisor de una cadena compleja de emisores dispuestos a hacer llegar un producto determinado a una audiencia determinada. También forma parte de una cadena múltiple de receptores, o intermediarios que modifican el producto original para una correcta lectura y comprensión del texto audiovisual por parte del receptor último y definitivo, los espectadores.

Sin embargo, habitualmente se ignora que el doblaje conlleva una responsabilidad compartida desde el principio hasta el final, y que el traductor no es el que tiene la decisión final, tal como ponen de manifiesto Gilabert, Ledesma y Trifol (2001: 35).

En general, en el proceso de doblaje intervienen diferentes especialistas, que dirigen la función artística (los traductores, los ajustadores de diálogos, los actores de doblaje) y la función técnica (los técnicos de sonido y de mezclas), tal como precisa Chaume (2004: 65-66). Todo esto implica que el doblaje adquiera un coste más elevado, y este puede ser el motivo de su rechazo en algunos países, como en nuestro caso, Rumanía, tal como se ha podido observar en los capítulos anteriores.

Como veíamos en el capítulo anterior, la evolución del doblaje en Rumanía se puede dividir, del mismo modo que la subtitulación, en dos etapas fundamentales que marcan la evolución de esta modalidad de traducción audiovisual, dado que los factores socio-políticos repercuten en ambas prácticas, aunque de forma distinta: 
- La primera etapa se estructura desde el año 1956, año que marcó la aparición de la cadena TVR, hasta el año 1989, el año del cambio político.

- La segunda etapa se enmarcaría en el ámbito de nuestro estudio, desde el año 1989 hasta la actualidad.

Los productos audiovisuales pioneros en los que se empleó esta modalidad fueron los dibujos animados. Tratándose de producciones que se dirigían al público infantil, se consideró adecuado, tanto por el coste como por el tipo de receptores en la lengua meta, utilizar esta mezcla de doblaje y voice-over en la que se empleaba una sola voz para interpretar a todos los personajes.

Previamente a su emisión, el contenido y la traducción de las películas infantiles eran estrictamente examinados, y a pesar de que hablamos de material televisivo que iba dirigido a los niños; la censura que se les aplicaba era exhaustiva, pero de exigua profesionalidad.

Por tanto, la labor del traductor se vio restringida por una parte por la censura comunista y por otra parte por las pautas que implican el proceso de la traducción, aunque desgraciadamente la que predominó en esa época fue la primera. La aceptación de la censura conllevó en varias ocasiones la alteración del mensaje en la lengua meta, según afirmaba en una entrevista concedida al periódico digital Historia (2011), Viorica Bucur traductora y realizadora de programas infantiles:

La expresión "Merry Christmas" se empleaba en la lengua meta como Felicidades o Feliz cumpleaños, por la prohibición en la tele de palabras con contenido religioso. La parte divertida de la alteración de las palabras en la lengua meta es que un día un niño felicitó a su amigo por su cumpleaños con la frase Merry Christmas, porque la había oído en la tele. [La traducción es nuestra].

Partiendo de esta declaración, podemos observar que el rol del traductor en el proceso de traducción audiovisual es fundamental, dado que a posteriori el resultado de su trabajo influye en el desarrollo lingüístico de la sociedad.

Otra de las pioneras del doblaje en Rumanía en esa época fue la mencionada anteriormente, Irina Margareta Nistor. Además de traducir las películas extranjeras que se emitían en la televisión pública, contribuyó al entretenimiento de muchas familias rumanas, traduciendo e interpretando películas que se difundían de modo ilícito en formato VHS. La joven traductora se convirtió en la voz de la libertad, doblando miles de 
películas de contrabando, que permitieron al pueblo rumano conocer otro mundo distinto al que vivía, tal como recogía recientemente Ilinca Călugăreanu, la directora del documental Chuck Norris vs Comunismo (2015).

En el proceso de doblaje que realizó en ese periodo, la joven traductora desempeñó distintos roles implicados en el proceso (traductora, revisora, directora, actriz...). Se trataba de un trabajo irregular realizado en condiciones laborales y técnicas difíciles y, sin embargo, tolerado por los comunistas, según afirma la traductora en una entrevista concedida al periódico Adevărul (2013):

\footnotetext{
Aunque soy adepta a la subtitulación, el doblaje en ese momento era un mal necesario, un trueque tolerado por los comunistas, que veían en él una vía de escape para la población ante una posible rebelión. El doblaje que realizaba se hacía a primera vista y tenía que hacer la traducción y el doblaje de dos películas consecutivas. Entonces, durante tres o cuatro horas no podías parar, porque en el momento que parabas el resultado era más asincrónico que una conversación por Skype. De modo que, si parabas, tenías que empezar otra vez desde el principio. [La traducción es nuestra].
}

Este tipo de doblaje/voice-over realizado en coyunturas atípicas, tanto técnicas como profesionales, marcó el inicio del doblaje en Rumanía.

Posteriormente a la revolución del año 1989, el cambio socio-político contribuyó también al avance de la traducción audiovisual en Rumanía. Lo que hemos delimitado en nuestro estudio como la segunda etapa de la evolución del doblaje en este país marca el período en que esta modalidad de traducción audiovisual logrará alcanzar un número mayor de adeptos, tanto por parte de los profesionales como por parte del público.

El desarrollo del doblaje supuso implícitamente el avance tecnológico y la variación del perfil del traductor audiovisual habituado a la subtitulación. Paulatinamente, tal como hemos podido observar en el capítulo anterior, las cadenas privadas con programas dedicados exclusivamente al público infantil, como por ejemplo Jetix, Disney Channel o Cartoon Network, y las empresas que se dedican al doblaje, descubrieron que esta modalidad podría ser una forma de incrementar sus ingresos y su número de empleados, lo que facilitó el desarrollo colateral de la industria cinematográfica.

En el año 2004, Rumanía se encontraba aún en la fase inicial, en lo que concierne a este tipo de traducción audiovisual, tal como se define en el medio de comunicación Ziarul Financiar (Rif, Simai, Ciriperu, 2004): 
El doblaje es un ámbito extremadamente controvertido en Rumanía. Visto por muchos de los representantes de la élite cultural como un exponente de una subcultura por las modificaciones que realiza en la obra original, este ha irrumpido en el mercado rumano a través de las grandes productoras de dibujos animados. Después del año 1989 el mercado rumano fue invadido por las producciones más recientes dedicadas a los pequeños, y la posibilidad de realizar un negocio beneficioso en este ámbito dio sus resultados. Los grandes productores realizan numerosos estudios antes de abordar un nuevo mercado, mucho más si se trata de uno del este de Europa. Nada se hace al azar, y la imagen, aunque se trate de un simple cartel de dibujos animados, tiene muchos más significados. [La traducción es nuestra].

A pesar de su corta edad en Rumanía, en comparación con otros países europeos tradicionalmente dobladores como por ejemplo España, Francia, Alemania o Italia, los inversores comprendieron que el doblaje podría ser además de otra modalidad de traducción, un modo de percibir grandes y rápidos beneficios. Un ejemplo concreto puede ser el estudio de doblaje Zone Studio Oradea, que inició su actividad en el año 1999 colaborando con 10 actores; varios años más tarde fue traspasado a Broadcast Text (BTI Studios) y actualmente tiene una plantilla de 150 empleados de los cuales 70 son actores del Teatro del Estado o del Teatro de Títeres de Oradea, dado que es importante tener un número elevado de voces para encontrar el timbre más adecuado para el personaje que aparece en pantalla, según afirmaba Barany Laszlo, el gerente del estudio de Oradea, en una entrevista concedida al Ziarul Financiar (2004).

Como podemos ver, el doblaje no solo constituyó una nueva modalidad de traducción audiovisual en Rumanía, sino que además fue una manera de fomentar el mercado laboral para traductores, actores y otros especialistas que participan en este proceso.

Al constituir los traductores el primer eslabón del proceso doblaje, fueron estos los primeros que tuvieron que adaptarse a las características de esta modalidad de traducción audiovisual bastante desconocida pocos años atrás. Además, el resultado de su trabajo repercute en la siguiente etapa del doblaje, la interpretación de los actores, tal como afirma Ionuț Ionescu, gerente y actor del estudio de doblaje Fast Production Film, en una entrevista concedida a la cadena de televisión DIGI24HD (2013):

Es muy importante que el traductor acierte la velocidad y el ritmo de la traducción, dado que el doblaje tiene una forma especial de articular las palabras, un tipo especial de ritmo que se tiene que conservar y, además, la misma extensión de la réplica, porque nosotros, los actores, también nos 
coordinamos con los movimientos de la boca del personaje original y es necesario conservar el mismo tiempo de pronunciar las palabras. [La traducción es nuestra].

Por tanto, una de las características más importantes de esta modalidad de traducción audiovisual, y además esencial para la siguiente etapa según explica Ionuț Ionescu, es conservar el ritmo del texto original en el texto meta para realizar una sincronía perfecta.

En la misma línea de las declaraciones anteriores, por su parte, Andrea Puticiu $(2017)^{33}$, traductora audiovisual en Rumanía con una vasta experiencia profesional en este ámbito, confirma la relevancia de esta particularidad en el doblaje:

El aspecto más importante en la traducción para el doblaje es que la traducción tiene que acatar el número de sílabas del texto original para realizar una isocronía lo más verídica posible. A diferencia de la traducción para la subtitulación, donde el objetivo es leer los subtítulos con facilidad y por eso se recurre mucho a la adecuación y a la reducción, la traducción para el doblaje tiene que ser lo más similar posible al original, y además se reproducen todas las onomatopeyas y los sonidos existentes en el texto original, como por ejemplo: "Hey, Well, Huh, Oh, Wow...”, sonidos que normalmente se omiten en subtitulación.

Además, se realiza la traducción — para los actores que van a grabar las voces — de los sonidos tipo suspiros, gruñidos, risas, gritos, estornudos, etc. [La traducción es nuestra].

El doblaje, tal como hemos expuesto anteriormente, es una modalidad novedosa de traducción audiovisual en Rumanía. No obstante, podemos observar que los profesionales tanto de los estudios de doblaje como los traductores coinciden en la importancia de la sincronía. Para conseguirla es necesario que el traductor tenga en cuenta la particularidad de los textos audiovisuales de combinar el código visual y el sonoro; además de las características propias de la oralidad, como la naturalidad, la espontaneidad, las frases inacabadas, las onomatopeyas y el lenguaje empleado dado que casi siempre el destinatario al que va dirigido el producto son niñas/niños.

Dado que la sincronía es un factor importante en el proceso de doblaje, en Rumanía no podemos ignorar la afirmación de Chaves (2000: 158), en la que remarca la extrema importancia de este tipo de sincronía o ajuste:

\footnotetext{
${ }^{33}$ Correo personal con la traductora.
} 
En doblaje se va a tratar constantemente de llegar a un compromiso entre la fidelidad al sentido y la sincronía, y en muchas ocasiones, para seguir manteniendo la credibilidad y la ilusión en el espectador, va a primar la segunda en detrimento de la primera.

En cuanto a las normas que se aplican en este proceso o al grado de dificultad del registro lingüístico, que podría conllevar el doblaje por parte del traductor, ambas modalidades —doblaje y subtitulación — tal como afirma la traductora Andrea Puticiu $(2017)^{34}$, suponen el mismo esfuerzo por parte del traductor, ya que el objetivo principal es realizar una buena traducción del texto original al texto meta:

\footnotetext{
Las normas son las mismas. El tiempo de trabajo que requieren es casi igual. No podría clasificar una como más fácil y otra como más complicada; cada modalidad tiene sus cosas buenas y malas, pero las posibles dificultades se pueden mostrar en ambas modalidades de igual forma. Lo más importante es que la traducción realizada resulte cuanto más natural posible en la lengua meta. [La traducción es nuestra].
}

Tal como hemos expuesto anteriormente (véase el apartado 2.1.2.), a pesar de su corta edad en el mercado de traducción audiovisual de Rumanía, el doblaje logró señalarse como la modalidad de traducción más utilizada para los productos extranjeros dirigidos al público infantil. Los traductores habituados a la subtitulación se adaptaron rápidamente y sin dificultades a los criterios que implica este "nuevo" tipo de traducción. La simultaneidad de los dos modos de traducción audiovisual — subtitulación y doblajeenriquecieron el ámbito audiovisual rumano aportando más variedad y múltiples opciones al público infantil y adulto, además de un incremento laboral gracias a la complejidad del doblaje.

\subsection{Tiempo de elaboración de la traducción para el subtitulado y doblaje}

"Lo quiero para ayer", afirmaba Fontcuberta (2001: 305) en uno de sus artículos dedicados a la maravillosa, pero compleja, profesión del traductor audiovisual, cuando definió el plazo que tienen los traductores para realizar los encargos que reciben de los estudios, televisiones, etc.

Como decíamos, el traductor es el primer eslabón en esta cadena y casi todo el proceso está afectado por la rapidez de la entrega del trabajo realizado, lo que conlleva

\footnotetext{
${ }^{34}$ Ibíd. 33
} 
una presión considerable sobre su figura. Sin embargo, su esfuerzo y su trabajo casi siempre permanecen desapercibidos si analizamos solamente el producto final, especialmente en el doblaje, tal como afirma Fontcuberta (2001: 305):

El primer eslabón de la cadena es, está claro, imprescindible, pero para el mundo del doblaje es el menos difícil e interesante; es como la base para la pizza, el lienzo para el cuadro, la tela para el vestido: tiene que estar lista para el comienzo de la semana laboral, cuando los artistas ponen manos a la obra.

Generalmente, un factor importante que influye en el plazo de entrega de los productos extranjeros que se les hace llegar a los traductores audiovisuales, es según Chaume y García de Toro (2001: 121), la falta de planificación de las televisiones, cines y filmotecas:

En varias ocasiones las cadenas de televisión no saben qué series de televisión emitirán en el plazo de un mes, y en innumerables ocasiones ni siquiera en el plazo de una semana. [...] La consecuencia es que al traductor se le exige la traducción de una película en un plazo de dos o tres días (en subtitulación, en especial en los festivales de cine, de un solo día y, en ocasiones de sólo unas horas).

El tiempo, casi siempre limitado, es el primer desafío al que se tiene que enfrentar el traductor en la complejidad del proceso de traducción audiovisual. Si a todo esto añadimos la recepción de guiones ilegibles, guiones con escenas cambiadas, imágenes sin guion, guion sin imágenes, guion en una lengua e imágenes en otra (Fontcuberta, 2001: 304) y sumamos los retos del registro lingüístico, podríamos comprender la presión laboral que conlleva esta profesión.

Podríamos pensar que el cliente es bastante condescendiente en este caso, sin embargo, existen diferentes factores que pueden obstruir el proceso general en la subtitulación, tal como afirma Díaz Cintas (2003: 111):

Es difícil calcular una media del tiempo que se tarda en subtitular una película de unos 90 minutos debido a variables como la densidad de diálogos, la dificultad del contenido, la fecha de proyección. En una situación “normal”, la localización de los diálogos requiere unos 2 días. Al traductor se le dan entre 4 y 7 días para la traducción y el ajuste de los subtítulos, que por regla general incluyen el fin de semana. A nivel puramente técnico, para llevar a cabo el subtitulado a láser de una película se suele tardar unas diez veces la duración de la película, dependiendo siempre del número de subtítulos. Así, para una película de una duración media de 90 minutos se tardarán de unas 15 a 20 
horas. La simulación suele durar una mañana o una tarde, y el pase por la máquina para imprimir los textos unos 2 o 3 días.

Por tanto, los factores que influyen en el tiempo que se tarda en realizar la traducción audiovisual de un producto extranjero pueden variar (densidad de diálogos, dificultad de contenido, el uso de más de un idioma, etc.). Además, también influye la modalidad de traducción empleada (subtitulación, doblaje, voice-over, etc.); sin embargo, el único factor invariable en todo este proceso es el plazo de entrega. En este sentido, Agost (1999: 15) sostiene lo siguiente:

$\mathrm{Al}$ traductor audiovisual se le exigen conocimientos especiales, no tan solo por el contenido, sino también por las técnicas particulares que se utilizan y condicionan la traducción audiovisual: el código oral, escrito y visual para los que no existe una manera única de traducirlos, y además bajo la presión temporal impuesta por el cliente.

En esta misma línea el gerente del estudio de doblaje Zone Studio de Rumanía, Barany Laszlo, explicaba en una entrevista para Ziarul Financiar (2004) el ritmo frenético al que se puede llegar a doblar una película o una serie en algunos casos concretos:

En principio, Zone Studio dispone aproximadamente de un plazo de tres meses para sincronizar una película. No obstante, si surge algún imprevisto nos podemos organizar muy bien. Por ejemplo, un bloque de ocho episodios de la película Star Trek, lo tradujimos, doblamos y enviamos en solamente tres días, porque tuvo que emitirse en una de las cadenas de televisión de Hungría. Para facilitar la grabación, la película se dividió en takes de 15-30 segundos. [La traducción es nuestra].

Generalmente, el cliente es el que impone tanto el tiempo como las normas lingüísticas que se emplean en el proceso de traducción, tal y como afirma Barany Laszlo en declaraciones para el medio de comunicación Ziarul Financiar (2004), lo que naturalmente conlleva un incremento del grado de meticulosidad del traductor:

Es un verdadero quebradero de cabeza. La política Minimax (cadena privada que emite productos dirigidos al público infantil) está clara: ¡sin violencia física ni verbal! Nuestros traductores hacen grandes esfuerzos para encontrar diferentes sinónimos para las expresiones, como por ejemplo: "Eres tonto", "Te voy a pegar", "Me muero de aburrimiento". Todo esto se tiene que montar de tal forma que parezca que los personajes articulan estos sinónimos. Si por ejemplo hay que sustituir una 
palabra que comienza con la letra $o$ y acaba en $a$, y esto se puede observar en la sincronía labial, se tiene que encontrar una palabra que empiece y termine con las mismas vocales. [La traducción es nuestra].

Dada la escasa bibliografía que aporta datos sobre cómo influye la presión temporal en la profesión del traductor audiovisual en Rumanía, suponemos que no habrá diferencias notables comparando esta situación con los otros países europeos. No obstante, esta será una cuestión que se estudiará en la fase analítica de nuestro trabajo.

\subsection{Derechos de autor y tarifas}

La subtitulación y el doblaje se tienen que entender como una parte integral del proceso de creación artística de una película y no como algo sujeto a las leyes del mercado, tal y como afirman Díaz Cintas y Remael (2007: 38). Por tanto, como cualquier creación artística, tiene que estar sujeta a leyes que regulen y amparen sus derechos y sus valores, tanto de la obra como del autor.

Referente a esta legislación, los autores (Díaz Cintas y Remael, 2007: 41), recopilan los derechos de los traductores publicados en el Punto 7 de la Sección III de la Recomendación sobre la protección jurídica de los traductores y de las traducciones y sobre los medios prácticos de mejorar la situación de los traductores (UNESCO, 1976):

\footnotetext{
Member States should also promote measures to ensure effective representation of translators and to encourage the creation and development of professional organizations of translators and other organizations or associations representing them, to define the rules and duties which should govern the exercise of the profession, to defend the moral and material interests of translators and to facilitate linguistic, cultural, scientific and technical exchanges among translators and between translators and the authors of works to be translated.
}

Por su parte, Chaume (2004: 107) delimita sus hallazgos y especifica las dificultades legislativas en el área de la traducción audiovisual:

Una profesión apasionante, que sin embargo, está sujeta a las idas y venidas de cualquier actividad por cuenta propia, a las voluntades poco previsibles de televisiones, distribuidoras, estudios de doblaje y subtitulación, a la legislación vigente, contraria a la dignidad profesional a cualquier actividad por cuenta propia sin tener en cuenta los grandes altibajos que en ella se producen. 
En el año 1996 se aprobó en Rumanía la ley sobre "Los derechos de autor y los derechos conexos" (número 8/1996, últimas modificaciones realizadas en el año 2015). Esta ley incluye en el capítulo número III (El objeto del derecho de autor), el artículo número 8 , que prevé disposiciones especiales sobre los derechos de autor:

\footnotetext{
Sin perjudicar los derechos de los autores de las obras originales, constituye, igualmente, objeto del derecho del autor, las obras derivadas que fueron creadas partiendo de una o más obras preexistentes, como:

Las traducciones, las adaptaciones, las anotaciones, los trabajos documentales, los arreglos musicales y cualquier transformación de una obra literaria, artística o científica que represente un trabajo intelectual de creación. [La traducción es nuestra].
}

Por tanto, podemos observar que desde el año 1996 el trabajo de los traductores está al amparo de la legislación. No obstante, estos derechos son casi inexistentes en los contratos de los traductores audiovisuales, tal como afirma la traductora Andrea Puticiu $(2017)^{35}$ :

Los derechos del autor no se respetan y nadie quiere pagar un valor real, y en ningún caso porcentual por copia, como creo que sería normal. Probablemente esta situación se podría mejorar en el momento en el cual una ley impusiera unas reglas claras, pero de momento es sólo teoría, dado que de la práctica huye todo el mundo. [La traducción es nuestra].

Puesto que a veces la teoría no se emplea en la práctica, en múltiples casos los derechos de autor se quedan en una mera ley, un simple número de artículo que no se aplica en los contratos de los traductores audiovisuales, tal como veremos más adelante en la parte empírica del trabajo, en las respuestas a los cuestionarios dirigidos a los traductores rumanos. Asimismo, es necesario mencionar que en la actualidad no existe aún una asociación profesional específica en Rumanía que vele por los intereses de los miembros de esta profesión, como en el caso de otros países como por ejemplo España, donde existe la Asociación de Traducción y Adaptación Audiovisual de España (ATRAE), específica a este gremio.

En cuanto a las tarifas, un problema importante que destacaba Chaume (2004: 107) es la variabilidad de los encargos en esta profesión, dado que a veces los traductores

${ }^{35}$ Ibíd. 33. 
no pueden conseguir suficientes encargos de forma continua, lo que les permitiría trabajar exclusivamente en este campo:

El problema de la profesión no es que la traducción esté mal retribuida, sino que el traductor no tiene ninguna seguridad de poder trabajar de manera continuada: las traducciones suelen llegar en periodos concretos, y a ciclos de trabajo intenso suelen seguir ciclos en los que el traductor ha de buscar otros encargos de otras variedades de traducción para sobrevivir.

Autores como Chaume (2012: 26-27) y Díaz Cintas (2003: 112-113) han analizado las variables (género, cliente, etc.) que influyen en la práctica de las tarifas en diferentes países europeos, como por ejemplo España, Italia o Alemania, tanto en el doblaje como en la subtitulación, las dos modalidades de traducción audiovisual más empleadas en la actualidad. Sus datos sostienen la fluctuación del trabajo en esta profesión y, por tanto, la inestabilidad retributiva de los profesionales.

Actualmente, no existen datos sobre las tarifas que emplean los traductores audiovisuales en Rumanía. No obstante, esperamos aportar datos al respecto en este estudio, dado que esta es una de las cuestiones analizadas en la parte empírica de nuestro trabajo.

Sin embargo, es conocido que los precios que se aplican en este sector en Rumanía son el resultado de un amplio estudio mercantil, tal como afirma el director del estudio de doblaje Agerfilm, Nicolae Marginenu, en declaraciones a Ziarul Financiar (2004), por parte de las productoras extranjeras previamente al acuerdo de un contrato y durante el término del mismo:

Los de Walt Disney conocen muy bien los precios de Europa de Este. Todos los años les entregamos un cuestionario que contiene información sobre los sueldos que percibe en Rumanía un actor, un director o un traductor. Están muy bien informados sobre el nivel salarial de nuestro país, y en función de esto regulan anualmente el nivel de los contratos que se realizan en Rumanía. [La traducción es nuestra].

De esta forma, los derechos de autor y las tarifas son problemas notables, y podríamos afirmar que se consideran temas tabú en el campo de la traducción audiovisual en Rumanía, dado que en la actualidad no existen aún datos concretos que arrojen luz sobre esta incógnita. 


\subsection{Estado de la profesión}

Monzó (2006: 159) define el concepto de la profesión como una comunidad que ejerce y detenta en exclusiva la aplicación mercantil de un conjunto organizado de conocimientos en un contexto social determinado.

Asimismo, Panaia (2007: 15), retomando la definición de Wilensky (1964), afirma que la profesionalización de un colectivo está constituida por una sucesión temporal de cinco fases:

- aparición de una cierta actividad laboral como ocupación a tiempo completo

- instituciones de escuelas de formación especializadas

- nacimiento de asociaciones profesionales (generalmente primero a nivel local y luego a nivel nacional)

- conquista de la ley de protección de la actividad profesional (en general, cualquier forma de monopolio de la actividad o de protección del título ocupacional)

- elaboración de un código ético formal

Generalmente, se hace referencia al traductor como un mediador, tal como lo define Venuti (1995: 469), entre dos textos claramente diferenciados, escritos en dos idiomas diferentes:

Translation never communicates in an untroubled fashion because the translator negotiates the linguistic and cultural difference of the foreign text by reducing them and supplying another set of differences, basically domestic, drawn from the receiving language and culture to enable the foreign to be received there.

No obstante, el progreso social, como afirma Gambier (2001: 91), repercute y altera el perfil del traductor y el desarrollo de esta profesión a lo largo del tiempo:

Les évolutions du marché, l'augmentation et la diversification des demandes de traduction (avec de exigences accrues de rapidité), l'ambiguïté du rôle politico-culturel de la traduction (au service des entreprises dominantes, des secteurs de pointe, des producteurs de biens culturels de masse et/mains aussi de communautés aujourd hui minorées, fragilisées), les nouvelles hiérarchisations dans l'ordre linguistique mondial, l'essor rapide de l'informatisation des outils de travail, les mutations des conditions de la pratique professionnelle, tout cela brouille les profils du traducteur. 
En consecuencia, el avance tecnológico y la globalización, así como la jerarquización lingüística mundial, imponen su propia evolución al profesional de la traducción, y, en nuestro caso concreto, al traductor audiovisual. Por tanto, el profesional que desempeña esta actividad requiere una formación académica y tecnológica más compleja y más amplia para hacer frente a las nuevas exigencias imperantes actualmente en este sector.

En Rumanía, el desarrollo tanto profesional como tecnológico se realizó paulatinamente, tal como se ha podido observar a lo largo del presente capítulo. La dictadura comunista instauró barreras sociales y lingüísticas que repercutieron en la formación profesional y académica del escaso número de traductores audiovisuales que ejercieron en esa época. Sin embargo, el progreso social que se percibió después del año 1989, con el aumento de las cadenas privadas y el crecimiento de la demanda de profesionales especializados en esta disciplina, fomentó el interés hacia esta nueva disciplina, la traducción audiovisual.

En la actualidad, diferentes universidades ubicadas en grandes ciudades han implantado en su programa de formación cursos especializados para consolidar esta profesión ${ }^{36}$, como por ejemplo Bucarest (Universidad de Bucarest - Máster de subtitulación), Timișoara (Universidad Politécnica - Curso transversal de subtitulación) o Cluj (Universidad Babeș Bolyai - European Master's in Translation).

Dada la reciente implantación de esta formación, podemos suponer que, principalmente, los profesionales de la traducción audiovisual de este país tendrán formación académica en Filología o lenguas extranjeras, aunque posteriormente puedan continuar su formación mediante cursos especializados en el extranjero o son simplemente autodidactas, y que desarrollan sus competencias a través de la práctica realizada en el mercado laboral.

La inestabilidad profesional es otra característica común de este gremio, dado que la mayor parte ejerce como freelancer y compagina esta profesión con otras actividades, y un número exiguo está contratado permanentemente por una empresa que requiere sus servicios. Por otra parte, la inequidad entre los requisitos que exigen las empresas empleadoras y las tarifas que ofrecen es un problema generalizado, tal como observó Cerezo Merchán (2012) en su estudio sobre traducción audiovisual en España.

\footnotetext{
36 http://lege5.ro/Gratuit/geytsnztg4zq/hotararea-nr-376-2016-privind-aprobarea-nomenclatorului-domeniilor-si-al-specializarilorprogramelor-de-studii-universitare-si-a-structurii-institutiilor-de-invatamant-superior-pentru-anul-universitar/ [consulta realizada 19/03/2017].
} 
Con respeto a los programas informáticos específicos a esta disciplina, la máquina rudimentaria que describía anteriormente la traductora Irina Margareta Nistor, que utilizaba para crear los subtítulos, se dejó de usar, dado que en la actualidad en los países europeos se utilizan programas de subtitulación, como por ejemplo Subtitle Edit, Ledit, EZ Titles, Eddie Plus, Subtitle Workshop, DivX Land, etc. (Cerezo Merchán, 2012). Analizaremos este aspecto en el caso de Rumanía en los siguientes capítulos.

Por tanto, la evolución tecnológica influye en el perfil del traductor y en el desarrollo de sus competencias, tanto genéricas como específicas. El traductor actual tiene que ampliar y renovar continuamente sus conocimientos para mantenerse en el mercado laboral. No obstante, nos llama la atención la perduración de los problemas profesionales y académicos que aqueja aún en la actualidad la traducción audiovisual en Rumanía, muy similares a los que ponía de manifiesto Chaume (2000: 47-83) refiriéndose a España hace 17 años:

a) Vacío legislativo respecto a los profesionales de la traducción audiovisual, frente al reconocimiento de actores de doblaje, técnicos de sonido, directores de doblaje, etc.

b) Inexistencia de legislación fiscal especifica adaptada a las características del mercado en este sector.

c) Inexistencia de un colegio o asociación profesional que vele por unas prácticas profesionales justas y equitativas.

d) Escasa oferta universitaria de cursos de especialidad.

Asimismo, la invisibilidad del traductor en el proceso de traducción, que ponía de manifiesto Venuti (1995), también la evidencia en el contexto social Díaz Cintas (2003: 90) de la siguiente forma:

La invisibilidad de la figura del traductor audiovisual tiene un impacto negativo en su consideración social que se manifiesta en una falta de reconocimiento laboral.

Para concluir, consideramos que actualmente el desarrollo en esta área está limitado tanto en el plano formativo como en el profesional por la legislación y por el escaso interés que recibe socialmente. Tal como hemos expuesto anteriormente, la carencia de cursos o formación académica con carácter específico podría ser otro 
hándicap para hacer avanzar el aprendizaje y la práctica de esta disciplina. Profundizaremos en esta cuestión en el siguiente capítulo de este estudio.

\subsection{Perfil del traductor}

El desarrollo de cualquier tipo de actividad profesional requiere un conjunto de varios factores que, según Panaia (2007: 38), contribuyen e influyen en el acto del trabajo:

\footnotetext{
El individuo en el trabajo dispone de competencias y de recursos cognitivos y culturales que están comprometidos en el acto del trabajo, más allá del simple cumplimiento de tareas prescritas por el lugar ocupado en la división del trabajo. Si la evolución social y económica de las profesiones registra, hoy, tensiones muy fuertes entre la lógica de la acción pública y la lógica del mercado, y si la configuración de saberes comprometidos en el trabajo y las protecciones y las solidaridades negociadas alrededor del empleo, entra más abiertamente en la turbulencia de la competitividad, de los riesgos y de las trayectorias individuales e inequitativas, todo esto parece señalar que el análisis de las profesiones tiene muchas posibilidades, hoy, de conjugar la interdisciplina necesaria para construir mecanismos más adecuados de movilidad, carrera e inclusión.
}

En esta misma línea, Yániz (2004: 5) afirma que la base para definir un perfil profesional es el análisis de las funciones y tareas que llevan a cabo los profesionales en ejercicio, según los siguientes presupuestos:

- cualquier trabajo puede ser descrito en términos de funciones y tareas

- toda área de intervención requiere una serie de conocimientos, actitudes y habilidades identificables de manera concreta, que los profesionales deben tener para realizar su tarea

- los profesionales expertos y aquellos que realizan su trabajo de manera efectiva son la mejor fuente para describir y definir su ocupación

Este conjunto de competencias, habilidades, conocimientos, actitudes y destrezas que se emplean con el fin de conseguir unos objetivos determinados en el trabajo, se suelen dividir en el contexto educativo y profesional en competencias genéricas y competencias específicas. 
Para definir las competencias genéricas, en nuestro estudio hemos utilizado las que se emplean en el Proyecto Tuning ${ }^{37}$ (2003: 83-84):

\section{A. Competencias instrumentales:}

- Capacidad de análisis y síntesis

- Capacidad de organizar y planificar

- Conocimientos generales y básicos

- Conocimientos básicos de la profesion

- Comunicación oral y escrita en la propia lengua

- Conocimientos de una segunda lengua

- Habilidades básicas de manejo del ordenador

- Habilidades de gestión de la información

- Resolución de problemas

- Toma de decisiones

B. Competencias interpersonales:

- Capacidad crítica y autocrítica

- Trabajo en equipo

- Habilidades interpersonales

- Capacidad de trabajar en un equipo interdisciplinar

- Capacidad para comunicarse con expertos de otras áreas

- Apreciación de la diversidad y multiculturalidad

- Habilidad de trabajar en un contexto internacional

- Compromiso ético

C. Competencias sistémicas:

- Capacidad de aplicar los conocimientos en la práctica

- Habilidades de investigación

- Capacidad de aprender

- Capacidad para adaptarse a nuevas situaciones

\footnotetext{
${ }^{37}$ El proyecto Tuning abordó varias de las líneas de acción señaladas en Bolonia y se propuso determinar puntos de referencia para las competencias genéricas y las específicas de cada disciplina en una serie de ámbitos temáticos. Disponible en: http://www.unideusto.org/tuningeu/images/stories/documents/General_Brochure_Spanish_version.pdf [consulta realizada 8/06/2017]. 
- Capacidad para generar nuevas ideas

- Liderazgo

- Conocimiento de culturas y costumbres de otros países

- Habilidad para trabajar de forma autónoma

- Diseño y gestión de proyectos

- Iniciativa y espíritu emprendedor

- Preocupación por la calidad

- Motivación de logro

Tal como podemos observar, se trata de competencias o habilidades que se pueden aplicar en cualquier área profesional. Sin embargo, cualquier disciplina o profesión requiere, además, por parte del profesional, competencias específicas que se enmarcan y se aplican en ámbitos específicos.

En el ámbito concreto de la traducción, Mayoral (1999: 7) define al traductor como un profesional polifacético que precisa un amplio abanico de habilidades y capacidades (tanto genéricas como específicas) para desarrollar su trabajo:

Las demandas presentes y previsibles del mercado aconsejan ya que los traductores cuya mirada se dirige a la localización o a la traducción audiovisual ofrezcan un perfil profesional polifacético y flexible en el que se integre la capacidad para diferentes tareas que antes correspondían a diferentes tipos de traductor o a profesiones diferentes a las de la traducción (imagen, sonido, ajuste, producción, compilación, etc.). Las razones para este perfil se originan tanto en el proceso de traducción como en el tipo de empresa en la que se genera. Tanto en la traducción audiovisual como en la localización se dan procesos de traducción complejos en los que intervienen de una manera o de otra en la traducción, profesionales que no son traductores. La experiencia muestra también la conveniencia de que estos candidatos a traductor posean conocimientos y habilidades relacionados con la gestión de la empresa, de forma que puedan acceder con mayores garantías a actividades de gestión que han de realizar junto con su actividad de traducción o independientemente de ella (product manager, quality controller, contabilidad, márketing, etc.). Este contacto del traductor con la gestión guarda relación no sólo con las peculiaridades de la localización sino también con la tendencia creciente a la diversificación de actividades de estas empresas.

En cuanto a las competencias específicas de los traductores, o lo que se conoce como "competencia traductora", son muchos los autores que han propuesto definiciones 
y taxonomías ${ }^{38}$. Nos centramos a continuación en las propuestas de Kelly (2002) y PACTE (2003 y siguientes) por ser dos de las más completas hasta la fecha. Kelly (2002: 9) define la competencia traductora como:

Un conjunto de capacidades, destrezas, conocimientos e incluso actitudes que reúnen los traductores profesionales y que intervienen en la traducción como actividad experta, es decir que, en su conjunto, distinguen al profesional del no profesional, al experto del no experto.

Este conjunto de capacidades, destrezas, conocimientos e incluso actitudes se desglosa en las siguientes subcompetencias, que Kelly (2002: 14-15) considera fundamentales en el proceso de traducción:

- Subcompetencia comunicativa y textual en al menos dos lenguas y culturas.

- Subcompetencia cultural que implica no sólo conocimientos enciclopédicos, sino también sobre valores, mitos, percepciones, creencias y comportamientos.

- Subcompetencia temática que abarca los conocimientos básicos sobre los campos temáticos en los que trabaja el traductor, los cuales le permiten el acceso a la comprensión del texto de origen o de la documentación adicional que emplee.

- Subcompetencia instrumental profesional, que comprende el uso de fuentes documentales de todo tipo, la búsqueda de terminología y la gestión de glosarios, bases de datos, el manejo de las aplicaciones informáticas más útiles para el ejercicio de la profesión (tratamiento de textos, autoedición, bases de datos, Internet, correo electrónico), así como conocimientos básicos para la gestión del ejercicio profesional (contratos, obligaciones fiscales, presupuestos y facturación, etc.) o de la deontología y el asociacionismo profesional.

- Subcompetencia psicofisiológica que engloba varias destrezas como la confianza en sí mismo, la capacidad de atención, de memoria.

- Subcompetencia interpersonal implica la capacidad para interrelacionarse y trabajar profesionalmente en equipo con diferentes niveles grupales (revisores, documentalistas, terminólogos, clientes, iniciadores, autores, usuarios, así como con expertos en las materias objeto de traducción).

\footnotetext{
${ }^{38}$ Véase Kelly (2002) para un exhaustivo repaso de estas propuestas.
} 
- Subcompetencia estratégica incluye los procedimientos que se aplican a la organización y realización del trabajo, a la identificación y resolución de problemas y a la autoevaluación y revisión.

En el planteamiento de Kelly todas las subcompetencias están relacionadas entre sí. No obstante, destaca la subcompetencia estratégica, dado que es la que dirige la aplicación de todas las demás a la realización de una tarea determinada, por lo que representa gráficamente su propuesta de forma de piramidal:

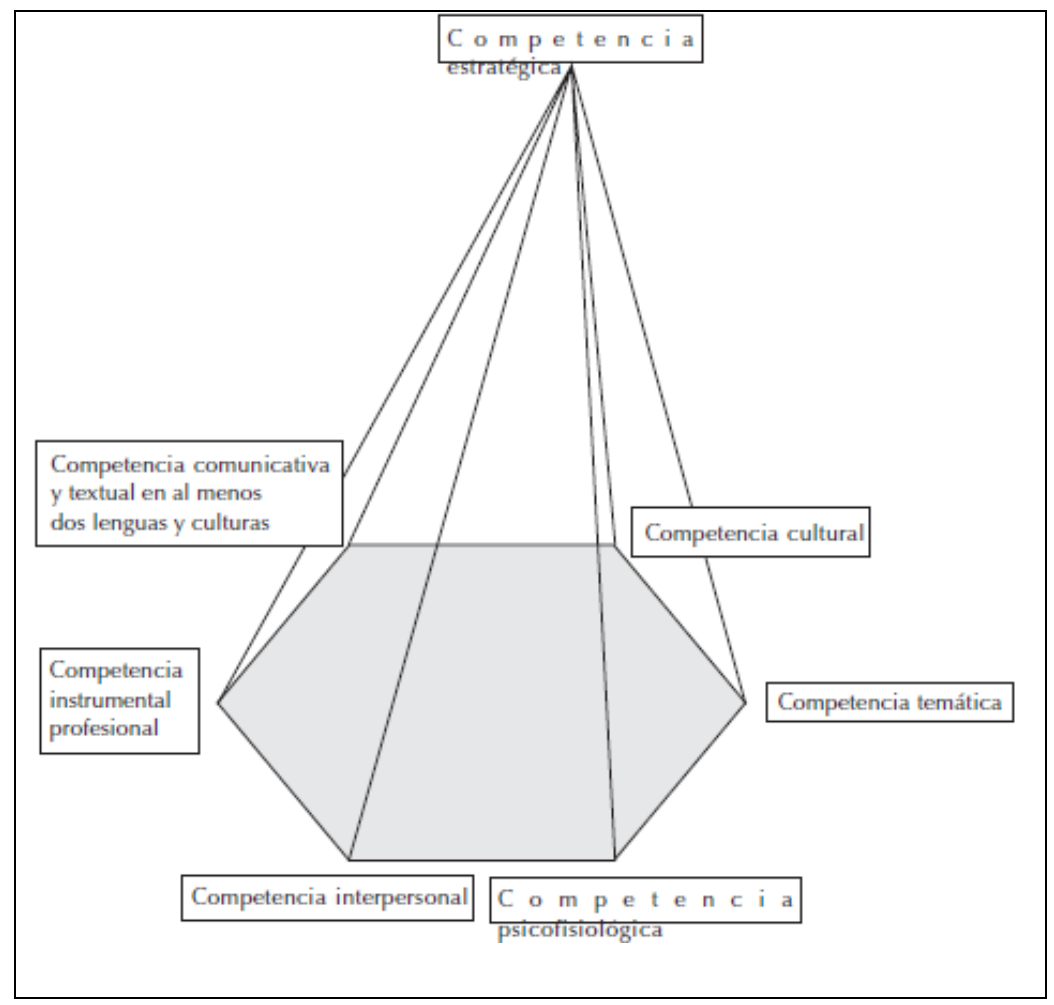

Figura 1. La competencia traductora, según Kelly (2002: 17-18)

PACTE $^{39}$ (2003), por su parte, propone un modelo holístico de competencias traductoras que se fundamenta en cuatro rasgos distintivos: la competencia traductora 1) es un conocimiento experto, que no posee todo bilingüe; 2) es un conocimiento básicamente operativo; 3 ) está formado por varias subcompetencias que actúan de manera

\footnotetext{
39 Desde 2000, PACTE investiga intensamente en el concepto de competencia traductora y en su adquisición: (http://grupsderecerca.uab.cat/pacte/es/content/publicaciones [consulta realizada 8/06/2017]. En 2003, PACTE propone su primer modelo competencial, en el que ha trabajado desde esa fecha.
} 
relacional; 4) como en todo conocimiento operativo, tiene gran importancia el componente estratégico. Asimismo, PACTE (2003: 57-58) elabora un modelo integrado por cinco competencias y componentes psicofisiológicos que actúan de manera conjunta:

- Subcompetencia bilingüe, concierne el conocimiento procedimental necesario para la comunicación lingüística entre dos lenguas, incluyendo varios conocimientos pragmáticos (permiten utilizar el lenguaje para expresar y comprender las funciones lingüísticas), sociolingüísticos (comprensión de los registros lingüísticos y de dialectos), textuales (mecanismos de coherencia y cohesión, formato, formas lingüísticas), y del código lingüístico (vocabulario, morfología, sintaxis, pronunciación/ortografía).

- Subcompetencia extralingüística, integra conocimientos biculturales (en la cultura de llegada y de partida), enciclopédicos (del mundo en general) y temáticos (de ámbitos específicos).

- Subcompetencia de conocimientos sobre la traducción comprende el saber de los principios que guían la traducción (procesos requeridos, métodos, estrategias, tipos de problemas) así como los conocimientos derivados de la práctica profesional (mercado laboral, asociaciones, tarifas, tipos de encargo y de destinatario).

- Subcompetencia instrumental incluye los conocimientos de tipo operativo referentes a la utilización de fuentes y recursos documentales, tecnologías de la información y comunicación aplicadas a la traducción (diccionarios, enciclopedias, textos paralelos, corpus electrónicos).

- Subcompetencia estratégica es una competencia esencial, dado que afecta e interrelaciona a todas las demás, ya que dirige el proceso traductor (elabora el proyecto traductor y planifica el proceso, evalúa el proceso y los resultados parciales obtenidos, activa las diferentes subcompetencias del modelo y compensa deficiencias en ellas, identifica problemas de traducción y aplica los procedimientos convenientes para su resolución).

- Componentes psicofisiológicos ocupan un plano transversal e influyen en todo el proceso de traducción, dado que se trata componentes cognitivos y actitudinales de diferente índole, así como mecanismos psicomotores (la memoria, la percepción, la atención, la emoción, curiosidad intelectual, espíritu crítico, conocimiento y confianza en sus propias capacidades, saber medir sus propias 
posibilidades, motivación, habilidades como creatividad, razonamiento lógico, análisis y síntesis).

Todas estas subcompetencias interactúan entre sí en el proceso de traducción. Sin embargo, en este modelo holístico prevalecen jerárquicamente las tres subcompetencias siguientes: la estratégica, la instrumental y la de conocimientos de traducción, tal como se puede observar en la siguiente figura:

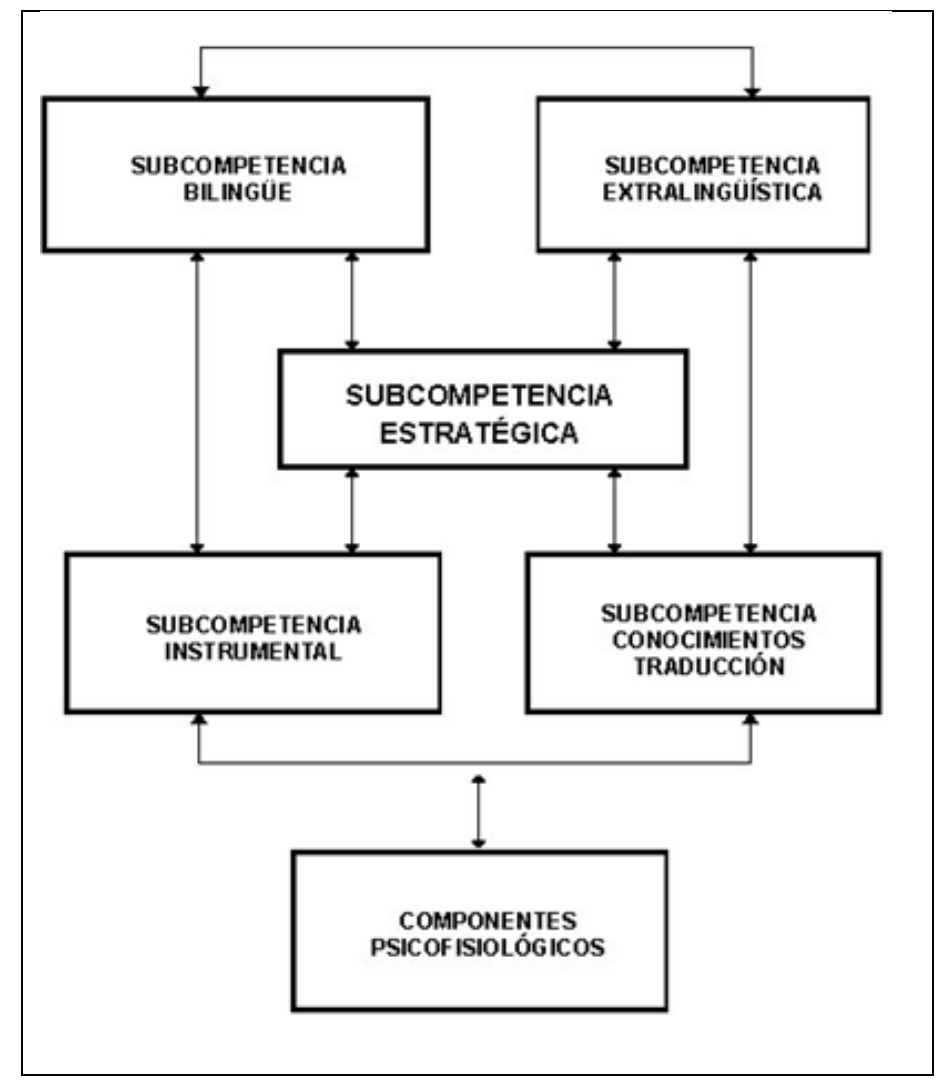

Figura 2. Modelo holístico de la competencia traductora, según PACTE (2003: 57-58)

De estos dos modelos podemos inferir que la competencia traductora es un concepto amplio, difícil de definir y clasificar. No obstante, ambos modelos nos han ayudado en la realización de nuestro diseño del bloque dedicado a las competencias traductoras, al objeto de analizar el perfil del traductor audiovisual en la actualidad en Rumanía.

Ya más concretamente en cuanto a las competencias específicas del traductor audiovisual, al igual que Cerezo Merchán (2012,113-114), nos basamos en la siguiente hipótesis formulada por Chaume (2003: 272): 
If we agree that AVT is a specific and singular practice that requires a particular epistemological approach, it seems now justifiable to assume that translation competence in the field of audiovisual professional practice includes a concrete aspect that tentatively can be labelled as the "audiovisual component".

Según esta hipótesis, partiendo de la base de que los textos audiovisuales son un tipo de textos especiales, cuya información se transmite a través de múltiples códigos de significación que viajan a través de los canales acústico y visual, parece lógico pensar que los traductores de textos audiovisuales necesitarán determinadas competencias comunes que nos permitan distinguir su perfil del de otros traductores que solo realicen traducciones de textos escritos.

A continuación recogemos las competencias específicas de los traductores audiovisuales que propone Cerezo Merchán (2012: 338-339) tras un amplio repaso de lo que otros expertos han establecido sobre qué debe saber, qué debe saber hacer y qué actitud debe tener un buen profesional de la traducción audiovisual:

- Conocimiento exhaustivo de la lengua meta en todas sus dimensiones (ortográfica, morfológica, fonética, sintáctica. léxica, fraseológica y textual)

- Dominio de la lengua origen (excelente comprensión escrita y oral, reconocimiento de registros y variedades coloquiales, dialectos)

- Capacidad de síntesis y paráfrasis (conocimiento de técnicas de reducción y ampliación de la información en la traducción)

- Creatividad lingüística

- Capacidad para analizar y producir textos a partir de su modo del discurso (falsa oralidad, oralidad fingida)

- Buenos conocimientos de las culturas de trabajo y adecuación de la traducción a las exigencias de la cultura meta

- Dominio en el manejo de programas específicos de traducción audiovisual (de subtitulación, doblaje, audiodescripción, etc.)

- Nociones de localización de software

- Dominio de programas para digitalizar, codificar o convertir a otro formato material audiovisual

- Conocimientos sobre programas de reconocimiento del habla 
- Buena disposición y talante para el aprendizaje de nuevos programas y paquetes informáticos

- Dominio de estrategias de búsqueda de recursos y documentación

- Conocimiento de locución

- Dominio de técnicas de lengua de signos

- Dominio de la visualización conjunta de texto e imagen

- Dominio de los procedimientos de ajuste en doblaje y voice-over, la división en takes, los símbolos utilizados, el uso de los códigos de tiempo, etc.

- Dominio del pautado o localización y ajuste de los subtitulos a las velocidades de lectura de la audiencia meta

- Conocimiento de estrategias y técnicas de traducción más apropiadas para traducir diferentes géneros audiovisuales

- Capacidad de dirección de proyectos de traducción audiovisual (capacidad de elaboración, desarrollo y organización de proyectos, trabajos en equipo)

- Conocimientos de la profesión y de la situación del mercado de trabajo

- Conocimiento exhaustivo de las características especificas de la audiencia meta

- Conocimientos de cine

- Conocimientos de teatro

- Conocimientos teóricos de una o varias modalidades de traducción audiovisual

- Conocimiento del lenguaje cinematográfico y la semiótica de la imagen

- Conocimiento de las características de diferentes generos audiovisuales

En este estudio emplearemos estas competencias recogidas por Cerezo Merchán (2012) en nuestro estudio para concretar las habilidades y aptitudes que consideran necesarias los profesionales en este ámbito en Rumanía.

\subsection{Síntesis y conclusiones}

A lo largo de este capítulo hemos presentado, con la información de la bibliografía existente, la situación y la evolución de esta profesión en el territorio rumano. Estos datos preliminares son únicamente una introducción, dado que la investigación objeto de esta tesis nos permitirá dar una visión más actualizada y con datos concretos de la situación actual en este país en el apartado dedicado al análisis de datos. 
Puesto que la subtitulación y el doblaje son las modalidades más empleadas en la actualidad en este país, hemos descrito y analizado el entorno profesional del traductor audiovisual centrándonos en estas dos modalidades de traducción con sus características particulares y las transformaciones que han experimentado en las últimas dos décadas.

Por tanto, se ha podido observar que, a pesar de su corta edad en el mercado de la traducción audiovisual de Rumanía, el doblaje se ha posicionado como la modalidad de traducción más utilizada para los productos extranjeros dirigidos al público infantil. Los traductores, habituados a la subtitulación, se adaptaron rápidamente y sin dificultades a los criterios que implicaba este "nuevo" tipo de traducción. La simultaneidad de los dos modos de traducción audiovisual — subtitulación y doblaje - enriquecieron el ámbito audiovisual rumano aportando más variedad y múltiples opciones al público infantil y adulto, además de un incremento laboral, especialmente en el sector de los actores, gracias a la complejidad del doblaje.

Asimismo, conceptuamos cómo la evolución tecnológica y el cambio sociopolítico fueron dos factores fundamentales que determinaron la variación del perfil del actual traductor audiovisual y del mercado laboral en Rumanía. No obstante, destacamos que algunas particularidades de esta profesión se generalizan y perduran en el tiempo, como por ejemplo el escaso tiempo de elaboración de la traducción, los hipotéticos derechos de autor o la inestabilidad laboral.

A modo de conclusión podemos afirmar que el incremento del número de profesionales de esta disciplina surgió gracias a la aparición repentina después del año 1989 de un gran número de cadenas privadas que ofrecieron una variedad amplia de programas. Por tanto, aumentó la demanda en el mercado laboral y al mismo tiempo se instauró otra modalidad de traducción audiovisual, poco empleada hasta esa fecha, el doblaje, así como nuevos cursos formativos para consolidar y formar los nuevos o actuales profesionales en este ámbito en Rumanía. 


\section{Capítulo 4: Metodología}

En este capítulo vamos a presentar y argumentar el uso de la metodología seleccionada para realizar la presente investigación. A su vez, esta parte de nuestro estudio se divide en dos subcapítulos que describen el marco teórico y el marco analítico de la metodología de investigación seguida.

En el marco teórico plantemos el problema de la investigación, nuestros objetivos, y justificamos teóricamente la elección de la metodología y de las estrategias para recabar los datos.

En el marco analítico describimos la población objeto de estudio, el diseño y la aplicación de los instrumentos que vamos a utilizar para la obtención de datos. En concreto, para recopilar la información pertinente a nuestro estudio emplearemos cuestionarios como instrumentos de recogida de datos cuantitativos, y entrevistas como instrumentos de recogida de datos cualitativos, entrevistas que estarán dirigidas tanto a los traductores como a las empresas empleadoras.

\subsection{Marco teórico}

\subsubsection{Las preguntas de la investigación}

El cambio político que sufrió Rumanía en el año 1989 repercute también en la vida socio-profesional de la población. La aparición repentina de varias cadenas de televisión, con diversos formatos, tal como hemos expuesto anteriormente (véase la sección 2.3.1.), ha significado una transformación considerable, tanto para el público como para los profesionales de la traducción audiovisual y los empleadores. Para el espectador se amplían las posibilidades de seleccionar programas y cadenas de televisión, algo que antes de la revolución parecía una utopía. En el caso de los profesionales que se dedican a la traducción de los productos extranjeros, se amplía su campo profesional, ya que aumenta el número de empleadores. En consecuencia, se necesitan más profesionales, con más variedad de idiomas, lo que supone implícitamente una preparación académica adecuada. 
A raíz de esta transformación socio-política, la figura del traductor audiovisual y del empleador cambia radicalmente, y consideramos necesario definir actualmente su posición y su perfil en el campo de la traducción audiovisual rumano.

Por tanto, la pregunta general que planteamos en nuestro estudio es: ¿Cuál es el perfil actual del traductor de productos extranjeros audiovisuales en Rumanía? Partiendo de esta pregunta y mediante preguntas más específicas como por ejemplo: “Considera que ha tenido una formación académica adecuada para la labor profesional que ejerce?”, “Conoce y aplica convenciones especificas de traducción audiovisual?”, “¿Qué tipo de empresa le contrata/contacta?”, “QQué idiomas se utilizan con más frecuencia en esta área?”, “Existen en Rumanía centros de formación con contenido específico para formar profesionales de traducción audiovisual?”, y otras que formulamos en los cuestionarios y las entrevistas dirigidos a los traductores y a las empresas, intentaremos arrojar luz sobre la naturaleza y estado de la traducción audiovisual en Rumanía y sobre el perfil actual del traductor audiovisual en este país.

\subsubsection{Objetivos}

Dado que no existen estudios específicos sobre el perfil del traductor audiovisual en Rumanía, nos planteamos en nuestra investigación, como objetivo general:

- Describir y analizar el perfil formativo y socioprofesional del traductor audiovisual en la actualidad en Rumanía.

Este objetivo general se complementa con cinco objetivos específicos:

- Describir y destacar las modalidades de traducción audiovisual, que se utilizan en Rumanía.

- Estudiar el entorno laboral de la traducción audiovisual en Rumanía.

- Determinar las competencias que ponen en ejercicio los traductores en su actividad profesional y requieren las empresas empleadoras.

- Describir el entorno formativo de la traducción audiovisual en Rumanía.

- Conocer el perfil laboral de las empresas que proporcionan servicios de traducción audiovisual en Rumanía. 


\subsubsection{Diseño del estudio empírico}

El término "metodología" hace referencia al procedimiento utilizado para enfocar el problema y buscar las respuestas a las preguntas de investigación. En las ciencias sociales han destacado históricamente dos perspectivas teóricas principales: el positivismo y la fenomenología. Por un lado, los positivistas (especialmente Comte, 1896; Durkheim, 1938, 1951) buscan las causas de los fenómenos sociales con independencia de los estados subjetivos de los individuos, mediante métodos como cuestionarios, inventarios y estudios demográficos, que producen datos susceptibles de análisis estadístico. Sin embargo, por otro lado, los fenomenólogos (Berger y Luckmann, 1967; Bruyn, 1966; Husserl; 1913, Psathas, 1973; Schutz, 1962) pretenden entender y analizar los fenómenos sociales desde la propia perspectiva del individuo, buscando la comprensión por medios cualitativos como la observación participativa o la entrevista en profundidad para generar datos descriptivos (Taylor y Bogdan, 1987: 15-16).

El siglo XX comenzó con un enfoque analítico principal, el cuantitativo, y finalizó con dos enfoques fundamentales: el cuantitativo y el cualitativo. No se trata de la sustitución del primero por el segundo, sino de que el segundo se sumó al primero. Ambos enfoques han sido considerados usualmente como paradigmas de la investigación científica, es decir, como realizaciones científicas universalmente reconocidas que, durante cierto tiempo, proporcionan modelos de problemas y soluciones a una comunidad científica, según Kuhn (1971: 13). Los dos enfoques emplean procesos cuidadosos, metódicos y empíricos en su esfuerzo para generar conocimiento. Grinnell (1997), citado por Hernández, Fernández y Baptista (2010: 4), identifica cinco características similares y relacionadas entre sí, que son comunes a ambos enfoques:

1. Llevan a cabo la observación y evaluación de fenómenos.

2. Establecen suposiciones o ideas como consecuencia de la observación y evaluación realizadas.

3. Demuestran el grado en que las suposiciones o ideas tienen fundamento.

4. Revisan tales suposiciones o ideas sobre la base de las pruebas o del análisis.

5. Proponen nuevas observaciones y evaluaciones para esclarecer, modificar y fundamentar las suposiciones e ideas; o incluso para generar otras. 
No obstante, a pesar de sus similitudes, cada enfoque, tanto el cuantitativo, como el cualitativo, se caracterizan por sus particularidades. Varios autores han definido y caracterizado los dos enfoques (véase Grinnelli, 1997; Jiménez-Domínguez, 2000; Amescua y Gálvez, 2002; Denis y Gutiérrez, 2003; Mertens, 2005; Creswell, 2005). En nuestro estudio, y con la finalidad de realizar un análisis de las características que los diferencian, emplearemos la contribución de Hernández, Fernández y Baptista (2010: 16), donde podemos observar que, a pesar de utilizar los mismos métodos, muestran diferencias en las distintas etapas de investigación:

\begin{tabular}{|c|c|c|}
\hline $\begin{array}{c}\text { Características } \\
\text { cuantitativas }\end{array}$ & $\begin{array}{l}\text { Procesos fundamentales } \\
\text { del proceso general de } \\
\text { investigación }\end{array}$ & Características cualitativas \\
\hline $\begin{array}{l}\text { Orientación hacia la } \\
\text { descripción, predicción y } \\
\text { explicación. } \\
\text { Específico y acotado. } \\
\text { Dirigido hacia datos } \\
\text { medibles u observables. }\end{array}$ & $\begin{array}{c}\text { Planteamiento del } \\
\text { problema }\end{array}$ & $\begin{array}{l}\text { Orientación hacia la } \\
\text { exploración, la descripción } \\
\text { y el entendimiento. } \\
\text { General y amplio. } \\
\text { Dirigido a las experiencias } \\
\text { de los participantes. }\end{array}$ \\
\hline $\begin{array}{l}\text { Rol fundamental. } \\
\text { Justificación para el } \\
\text { planteamiento y } \quad \text { y } \\
\text { necesidad del estudio. }\end{array}$ & Revisión de la literatura & $\begin{array}{ll}\text { Rol secundario. } & \\
\text { Justificación para } & \text { el } \\
\text { planteamiento } \quad \text { y } & \text { la } \\
\text { necesidad del estudio. }\end{array}$ \\
\hline $\begin{array}{l}\text { Instrumentos } \\
\text { predeterminados. } \\
\text { Datos numéricos. } \\
\text { Número considerable de } \\
\text { casos. }\end{array}$ & Recolección de datos & $\begin{array}{l}\text { Los datos emergen poco a } \\
\text { poco. } \\
\text { Datos en texto o imagen. } \\
\text { Número relativamente } \\
\text { pequeño de casos. }\end{array}$ \\
\hline $\begin{array}{l}\text { Análisis estadístico. } \\
\text { Descripción de tendencias, } \\
\text { comparación de grupos o } \\
\text { relación entre variables. } \\
\text { Comparación de resultados } \\
\text { con predicciones y estudios } \\
\text { previos. }\end{array}$ & Análisis de los datos & $\begin{array}{l}\text { Análisis de textos y } \\
\text { material audiovisual. } \\
\text { Descripción, análisis y } \\
\text { desarrollo de temas. } \\
\text { Significado profundo de } \\
\text { los resultados. }\end{array}$ \\
\hline
\end{tabular}




\begin{tabular}{|l|l|l|}
\hline $\begin{array}{l}\text { Estándar y fijo. } \\
\text { Objetivo y sin tendencias. }\end{array}$ & $\begin{array}{l}\text { Emergente y flexible. } \\
\text { Reflexivo y con aceptación } \\
\text { de tendencias. }\end{array}$ \\
\hline
\end{tabular}

Tabla 15. Comparación de las etapas de investigación de los enfoques cuantitativo y cualitativo Hernández, Fernández y Baptista (2010: 16)

Sin embargo, como respuesta a los diversos interrogantes originados por los teóricos sobre la validez de un método o del otro, el siglo XXI se inició con un tercer enfoque, que venía perfilándose décadas atrás: el enfoque mixto. Se trata de un proceso que recopila, analiza y vincula datos cuantitativos y cualitativos en un mismo estudio o una serie de investigaciones para responder a un planteamiento del problema (Hernández, Fernández y Baptista, 2006: 755).

Los teóricos Creswell y Clark (2007: 5) también consideran que el enfoque mixto conceptualiza una forma diferente, pero compleja, de observación y análisis de la sociedad y lo definen de la siguiente forma:

\footnotetext{
Mixed methods research is a research design with philosophical assumptions as well as methods of inquiry. As a methodology, it involves philosophical assumptions that guide the direction of the collection and analysis and the mixture of qualitative and quantitative approaches in many phases of the research process. As a method, it focuses on collecting, analyzing and mixing both quantitative and qualitative data in a single study or series of studies. Its central premise is that the use of quantitative and qualitative approaches, in combination, provides a better understanding of research problems than either approach alone.
}

Por su parte Mertens (2005), Stake (2006), Yin (2009) y Creswell (2009) consideran que en un estudio de caso es necesaria la triangulación de fuentes de datos, y que se pueden utilizar distintas herramientas, tanto cuantitativas como cualitativas. De esta forma se minimizan las limitaciones que tienen por separado, y pueden aportar amplitud y profundidad a la investigación.

Todd, Nerlich y McKeown (2004), citados por Hernández, Fernández y Baptista, (2006:755-756) mencionan las ventajas que puede aportar el método mixto: 
- Se logra una perspectiva más precisa del fenómeno, dado que se emplea la fortaleza de ambos enfoques cuantitativo-cualitativo, lo cual refuerza la confianza del investigador proporcionándole una visión panorámica de la realidad.

- Ayuda a clarificar y a formular el planteamiento del problema, y al mismo tiempo a encontrar la modalidad más adecuada para estudiar y teorizar la incógnita de investigación.

- Aporta variedad de datos, dado que su aplicación potencia la creatividad teórica, tipos de datos, contextos y análisis.

- Amplía posibilidades y dimensiones del proyecto de investigación, y contribuye a la vez a un mayor y más rápido y entendimiento.

- Apoya con mayor solidez las inferencias científicas.

- Ayuda al investigador a "explorar y explotar" mejor los datos.

- Es útil para presentar resultados a una audiencia hostil (adepta al enfoque cuantitativo o cualitativo), dado que es una combinación de ambos.

Tras la breve descripción de los tres tipos de enfoques metodológicos, podemos observar que a pese a que sean diferentes, resultan complementarios. En consecuencia, la elección del método o combinación de métodos, por parte del investigador, dependerá de si estos responden o no a los objetivos de su estudio. Por tanto, en nuestro estudio nos decantamos por emplear el enfoque mixto, un enfoque que ya se ha empleado en trabajos previos de tipo socioprofesional relativos a diferentes ámbitos de la traducción (véanse Monzó Nebot, 2002; Cerezo Merchán, 2012 o Muñoz Miquel, 2014).

Creswell y Clark (2011: 70-72) detallan la tipología de los métodos mixtos de investigación considerando dos factores para su instrumentación: 1) la prioridad o importancia que se otorga a cada paradigma, y 2) la secuencia de recolección de datos cuantitativos y cualitativos simultánea o secuencial, proponiendo varios tipos de diseños:

- Paralelo convergente: el investigador utiliza en la misma fase y al mismo tiempo los dos métodos cuantitativo y cualitativo, priorizando los dos métodos de modo equitativo, y combinándolos para interpretar y establecer posibles convergencias o divergencias entre ellos.

- Secuencial explicativo: el investigador divide en dos fases su estudio. Este diseño prioriza y empieza con la recolección y análisis de datos cuantitativos, y continua con la segunda fase cualitativa, diseñada a partir de los datos cuantitativos 
obtenidos. En esta fase los resultados de la fase cualitativa ayudan a interpretar los resultados de la fase cuantitativa.

- Secuencial exploratorio: consiste en dos fases, pero es el reverso del diseño expuesto anteriormente. El investigador prioriza la recolección y el análisis de datos cualitativos, y continua con la segunda fase cuantitativa, diseñada a partir de los datos cualitativos obtenidos. En esta fase los resultados de la fase cuantitativa ayudan a interpretar y generalizar los resultados de la fase cualitativa.

- Integrado: el investigador incluye la recolección de datos tanto cuantitativos como cualitativos, pero uno de los tipos de datos desempeña un papel complementario en el diseño global.

- Transformativo: el investigador utiliza dos fases en su estudio (cuantitativo y cualitativo), pero el marco teórico está adaptado a la fase a la que se le otorga mayor prioridad.

- En fases múltiples: el investigador combina métodos que se aplican de forma secuencial y concurrente, durante un periodo de tiempo para lograr el objetivo general del estudio.

Tras analizar los tipos de diseño de investigación, que proponen los dos autores, Creswell y Clark (2011), en nuestro estudio vamos a aplicar el método secuencial explicativo, de modo que iniciamos la búsqueda y la recolección de datos cuantitativos, continuada y complementada por la fase cualitativa. Además, como los estudios de datos cuantitativo y cualitativo concurren en la parte final, podemos considerar que el diseño de la investigación es también paralelo convergente en la fase final.

A efectos prácticos, recopilaremos datos cuantitativos y cualitativos a través de cuestionarios y entrevistas, ya que nos ayudarán a profundizar en el análisis y la descripción del perfil socioprofesional del traductor audiovisual en Rumanía. Los datos cualitativos nos aportarán información más detallada sobre las características de esta profesión y de este gremio de profesionales.

\subsubsection{Estrategias para recabar los datos}

Como hemos expuesto anteriormente, en nuestro estudio utilizaremos como método de investigación el enfoque mixto. Este tipo de enfoque se caracteriza por un 
concepto que se define como la triangulación. Esta noción, según afirman Hernández y Mendoza (2008), se extendió más allá de la comparación e integración de datos cuantitativos y cualitativos, por lo que podemos hablar de diversos tipos de triangulación que se pueden emplear en una investigación y que vamos a presentar a continuación:

\begin{tabular}{|c|c|}
\hline $\begin{array}{c}\text { TIPOS DE } \\
\text { TRIANGULACIÓN }\end{array}$ & CARACTERÍSTICAS \\
\hline Triangulación de datos & $\begin{array}{l}\text { - De distinta naturaleza (cuantitativos-cualitativos). } \\
\text { - } \text { De diferentes fuentes (archivos, cuestionarios } \\
\text { - } \quad \text { De distindarizados, observación). } \\
\text { de tiempos, experimentos cronológicos; inducción } \\
\text { enfocada paulatinamente). } \\
\text { - De bases de datos (conversión de una clase de } \\
\text { datos a otra y viceversa). }\end{array}$ \\
\hline $\begin{array}{l}\text { Triangulación de } \\
\text { métodos }\end{array}$ & $\begin{array}{l}\text { - Dentro de cada método. } \\
\text { - Entre métodos (cuantitativo y cualitativo): } \\
\text { a) Diseños concurrentes. } \\
\text { b) Diseños secuenciales. } \\
\text { c) Diseños de conversión } \\
\text { d) Diseños de integración. }\end{array}$ \\
\hline $\begin{array}{l}\text { Triangulación de } \\
\text { investigadores }\end{array}$ & $\begin{array}{l}\text { - } \quad \text { Mismo método (auditoría). } \\
\text { - Distintos métodos (colaboración en equipo). }\end{array}$ \\
\hline Triangulación de teorías & $\begin{array}{l}\text { - Construir una nueva teoría que aglutine principios } \\
\text { de otras. } \\
\text { - Desarrollar una perspectiva teórica para una } \\
\text { investigación en particular. } \\
\text { Concurrencia de varias teorías y modelos para } \\
\text { consolidar y ampliar el entendimiento de un } \\
\text { fenómeno o problema de estudio. }\end{array}$ \\
\hline
\end{tabular}




\begin{tabular}{|l|ll|}
\hline & $\bullet \begin{array}{l}\text { Enfocar el problema desde varias ciencias o } \\
\text { disciplinas. }\end{array}$ \\
$\begin{array}{l}\text { Triangulación de } \\
\text { ciencias o disciplinas }\end{array}$ & $\begin{array}{l}\text { Convocar conocimiento y técnicas desde distintas } \\
\text { ciencias o disciplinas. }\end{array}$ \\
\hline
\end{tabular}

Tabla 16. Tipos de triangulación en el enfoque mixto

Según la clasificación presentada anteriormente, podemos decir que en el presente estudio utilizaremos la triangulación de métodos (recopilación y análisis de información teórica, cuestionarios como instrumentos de recogida de datos cuantitativos y entrevistas como instrumentos recogida de datos cualitativos) y la triangulación de datos recabados (cuantitativos y cualitativos, procedentes de distintas fuentes).

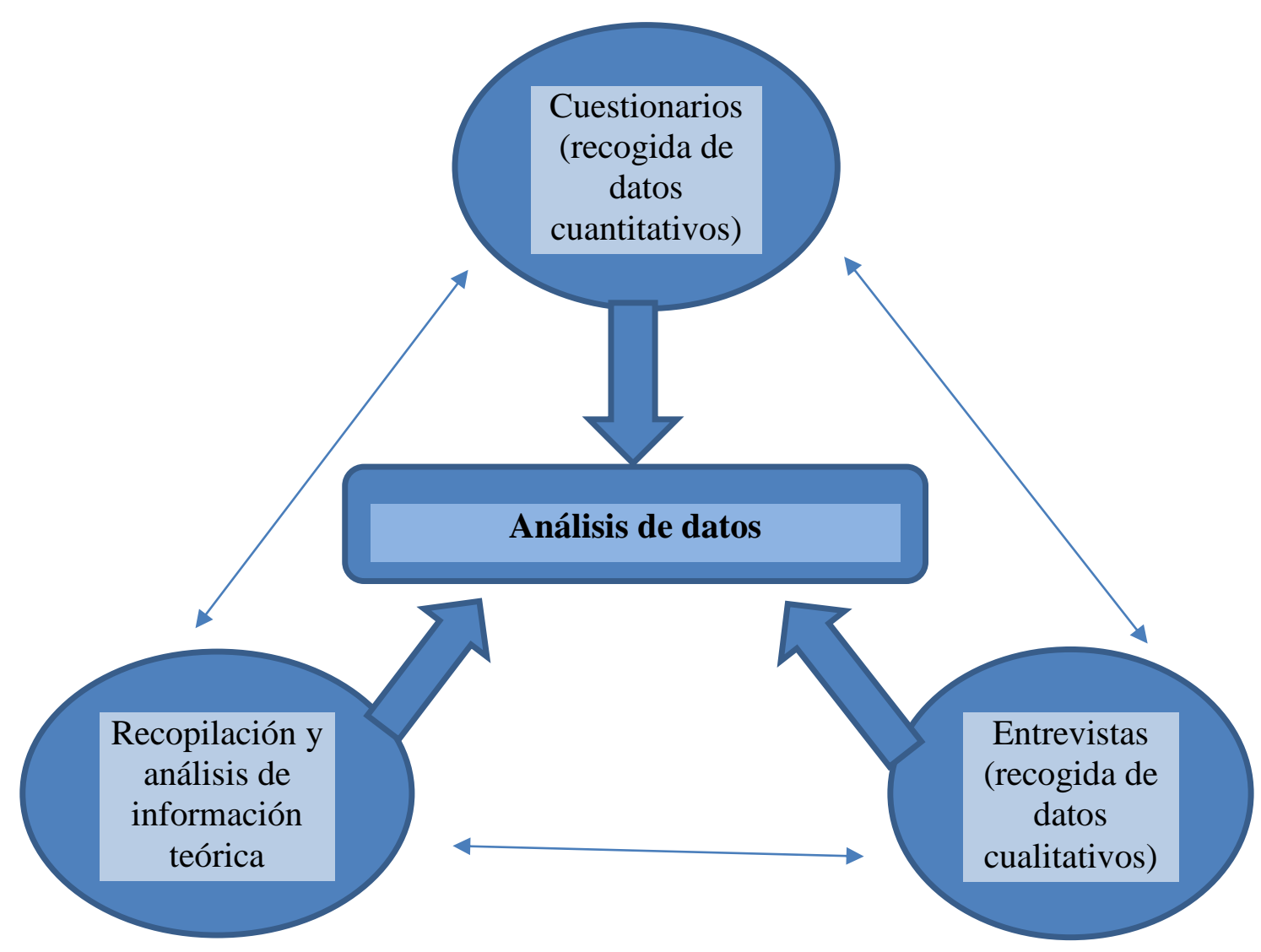

Figura 3. Triangulación de métodos 
Esta triangulación de métodos y recogida de datos nos aportará la información pertinente para realizar el análisis y la descripción del perfil actual del traductor en Rumanía.

\subsection{Marco analítico}

\subsubsection{Población objeto de estudio}

Hurtado y Toro (1998: 79) afirman que la población es el total de los individuos o elementos a quienes se refiere la investigación, es decir, todos los elementos que vamos a estudiar, y por ello también se le llama universo. Mientras que Hernández, Fernández y Baptista (2006: 239) la definen como el conjunto de todos los casos que concuerdan con determinadas especificaciones, por tanto las poblaciones deben situarse claramente en torno a sus características de contenido, de lugar y en el tiempo. En caso de que la población sea tan grande o inaccesible que no se pueda estudiar toda, entonces el investigador tendrá la posibilidad de seleccionar una muestra (De Barrera, 2008: 141).

Dicha muestra debe responder a la posibilidad de reconstruir la estructura interna del objeto que se estudia y la estabilidad de la misma como generadora de múltiples manifestaciones. Según la contribución de Hernández, Fernández y Baptista (2006: 241), existen dos tipos de muestras: no probabilísticas y probabilísticas. La muestra probabilística define el subgrupo de la población en el que todos los elementos de ésta tienen la misma posibilidad de ser elegidos. La muestra no probabilística o dirigida define el subgrupo de la población en la que la elección de los elementos no depende de la probabilidad, sino de las características de la investigación.

En este estudio utilizaremos la muestra dirigida, considerando que nuestro principal objeto de análisis es el traductor audiovisual en Rumanía, y por tanto se trata de un subgrupo de población que tiene características similares. Sin embargo, la inexistencia actual de un censo oficial de traductores audiovisuales en Rumanía (de acuerdo con nuestras investigaciones), así como de una asociación específica a este gremio (véase el capítulo 3) nos imposibilita determinar con exactitud el número de profesionales que ejerce esta labor en este país.

Asimismo, según Hernández, Fernández y Baptista (2006: 190) cabe destacar que este tipo de muestra se aplica: 
[...] Para determinado diseño de estudio que requiere no tanto una "representatividad" de elementos de una población, sino una cuidadosa y controlada elección de casos con ciertas características especificadas previamente en el planteamiento del problema. Para el enfoque cualitativo, al no interesar tanto la posibilidad de generalizar los resultados, las muestras no probabilísticas o dirigidas son de gran valor, pues logran obtener los casos (personas, contextos, situaciones) que interesan al investigador y que llegan a ofrecer una gran riqueza para la recolección y el análisis de los datos.

Teniendo en cuenta las limitaciones anteriormente mencionadas, y dado el número reducido de cursos de formación académica orientados a la traducción audiovisual que se ofrecen actualmente en las universidades de Rumanía, como se comprueba en nuestros cuestionarios y entrevistas, nuestros criterios de inclusión de los traductores egresados en la muestra de este estudio se fundamenta en dos factores que consideramos significativos en este caso particular:

a) Tener una experiencia profesional de más de tres años.

b) Haber ejercido la profesión de traductor de textos audiovisuales en los últimos tres años.

No obstante, hemos considerado necesario añadir a nuestro análisis, como objeto secundario, las empresas que les contratan, puesto que directamente o indirectamente influyen en la situación socioprofesional, que ocupan los traductores audiovisuales en este país. Así pues, los criterios de inclusión del grupo de empleadores en la muestra de nuestro estudio son:

a) Tener la sede ubicada en Rumanía.

b) Tener como mínimo tres años de actividad en el mercado rumano.

c) Dedicar por lo menos $50 \%$ de su actividad a la traducción audiovisual.

d) Haber contratado el servicio de un traductor audiovisual en los dos últimos años.

Consideramos que estos dos grupos de población son los dos factores relevantes para nuestro estudio, dado que se complementan y se completan conjuntamente, lo que nos ayudará a analizar, describir y definir el perfil del traductor audiovisual en la actualidad en Rumanía, gracias a la información cruzada que nos pueden aportar. 
Por tanto, para la selección de los participantes aplicamos los criterios anteriormente expuestos e intentamos reunir el mayor número posible de participantes, a pesar de que nuestra intención en este estudio no es generalizar, sino describir, el perfil actual del traductor de productos extranjeros audiovisuales en este país. No obstante, el tamaño de nuestra muestra se ha visto restringido por dos motivos: el reducido número de profesionales que ejercen traducción audiovisual en Rumanía; y, por otra parte, la reticencia de algunos miembros de este gremio para participar en este estudio, a pesar de nuestra reiteración. Aun así, consideramos que la muestra que utilizamos en esta investigación, tanto de traductores como empresas empleadoras, puede resultar suficiente para responder a las preguntas que hemos planteado, así como para cumplir los objetivos de nuestro estudio.

\subsubsection{Métodos empleados para obtener los datos}

\subsubsection{Cuestionarios}

El cuestionario es un instrumento de recogida de datos que consiste simplemente en una serie de preguntas o ítems acerca de un problema previamente determinado, cuyas respuestas se han de contestar por escrito. Por ello, esta técnica nos permite la recopilación de datos que consideramos pertinentes para alcanzar nuestros objetivos, tal como mencionan Rodríguez, Gil y García (1996: 185):

Este instrumento se asocia a enfoques y diseños de investigación típicamente cuantitativos, porque se construye para contrastar puntos de vista, porque favorece el acercamiento a formas de conocimiento nomotético no ideográfico, porque su análisis se apoya en el uso de estadísticos, que pretenden acercar los resultados en unos pocos elementos (muestra) a un punto de referencia más amplio y definitorio (población) y en definitiva, porque suelen diseñarse y analizarse sin contar con otras perspectivas que aquella que refleja el punto de vista del investigador.

Esta técnica permite obtener información directa sobre el problema que nos interesa a través de una formulación de preguntas previamente preparadas y seleccionadas después de un minucioso estudio. La información obtenida se limita a las respuestas contestadas por el sujeto encuestado. Por tanto, nos permite conocer y analizar, según afirma Canales Cerón (2006: 22): 
[...] las respuestas, entendiendo por tal la operación de reducir el conjunto de respuestas efectuadas, a un conjunto de "respuestas" tipificadas. Así, cada respuesta efectiva corresponde a alguna de las tipificadas, y cada una de estas últimas corresponde a múltiples de las primeras. El código así, como un azar congelado al decir de Monod, permite "describir" con un conjunto de tipos "generadores" el conjunto de respuestas manifestadas.

No obstante, el empleo de este método, interpretado por varios teóricos como Peñuelas (2008), Calvos Encinas (2009), Hernández, Fernández y Baptista (2010) o Creswell y Clark (2011), puede aportar al investigador ventajas y retos para la recolección de datos.

De acuerdo con Hernández, Fernández y Baptista (2010: 271), mostraremos en la siguiente tabla los factores positivos y negativos que definen el cuestionario y que pueden favorecer o dificultar el objetivo de la investigación:

\begin{tabular}{|c|c|c|c|}
\hline MÉTODO & $\begin{array}{c}\text { PROPÓSITO } \\
\text { GENERAL BÁSICO }\end{array}$ & VENTAJAS & RETOS \\
\hline $\begin{array}{l}\text { Pruebas } \\
\text { estandarizadas }\end{array}$ & $\begin{array}{l}\text {-Obtener de manera } \\
\text { relativamente rápida } \\
\text { datos sobre los } \\
\text { variables. } \\
\text {-Propios para } \\
\text { actitudes, } \\
\text { expectativas, } \\
\text { opiniones y variables } \\
\text { que pueden } \\
\text { medirse mediante } \\
\text { expresiones escritas, o } \\
\text { que el mismo } \\
\text { participante puede } \\
\text { ubicar en las } \\
\text { categorías de las }\end{array}$ & $\begin{array}{l}\text {-Puede ser } \\
\text { anónimo. } \\
\text {-Poco costosa su } \\
\text { aplicación } \\
\text { individual. } \\
\text {-Relativamente } \\
\text { fácil de } \\
\text { responder. } \\
\text {-Relativamente } \\
\text { fácil de analizar } \\
\text { y comparar. } \\
\text {-Puede } \\
\text { administrarse a } \\
\text { un considerable } \\
\text { número de } \\
\text { personas. }\end{array}$ & $\begin{array}{l}\text {-Regularmente no se } \\
\text { obtiene } \\
\text { retroalimentación } \\
\text { detallada de parte de } \\
\text { los intervinientes. } \\
\text {-Se evalúan actitudes y } \\
\text { proyecciones no } \\
\text { comportamientos } \\
\text { (mediciones } \\
\text { indirectas). } \\
\text {-El manejo del lenguaje } \\
\text { puede ser una fuente de } \\
\text { sesgos e influir en las } \\
\text { respuestas. } \\
\text {-Son impersonales. } \\
\text {-No nos proporcionan }\end{array}$ \\
\hline
\end{tabular}




\begin{tabular}{|l|l|l|l|}
\hline variables & -Normalmente & información sobre el \\
(autoubicación). & disponemos de & individuo, excepto en \\
& versiones previas & las variables medidas. \\
& para escoger o & \\
& basarnos en & \\
& éstas. & \\
\hline
\end{tabular}

Tabla 17. Ventajas y retos del uso del cuestionario (Hernández, Fernández y Baptista, 2010: 271)

En nuestro caso, la elección de esta herramienta está motivada por la pretensión de hacerla llegar a un número máximo de elementos de la población y por ser fácil de responder, por eso optamos por un cuestionario con una configuración sencilla en formato formulario de Google Forms, para agilizar y estimular a los encuestados (traductores y empresas) a contestar a nuestras preguntas en un breve espacio de tiempo, y así intentar contar con un número elevado de participantes.

\section{A. Diseño del cuestionario}

Para formular las preguntas del cuestionario hemos considerado las características y los criterios que plantean Iarossi (2005: 29-43) y Hernández, Fernández y Baptista (2010: 225-229), tal como enunciamos a continuación:

a) Las preguntas tienen que ser claras, precisas y comprensibles para los sujetos encuestados, y deben evitar términos confusos, ambiguos y de doble sentido.

b) Las preguntas tienen que ser lo más breves posible, porque las preguntas largas suelen resultar tediosas, toman más tiempo y pueden distraer al participante; pero sin sacrificar la claridad por la concisión.

c) El lenguaje de las preguntas debe adaptarse al habla de la población a la que van dirigidas las preguntas, y por tanto deben formularse con un vocabulario simple, directo y familiar para los participantes.

d) Las preguntas deben referirse preferentemente a un solo aspecto o una relación lógica.

e) Las preguntas no habrán de inducir las respuestas, se tienen que evitar preguntas tendenciosas o que dan pie a elegir un tipo de respuesta (directivas). 
Por tanto, hemos realizado un cuestionario congruente con el planteamiento del problema e hipótesis (Brace, 2008), con preguntas breves, claras, precisas y comprensibles para los sujetos encuestados, intentado excluir las preguntas innecesarias o injustificadas. Dicho cuestionario se divide en cuatro bloques específicos, donde indagamos sobre temas generales y específicos, tanto para el grupo de profesionales, como para las empresas empleadoras.

En cuanto a la formulación de las preguntas, tal como afirma Hernández, Fernández y Baptista (2010: 217) el contenido es tan variado como los aspectos que mide, pero básicamente se consideran dos tipos de preguntas: cerradas y abiertas.

Las preguntas abiertas no delimitan previamente las alternativas de respuesta, por lo cual el número de categorías de respuesta es muy elevado; sin embargo tienen algunos inconvenientes, tanto por parte del entrevistado como por parte del encuestador. Este tipo de pregunta supone más tiempo y más esfuerzo para redactar la respuesta, y por eso existe la posibilidad que el participante no conteste, además puede dificultar el análisis de datos, dado que es difícil su categorización.

Las preguntas cerradas contienen categorías u opciones de respuesta que han sido previamente delimitadas. Es decir, se presentan las posibilidades de respuesta a los participantes, quienes deben restringirse a éstas. Pueden ser dicotómicas (dos posibilidades de respuesta) o incluir varias opciones de respuesta. También son más fáciles de decodificar y analizar (Hernández, Fernández y Baptista, 2010: 217).

Por tanto, y después de analizar las características de los tipos de preguntas, sus ventajas e inconvenientes en la construcción de ambos cuestionarios, que dirigimos tanto a profesionales como a las empresas empleadoras, hemos utilizado mayoritariamente preguntas cerradas dicotómicas o de elección múltiple, aunque casi siempre añadimos un apartado de comentarios, por si el encuestado quiere desarrollar la respuesta. A continuación se presentan algunos ejemplos:

- Preguntas de elección única: al ser excluyentes entre sí, se puede elegir solo una opción. No obstante, al añadir el apartado de comentarios, algunos encuestados pueden justificar su respuesta aportándonos más información para el proceso de análisis de datos. 


\section{2. ¿Considera que el tiempo de que dispone para realizar el trabajo es suficiente?}

$\square$ Sí

$\square$ No

$\square$ Comentarios

Tabla 18. Ejemplo de pregunta de elección única

○ Preguntas de elección múltiple: no son excluyentes entre sí y, por tanto, el encuestado puede marcar varias opciones.

13. ¿En qué combinación lingüística, suele realizar las traducciones audiovisuales? (Puede marcar más de una opción)

$\square$ Inglés- Rumano

$\square$ Francés- Rumano

$\square$ Español-Rumano

$\square$ Alemán-Rumano

$\square$ Chino-Rumano

$\square$ Otros (especifique, por favor)

Tabla 19. Ejemplo de pregunta de elección múltiple

- Preguntas de escala tipo Likert: se utilizan para medir actitudes. En nuestro caso pensamos que sería conveniente utilizar este tipo de pregunta en el cuestionario dirigido a las empresas empleadoras, para poder analizar la valoración que se le otorga particularmente a la traducción.

35. Con una escala Likert del 1 al 5, ¿cuánto considera que influye una buena traducción en el éxito de audiencia de un producto audiovisual, ya sea una película, serie o documental?

$\square 1$ muy poco

$\square 2$ poco 


\section{$\square 3$ algo \\ $\square 4$ bastante \\ $\square 5$ mucho}

Tabla 20. Ejemplo de pregunta de escala tipo Likert

Cabe destacar que las preguntas son de respuesta opcional, de modo que ninguna pregunta obliga al encuestado a contestar para poder pasar a la siguiente.

Para redactar las preguntas hemos seguido las pautas mencionadas por León y Montero (2003), citados por Hernández, Fernández y Baptista (2010: 39), que son los siguientes:

- Que no se conozcan las respuestas (si se conocen, no valdría la pena realizar el estudio).

- Que puedan responderse con evidencia empírica (datos observables o medibles).

- Que impliquen usar medios éticos.

- Que sean claras.

- Que el conocimiento que se obtenga sea sustancial (que aporte conocimiento a un campo de estudio).

Asimismo, utilizamos la misma meticulosidad en el orden del planteamiento de las preguntas, y por ello hemos considerado conveniente dividir el cuestionario dirigido a los traductores en cuatro bloques; cada uno de ellos trata aspectos diferentes, pero a la vez complementarios de la actividad y la formación del traductor audiovisual en Rumanía.

Tal como hemos expuesto anteriormente, para ambos cuestionarios utilizamos el formato de Google Docs. Esta elección se debe a su sencillez, dado que nuestra intención inicial ha sido lograr un elevado número de encuestados de los que cumplen los requisitos actualmente en Rumanía. Asimismo, tenemos certeza de la profesionalidad de cada uno de los encuestados, dado que contactamos personalmente con cada uno de ellos, vía correo electrónico. Sin emabargo, no desvelamos su identidad en nuestro estudio.

En la parte de introducción de los cuestionarios, expusimos, según sugieren Hernández, Fernández y Baptista (2010: 230), el propósito general del estudio, la importancia de la participación de los encuestados en este estudio, el tiempo aproximado 
de respuesta y nuestro nombre y datos de contacto. A continuación, los participantes podían contestar libremente a las preguntas formuladas en nuestra encuesta. En la parte final añadimos un parágrafo de agradecimiento por la colaboración y por dedicarnos una parte de su tiempo aportando datos a nuestra investigación.

Considerando, por tanto, los planteamientos teóricos y los objetivos que tenía que alcanzar nuestro estudio, proyectamos la elaboración de los cuestionarios de la siguiente forma:

- Cuestionario para traductores

\begin{tabular}{|c|c|c|}
\hline Bloque & Ítems & Objetivo \\
\hline Perfil del traductor & $\begin{array}{l}\text { - Ubicación territorial. } \\
\text { - Formación para } \\
\text { desempeñar esta profesión. } \\
\text { - Modalidad/es de TAV } \\
\text { - Combinación lingüística. } \\
\text { - Régimen laboral. } \\
\text { - Tipo de convenciones } \\
\text { que sigue para realizar la } \\
\text { traducción audiovisual. } \\
\text { - Recursos tecnológicos. } \\
\text { - Tipos de restricciones. } \\
\text { - Derechos de autor. }\end{array}$ & $\begin{array}{l}\text { Estudiar el entorno laboral } \\
\text { de la traducción } \\
\text { audiovisual en Rumanía. }\end{array}$ \\
\hline $\begin{array}{l}\text { Valoración de la } \\
\text { profesión }\end{array}$ & $\begin{array}{l}\text { - Repercusión de la } \\
\text { traducción en el producto } \\
\text { final. } \\
\text { - Reconocimiento público } \\
\text { y social. } \\
\text { - Remuneración } \\
\text { económica. }\end{array}$ & $\begin{array}{l}\text { Estudiar el entorno laboral } \\
\text { de la traducción } \\
\text { audiovisual en Rumanía. }\end{array}$ \\
\hline $\begin{array}{l}\text { Valoración de la } \\
\text { formación }\end{array}$ & $\begin{array}{l}\text { - Valoración de la } \\
\text { formación académica que }\end{array}$ & $\begin{array}{l}\text { Describir el entorno } \\
\text { formativo de la traducción } \\
\text { audiovisual en Rumanía. }\end{array}$ \\
\hline
\end{tabular}




\begin{tabular}{|l|l|l|}
\hline & $\begin{array}{l}\text { existe actualmente en } \\
\text { Rumanía. }\end{array}$ & \\
\hline \multirow{3}{*}{ Competencias } & $\begin{array}{l}\text { - Competencias } \\
\text { específicas. } \\
\text { - Competencias genéricas. }\end{array}$ & $\begin{array}{l}\text { Determinar las } \\
\text { competencias que ponen } \\
\text { en ejercicio los } \\
\text { traductores. }\end{array}$ \\
\hline
\end{tabular}

Tabla 21. Bloque, ítems y objetivo del cuestionario dirigido a los traductores

- Cuestionario para empresas

\begin{tabular}{|c|c|c|}
\hline Bloque & Ítems & Objetivo \\
\hline Perfil de la empresa & $\begin{array}{l}\text { - Datos de identificación y } \\
\text { actividades. } \\
\text { - Relación con traductores. } \\
\text { - Relación con la } \\
\text { universidad. }\end{array}$ & $\begin{array}{l}\text { Conocer el perfil laboral } \\
\text { de las empresas que } \\
\text { proporcionan servicios de } \\
\text { traducción audiovisual en } \\
\text { Rumanía. } \\
\text { Estudiar el entorno laboral } \\
\text { de la traducción } \\
\text { audiovisual en Rumanía. }\end{array}$ \\
\hline Competencias & $\begin{array}{l}\text { - Competencias } \\
\text { específicas. } \\
\text { - Competencias genéricas. }\end{array}$ & $\begin{array}{l}\text { Determinar las } \\
\text { competencias que ponen } \\
\text { en ejercicio los } \\
\text { traductores. }\end{array}$ \\
\hline
\end{tabular}

Tabla 22. Bloque, ítems y objetivo del cuestionario dirigido a las empresas

Ambos cuestionarios pueden consultarse, en su totalidad, en el correspondiente Anexo (Anexo I).

Dado que los destinatarios de esta investigación son traductores y empresas que ejercen su actividad en Rumanía, la lengua vehicular de la redacción de los cuestionarios ha sido la lengua rumana. No obstante, se puede encontrar una versión de los cuestionarios traducida al español en el correspondiente Anexo (Anexo II). 


\section{B. Validación del instrumento}

La validez y la fiabilidad de los cuestionarios se comprobaron en diferentes etapas y por medio de varios expertos.

El primer paso fue la evaluación de los expertos (Hernández, Fernández y Baptista, 2010: 204), que determinaron la idoneidad y la congruencia de la estructura de nuestros cuestionarios. El panel de expertos fue constituido por:

- La Dra. Beatriz Cerezo Merchán, de la Universidad de Valencia, una de las directoras de esta tesis, quien nos guió en la creación adecuada del cuestionario para abarcar todos los interrogantes a los que queríamos encontrar respuesta mediante esta herramienta, dado que su tesis doctoral tuvo algunos objetivos de investigación similares a los nuestros.

- El Dr. José Luis Martí Ferriol, de la Universidad Jaime I, y también director de la presente investigación, quien evaluó los cuestionarios desde un punto de vista formal, teniendo presente que la formulación de las preguntas podría repercutir en el análisis posterior de los datos cuantitativos.

- La Dra. Ana Giménez Adelantado, de la Universidad de Jaime I, con una amplia experiencia en el ámbito de la investigación social, quien corroboró que los cuestionarios tenían la robustez científica desde el punto de vista sociológico para aportarnos los datos pertinentes a nuestro estudio.

Los expertos evaluaron de forma positiva la configuración de ambos cuestionarios y nos sugirieron reformular algunos aspectos como:

a. Estructurar y seleccionar adecuadamente las competencias necesarias para desarrollar esta profesión.

b. Corregir el planteamiento de algunas preguntas que generaban ambigüedad.

Tras realizar los cambios sugeridos, pasamos a la siguiente fase de valoración de los cuestionarios. 
La segunda evaluación consistió en la prueba piloto que se efectuó en el mes de mayo de 2016. Para la prueba de los cuestionarios contactamos por correo electrónico con dos profesionales de traducción audiovisual de Rumanía. Les informamos sobre nuestro objetivo de estudio y la finalidad de los cuestionarios, recalcando la importancia de su colaboración. Se trataba de expertos con una larga trayectoria profesional, aunque de generaciones diferentes, lo que contribuyó a la validación del cuestionario desde diferentes perspectivas, es decir, que se llevó a cabo una validación que se podría considerar diacrónica. La elección de los participantes en la prueba piloto se justifica por varios criterios que citamos a continuación: diferentes edades y distinta formación (uno de ellos es traductor y también se dedica a la formación universitaria de esta disciplina en Rumanía). Pero especialmente, el ctiterio que prevaleció fue su amplia e ininterrumpida experiencia en este ámbito.

Para realizar la prueba piloto, también contactamos con dos empleadores para validar los cuestionarios dirigidos a las empresas, y utilizamos los mismos criterios de selección anteriormente enunciados: larga e ininterrumpida experiencia, actividad global dedicada a la traducción audiovisual, y la distribución de un número elevado de productos audiovisuales extranjeros traducidos en los últimos cinco años.

A continuación, en la prueba de robustez de diseño (Calvo, 2010: 358), se evaluaron los siguientes aspectos: el vocabulario y la fraseología empleados en la construcción del cuestionario, la adscripción de las preguntas formuladas con el objetivo del estudio, el tiempo que habían empleado para completarlo, la estructura del cuestionario, así como cualquier sugerencia que consideraban pertinente para mejorar el mismo.

Los profesionales y las empresas valoraron positivamente el cuestionario. Nos sugerieron algunas correcciones de signos diacríticos (que existen en la lengua rumana y habíamos ignorado, por el cambio del programa del ordenador), así como la reformulación de la pregunta número 1 incluida en el bloque 4 (A). Tras efectuar las modificaciones mencionadas, los resultados fueron los siguientes:

a) El vocabulario y la fraseología empleados en la construcción del cuestionario no suponía ningún problema a los encuestados, para comprender y contestar a las preguntas formuladas.

b) La estructura del cuestionario estaba bien dividida en los cuatro bloques y facilitaba la respuesta del encuestado. 
c) Las preguntas eran apropiadas para conseguir nuestros objetivos.

d) El tiempo empleado para completar el cuestionario era el que habíamos considerado, es decir, unos 15-20 minutos.

Tras finalizar satisfactoriamente la prueba piloto pasamos a la siguiente fase, el envío del cuestionario a los encuestados.

\section{Procedimiento de recogida de datos y tasa de respuesta}

Conocíamos previamente las dificultades que tendríamos que afrontar para lograr la colaboración de los traductores, dado que en el año 2013 realizamos un estudio previo de un tema similar y el interés y la participación por parte de los profesionales fueron casi nulas. Se aportaron por su parte varios argumentos: contratos de confidencialidad que habían firmado con los empleadores, falta de tiempo, o escaso interés. A pesar de nuestra insistencia, de algunos traductores no recibimos ningún tipo de respuesta.

La falta de censo de los profesionales que se dedican a la traducción audiovisual en este país fue otro inconveniente que tuvimos que tener presente, dado que nos imposibilitaba conocer con certeza el número real de traductores (la población).

Por ello, descartamos desde un principio utilizar un cuestionario en línea, y utilizamos varias estrategias para poder reunir un número elevado de participantes para las encuestas. La primera de ellas fue contactar con un traductor que ya conocíamos previamente, y que había colaborado con nosotros en el anterior estudio ${ }^{40}$. Adicionalmente, también enviamos un correo electrónico a una de las traductoras que tiene una amplia experiencia en este ámbito en Rumanía. Ella nos contestó afirmativamente, aceptando la colaboración en nuestro estudio.

En segundo lugar, recopilamos información de las empresas distribuidoras de productos audiovisuales en Rumanía y les expusimos vía correo electrónico nuestro objetivo de investigación, al mismo tiempo que solicitábamos su participación. En este caso, algunas de las empresas nos contestaron positivamente. Otras, sin embargo, y pese a nuestra insistencia, simplemente ignoraron nuestra solicitud. No obstante, gracias a una empresa empleadora, una de las primeras que accedió a nuestra propuesta, hemos podido emplear el método que Taylor y Bogdan (1984: 109) denominan bola de nieve, puesto

\footnotetext{
40 Véase el Trabajo de Fin de Máster, La Traducción Audiovisual en Rumania: Análisis de la subtitulación Pirates of the Caribbean: On Stranger Tides Inglés-Rumano (Vulpoiu, 2013).
} 
que la empresa nos facilitó direcciones de correo electrónico de otras empresas distribuidoras, que a su vez nos pusieron en contacto con los traductores que tenían contratados o con los que suelen contactar, para realizar las traducciones de productos audiovisuales extranjeros.

Los primeros cuestionarios completados fueron recibidos durante el mes de junio de 2016. Sin embargo, con la pretensión de ampliar nuestro número de participantes, decidimos extender el plazo de recepción de cuestionarios cumplimentados. Así, remitimos dos tandas de correos electrónicos de recordatorio, durante los meses de diciembre de 2016 y de febrero de 2017, a los traductores y empresas que habíamos contactado anteriormente, pero que no nos habían contestado. Los últimos cuestionarios cumplimentados datan del 17.02.2017, momento en que decidimos cerrar la encuesta y proceder a realizar el análisis de datos, una fase que detallaremos en el siguiente capítulo.

En total, logramos reunir 9 cuestionarios dirigidos a los traductores y 5 cuestionarios dirigidos a los empleadores, un total de 14. Por consiguiente, conscientes de la limitación muestral de nuestro estudio, y antes incluso de llevar a cabo ningún tipo de análisis, debemos señalar que nuestra pretensión en esta investigación no es en absoluto generalizar, sino más bien describir, a grandes rasgos, el perfil socioprofesional del traductor audiovisual actualmente en Rumanía. Por otra parte, cabe destacar que la aportación de los participantes puede aportar cierto rigor a esta investigación, dado que los datos fueron proporcionados por sujetos determinados, y que nuestro diseño de estudio persigue no tanto una "representatividad" de elementos de una población, sino más bien una cuidadosa y controlada elección de casos con ciertas características, especificadas previamente en el planteamiento del problema (Hernández, Fernández y Baptista, 2006: 190).

\subsubsection{Entrevistas}

En la entrevista, a través de preguntas y respuestas, se logra una comunicación y una construcción conjunta de significados respeto a un tema (Janesick, 1998). Es un método de recopilación de datos no estandarizados ni completamente predeterminados. Por medio de esta herramienta no se efectúa una medición numérica, por lo cual el análisis no es cuantitativo, sino cualitativo. La recolección de datos consiste en obtener las perspectivas y puntos de vista de los participantes, así como las interacciones entre 
individuos, grupos y colectividades, a través del lenguaje escrito, verbal y no verbal (Hernández, Fernández y Baptista, 2010: 9).

Por consiguiente, nos reafirmamos en las limitaciones muestrales inherentes a nuestro estudio, tal como han mencionado anteriormente autores como Hernández, Fernández y Baptista (2010: 369), que afirman:

Mertens (2005), además de Coleman y Unrau (2005) consideran que la investigación cualitativa es particularmente útil cuando el fenómeno de interés es muy difícil de medir o no se ha medido anteriormente (deficiencias en el conocimiento del problema).

Por tanto, consideramos que esta herramienta de investigación cualitativa se puede aplicar a sujetos, tanto traductores como empresas, que pueden aportar información amplia y detallada sobre nuestro objeto de estudio, tal como afirman Taylor y Bogdan (1992: 104):

La elección del método de investigación debe estar determinada por los intereses de la investigación, las circunstancias del escenario o de las personas a estudiar, y por las limitaciones prácticas que enfrenta el investigador.

Las entrevistas se dividen a su vez en estructuradas, semiestructuradas o no estructuradas (abiertas), tal como las clasifican y definen Grinnell y Unrau (2007), y Hernández, Fernández y Baptista (2010: 418):

- Estructuradas: el investigador realiza su labor con base en una guía de preguntas específicas y se sujeta exclusivamente a esta, respetando las preguntas elaboradas y su orden.

- Semiestructuradas: el investigador parte de una guía de preguntas predeterminadas, pero tiene la libertad de introducir preguntas adicionales para precisar conceptos u obtener mayor información sobre los temas deseados.

- Abiertas (no estructuradas): el investigador posee toda la flexibilidad para manejar la guía general del contenido.

En cualquier caso, la información que podamos recabar por medio de las entrevistas contribuirá a ampliar la información (aunque sea de otro tipo, es decir, 
cualitativa), que previamente hayamos recopilado mediante los cuestionarios (cuantitativa).

\section{A. Guía de las entrevistas}

En nuestro estudio hemos empleado las entrevistas de tipo semiestructuradas, porque hemos considerado que es el método más adecuado para facilitar la recopilación de los datos que pretendemos obtener.

Por ello, diseñamos una guía de preguntas predeterminadas estructurada en diferentes bloques y con ítems similares a las preguntas formuladas en los cuestionarios, con el fin de encauzar nuestra recopilación de datos cualitativos hacia los temas que se podrían considerar "tabú" en este país.

No obstante, contemplamos la posibilidad de añadir, en caso necesario, algunas preguntas más, pero sin forzar al entrevistado a contestar, si advertíamos por su parte en algún momento una actitud incómoda. Puesto que las entrevistas se desarrollaron de forma idónea y la conversación con los entrevistados fluyó de modo natural, no siempre se respetó el orden de las preguntas que habíamos planteado en nuestro guion. En consecuencia, la guía nos sirvió básicamente como herramienta para considerar los objetivos de nuestro estudio.

Así pues, la estructura de las dos guías, dirigidas a los traductores y a los empleadores, se diseñó de siguiente forma, tal como se detalla a continuación.

- Diseño de la guía dirigida a los traductores

\begin{tabular}{|l|l|}
\hline \multicolumn{1}{|c|}{ Bloque } & \multicolumn{1}{c|}{ Ítems } \\
\hline \multirow{2}{*}{ Perfil del traductor } & Tipo de formación. \\
& $\begin{array}{l}\text { Combinación lingüística. } \\
\text { Modalidad de traducción audiovisual } \\
\text { empleada. }\end{array}$ \\
\hline \multirow{2}{*}{ Valoración de la profesión } & $\begin{array}{l}\text { Requisitos exigidos por empleadores. } \\
\text { Tipo de contrato. } \\
\text { Tipo de empresas empleadoras. } \\
\text { Restricciones. }\end{array}$ \\
\hline
\end{tabular}




\begin{tabular}{|l|l|}
\hline & Tarifas y tiempo empleado. \\
& $\begin{array}{l}\text { Importancia de la traducción en el } \\
\text { producto final. } \\
\text { Derechos de autor y reconocimiento } \\
\text { público. }\end{array}$ \\
\hline Competencias & $\begin{array}{l}\text { Competencias generales y específicas } \\
\text { necesarias para llevar a cabo su labor } \\
\text { como traductores de textos audiovisuales. }\end{array}$ \\
\hline
\end{tabular}

Tabla 23. Guía de entrevista dirigida a los traductores

- Diseño de la guía dirigida a las empresas empleadoras

\begin{tabular}{|l|l|}
\hline \multicolumn{1}{|c|}{ Bloque } & \multicolumn{1}{c|}{ Ítems } \\
\hline Perfil de la empresa & Datos básicos identificativos. \\
\hline & $\begin{array}{l}\text { Criterios de selección. } \\
\text { Tarifas. } \\
\text { Perfil del traductor } \\
\text { contactado/contractado }\end{array}$ \\
& $\begin{array}{l}\text { Tipos de restricciones y pautas. } \\
\text { Valoración de la traducción en el producto } \\
\text { final. }\end{array}$ \\
\hline Competencias & $\begin{array}{l}\text { Competencias generales y específicas que } \\
\text { consideran necesarias en los traductores } \\
\text { de textos audiovisuales. }\end{array}$ \\
\hline
\end{tabular}

Tabla 24. Guía de entrevista dirigida a las empresas

\section{B. Participantes y desarrollo de las entrevistas}

En la selección de los entrevistados aplicamos los mismos criterios que empleamos para los participantes de la encuesta. Además, dado que nos mantuvimos en contacto con algunos traductores y empresas empleadoras que habían participado en la encuesta, este hecho nos ayudó a ampliar nuestras redes de profesionales y nos facilitó el acceso a la recopilación de datos cuantitativos. En la realización de las entrevistas siempre 
hemos tenido presentes las recomendaciones de Hernández, Fernández y Baptista (2010: 420-423).

En total, hemos realiazado 4 entrevistas individuales, 3 para el grupo de traductores audiovisuales y 1 para el grupo de empresas empleadoras, entre los meses de junio 2016 y abril 2017. Dichas entrevistas fueron grabadas previo consentimiento de los participantes. Puesto que los entrevistados residen en Rumanía, por limitaciones económicas y también de tiempo, realizamos 1 entrevista en persona, 2 mediante el programa Skype, y una por correo electrónico, dado que el informante de esta última, por problemas de disponibilidad, preferió realizar la entrevista por escrito, por lo que se le enviaron las preguntas por este medio. Además, para realizar las entrevistas a los profesionales, y conscientes de la limitación de nuestra muestra, consideramos apropiado seleccionar tres perfiles con formación específica distinta, que nos podrían aportar datos desde varias perspectivas de esta profesion en Rumanía.

Las entrevistas se realizaron de forma amena, dado que los participantes se mostraron interesados en el objetivo de nuestro estudio, y nos aportaron detalles sobre datos que no habíamos podido obtener en la fase cuantitativa del estudio.

Por lo que se refiere a las limitaciones muestrales en los estudios cualitativos, el tamaño de muestra no es importante desde una perspectiva probabilística (Hernández, Fernández y Baptista, 2010: 402-422), sino que lo que importa es la capacitación de cada caso, tal como afirman los autores Taylor y Bogdan (1987: 108):

[...] El número de "casos" estudiados carece relativamente de importancia. Lo importante es el potencial de cada "caso" para ayudar al investigador en el desarrollo de comprensiones teóricas sobre el área estudiada de la vida social.

Puesto que nuestra pretensión no es generalizar, sino describir y arrojar luz sobre el estado de la traducción audiovisual en Rumanía y sobre el perfil actual del traductor audiovisual en este país, y si además sumamos a ello las dificultades encontradas para involucrar a los miembros de este grupo en nuestro estudio, consideramos que los datos recopilados en esta fase nos pueden aportar la información pertinente y necesaria para lograr nuestros objetivos, y así responder a las preguntas que habíamos formulado al inicio del presente capitulo. 
C. Transcripción y análisis de datos de las entrevistas

Siguiendo los criterios que destacan Hernández, Fernández y Baptista (2010: 446447) efectuamos la transcripción de todas las entrevistas realizadas, para proceder posteriormente a realizar el análisis de los datos cualitativos.

Por consiguiente, utilizamos los bloques y los ítems empleados en nuestro guion para organizar las categorías de clasificación de datos, y diseñamos además un cuadro de síntesis para clasificar y ordenar toda la información recopilada de una forma estructurada que nos facilitara su análisis.

La fase final de esta etapa consistirá en analizar, interpretar y colegir las conclusiones de todos los datos que hemos reunido mediante el método cualitativo, y que vamos a presentar, así como en el caso de los datos cualitativos, en el siguiente capítulo de este estudio.

Los guiones de las entrevistas pueden consultarse en los correspondientes Anexos (Anexo III).

Dado que los destinatarios de esta investigación son traductores y empresas que ejercen su actividad en Rumanía, la lengua vehicular de la realización de las entrevistas ha sido la lengua rumana. No obstante, se puede encontrar una transcripción de las entrevistas traducida al español en el correspondiente Anexo (Anexo IV). 


\section{Capítulo 5: Análisis de datos e interpretación de resultados}

En el presente capítulo analizaremos los datos recabados mediante el cuestionario, que constituye nuestra principal herramienta de recogida de datos, principalmente cuantitativos. Expondremos los resultados obtenidos desde un punto de vista cuantitativo y descriptivo a partir del análisis de cada uno de los dos tipos de cuestionarios empleados en este estudio (uno dirigido a los traductores y otro a las empresas empleadoras). Para ello se seguirá una estructura por bloques, reproduciendo la misma organización seguida en los cuestionarios. Los resultados cuantitativos se formularán en forma de tabla o de gráfico, extraídos de nuestra hoja de Excel de vaciado de resultados, y en algunos casos irán acompañados de comentarios de tipo cualitativo que algunos de los encuestados han aportado a determinadas preguntas en la sección de comentarios.

A este análisis fundamentalmente cuantitativo añadiremos los datos cualitativos que hemos recabado durante las entrevistas realizadas en la fase posterior a la encuesta, las cuales nos permitirán matizar y añadir información a los datos derivados de las respuestas de preguntas cerradas de los cuestionarios.

\subsection{Análisis de datos e interpretación de resultados: traductores de textos audiovisuales}

Tal como hemos presentado en el capítulo anterior, el cuestionario dirigido a los profesionales se compone de cuatro bloques, que analizaremos según el orden de las preguntas formuladas. En este sentido, e impulsados por la pretensión de descubrir e interpretar diferentes aspectos que configuran el perfil del traductor en este país, en el primer bloque del cuestionario (el que define el perfil del traductor) hemos formulado también varias preguntas dirigidas a obtener información de los diferentes aspectos de esta profesión. Por tanto, dada su amplitud, para realizar un análisis coherente de los datos recabados, desglosaremos el primer bloque en cinco subapartados con los ítems pertinentes para definir esta actividad en Rumanía.

Analizaremos la información de los nueve cuestionarios completados por los traductores de textos audiovisuales que han participado en nuestra encuesta. No obstante, observamos que uno de los cuestionarios tenía varias preguntas (bloque 2, 3, 4) sin respuesta, y pese a que conocíamos la identidad del encuestado, no quisimos cuestionar su decisión de no rellenarlo totalmente, por no variar la exactitud de los datos recopilados. 
Empleamos, pues, de este cuestionario, las respuestas al primer bloque de preguntas, que nos aportan más datos sobre el perfil del traductor en este país.

La información recabada de los cuestionarios se encuentra en la lengua rumana. Debido a la imposibilidad de cambiar la lengua de los gráficos, cuando se insertan gráficos durante este capítulo, se asocia a cada uno de ellos una nota a pie con la traducción en lengua española de las leyendas del gráfico.

\subsubsection{Perfil del traductor}

\subsubsection{Datos sociodemográficos}

Nos pareció importante, y al mismo tiempo relevante, formular la primera pregunta sobre la edad de nuestros encuestados (véase bloque 1, pregunta 1), puesto que el cambio sociopolítico que ha experimentado este país durante los últimos 25 años podría haber influido en la transformación del perfil de este profesional, tal como se ha explicado en las secciones 3.1 y 3.2 de este estudio.

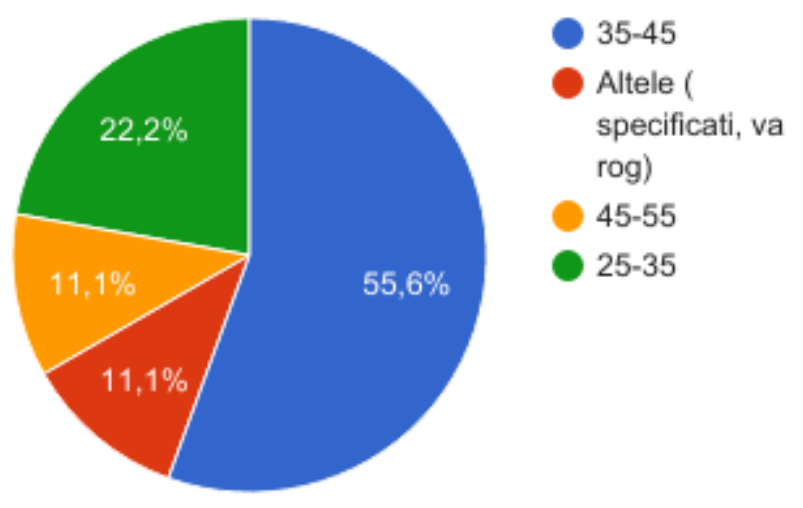

Figura 4. Edad (profesionales) $)^{41}$

Podemos observar que predomina la edad de entre 35-45 años, con más de un 55\% de los resultados. Estos profesionales podrían constituir la primera generación postcomunista de traductores en al ámbito audiovisual que se ha formado en Rumanía.

\footnotetext{
${ }^{41}$ Figura 4. Edad (profesionales) $\rightarrow{ }^{*} 35-45$ ani $=35-45$ años; $*$ Altele (specificati va rog) $=$ Otras (especifique, por favor); ${ }^{*} 45-55$ ani $=45-55$ años; $* 25-35$ ani $=25-35$ años.
} 
En cuanto a la ubicación de nuestros entrevistados (véase bloque 1, pregunta 2), hemos podido observar que residen en Bucarest (capital) o en Transilvania, la zona oeste de Rumanía, donde está situada la empresa de doblaje Zone Studio Oradea, que proporciona trabajo tanto a traductores como actores, como expusimos en la sección 3.2 del presente trabajo.

8

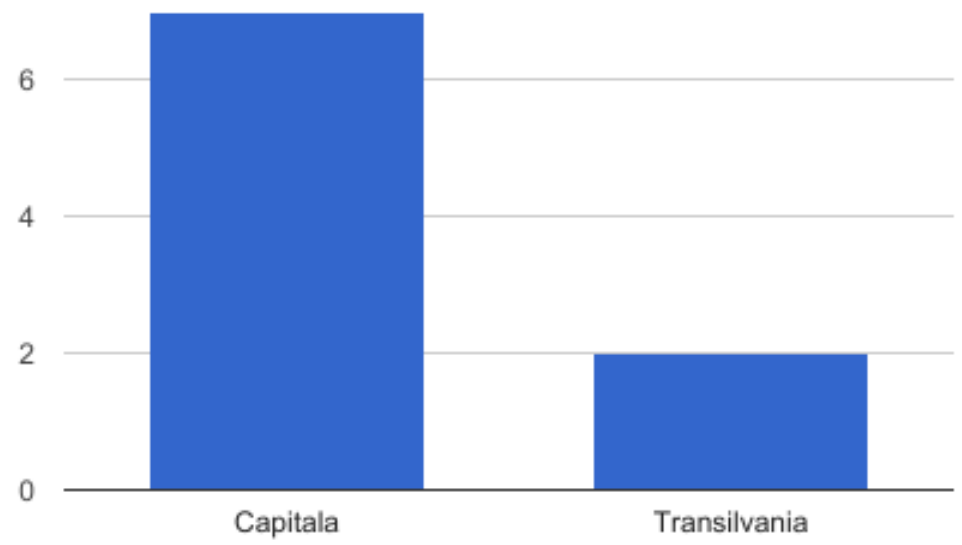

Figura 5. Ubicación (profesionales) ${ }^{42}$

Se puede observar que del total de los nueve encuestados, siete residen en Bucarest y dos residen en Transilvania, por lo que podemos interpretar que los núcleos dedicados a esta profesión se centran en estas dos partes de Rumanía.

Otro dato importante para nuestro estudio, y que además era un requisito importante para cumplimentar el cuestionario, lo constituía el nivel de experiencia profesional de los encuestados (véase bloque 1, pregunta 3).

\footnotetext{
${ }^{42}$ Figura 5. Ubicación (profesionales) $\rightarrow$ Transilvania (zona oeste de Rumanía); Capitala (Capital-Bucarest).
} 


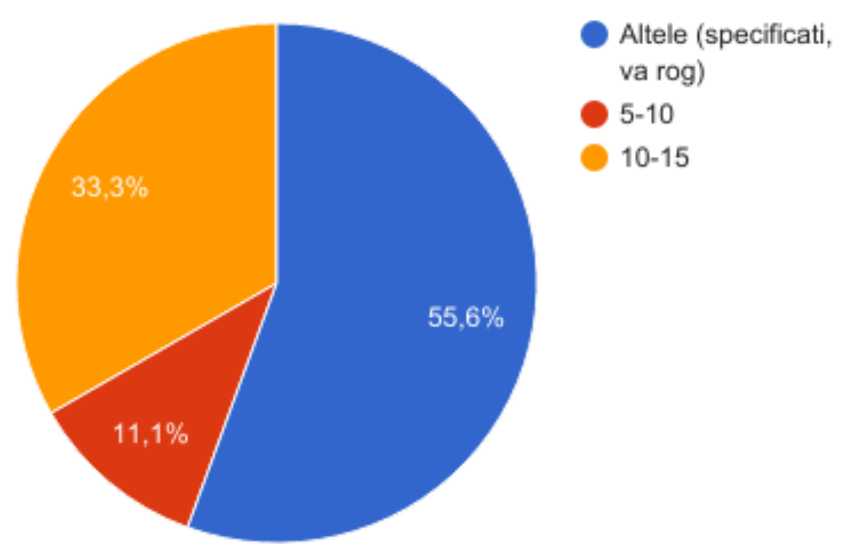

Figura 6. Experiencia (profesionales) $)^{43}$

Tal como podemos observar en la figura anterior, destaca con un 55,6\% el grado de experiencia que hemos marcado en nuestro cuestionario como "Otros", y que según hemos podido comprobar mediante los datos recabados, marca una amplia experiencia en este ámbito de entre 21 y 36 años, según han señalado algunos profesionales. Asimismo, el 33,3\% de los participantes en nuestra encuesta tiene entre 10 y 15 años de experiencia profesional en este ámbito, mientras que el 11,1\% de los encuestados lleva entre 5 y 10 años ejerciendo esta profesion en Rumanía.

\subsubsection{Perfil formativo}

El perfil formativo del traductor audiovisual en Rumanía es otra cuestión de gran interés para nuestro estudio. Por tanto, formulamos algunas preguntas sobre este tema para determinar la formación académica de los traductores de textos audiovisuales en este país. Una de las preguntas más importantes, que de hecho fue la primera que planteamos en este subapartado, indagaba sobre el tipo de formación que tiene en la actualidad el traductor audiovisual que ejerce esta profesión en este país (véase bloque 1, pregunta 4).

\begin{tabular}{|l|c|c|c|}
\hline \multicolumn{4}{|c|}{ 4. ¿Qué tipo de formación tiene? (Puede marcar más de una opción) } \\
\hline Opciones de respuesta & $\begin{array}{c}\text { Total } \\
\text { respuestas }\end{array}$ & $\begin{array}{c}\text { Recuento } \\
\text { respuestas }\end{array}$ & Porcentaje \\
\hline
\end{tabular}

\footnotetext{
${ }^{43}$ Figura 6. Experiencia (profesionales) $\rightarrow{ }^{*}$ Altele (specificati va rog) $=$ Otros (especifique, por favor); ${ }^{*}$ 5-10 ani $=5-10$ años; * $10-15$ ani $=10-15$ años.
} 


\begin{tabular}{|c|c|c|c|}
\hline Estudios de Filología & 9 & 8 & $88,8 \%$ \\
\hline $\begin{array}{c}\text { Formación interna en } \\
\text { empresas }\end{array}$ & 9 & 5 & $55,5 \%$ \\
\hline $\begin{array}{c}\text { Autodidacta (lecturas, } \\
\text { práctica profesional, } \\
\text { aprendizaje de los } \\
\text { compañeros) }\end{array}$ & 9 & 4 & $44,4 \%$ \\
\hline $\begin{array}{c}\text { Estudios de } \\
\text { Traducción }\end{array}$ & 9 & 3 & $33,3 \%$ \\
\hline
\end{tabular}

Tabla 25. Formación académica

Según nuestros datos cuantitativos, podemos observar que ese trata un grupo homogéneo, dado que los estudios de Filología destacan en la formación académica (89\%), así como la formación en las empresas (que está en el segundo lugar, con un 55\%), y los estudios autodidactas, en el tercer lugar. De los nueve encuestados, solamente tres han realizado estudios específicos de traducción. Estimamos que es un dato importante, que habíamos mencionado en la sección 3.5 al destacar la escasez de cursos de traducción audiovisual que se imparten actualmente en Rumanía, y que comprobaremos con otros datos a lo largo del presente capítulo.

Por ello, consideramos pertinente desarrollar este dato por medio de algunas de las entrevistas realizadas posteriormente a las encuestas, donde se investigó sobre el resultado de este ítem:

Pregunta: En su gran mayoría, los traductores tienen estudios de filología, ¿consideras que es suficiente para trabajar en traducción audiovisual?

Traductor 2: No.

Pregunta: ¿Cómo se puede compensar esta carencia?

Traductor 2: En este tipo de traducción existe la parte práctica, que aprendes en el lugar de trabajo ... hay cosas que no aprendes en la universidad, son cosas más técnicas como por ejemplo el pautado, redactar los subtítulos, cuándo entran y cuándo salen... son muchas técnicas que implican práctica. 
La siguiente pregunta también trata el tema de la formación, pero se centra en una cuestión más concreta: los cursos específicos de traducción audiovisual realizados por nuestros encuestados (véase bloque 1, pregunta 5).

\begin{tabular}{|c|c|c|c|}
\hline \multicolumn{4}{|c|}{$\begin{array}{c}\text { 5. ¿Ha realizado cursos específicos de traducción audiovisual en Rumanía o en otros } \\
\text { países? }\end{array}$} \\
\hline $\begin{array}{c}\text { Opciones de } \\
\text { respuesta }\end{array}$ & Total respuestas & $\begin{array}{c}\text { Recuento } \\
\text { respuestas }\end{array}$ & Porcentaje \\
\hline Rumanía & 9 & 4 & $44,5 \%$ \\
\hline No & 9 & 3 & $33,3 \%$ \\
\hline Ambos & 9 & 2 & $22,2 \%$ \\
\hline Otros países & 9 & 0 & 0 \\
\hline
\end{tabular}

Tabla 26. Cursos específicos de traducción audiovisual

Como se puede apreciar, a pesar de que los encuestados tienen como base formativa los estudios de Filología, mayoritariamente los traductores continúan y completan su formación con cursos específicos de este tipo de traducción en Rumanía, tal como nos indican los resultados (44,5\%), o han completado su formación en Rumanía y otros países, tal como nos indican los resultados (22,2\%). Sin embargo, el 33,3\% de los participantes en la encuesta no ha realizado este tipo de estudios, ni en Rumanía ni en otros países.

También nos interesaba concretar el tipo de cursos que habían realizado, si se trataba de cursos universitarios o no universitarios, y por ello incluimos la siguiente pregunta dirigida a los encuestados (véase bloque 1, pregunta 6). 




Figura 7. Cursos universitarios/no universitarios ${ }^{44}$

Se puede observar que destacan los cursos no universitarios, y que posiblemente en algunos casos son las propias empresas las que facilitan la formación continua del traductor audiovisual, tal como especificó uno de los encuestados en la sección de comentarios de esta pregunta; pero se trata de cursos que los traductores consideran necesarios para actualizar su formación profesional. Tal y como hemos expuesto anteriormente, la información cualitativa recabada en los comentarios de algunas de las preguntas de la encuesta se empleará para completar o matizar nuestros datos cuantitativos:

\section{Comentarios}

Otros (cursos clásicos/online organizados por las agencias de traducción con las que colaboro).

El siguiente comentario, realizado también por uno de los encuestados en la sección de comentarios de la pregunta, nos pareció extraño en un primer momento:

\section{Comentarios}

No es el caso.

\footnotetext{
${ }^{44}$ Figura 7. Cursos universitarios/no universitarios $\rightarrow{ }^{*}$ Altele (specificati va rog) $=$ Otras (especifique por favor); ${ }^{*} \mathrm{Nu}$ universitare $=$ No universitarios; ${ }^{*}$ Universitare $=$ Universitarios.
} 
Sin embargo, tras comprobar el nivel de experiencia (36 años) que tenía ejerciendo esta profesión, consideramos que esta afirmación tenía su fundamento y era compartida por más profesionales participantes en la encuesta, ya que la experiencia puede cubrir las carencias de estudios específicos dirigidos a la traducción audiovisual y avala su habilidad y destreza en este ámbito, tal como veremos a continuación.

La modalidad de traducción audiovisual en la que habían recibido la formación fue otro aspecto que incluimos en el perfil del traductor de textos audiovisuales (véase bloque 1, pregunta 7), dado que según hemos podido destacar en la sección 2.2 del presente estudio, la subtitulación es la modalidad que destaca en Rumanía en la traducción de los productos audiovisuales extranjeros. Sin embargo, el resultado del análisis de nuestros datos refleja que en la actualidad los profesionales perfeccionan su formación también en doblaje o voice-over, tal como se muestra en la siguiente figura.

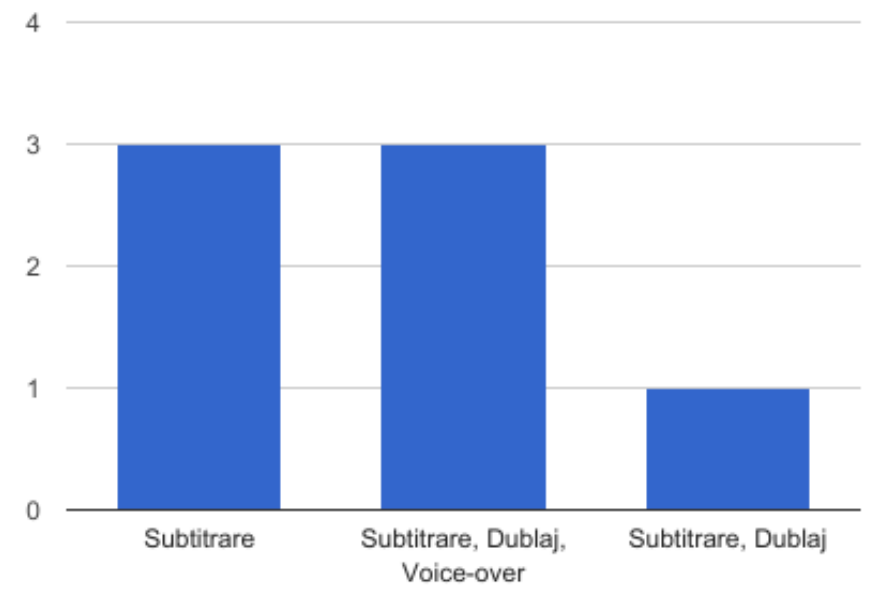

Figura 8. Formación en modalidades de traducción audiovisual ${ }^{45}$

Como se puede apreciar, sigue destacando la formación únicamente en subtitulación $(42,9 \%)$; no obstante, podemos observar que con un porcentaje igual $(42,9 \%)$, se añaden a esta otras modalidades de traducción audiovisual (formación en subtitulación, doblaje y voice-over). Y, por último, en un 14,3\% de los casos, la respuesta incluye subtitulación y doblaje, por lo que podemos concluir que la subtitulación impera en la actualidad en la formación traducción audiovisual, seguida por el doblaje. Esta formación en doblaje puede haber aparecido y crecido por la implantación de nuevos programas televisivos y cadenas privadas dedicados exclusivamente al público infantil, o

\footnotetext{
${ }^{45}$ Figura 8. Formación en modalidades de traducción audiovisual $\rightarrow$ Subtitrare $=$ Subtitulación; Subtitrare, Dublaj, Voice-Over $=$ Subtitulación, Doblaje, Voice-over; Subtitrare, Dublaj = Subtitulación, Doblaje.
} 
por el estreno en los cines de un número elevado de películas infantiles, que requieren el doblaje como modalidad de traducción audiovisual.

\subsubsection{Régimen laboral}

La condición laboral es otro tema de suma importancia en nuestro estudio para poder dibujar el perfil socioprofesional de los traductores. Tal como expusimos en el epígrafe 2.3, los medios que utilizan la traducción audiovisual en Rumanía experimentaron un cambio considerable después de la caída del régimen comunista. Toda esta situación influyó indudablemente en el crecimiento del volumen de trabajo y en la demanda de nuevos profesionales en este ámbito. Por tanto, intentaremos definir la situación de esta profesión en el mercado rumano actual.

Consideramos que era importante conocer el tipo de contrato laboral que tenían nuestros encuestados (véase bloque 1, pregunta 8), dado que tal y como expusimos en la sección 3.5, la profesión del traductor audiovisual se caracteriza por su inestabilidad en el mercado.

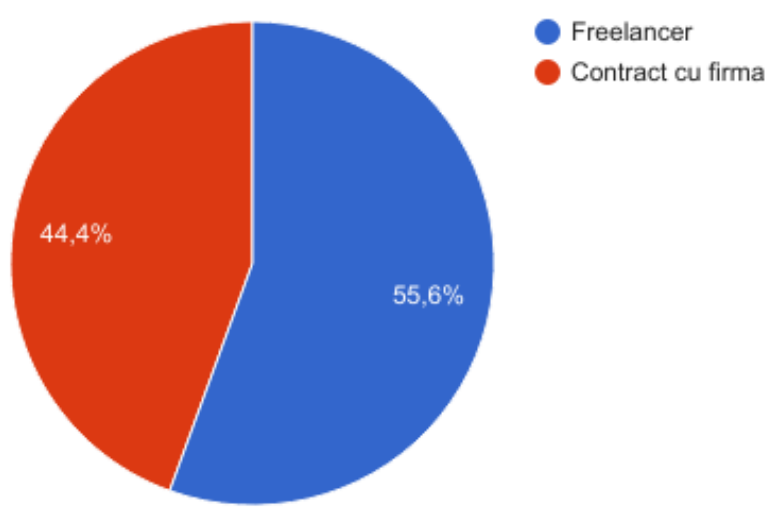

Figura 9. Tipo de contrato ${ }^{46}$

Pese al número reducido de sujetos de nuestra muestra (que no nos permite generalizar), los resultados revelan que, a pesar del incremento de empresas empleadoras en el mercado rumano, así como del aumento del producto audiovisual extranjero que se emite actualmente en Rumanía, el régimen laboral de este profesional sigue destacando por su inestabilidad, puesto que más de la mitad $(55,6 \%)$ de los encuestados ejercen esta profesión como freelancers. Recibir un contrato por parte de las empresas o por parte de

${ }^{46}$ Figura 9. Tipo de contrato $\rightarrow{ }^{*}$ Freelancer $=$ Freelancer; ${ }^{*}$ Contract cu firma $=$ Contratado por la empresa. 
las cadenas de televisión parece, a día de hoy, un objetivo inalcazable. El resultado, en consecuencia, es la transitoriedad colectiva, tal como nos comentó uno de nuestros entrevistados:

Traducator 2: Creo que se contratan muy difícilmente los traductores, la mayoría de las empresas prefieren trabajar en sistema de colaboración, lo que supone para los traductores una situación inestable. No tienen contrato de trabajo, no tienen antigüedad profesional, no tienen nada para demostrar que, por ejemplo, llevan trabajando diez años. El periodo de trabajo llega en olas, durante un mes puedes trabajar muchísimo y el mes siguiente estar sin hacer nada, es muy agotador. [...] Es una profesión muy bonita y tenemos que promoverla, pero la parte financiera... no compensa, no oyes nunca que te contratan, ni siquiera la televisión nacional, que es una televisión pública; los traductores no están contratados, los editores sí, pero los traductores son colaboradores.

En el caso de los profesionales que trabajan en plantilla, el 44,6\%, representado en la Figura 9, la siguiente pregunta contribuyó a la especificación en detalle de los datos anteriores. Por tanto, preguntamos qué tipo de empresa solicitaba más la colaboración de este gremio (véase bloque 1, pregunta 9).

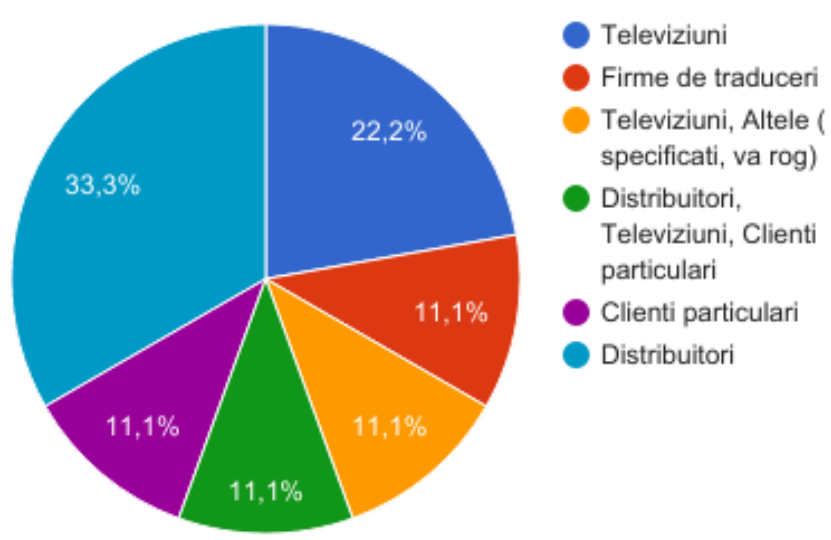

Figura 10. Tipo de empresa ${ }^{47}$

\footnotetext{
${ }^{47}$ Figura 11. Tipo de empresa $\rightarrow$ *Televiziuni = Cadenas de televisión; $*$ Firme de traduceri = Empresas de traducción; $*$ Televiziuni, Altele (specificati va rog) = Cadenas de televisión, Especifique (por favor); *Distribuitori, Telviziuni, Clienți particulari = Distribuidoras, Cadenas de televisión, Clientes particulares; $*$ Clienți particulari $=$ Clientes particulares; $*$ Distribuitori $=$ Distribuidoras.
} 
Tal como reflejan los datos anteriores, la variedad de las empresas empleadoras en este ámbito aporta a los traductores audiovisuales más amplitud de ofertas de empleo, pero no mejoras laborales. El cambio sociopolítico que sufrió Rumanía después de la revolución del año 1989 contribuyó a la transformación del mercado dedicado a este perfil, pero no a las condiciones contractuales, tal como hemos observado anteriormente. Principalmente, las empresas que aportan más encargos en esta área son las distribuidoras $(33,3 \%)$ y las televisiones $(22,2 \%)$. Sin embargo, se incorporan también con el mismo porcentaje $(11,1 \%)$ los clientes particulares o los festivales, así como las distribuidoras, clientes particulares y cadenas de televisión, o cadenas de televisión y otros tipos de clientes que no se especifican, y que contribuyen al crecimiento de la oferta laboral en este país.

La siguiente pregunta que formulamos en nuestro cuestionario se refería al tipo de actividad (o actividades) que realizaba la empresa empleadora (véase bloque 1, pregunta 10). Según se puede apreciar en el siguiente gráfico, Figura 11, el 66,7\% de las empresas que solicitan la labor del traductor audiovisual se dedican únicamente a la traducción audiovisual y el $22,2 \%$, un porcentaje mucho más reducido, se dedica a más tipos de traducción. Un $11,1 \%$ de los encuestados maracaron la opción "otros", pero no especificaron ningún dato al respecto.

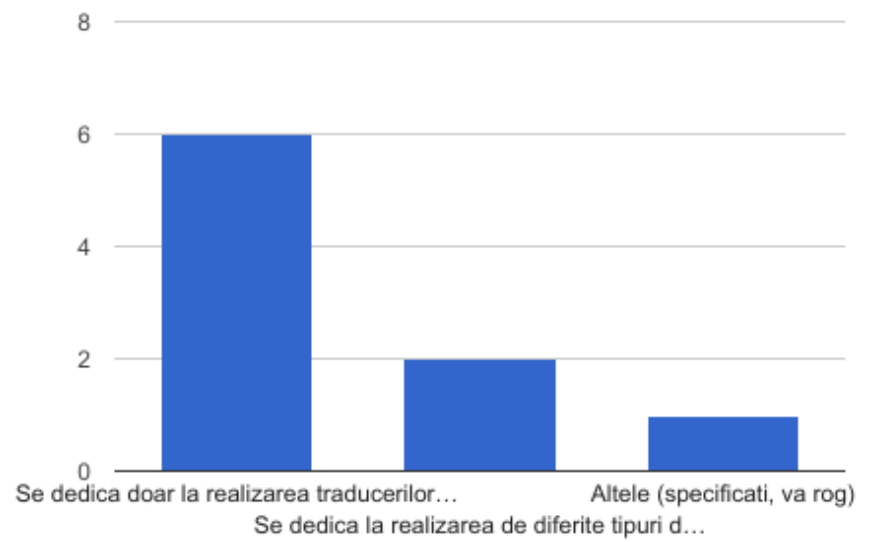

Figura 11. El porcentaje que la empresa dedica a la traducción audiovisual ${ }^{48}$

Otro aspecto importante en el que destaca generalmente la profesión del traductor de textos audiovisuales es compaginar esta profesión con otras, principalmente por su

\footnotetext{
${ }^{48}$ Figura 11. El porcentaje que la empresa dedica a la traducción audiovisual $\rightarrow$ Se dedică doar la realizarea traducerilor audiovizuale = Empresa dedicada únicamente a la traducción audiovisual; Se dedică la realizarea de diferite tipuri de traduceri = Empresa dedicada a diversos tipos de traducción; Altele (specificați, vă rog) = Otros (especifique, por favor).
} 
inestabilidad laboral, tal como hemos podido observar. Por consiguiente, consideramos relevante indagar en el grado de dedicación profesional de nuestros encuestados, preguntando si se dedicaban únicamente a la traducción audiovisual o realizaban también otras actividades profesionales relacionadas o no con la traducción (véase bloque 1 , pregunta 11).

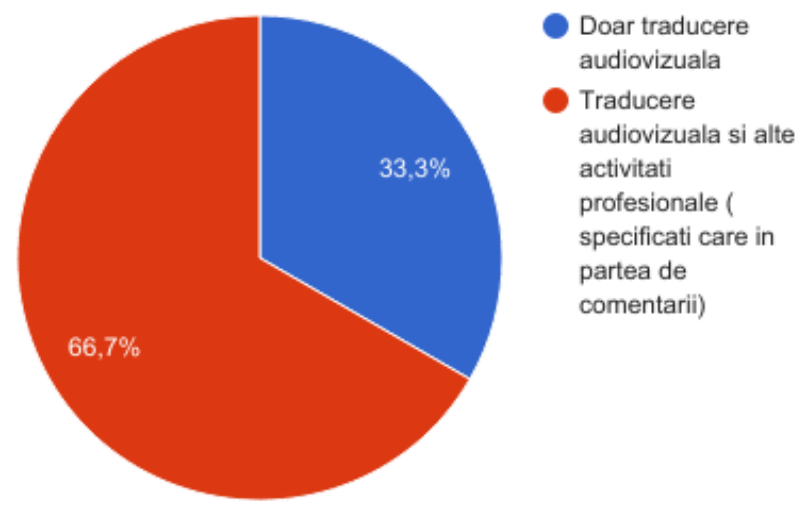

Figura 12. Porcentaje dedicado a la traducción audiovisual y otras actividades 49

Tal como se puede observar en la Figura 12, el 66,7\% se dedica a la traducción audiovisual además de a otras actividades, resultado nada sorprendente dada la situación general de esta profesión, mientras que el 33,3\% de los encuestados dedica su actividad solamente a este tipo de traducción. En el apartado de comentarios de esta parte del cuestionario, algunos traductores participantes en la encuesta nos revelaron las diferentes actividades a las que se dedicaban, además de a la de traductor audiovisual, tal como precisamos a continuación:

\begin{tabular}{|l|}
\hline Comentarios \\
\hline Traducción en diversas especialidades, transcripciones, revisiones. \\
\hline Crítica de cine, televisión y radio, además organizadora de festivales o selecciones de \\
cortometrajes. \\
\hline Archivista, redactor. \\
\hline Profesor de cursos universitarios de subtitulación y doblaje. \\
\hline
\end{tabular}

${ }^{49}$ Figura 12. Porcentaje dedicado a la traducción audiovisual y otras actividades $\rightarrow *$ Doar traducere audiovizuală $=$ Únicamente a la traducción audiovisual; *Traducere audiovizuala și alte activități profesionale (specificați care în partea de comentarii a acestei întrebări) = A la traducción audiovisual y a otras actividades profesionales (especifique a cuáles en el apartado de comentarios de esta pregunta) 
Traducción en diversos ámbitos, proof-reading.

Como podemos observar, a pesar de la variedad de profesiones que desempeñan algunos de nuestros encuestados, sus actividades están relacionadas con la traducción o con los productos audiovisuales.

Tal como habíamos expuesto en el epígrafe 2.2 de nuestro estudio, en Rumanía la subtitulación es la modalidad más empleada en la traducción audiovisual de los productos extranjeros. Por tanto, consideramos que sería relevante conocer la modalidad de traducción audiovisual en la que trabajan con más frecuencia los traductores en este país (véase bloque 1, pregunta 12).

12. ¿Qué modalidad de traducción audiovisual utiliza con más frecuencia? (Puede marcar más de una opción)

\begin{tabular}{|l|c|c|c|}
\hline $\begin{array}{l}\text { Opciones de } \\
\text { respuesta }\end{array}$ & Total respuestas & $\begin{array}{c}\text { Recuento } \\
\text { respuestas }\end{array}$ & Porcentaje \\
\hline Subtitulación & 9 & 7 & $77,8 \%$ \\
\hline Doblaje & 9 & 2 & $22,2 \%$ \\
\hline Voice-over & 9 & 0 & $0,0 \%$ \\
\hline $\begin{array}{l}\text { Traducción de } \\
\text { videojuegos }\end{array}$ & 9 & 0 & $0,0 \%$ \\
\hline
\end{tabular}

Tabla 27. Modalidad de traducción audiovisual empleada con más frecuencia

Como opciones de respuesta aparecen diferentes modalidades de traducción audiovisual. Sin embargo, destaca la subtitulación con un $77,8 \%$ de respuestas, seguida del doblaje, con un 22,2\%. Pese a que algunos traductores tenían formación en otras modalidades, como por ejemplo voice-over, según hemos comprobado anteriormente, ninguno de nuestros encuestados trabaja en esta modalidad o en la traducción de videojuegos.

Conscientes de que la lengua inglesa es considerada actualmente como una lingua franca, y dado que la mayoría de los productos audiovisuales se producen en este idioma en el mercado, formulamos la siguiente pregunta sobre las combinaciones lingüísticas 
más empleadas para comprobar con datos empíricos nuestra suposición inicial (véase bloque 1, pregunta 13).

13. ¿En qué combinación lingüística, suele realizar las traducciones audiovisuales? (Puede marcar más de una opción)

\begin{tabular}{|l|c|c|c|}
\hline $\begin{array}{l}\text { Opciones de } \\
\text { respuesta }\end{array}$ & Total respuestas & $\begin{array}{c}\text { Recuento } \\
\text { respuestas }\end{array}$ & Porcentaje \\
\hline Inglés- Rumano & 9 & 9 & $100 \%$ \\
\hline Francés- Rumano & 9 & 6 & $66,7 \%$ \\
\hline $\begin{array}{l}\text { Otros (especifique, } \\
\text { por favor) }\end{array}$ & 9 & 2 & $22,2 \%$ \\
\hline Español-Rumano & 9 & 1 & $0,0 \%$ \\
\hline Chino-Rumano & 9 & 0 & $0,0 \%$ \\
\hline Alemán-Rumano & 9 & 0 & $11,1 \%$ \\
\hline
\end{tabular}

Tabla 28. Combinación lingüística

Se puede apreciar que el $100 \%$ de nuestros encuestados utiliza la combinación lingüística inglés-rumano, tal como esperábamos. No obstante, podemos observar que la diferencia entre esta combinación y la de francés-rumano no es demasiado significativa, puesto que el $66,6 \%$ de los encuestados utiliza esta combinación en el proceso de traducción. Lo que resulta sorprendente es la casi ausencia de la combinación españolrumano, porque Rumanía es un gran consumidor de productos televisivos en esta lengua, como por ejemplo las teleseries producidas en países de América Latina. Otras combinaciones lingüísticas utilizadas por algunos de nuestros encuestados, que anotaron en el apartado de "Otros", son italiano-rumano y español-rumano, ambas con un 22,2\% de respuestas.

En cuanto al tipo de destinatario al que va dirigido el producto audiovisual final (véase bloque 1, pregunta 14), ninguno de los encuestados se dedica exclusivamente a la traducción para el público infantil, puesto que van combinando ambas familias de géneros (infantil/adultos), con el 44\%, o prima (56\%) el producto que se dirige al público adulto, tal como se muestra en la siguiente tabla. 


\begin{tabular}{|l|c|c|c|}
\hline 14. ¿Para qué tipo de público traduce con más frecuencia? \\
\hline $\begin{array}{l}\text { Opciones de } \\
\text { respuesta }\end{array}$ & Total respuestas & $\begin{array}{c}\text { Recuento } \\
\text { respuestas }\end{array}$ & Porcentaje \\
\hline Adultos & 9 & 5 & $55,6 \%$ \\
\hline Ambos & 9 & 4 & $44,4 \%$ \\
\hline Infantil & 9 & 0 & $0,0 \%$ \\
\hline $\begin{array}{l}\text { Otros (especifique, } \\
\text { por favor) }\end{array}$ & & 0 & \\
\hline
\end{tabular}

Tabla 29. El destinatario de los productos audiovisuales en la lengua meta (profesionales)

Uno de los hipotéticos motivos de este resultado podría ser la dedicación de una mayor inversión en productos audiovisuales extranjeros dirigidos al público adulto por parte de las televisiones y las distribuidoras, las principales empresas empleadoras de nuestros encuestados.

La siguiente pregunta está encaminada a averiguar el medio final de distribución de los productos audiovisuales extranjeros que traducen nuestros encuestados y que exponemos a continuación (véase bloque 1, pregunta 15).

15. ¿Cuál es el canal final de distribución para sus productos? (Puede marcar más de una opción)

\begin{tabular}{|l|c|c|c|}
\hline $\begin{array}{l}\text { Opciones de } \\
\text { respuesta }\end{array}$ & Total respuestas & $\begin{array}{c}\text { Recuento } \\
\text { respuestas }\end{array}$ & Porcentaje \\
\hline Televisión & 9 & 7 & $77,7 \%$ \\
\hline Cine & 9 & 4 & $44,4 \%$ \\
\hline Festivales & 9 & 4 & $44,4 \%$ \\
\hline DVD/ Blue-Ray & 9 & 3 & $33,3 \%$ \\
\hline
\end{tabular}

Tabla 30. Canal de distribución

Según los datos recogidos, se aprecia que la televisión es el principal medio de distribución de estos productos $(77,7 \%)$, seguida por el cine y los festivales, con un resultado similar $(44,4 \%)$, y por los DVD/ Blue-Ray (33,3\%). Además, a todo esto se 
añade otro canal de distribución, que nosotros habíamos ignorado en nuestro cuestionario, pero que propociona encargos a algunos de los encuestados, tal como especificaron en el apartado de "Otros" de la correspondiete pregunta de la encuesta.

\section{Comentarios}

Online, por ejemplo, Netflix.

En cuanto a la procedencia de los encargos recibidos, y como se indica en la Figura 13, el 55,6\% de los mismos provienen de Rumanía y de otros países (véase bloque 1, pregunta 16). Por otra parte, podemos observar que una cantidad significativa de los encargos (el 33,3\%) proviene solamente de Rumanía, y podrían proceder de las distribuidoras locales que se dedican a distribuir los estrenos de los productos audiovisuales extranjeros en los cines de este país. El menor porcentaje $(11,1 \%)$ corresponde a otros países, que según podemos ver es una fuente de trabajo bastante inferior a las dos anteriores.

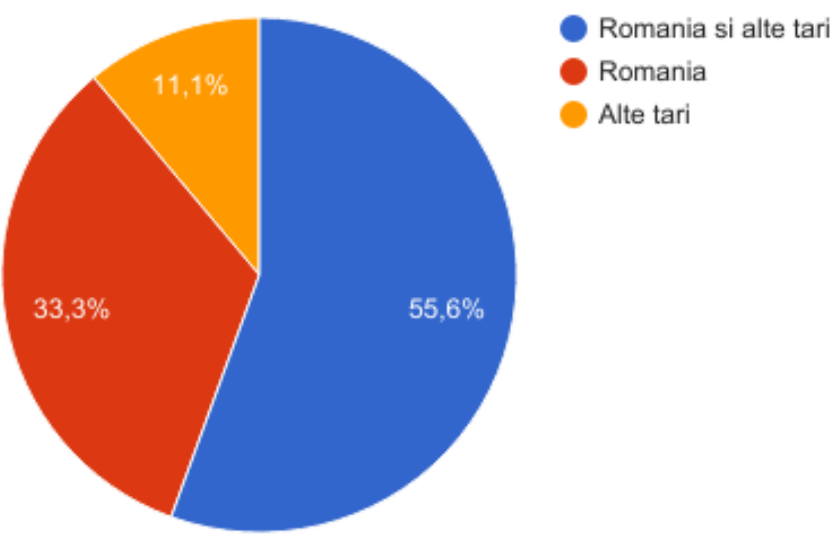

Figura 13. Procedencia de encargos ${ }^{50}$

Como conclusiones de los tres primeros aspectos este subapartado (5.1.1. Perfil del traductor) hemos podido observar que, según la información recibida por parte de nuestros encuestados sobre los datos demográficos, estos se ubican generalmente en Bucarest o Transilvania, dado que son los puntos importantes que ofrecen trabajo en

\footnotetext{
${ }^{50}$ Figura 13. Procedencia de encargos $\rightarrow$ * România și alte țări $=$ Rumanía y otros países; * România= Rumanía; * Alte țări $=$ Otros países.
} 
este ámbito. No ignoramos en ningún momento a la hora de extraer conclusiones la muestra reducida de nuestro estudio, ni tampoco el hecho que, gracias a Internet, actualmente los profesionales que se dedican a este tipo de traducción no necesitan un contacto presencial con el cliente, y que en consecuencia pueden residir en cualquier otra ciudad de Rumanía.

En cuanto al perfil formativo, según los datos recabados, hemos podido constatar que la base formativa de la mayoría de los encuestados son los estudios de Filología, perfecionada posteriormente en algunos casos: en un número limitado por medio de cursos específicos de traducción audiovisual ofertados por las empresas empleadoras, así como por medio de formación interna u obtenida en otros países. No obstante, hemos podido comprobar en algunos casos que una amplia experiencia profesional puede suplir la formación académica en esta profesión.

Conscientes de que la estabilidad laboral no destaca en esta profesión, en Rumanía, los resultados recabados así revelan la situación actual de este gremio. Tal como hemos podido observar, el número de profesionales que están contratados es inferior al de los que trabajan en situación de freelancers. Pese al incremento de las cadenas de televisión y a las empresas empledoras, la oscilación en el volumen de encargos y la inestabilidad laboral define esta profesión en Rumanía. De nuevo, conscientes del tamaño reducido de nuestra muestra y de que, además, en la actualidad no existe un censo para determinar una cifra exacta, no podemos generalizar esta afirmación, con lo que nos limitamos a exponer los datos obtenidos en nuestro estudio.

Las principales empresas empleadoras son las cadenas de televisión y las distribuidoras. Dada la variabilidad retributiva de esta profesión, que depende de los encargos que se reciben, la mayoría de los traductores de nuestra muestra compagina la traducción audiovisual con actividades relacionadas con esta, como por ejemplo con crítica de cine, televisión y radio, organización de festivales, redacción o la docencia de subtitulación y doblaje.

La principal modalidad de traducción audiovisual a que se dedican es la subtitulación, aunque el doblaje es la segunda modalidad con más dedicación. En el apartado de voice-over o traducción de videojuegos no hemos recibido ninguna respuesta afirmativa.

Las combinaciones lingüísticas que los traductores utilizan con más frecuencia para realizar los encargos de traducción audiovisual son inglés-rumano y francés- 
rumano, seguidas por italiano-rumano y español-rumano, aunque en mucha menor medida.

En cuanto a los clientes, la mayoría de los traductores encuestados reciben encargos de Rumanía y de otros países, y solo un pequeño porcentaje de ellos recibe encargos solamente de otros países.

Por lo que se refiere al canal (o medio) final de distribución para sus productos, los que ocupan el primer puesto son las cadenas de televisión, seguidos por el cine, los festivales y el DVD/ Blue-Ray. Por otra parte, el destinatario al que se dirigen finalmente los productos audiovisuales que traducen con más frecuencia es tanto el público infantil como el adulto. Sin embargo, llama la atención que ninguno de los encuestados se dedique exclusivamente a la traducción de productos extranjeros dirigidos al público infantil. Esto que nos hace deducir que el número de encargos de productos audiovisuales dirigidos a este tipo de público debe de ser más limitado.

\subsubsection{Recursos tecnológicos y programas informáticos}

Conscientes de que los recursos tecnológicos son una herramienta fundamental para ejercer esta profesión, dedicamos el siguiente subapartado del primer bloque de preguntas del cuestionario a este tema (véase bloque 1, pregunta 17).

\begin{tabular}{|c|c|c|c|}
\hline $\begin{array}{ll}\text { Opciones } & \text { de } \\
\text { respuesta } & \end{array}$ & Total respuestas & $\begin{array}{l}\text { Recuento } \\
\text { respuestas }\end{array}$ & Porcentaje \\
\hline $\begin{array}{l}\text { Programas propios } \\
\text { de las empresas } \\
\text { que le contratan }\end{array}$ & 9 & 7 & $77,7 \%$ \\
\hline $\begin{array}{l}\text { Programas } \\
\text { gratuitos }\end{array}$ & 9 & 3 & $33,3 \%$ \\
\hline $\begin{array}{l}\text { Programas } \\
\text { comerciales de } \\
\text { pago }\end{array}$ & 9 & 2 & $22,2 \%$ \\
\hline
\end{tabular}

Tabla 31. Tipos de programas empleados para realizar las traducciones 
Como podemos ver en la tabla anterior, prevalecen (con bastante diferencia, $77,7 \%$ ) los programas propios que las empresas empleadoras proporcionan a los traductores. Además, a este tipo de programas se añaden los programas gratuitos (con $33,3 \%$ ) y los programas comerciales de pago, con un porcentaje del 22,2\%.

En cuanto al tipo de programas específicos para este tipo de traducción, obtuvimos diferentes respuestas y comentarios (véase bloque 1, pregunta 18).

\begin{tabular}{|c|c|c|c|}
\hline \multicolumn{4}{|c|}{$\begin{array}{l}\text { 18. ¿Utiliza programas específicos de traducción audiovisual (WinCaps, Fab Subtitler, } \\
\text { etc)? }\end{array}$} \\
\hline \multicolumn{4}{|c|}{ 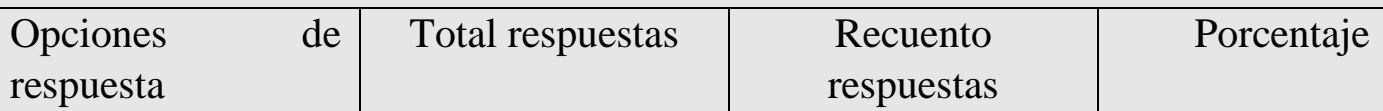 } \\
\hline Sí & 9 & 6 & $66,6 \%$ \\
\hline $\mathrm{No}$ & 9 & 3 & $33,3 \%$ \\
\hline
\end{tabular}

Tabla 32. Programas específicos de traducción audiovisual

Como se aprecia en la tabla, el 66,6\% de nuestros encuestados utilizan programas específicos de traducción audiovisual, y la mitad de los anteriores $(33,3 \%)$ no los utilizan. Además, en el apartado de comentarios que hemos incorporado a la pregunta algunos traductores nos han indicado el tipo de programa que utilizan.

\begin{tabular}{|l|}
\hline Comentarios \\
\hline Confidencial. \\
\hline Software cliente. \\
\hline Subtitle Edit, Ledit, EZ Titles, Eddie Plus. \\
\hline Subtitle Workshop, DivX Land. \\
\hline
\end{tabular}

Para justificar la utilización de estos tipos de programa (véase bloque 1, pregunta 19), a pesar de la diversidad de las respuestas reflejada en la Figura 14, observamos que el 33,3\% de los encuestados que los usan lo hacen por los formatos en que permiten trabajar, y que otro $33,3 \%$ los usan porque son impuestos por el cliente/empresa. Por otra parte, un $11,1 \%$ los emplean por los formatos en los que permiten trabajar y porque son 
impuestos por la empresa, otro $11,1 \%$ por su calidad, y el $11,1 \%$ restante los utiliza por otros motivos que desconocemos, puesto que han seleccionado el apartado "otro" de nuestro cuestionario sin especificar su elección.

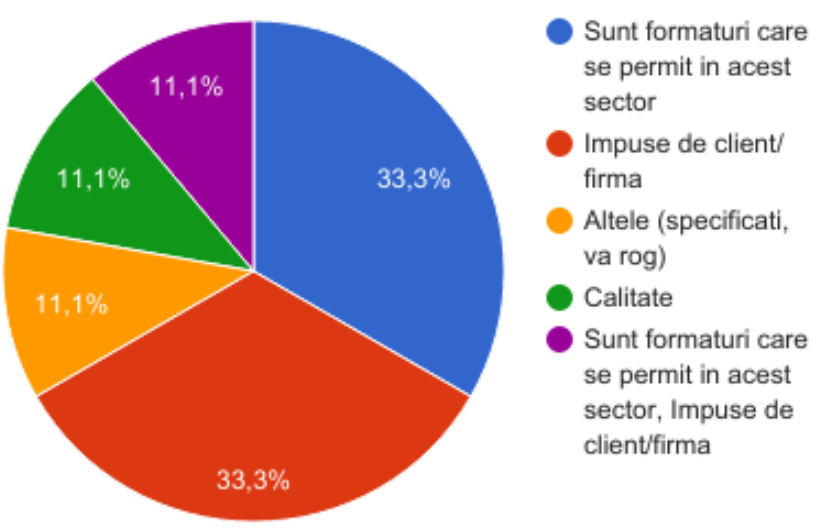

Figura 14. Justificación de empleo de estos programas ${ }^{51}$

\subsubsection{Normas, convenciones y especificidades de la profesión en la TAV}

En el último subapartado del primer bloque de nuestro cuestionario, dirigimos nuestras preguntas hacia las particularidades que implica esta profesión.

El material que reciben los profesionales audiovisuales para realizar la traducción, puede facilitar o dificultar el trabajo que realizan (véase bloque 1, pregunta 20), tal como hemos expuesto en la sección 3.3.

\begin{tabular}{|l|c|c|c|}
\hline 20. ¿Cuál es el material que recibe previamente para realizar este trabajo? \\
\hline $\begin{array}{l}\text { Opciones de } \\
\text { respuesta }\end{array}$ & Total respuestas & $\begin{array}{c}\text { Recuento } \\
\text { respuestas }\end{array}$ & Porcentaje \\
\hline Guion & 9 & 8 & $88,8 \%$ \\
\hline Video & 9 & 8 & $88,8 \%$ \\
\hline Lista de diálogos & 9 & 7 & $77,7 \%$ \\
\hline
\end{tabular}

Tabla 33. Tipo de material que recibe previamente

\footnotetext{
${ }^{51}$ Figura 14. Justificación de empleo de estos programas $\rightarrow *$ Sunt formaturi care se permit în acest sector $=$ Formatos en que permiten trabajar; *Impuse de client/firmă = Imposición del cliente/empresa; *Altele (specificați, vă rog) = Otros (especifique, por favor); *Calitate = Calidad; *Sunt formaturi care se permit în acest sector, Impuse de client/firmă $=$ Formatos en que permiten trabajar, Imposición del cliente/empresa.
} 
Como podemos observar en la tabla, a pesar de que en el apartado de esta pregunta habíamos incluido una opción de "Otros" por si alguno de los encuestados recibía el material de forma diferente, todos optaron por las opciones que redactamos como posibles respuestas. En algunos casos, los encuestados marcaron las tres opciones, pero en el apartado de comentarios nos explicaron que el material lo podían recibir en una de las tres variantes, pero no simultáneamente.

El procedimiento para recibir el material es variado; sin embargo, observamos que la modalidad más utilizada es vía email y File Transfer Protocol (véase Figura 15 a continuación), dado que un 55,6\% de los encuestados marcaron ambas opciones (véase bloque 1, pregunta 21).

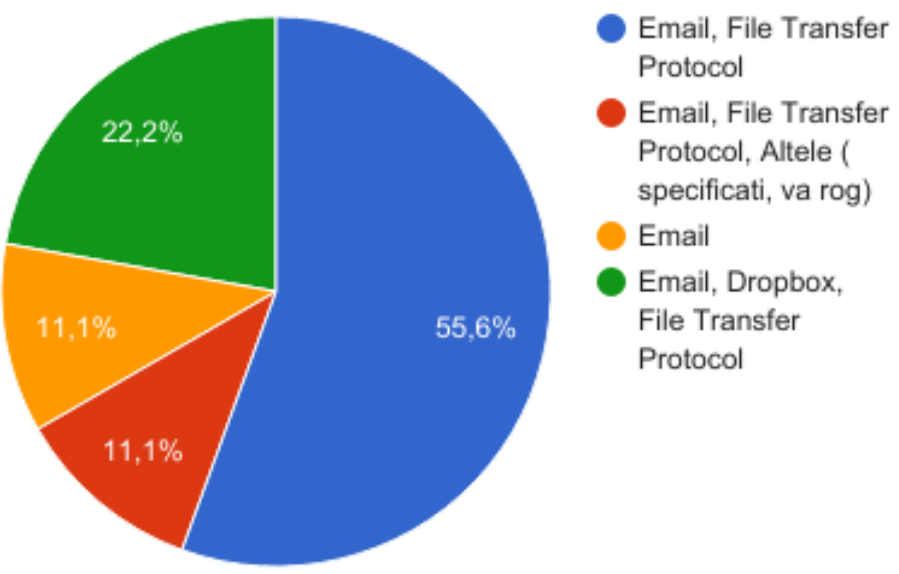

Figura 15. Vía recepción de material ${ }^{52}$

El tiempo asignado para realizar los encargos es variable. Suponíamos, en primera aproximación, que este ítem sería difícil de delimitar, dadas las características de los productos audiovisuales (género, densidad de diálogos, etc.). Sin embargo, consideramos interesante conocer la opinión de los traductores sobre las características de este aspecto fundamental de la profesión, también en Rumanía (véase bloque 1, pregunta 22).

\footnotetext{
${ }^{52}$ Figura 15. Via recepción de material $\rightarrow$ *Email, File Transfer Protocol $(\mathrm{FTP})=$ Correo electrónico, File Transfer Protocol $(\mathrm{FTP})$; *Email, File Transfer Protocol (FTP), Altele (specificați, va rog) = Correo electrónico, File Transfer Protocol (FTP), Otros (especifique, por favor); *Email = Correo electrónico; *Email, Dropbox, File Transfer Protocol $(\mathrm{FTP})=$ Correo electrónico, Dropbox, File Transfer Protocol (FTP)
} 


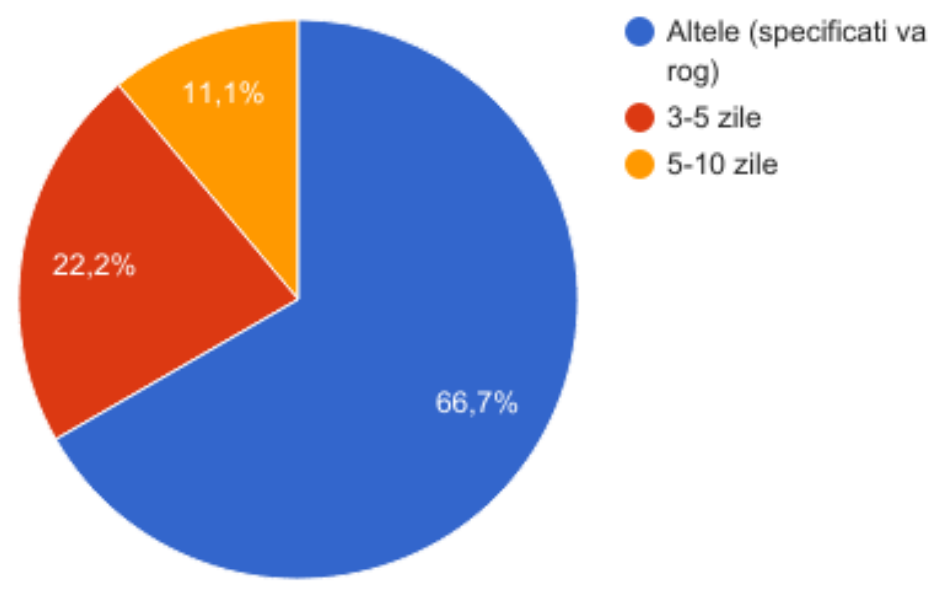

Figura 16. Tiempo para realizar la traducción ${ }^{53}$

Tal como habíamos esperado, las respuestas fueron distintas (en términos de días), como se muestra en la Figura 16. Además, gracias a los cometarios que nos aportaron algunos traductores, podemos puntualizar algunos detalles al respecto. Entre estos comentarios, destacan:

\begin{tabular}{|l|}
\hline Comentarios \\
\hline $\begin{array}{l}\text { Reporte normal 1/6: } 1 \text { minuto de película=6 minutos de tiempo físico de traducción y } \\
\text { subtitulación. }\end{array}$ \\
\hline Depende del cliente. \\
\hline A veces una noche para traducir una película, el texto lo dicto. \\
\hline
\end{tabular}

Asimismo, consideramos interesante conocer la opinión de los traductores sobre las características de este elemento crucial de la profesión en Rumanía y formulamos una pregunta similar en las entrevistas:

Pregunta: Por ejemplo, una película de 90 minutos, ¿en cuánto tiempo se puede subtitular?

Traductor 2: Yo diría que una semana. Una película que tienes que traducir, redactar y corregir, creo que una semana.

\footnotetext{
${ }^{53}$ Figura 16. Tiempo para realizar la traducción $\rightarrow *$ Altele (specificați, va rog) $=$ Otros (especifique, por favor); *3-5 zile = 3-5 días; 5-10 zile $=5-10$ días 
Pregunta: ¿Y tiene una semana por parte de la empresa?

Traductor 2: No, cuatro o cinco días, o menos a veces. Trabajas en tiempo límite; por ejemplo, te dan hoy el material y te dicen que en dos días tiene que estar finalizado. Tienes que trabajar por la noche, estás cansado, te equivocas, pero la gente no lo entiende.

Al preguntar sobre la adecuación del tiempo que tienen para realizar la traducción, el $66,7 \%$ de los traductores han contestado que es suficiente, el $22,2 \%$ han puntualizado en el apartado de "Otros" que depende de las características del encargo solicitado, y el $11,1 \%$ lo han apreciado como poco para realizar el trabajo (véase bloque 1, pregunta 23). Dichos valores están representados en la figura que se muestra a continuación:

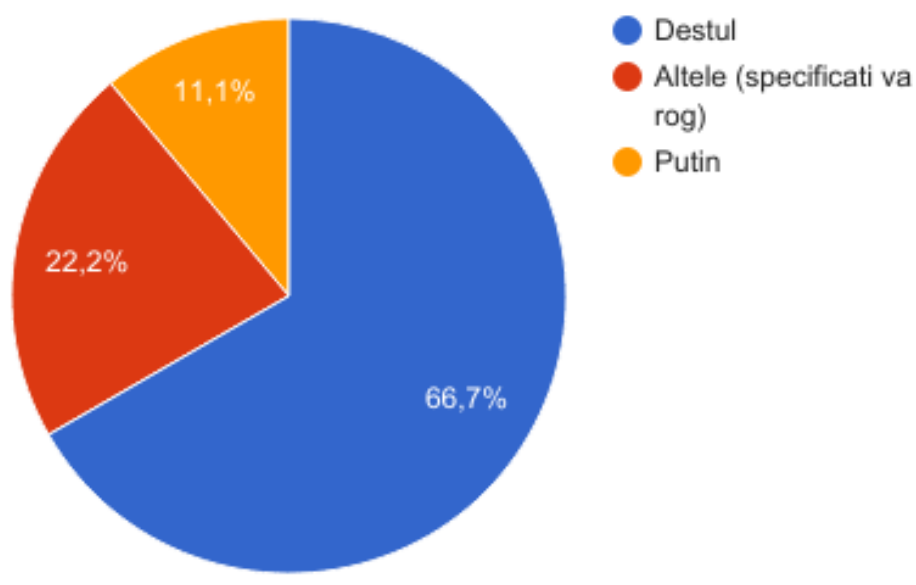

Figura 17. Estimación del tiempo para realizar la traducción ${ }^{54}$

La siguiente pregunta que planteamos fue si el tiempo de que se disponen para realizar la traducción puede influir en la calidad del producto (véase bloque 1, pregunta 24). A la vista de nuestros datos, podemos observar que las tres variantes que habíamos propuesto como respuesta obtienen un valor de $33,3 \%$. Un 33,3\% de los encuestados responden negativamente. Otro 33,3\% contestan de forma afirmativa y consideran que la insuficiencia de tiempo para realizar el trabajo puede repercutir en la calidad final del producto audiovisual. El 33,3\% restante, que han contestado "a veces", reafirman la relación "tiempo=calidad".

\footnotetext{
${ }^{54}$ Figura 17. Estimación del tiempo para realizar la traducción $\rightarrow *$ Destul $=$ Bastante; *Altele (specificați, va rog) $=$ Otros (especifique, por favor); ${ }^{*}$ Puțin $=$ Poco.
} 




Figura 18. Estimación de la repercusión tiempo/calidad ${ }^{55}$

Respeto a los materiales de apoyo que suelen utilizar con más frecuencia para realizar el trabajo, tal como se observa a continuación, los resultados muestran que el $100 \%$ de los encuestados utilizan los diccionarios como principal herramienta de apoyo, mientras que solamente un $44,4 \%$ utiliza recursos textuales, como por ejemplo Gutenberg, Oxford Text Archive o Biblegateway. Además, a estas opciones de respuesta añadimos una posibilidad con "Otros", por si alguno de nuestros encuestados mencionaba algún otro recurso que no habíamos propuesto como variante de respuesta. Sin embargo, esa casilla se quedó vacía, no sabemos si por falta de tiempo para rellenar la encuesta o por falta de utilización de otros materiales específicos de este tipo de traducción (véase bloque 1, pregunta 25).

25. ¿Qué tipo de materiales de apoyo suele utilizar para realizar el trabajo?

\begin{tabular}{|l|c|c|c|}
\hline Opciones de respuesta & $\begin{array}{c}\text { Total } \\
\text { respuestas }\end{array}$ & $\begin{array}{c}\text { Recuento } \\
\text { respuestas }\end{array}$ & Porcentaje \\
\hline $\begin{array}{l}\text { Recursos lexicográficos } \\
\text { (diccionarios) }\end{array}$ & 9 & 9 & $100 \%$ \\
\hline $\begin{array}{l}\text { Recursos terminológicos y } \\
\text { especializados (bancos de } \\
\text { datos terminológicos de }\end{array}$ & 9 & 8 & $88,88 \%$ \\
\hline
\end{tabular}

${ }^{55}$ Figura 18. Estimación de la repercusión tiempo/calidad $\rightarrow{ }^{*}$ Câteodată $=$ A veces; ${ }^{*} \mathrm{Nu}=\mathrm{No} ;{ }^{*} \mathrm{Da}=$ Sí. 


\begin{tabular}{|l|c|c|c|}
\hline $\begin{array}{l}\text { temáticas y combinaciones } \\
\text { lingüísticas distintas) }\end{array}$ & & \\
\hline Recursos enciclopédicos & 9 & 7 & $77,77 \%$ \\
\hline $\begin{array}{l}\text { Recursos textuales } \\
\text { (Gutenberg, Oxford Text } \\
\text { Archive o Biblegateway) }\end{array}$ & 9 & 4 & $44,44 \%$ \\
\hline
\end{tabular}

Tabla 34. Materiales de apoyo

Sin embargo, en una de las entrevistas realizadas encontramos la explicación para el uso unánime de diccionarios:

Traductor 1: [...] los diccionarios deberían estar en todas las casas como en la mía, muy desgastados, porque todo el tiempo busco en los diccionarios, no solamente en Internet. Internet no está tan verificado como estaban inicialmente los diccionarios, paradójicamente antes del 89, y no me refiero a que estaba mejor en la época comunista, que quede claro, se trata de profesionalismo y esperemos que la profesionalidad se haga notar en la actualidad otra vez.

A partir de esta pregunta, planteamos otras cuestiones que se refieren directamente a la realización del proceso de traducción audiovisual, donde se abordaron características particulares referentes a este tipo de traducción.

Como público, casi siempre cuestionamos el equivalente del título del producto audiovisual extranjero en la lengua meta, y nos pareció apropiado intentar desvelar el responsable de esta decisión tan cuestionada en el caso particular de Rumanía.

En este sentido, se puede comprobar en la siguiente figura (Figura 19) que la decisión sobre este asunto corresponde mayoritariamente a las distribuidoras (66,7\%). Sin embargo, en algunos casos, la resolución de esta cuestión concierne solamente al traductor $(11,1 \%)$, a traductor y distribuidor $(11,1 \%)$, o a otras personas cuya función en este proceso desconocemos, puesto que la respuesta seleccionada en el apartado de "otros" queda sin concretar (véase bloque 1, pregunta 26). 
8

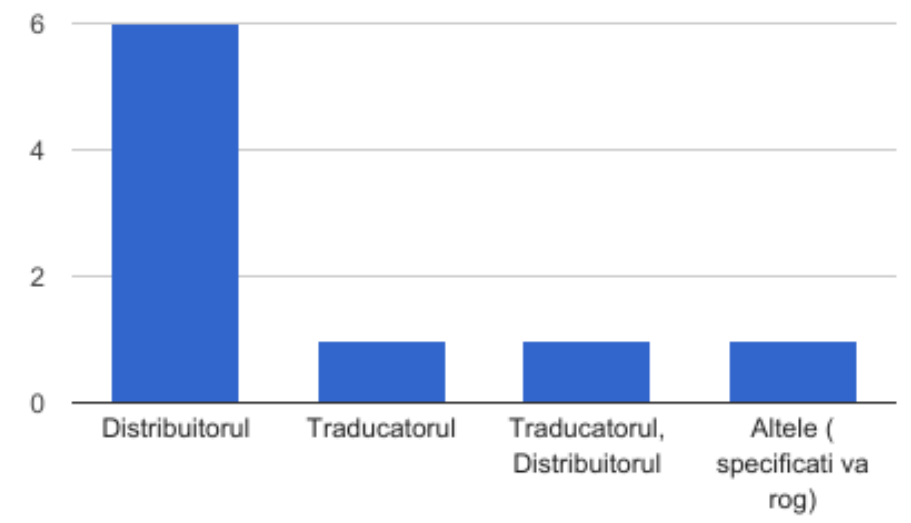

Figura 19. Traducción del título ${ }^{56}$

La intervención final de un revisor lingüístico, figura que existía en la época comunista (como hemos expuesto en la sección 2.1.1), parece que en la actualidad no es imprescindible a lo largo del proceso, según muestran nuestros resultados (véase bloque 1, pregunta 27).

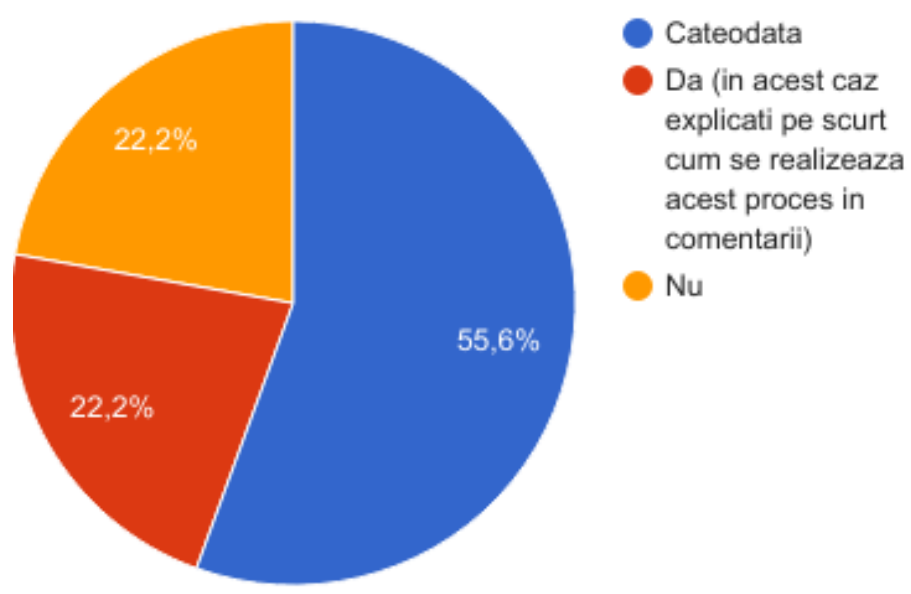

Figura 20. Revisor lingüístico ${ }^{57}$

Como podemos apreciar en la figura anterior, un porcentaje del 55,6\% de los encuestados ha contestado que a veces la traducción final es revisada por un revisor lingüístico, y en el apartado de comentarios han puntualizado algunas características de

\footnotetext{
${ }^{56}$ Figura 19. Traducción del título $\rightarrow$ Distribuitorul $=$ La distribuidora; Traducătorul $=$ El traductor; Traducătorul, Distribuitorul $=$ El traductor, La distribuidora; Altele (specificați, va rog) = Otros (especifique por favor).

${ }^{57}$ Figura 20. Revisor lingüístico $\rightarrow$ *Câteodată $=$ A veces; *Da (în acest caz explicați pe scurt cum se realizează acest proces, în comentarii) = Sí (en caso afirmativo, explique brevemente el proceso que se sigue en el apartado de comentarios de esta pregunta); $* \mathrm{Nu}=\mathrm{No}$.
} 
este aspecto. Asimismo, el 22,2\% de los traductores han contestado de forma negativa y han argumentado la respuesta por medio de razones que ya intuíamos.

\begin{tabular}{|l|}
\hline Comentarios \\
\hline Desafortunadamente, no. Anteriormente, en la TVR (Televisión Rumana) existía una \\
persona que refinaba los subtítulos, ahora, por falta de presupuesto y tiempo ha dejado \\
de existir esta práctica. \\
\hline $\begin{array}{l}\text { La traducción llega al revisor, luego vuelve al traductor que decide si las correcciones } \\
\text { son objetivas y si las acepta o no. }\end{array}$ \\
\hline $\begin{array}{l}\text { Existe un editor que realiza las correcciones o las sugerencias. La decisión final } \\
\text { pertenece al traductor (en mi caso). }\end{array}$ \\
\hline
\end{tabular}

Dado que la subtitulación y el doblaje son las dos modalidades de traducción audiovisual empleadas actualmente en Rumanía, consideramos conveniente intentar obtener información sobre características de estas prácticas, y en concreto, referentes a la realización del pautado y del ajuste.

En el caso de la subtitulación, como observamos en la siguiente figura (Figura $21)$, las respuestas varían muy poco. En el 77,8\% de los casos el pautado lo realiza el traductor, porcentaje seguido por un $11,1 \%$ cuando lo realiza el técnico/editor, y por un $11,1 \%$ cuando lo realiza el técnico/editor y el traductor (véase bloque 1, pregunta 28).

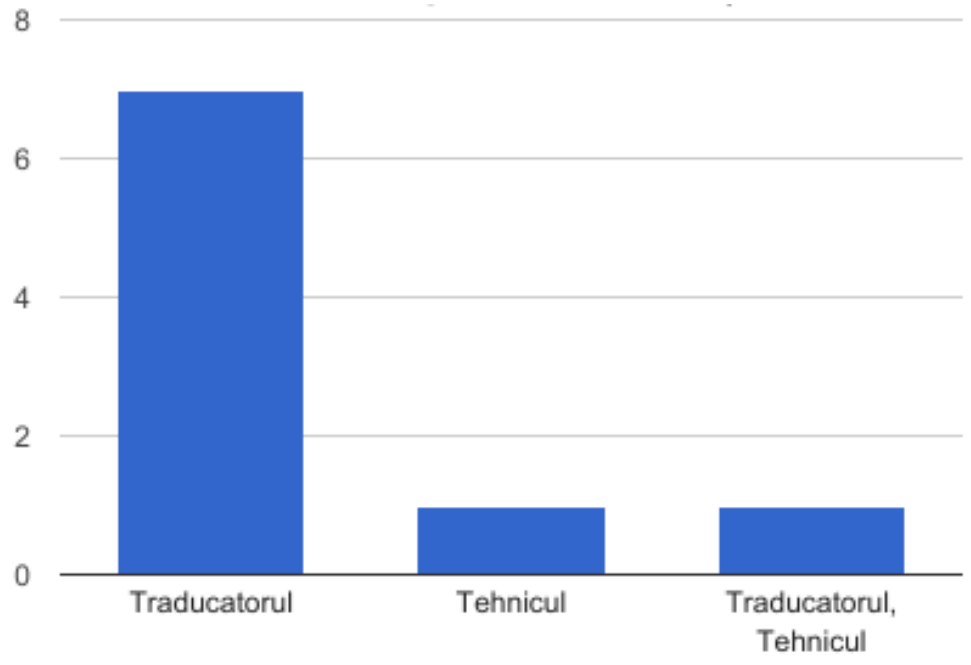

Figura 21. Realización del pautado ${ }^{58}$

\footnotetext{
${ }^{58}$ Figura 21. Realización del pautado $\rightarrow$ Traducătorul $=$ El traductor; Tehnicul $=$ El técnico; Traducătorul, Tehnicul $=$ El traductor, El técnico.
} 
En el caso del doblaje, según nuestros resultados, un 66,7\% de los traductores realizan también el ajuste, mientras que en el 33,3\% de los casos, este proceso corresponde a las atribuciones del técnico/editor (véase bloque 1, pregunta 29).



Figura 22. Realización del ajuste ${ }^{59}$

En cuanto al tipo de convenciones que se aplican para realizar la traducción audiovisual (subtitulación, doblaje, etc.), en este país, pese a la diversidad de las respuestas, podemos observar a continuación que un considerable porcentaje de las respuestas $(33,3 \%)$ indican que los traductores acatan las convenciones facilitadas por el cliente/distribuidora, mientras que otro tercio $(33,3 \%)$ se ciñe a las convenciones generales extraídas de los libros especializados en traducción audiovisual.

Asimismo, un $11,1 \%$ de los encuestados utiliza en sus traducciones convenciones facilitadas por el cliente y convenciones generales, otro $11,1 \%$ aplica las convenciones generales y otras, y por último, un $11,1 \%$ de los traductores utiliza otras convenciones que no han detallado (véase bloque 1, pregunta 30).

${ }^{59}$ Figura 22. Realización del ajuste $\rightarrow$ Tehnicul $=$ El técnico; Traducătorul $=$ El traductor. 


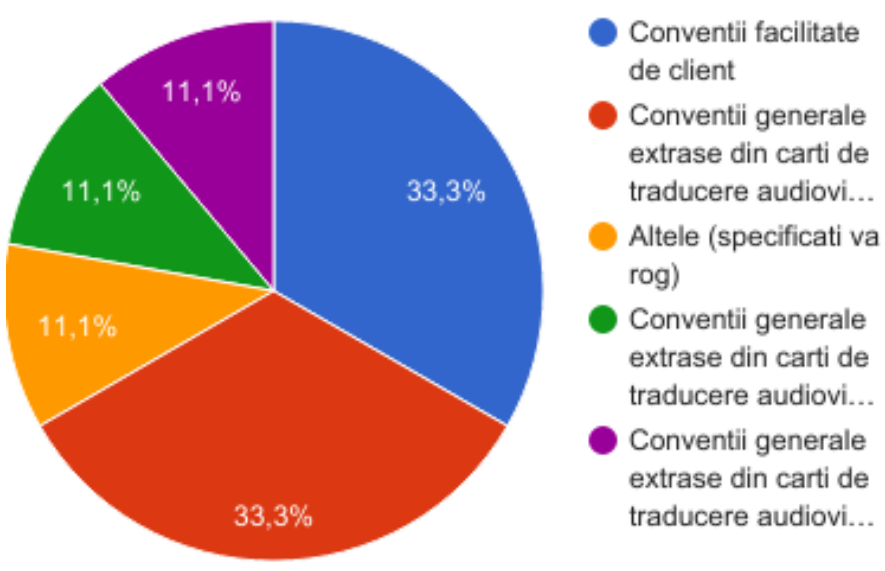

Figura 23. Tipo de convenciones ${ }^{60}$

A la pregunta de si las empresas empleadoras imponen restricciones o pautas en la traducción que encargan, el 50\% de los traductores de textos audiovisuales que han participado en nuestro estudio han contestado que “a veces". Destacan también, con un porcentaje de 37,5\%, los traductores que no reciben ninguna restricción, mientras que el 12,5\% restante nos confirma que sí se le imponen restricciones o pautas (véase bloque 1, pregunta 31).



Figura 24. Restricciones o pautas por parte de los empleadores ${ }^{61}$

\footnotetext{
${ }^{60}$ Figura 23. Tipo de convenciones $\rightarrow *$ Convenții facilitate de client $=$ Convenciones que facilita el cliente; * Convenții generale extrase din cărți de traducere audiovizuală = Convenciones generales extraídas de libros especializados en TAV; *Altele (specificați, vă rog) $=$ Otros (especifique, por favor); *Convenții generale extrase din cărți de traducere audiovizuală, Convenții facilitate de client $=$ Convenciones generales extraídas de libros especializados en TAV, Convenciones que facilita el cliente; *Convenții generale extrase din cărți de traducere audiovizuală, Convenții facilitate de client, Altele (specificați, vă rog) = Convenciones generales extraídas de libros especializados en TAV, Convenciones que facilita el cliente, Otros (especifique, por favor).

${ }^{61}$ Figura 24. Restricciones o pautas por parte de los empleadores $\rightarrow \mathrm{Nu}=$ No; $\mathrm{Da}=\mathrm{Sí}$; Câteodată $=\mathrm{A}$ veces.
} 
Tal como podemos observar en los comentarios que se muestran a continuación, en algunos casos estas restricciones o pautas varían en función de la empresa empleadora, mientras que otras veces se refieren solamente a las convenciones que gobiernan el proceso de traducción.

\section{Comentarios}

Depende de cada empresa.

Solamente número de caracteres per línea.

En la siguiente pregunta formulada intentamos averiguar si las restricciones/pautas impuestas por los clientes podrían repercutir en el trabajo final (véase bloque 1, pregunta 32).

El resultado a esta pregunta fue bastante sorprendente, dado que el 57,1\% de los traductores contestaron "a veces". Apreciamos que se trata de un porcentaje bastante elevado, si consideramos que el 14,3\% han seleccionado la opción afirmativa de la respuesta, y solamente un $28,6 \%$ de los participantes contestaron negativamente (véase Figura 25 a continuación).

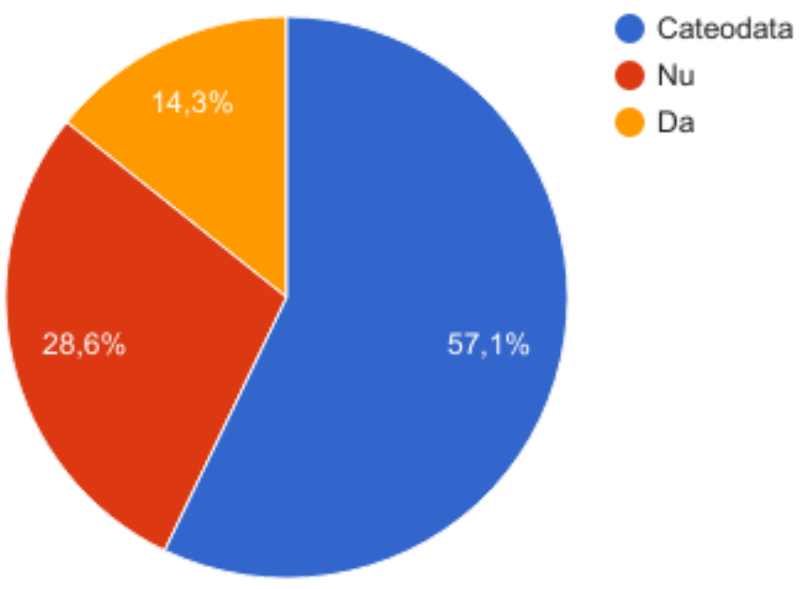

Figura 25. Repercuten en el trabajo final estas restricciones/pautas ${ }^{62}$

Tal como hemos expuesto en el epígrafe 1.8 de nuestro estudio, la autocensura, además de la censura, era una práctica que se aplicaba habitualmente en la época

${ }^{62}$ Figura 25. Repercuten en el trabajo final estas restricciones/pautas $\rightarrow{ }^{*}$ Câteodată $=\mathrm{A}$ veces; ${ }^{*} \mathrm{Nu}=\mathrm{No} ;{ }^{*} \mathrm{Da}=\mathrm{Sí}$ 
comunista. Al formular la siguiente pregunta de nuestro cuestionario (véase bloque 1, pregunta 33), quisimos comprobar si esta práctica sigue vigente en la actualidad en este país. Por tanto, preguntamos a los traductores encuestados si habían aplicado alguna vez la autocensura para suavizar el lenguaje utilizado en algunos productos audiovisuales. El gran número de respuestas afirmativas (recogidas en la Figura 26) nos sorprendió nuevamente, puesto que un $66,7 \%$ (más de la mitad de nuestros encuestados, dos tercios del total) siguen aplicándola actualmente en la traducción. El 22,2\% de los traductores audiovisuales la aplican alguna vez, y por otra parte, el 11,1\% nunca la utiliza en sus trabajos.

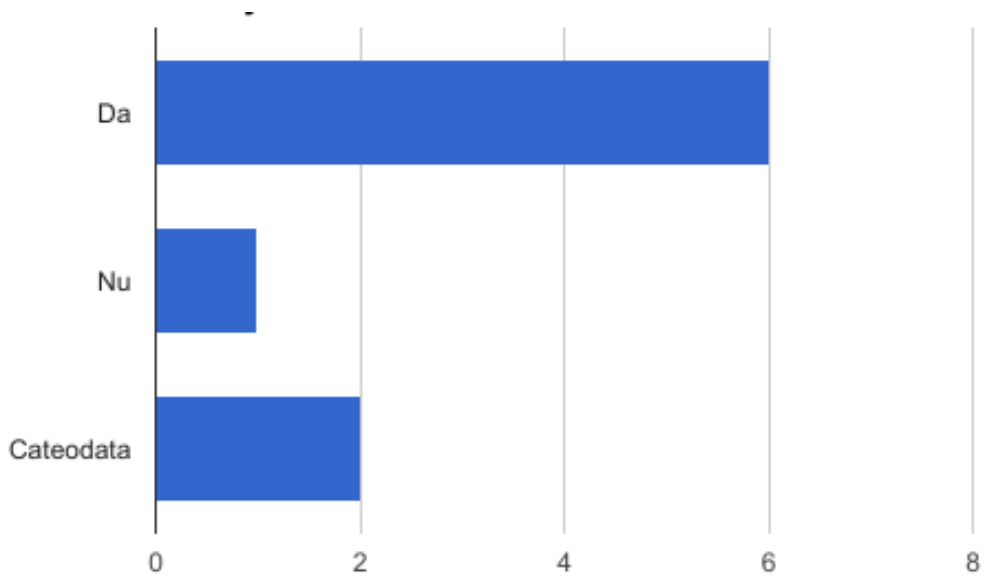

Figura 26. Aplicación de la autocensura ${ }^{63}$

Los comentarios a esta respuesta fueron variados, como se observa a continuación:

\section{Comentarios}

Existen prohibiciones para utilizar un lenguaje obsceno, impuestas por instituciones.

Condición impuesta por cliente, en función del canal de distribución (por ejemplo en la tele el lenguaje licencioso está parcialmente prohibido, online es más permisivo).

Una cuestión impuesta siempre por el cliente.

Dependiendo del público y del CNA (Consejo Nacional Audiovisual).

En función del registro lingüístico.

\footnotetext{
${ }^{63}$ Figura 26. Aplicación de la autocensura $\rightarrow \mathrm{Da}=\mathrm{Sí} ; \mathrm{Nu}=\mathrm{No}$; Câteodată $=\mathrm{A}$ veces
} 
No traduzco nunca palabrotas o vulgaridades, aunque me lo pidan.

Si analizamos los tres primeros comentarios, observamos que se enmarcan dentro de las restricciones o pautas por parte del cliente, y que los comentarios no se relacionan con el ítem concreto estudiado. Intuimos que los encuestados no habían entendido la pregunta. No obstante, los últimos tres comentarios confirman que la pregunta estaba bien formulada, dado que las observaciones son acordes a la cuestión planteada.

La siguiente pregunta se orienta al tipo de remuneración profesional que se recibe por el trabajo realizado, y se aportan varias opciones de respuesta (véase bloque 1, pregunta 34).

\begin{tabular}{|l|c|c|c|}
\hline \multicolumn{5}{|c|}{ 34. Suele cobrar el trabajo realizado por: (puede marcar más de una opción) } \\
\hline $\begin{array}{l}\text { Opciones de } \\
\text { respuesta }\end{array}$ & Total respuestas & $\begin{array}{c}\text { Recuento } \\
\text { respuestas }\end{array}$ & Porcentaje \\
\hline Otros & 9 & 3 & $33,3 \%$ \\
\hline Minuto & 9 & 3 & $33,3 \%$ \\
\hline $\begin{array}{l}\text { Tipo de programa } \\
\text { completo }\end{array}$ & 9 & 2 & $22,2 \%$ \\
\hline Horas & 9 & 1 & $11,1 \%$ \\
\hline Rollo (reel) & 9 & 0 & $0,0 \%$ \\
\hline Subtítulo & 9 & 2 & \\
\hline
\end{tabular}

Tabla 35. Tipo de remuneración profesional

Como se aprecia en la Figura 27, el 33,3\% de los traductores de textos audiovisuales que participaron a nuestra encuesta suelen cobrar el trabajo realizado por minuto. Un porcentaje inferior $(22,2 \%)$, suelen cobrar por horas o por tipo de programa completo. Solamente el 11,1\% aplica la tarifa por rollo (reel). En el apartado de "Otros", algunos traductores contestaron que cobran per film o proyecto, o tal como explicaron en el apartado de comentarios:

\section{Comentarios}

Depende del cliente, en general por minuto. 




Figura 27. Tipo de remuneración ${ }^{64}$

Dada la cautela con la que se trata este tema, (véase la sección 3.4 de este estudio), planteamos el mismo asunto en las entrevistas realizadas:

Pregunta: ¿Suele cobrar el trabajo realizado por minuto, hora, programa completo? Traductor 1: Por minuto, no lo sé. Casi siempre se aplica per film y está muy mal pagado, nosotros estábamos esperando que se cobrara una tarifa a nivel europeo, porque por fin estamos en Europa. Pero no pasó, y seguimos igual, mucho trabajo y poco dinero.

Traductor 2: Existen muchas formas: por minuto, hora... yo, personalmente, no estoy de acuerdo con ninguna. Se aplican también tarifas fijas, pero son las empresas las que las imponen. Algunas pagan por minuto, otras por subtitulo, otras por media hora, 20 minutos. Algunas, por ejemplo, no quieren pagar ni el espacio, que de hecho tú lo redactas, es tu tiempo, te pagan solamente por caracteres y las pausas no. La valoración de esta práctica y de nuestro tiempo se estima con precios muy bajos.

Pregunta: La siguiente pregunta es un poco tabú, sobre los precios que se aplican. Traductor 1: No creo que sea un tema tabú, pero los precios varían muchísimo y creo que por eso nadie dice nada. En principio se pagan unos $100 €$ per film, lo que

\footnotetext{
${ }^{64}$ Figura 27. Tipo de remuneración $\rightarrow$ *Minute $=$ Minutos; *Altele $($ specificați, va rog) $=$ Otros (especifique, por favor); * Ore = Horas; *Tip de program complet $=$ Tipo de programa completo. 
significa una cantidad extraordinariamente pequeña. Los precios son muy bajos... [...] Por ejemplo, por 12 takes que he interpretado para un doblaje me han pagado $50 €$ pero descontando las retenciones me quede con $30 €$ para un doblaje de Disney. [...] Pero los contratos son, generalmente, confidenciales. Es normal que no digan nada, no insistas porque no lo dirán. Siempre ha sido una profesión muy mal pagada, pero la pasión es demasiado grande para renunciar.

Traductor 2: Los contratos son casi en todas las empresas confidenciales y no se desvelan. [...] Probablemente existen algunas tarifas salariales, pero varían de empresa a empresa y bastante.

Traductor 3: Las tarifas para cada tipo de traducción audiovisual varían de empresa a empresa, dependiendo de la duración del programa, de la complejidad del contenido, de la lengua original, del tipo del producto audiovisual (película, documental, etc...).

Los derechos de autor es otro tema que consideramos importante abordar y con él, finalizar el primer bloque de preguntas de nuestro cuestionario, dirigido a los traductores (véase bloque 1, pregunta 35). Tal y como hemos expuesto en el epígrafe 3.4 y según algunas opiniones de profesionales rumanos que recogemos, legalmente se protege este derecho, pero su aplicación está muy limitada en la práctica. Por tanto, a la pregunta si en los contratos se estipula algún derecho de autor, las respuestas fueron variadas. 


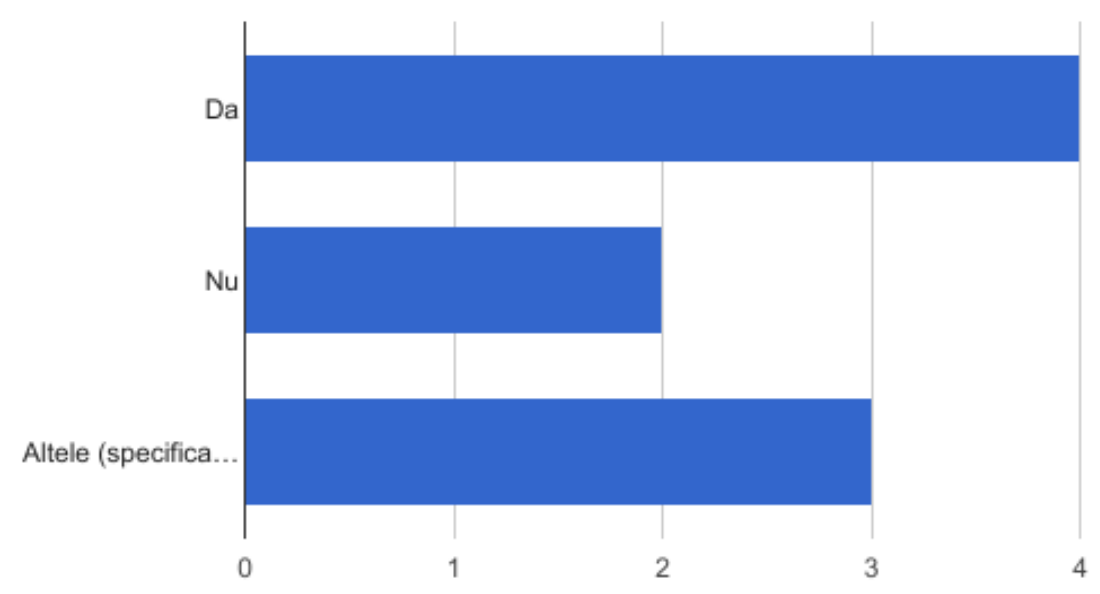

Figura 28. Derechos de autor ${ }^{65}$

Los datos del gráfico anterior (Figura 28) muestran que el 44,4\% de los traductores de productos audiovisuales en Rumanía tienen estipulado en sus contratos claúsulas sobre los derechos de autor, mientras que el 22,2\% han contestado negativamente. El 33,3\% de los encuestados marcaron la casilla de "Otros", sin especificar en qué consistía la respuesta.

En el apartado de comentarios, algunos añadieron:

\section{Comentarios}

Confidencial.

Los derechos de autor se utilizan siempre, pero sin pagar algo más, como en el caso de los libros.

Estos comentarios se completan a continuación con algunos datos de las entrevistas:

Traductor 2: Es mi derecho de concederlo o no, se supone. Por ejemplo, si yo trabajo para una empresa y realizo la traducción, digo que esta traducción no quiero que se ceda a otra empresa, pero si no estás de acuerdo buscan a otro traductor para hacerla.

\footnotetext{
${ }^{65}$ Figura 28. Derechos de autor $\rightarrow \mathrm{Da}=\mathrm{Sí} ; \mathrm{Nu}=\mathrm{No}$; Altele (specificați, vă rog) $=$ Otros (especifique, por favor)
} 
Pregunta: Es una condición, pero no se respeta...

Traductor 2: Sí, tú dices sí y ya está. Te dicen que has trabajado una vez y te han pagado por ello. Pero, para un libro, por ejemplo, lo escribes una vez y ya está, ese libro te lo pueden comprar tres millones de personas. Eso pasa con la traducción de una película... Yo no trabajo para siete empresas, no es normal que tú pases mi trabajo a otros.

Pregunta: No es normal, pero se hace.

Traductor 2: Sí se hace y a escondidas, algo así. No puedo generalizar, pero creo que es una práctica normal en este ámbito. Es muy difícil ganar en esta lucha, decir que es tu derecho. Verbalmente te dicen "sí, es así, pero yo hago lo que quiero".

Como conclusiones de las secciones 5.1.1.4 y 5.1.1.5, dedicadas a los recursos tecnológicos y programas informáticos, y a las normas, convenciones y especificidades de la práctica de la traducción audiovisual, respectivamente, hemos podido observar que, en general, son las empresas empleadoras las que imponen el tipo de programa específico (software) en este tipo de traducción. El 66,6\% de los encuestados utilizan estos programas porque permiten trabajar con formatos habituales en este ámbito.

En cuanto al material que reciben los profesionales audiovisuales para realizar la traducción, los tres tipos de materiales más empleados son la lista de diálogos, el guion o el video. El procedimiento para recibir el material es vía email y File Transfer Protocol. El tiempo de que se dispone para realizar los encargos es variable, dependiendo del cliente o del género del producto audiovisual. Respecto a los materiales de apoyo que se suelen emplear con más frecuencia para realizar el encargo, los resultados muestran que el $\mathbf{1 0 0 \%}$ de los encuestados utilizan los diccionarios como principal herramienta de apoyo.

Si nos centramos ahora en las características particulares referentes a este tipo de traducción, se ha podido constatar que la decisión de la traducción del título del producto audiovisual extranjero en la lengua meta corresponde mayoritariamente a las distribuidoras. En cuanto a la revisión final de la traducción, un porcentaje del 55,6\% de nuestros encuestados ha respondido que a veces la traducción final es revisada por un revisor lingüístico. Asimismo, en la subtitulación, en el 77,8\% de los casos el pautado lo realiza el traductor, igual que sucede en el caso del doblaje $(66,7 \%)$ para el ajuste. El tipo de convenciones que se aplican para realizar la traducción audiovisual (subtitulación, doblaje, etc.) son impuestas por el cliente/la distribuidora. Las 
restricciones o pautas que reciben varían en función de la empresa empleadora en un porcentaje considerable $(\mathbf{5 7 , 1 \%})$. Además, dichas restricciones pueden repercutir en el trabajo final y modificar la idea original.

Por lo que refiere al tipo de remuneración profesional que se aplica, se aprecia que el 33,3\% de los traductores audiovisuales que participaron en nuestra encuesta suele cobrar el trabajo realizado por minuto. Asimismo, con un porcentaje inferior del $\mathbf{2 2 , 2 \%}$, la remuneración se suele obtener por horas o por tipo de programa completo. Solamente en un $\mathbf{1 1 , 1 \%}$ se aplica la tarifa por rollo (reel). En cuanto a los derechos de autor, a pesar de estar estipulados en los contratos, pocas veces se aplican.

\subsubsection{Valoración de la profesión}

El bloque número dos de nuestro cuestionario lo dedicamos a la valoración de la profesión y, por tanto, abordamos cuestiones relacionadas con este tema con la intención de situar esta profesión en el mercado profesional rumano. También debemos mencionar que, a partir de este bloque, el traductor que nos envió el formulario incompleto (se comentó esta incidencia al inicio de este capítulo), dejó de contestar a las preguntas formuladas a continuación.

Iniciamos esta segunda parte de la encuesta con una pregunta de tipo ranking para analizar la opinión de los encuestados al plantear si una buena traducción puede influir en el éxito de audiencia de un producto audiovisual, ya sea una película, serie o documental (véase bloque 2, pregunta 36).

Como puede apreciarse en la Figura 29, la mayoría de encuestados opinan que una buena traducción está relacionada con el éxito del producto audiovisual, dado que un $37,5 \%$ y un $25 \%$ han seleccionado las variantes "mucho" y "bastante". Un $25 \%$ considera que "más o menos", mientras que el 12,5\% considera que "poco". Cabe destacar que ninguno de los traductores marcó la opción "muy poco", que habíamos identificado con el número 1 en la pregunta de tipo ranking. 


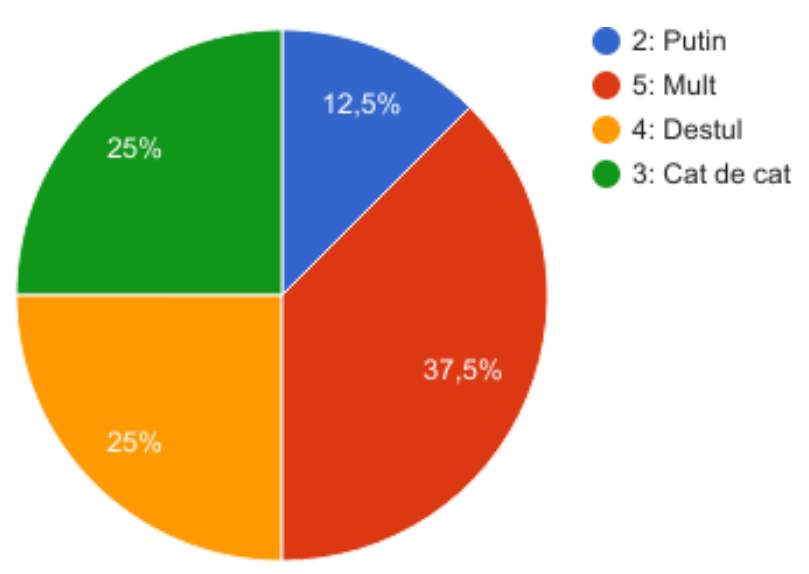

Figura 29. Calidad traducción/éxito de producto audiovisual ${ }^{66}$

El reconocimiento público es un factor poco habitual en esta profesión, puesto que, a priori, puede resultar difícil obtenerlo. A partir de esta idea, que podría ser subjetiva, formulamos la siguiente pregunta para indagar sobre este ítem en el ámbito geográfico de Rumanía (véase bloque 2, pregunta 37).

No obstante, tal como se observa en la Figura 30, del total de los traductores que han colaborado en nuestra encuesta, un $62,5 \%$ (5, en total) ha recibido reconocimiento público, mientras que el 37,5\% (3 traductores) ha contestado negativamente. Dado que, solamente un traductor ha precisado en el apartado de "Comentarios" el tipo de reconocimiento recibido, ignoramos la índole del resto.

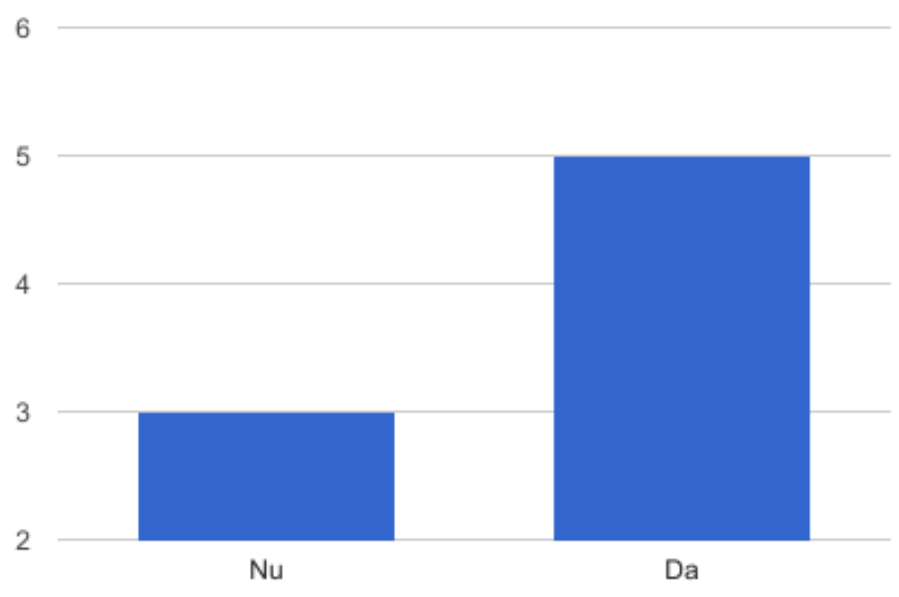

Figura 30. Reconocimiento público ${ }^{67}$

\footnotetext{
${ }^{66}$ Figura 29. Calidad traducción/éxito de producto audiovisual $\rightarrow{ }^{*}$ Puțin $=$ Poco; ${ }^{*}$ Mult $=$ Mucho; ${ }^{*}$ Destul = Bastante; ${ }^{*}$ Cât de cât $=$ Algo.

${ }^{67}$ Figura 30. Reconocimiento público $\rightarrow \mathrm{Nu}=\mathrm{No}$; $\mathrm{Da}=$ Sí. 
El comentario en cuestión fue el siguiente:

\section{Comentarios}

Sí, un artículo de cortesía, por ejemplo, para la serie sobre la vida de Wagner, más una película sobre mi carrera antes del año 1989, Chuck Norris vs comunismo, presentada también en Madrid y en el Canal Arte.

La siguiente pregunta que formulamos iba dirigida a la equivalencia entre remuneración recibida y calidad de la traducción realizada (véase bloque 2, pregunta 38), como se muestra en la siguiente tabla.

\begin{tabular}{|c|c|c|c|}
\hline \multicolumn{4}{|c|}{$\begin{array}{l}\text { 38. ¿La remuneración que percibe por parte del contratante influye en la calidad de la } \\
\text { traducción? }\end{array}$} \\
\hline \multicolumn{4}{|c|}{ 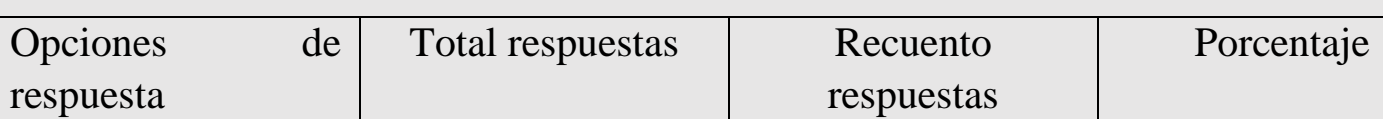 } \\
\hline \multicolumn{4}{|c|}{\begin{tabular}{|l|l|l|l} 
No & 8 & 8 & $100 \%$ \\
\end{tabular}} \\
\hline Sí & 8 & 0 & $0,0 \%$ \\
\hline A veces & 8 & 0 & $0,0 \%$ \\
\hline
\end{tabular}

Tabla 36. Remuneración/Calidad

Como se puede apreciar, los traductores opinan por unanimidad que la profesionalidad y la calidad de la traducción realizada no están relacionadas con la remuneración que recibe el traductor audiovisual, dado que el 100\% de los participantes en la encuesta contestaron negativamente a esta pregunta.

Conscientes de las dificultades que pueden presentarse en esta profesión, se consideró oportuno cuestionar el grado de satisfacción por la labor que realizan los encuestados. En este sentido, se planteó la siguiente pregunta (véase bloque 2, pregunta 39):

\begin{tabular}{|l|l|l|l|}
\hline \begin{tabular}{l} 
39. ¿Está contento con la profesión que ejerce? \\
\hline $\begin{array}{l}\text { Opciones de } \\
\text { respuesta }\end{array}$
\end{tabular} Total respuestas & $\begin{array}{l}\text { Recuento } \\
\text { respuestas }\end{array}$ & Porcentaje \\
\hline
\end{tabular}




\begin{tabular}{|l|c|c|c|}
\hline Sí & 8 & 8 & $100 \%$ \\
\hline No & 8 & 0 & $0, \%$ \\
\hline
\end{tabular}

Tabla 37. Profesión/Satisfacción

Como se observa una vez más, la selección de la respuesta a la pregunta fue unánime: todos los profesionales que participaron en la encuesta contestaron con un valor de $100 \%$ de forma afirmativa, y además uno añadió el siguiente comentario:

\section{Comentarios}

Amo mi profesión.

Sin embargo, el reconocimiento socioprofesional de esta labor no siempre está de acuerdo con las expectativas de los profesionales que la ejercen. Por ello, en la siguiente pregunta interrogamos sobre si cambiarían la actividad que realizan en la actualidad (véase bloque 2, pregunta 40).



Figura 31. Cambio de profesión ${ }^{68}$

En la Figura 31 se puede observar que hay una pequeña variación en las respuestas, puesto que, del total de los encuestados, un 12,5\% cambiaría esta profesión por otra. Sin embargo, un porcentaje muy considerable $(87,5 \%)$ de los traductores

\footnotetext{
${ }^{68}$ Figura 31. Cambio de profesión $\rightarrow{ }^{*} \mathrm{Da}=\mathrm{Sí} ;{ }^{*} \mathrm{Nu}=$ No.
} 
conservarían la labor que desempeñan actualmente. El comentario adicional que recogimos fue el siguiente:

\section{Comentarios}

Como traductor (y apasionado) de las películas, NO; como traductor de modo general, SÍ.

En cuanto a la valoración del trabajo del traductor audiovisual en Rumanía (véase bloque 2, pregunta 41), tal como observamos en la Figura 32, la gran mayoría de encuestados $(87,5 \%)$ considera que esta profesión no recibe la consideración adecuada en este país, mientras que el $12,5 \%$ estima lo contrario.



Figura 32. Valoración social de la profesión ${ }^{69}$

Algunos de los comentarios recogidos en la encuesta y en las entrevistas ayudan a interpretar los datos recabados. Se puede observar que el problema común que destacan los traductores está relacionado con la exigua retribución que reciben por los encargos, así como con los elevados estándares de calidad que se les exigen, y con la valoración profesional de esta labor actualmente en Rumanía:

\section{Comentarios \\ Está muy mal pagada.}

${ }^{69}$ Figura 32. Valoración social de la profesión $\rightarrow{ }^{*} \mathrm{Nu}=$ No; ${ }^{*} \mathrm{Da}=$ Sí. 
Porque todo el mundo considera que "cualquier persona puede hacer esto".

Insuficientemente pagada y poco apreciada, dado que Internet está lleno de subtitulaciones anónimas y de poca calidad.

Las tarifas son bastante pequeñas, y no solamente en Rumanía, sino también a nivel internacional.

Remuneración disconforme al volumen de trabajo, grado de dificultad, por tanto estándares internacionales de retribución.

Traductor 1: Muchas veces una larga carrera puede ser un impedimento, porque prefieren estudiantes que realizan la traducción gratis para acumular experiencia, o por sumas mиy pequeñas de dinero. También las empresas se imaginan que yo cobraría precios elevados, lo que es una equivocación en todos los casos.

Traductor 2: Posiblemente hay muchos traductores jóvenes, que se quieren dedicar a esta profesión y aceptan trabajar por muy poco dinero. Exigen calidad, pero bajo coste.

Traductor 3: [...] Creo que la profesión de traductor audiovisual se tiene que valorar con más respeto, porque es una profesión complicada y muy importante teniendo en cuenta el número elevado de productos subtitulados y doblados actualmente.

Tal y como comentaban anteriormente algunos de nuestros encuestados, la facilidad de acceso a las nuevas tecnologías puede perjudicar esta profesión en varios aspectos. Por tanto, la siguiente y última pregunta de este bloque la formulamos en este sentido (véase bloque 2, pregunta 42):

\begin{tabular}{|l|c|c|c|}
\hline \multicolumn{4}{|l|}{ 42. Considera que la piratería influye en: (puede marcar más de una opción) } \\
\hline $\begin{array}{l}\text { Opciones de } \\
\text { respuesta }\end{array}$ & Total respuestas & $\begin{array}{l}\text { Recuento } \\
\text { respuestas }\end{array}$ & Porcentaje \\
\hline $\begin{array}{l}\text { El volumen de } \\
\text { trabajo }\end{array}$ & 8 & 3 & $37,5 \%$ \\
\hline Otros & 8 & 3 & $37,5 \%$ \\
\hline La imagen social & 8 & 2 & $25,0 \%$ \\
\hline
\end{tabular}




\begin{tabular}{|l|c|c|c|}
\hline $\begin{array}{l}\text { Las condiciones } \\
\text { laborales }\end{array}$ & 8 & 1 & $12,5 \%$ \\
\hline
\end{tabular}

Tabla 38. Influencia de la piratería

Como podemos apreciar en la tabla anterior, la mayor preocupación $(37,5 \%)$ que puede originar la piratería a este gremio en Rumanía es la de disminuir el volumen de trabajo y por tanto, influir en las condiciones laborales (12,5\%). Asimismo, puede tener impacto en la imagen social (25\%), puesto que las traducciones que se publican en Internet carecen de autor y, por tanto, se le pueden atribuir a cualquiera de los traductores profesionales que ejerce en este país. Por último, un 37,5\% de los traductores añaden dos comentarios para justificar su respuesta, en el apartado de "Otros".

\begin{tabular}{|l|}
\hline Comentarios \\
\hline No influye. \\
\hline La comprensión de la película, porque existen todo tipo de traducciones fantasiosas. \\
\hline
\end{tabular}

Como primera conclusión del segundo bloque de preguntas, dedicado a la valoración profesional de este gremio en Rumanía, hemos podido observar que la calidad de la traducción es un componente importante en la labor de este gremio, dado que, en su opinión, está relacionada con el éxito del producto audiovisual en la lengua meta.

En cuanto al reconocimiento público, los traductores que han participado a nuestra encuesta lo han recibido mayoritariamente, no obstante, solamente uno ha concretado de qué tipo ha sido.

Asimismo, opinan que la remuneración que reciben habitualmente es insuficiente, dadas las condiciones laborales, pero piensan que no influye ni en su profesionalidad ni en la calidad del producto (y uno de ellos especifica en este sentido que "ama" su profesión).

Desde el punto de vista socioprofesional, los traductores audiovisuales de Rumanía están aún expectantes por regularizar las exigencias cualitativas de nivel internacional, que se les solicitan para realizar los encargos con la retribución exigua que reciben. 
Por otra parte, el desarrollo de las nuevas tecnologías marca un avance especialmente significativo para esta profesión, dado que estas constituyen una herramienta fundamental de su trabajo. Sin embargo, dichas tecnologías pueden llegar a constituir una preocupación, puesto que están al alcance de los no profesionales que realizan y publican traducciones "fantasiosas" de películas. Este hecho puede repercutir en su volumen de trabajo, sus condiciones laborales y su imagen social en este país.

\subsubsection{Valoración de la formación}

La formación específica de este tipo de traducción se imparte en Rumanía en algunas universidades (véase sección 3.5). Además, de acuerdo con lo revelado por los traductores audiovisuales participantes en la encuesta, muchos de ellos completan su formación previa realizando cursos en el extranjero. Por tanto, consideramos oportuno formular las preguntas del bloque 3 del cuestionario sobre este tema.

Como se explicó anteriormente, casi todos los traductores encuestados tenían formación académica de estudios filológicos. La primera pregunta que formulamos en este apartado es si los participantes consideran que la formación académica de que disponen es suficiente para desempeñar este trabajo (véase bloque 3, pregunta 43). Las respuestas que recibimos están repartidas de manera uniforme, puesto que el $50 \%$ consideran que sí, mientras que el restante 50\% considera que no (Figura 33). Recordemos también que un número bastante elevado opinaba que la experiencia puede suplir la falta de formación específica. En consecuencia, podemos deducir que los traductores que contestaron de forma afirmativa a esta pregunta se encuentran entre ellos, de acuerdo con los comentarios que aparecen después de la figura. 


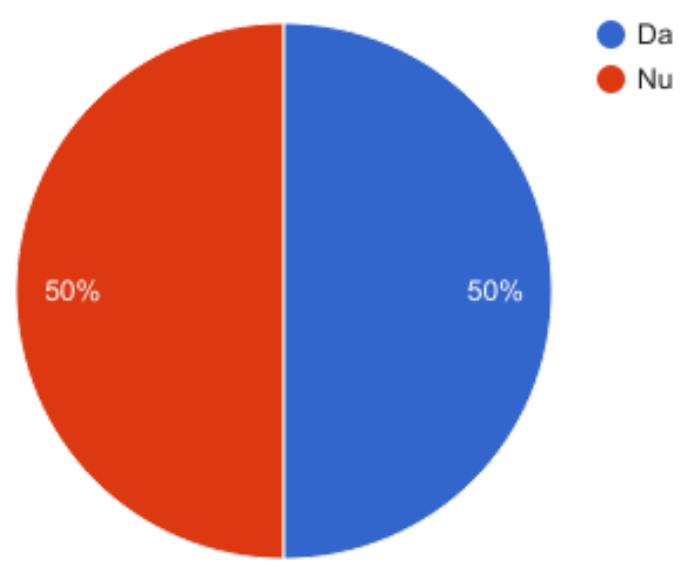

Figura 33. Valoración de la formación académica ${ }^{70}$

\section{Comentarios}

Independientemente de los estudios universitarios específicos de la traducción en general, estos son suficientes solamente para traducir, no para realizar traducción audiovisual, la preparación en el lugar del trabajo es, bajo mi punto de vista, esencial para poder realizar traducción audiovisual.

Existe una parte técnica que la aprendes solo trabajando.

Porque interviene también la experiencia de más de 30 años (15000 películas visionadas, 5000 dobladas y 1000 subtituladas).

Además, los datos cualitativos recabados en las entrevistas confirman los datos expuestos anteriormente:

Traductor 2: Tuve que elegir una nueva compañera y tuve que examinarla. $Y$, pese a que había hecho una traducción muy bonita, natural del texto en la lengua rumana, en la parte técnica no sabía ni siquiera hacer un pautado, introducir los subtítulos. No podía comprender que una réplica entra donde se escucha. No pudo hacer la parte técnica. Esto es muy importante, si no sabes, no sirve de nada traducir muy, muy bien. Muchos no entienden la parte técnica de la subtitulación, que tú tienes una parte muy pequeña de tiempo y tienes que sintetizar el contenido. Que el subtítulo entra donde y cuando se necesita, ni antes ni después. [...] Creo

\footnotetext{
${ }^{70}$ Figura 33. Valoración de la formación académica $\rightarrow{ }^{*} \mathrm{Da}=\mathrm{Sí} ;{ }^{*} \mathrm{Nu}=$ No.
} 
que se necesita talento y mucha práctica. Son muchas cosas que aprendes practicando.

Traductor 3: Evidentemente, teniendo en cuenta que existen muchas personas que piensan que saben realizar la traducción audiovisual, aunque no tienen ni la experiencia, ni los conocimientos teóricos para ejercer esta profesión. El público tiene que recibir solamente traducciones de calidad, realizadas por profesionales de este ámbito, pero la profesionalidad se puede obtener después de muchos años de experiencia o formándose mediante cursos específicos.

Dada la evolución continúa de las herramientas que se emplean en esta profesión, en la siguiente pregunta planteamos si consideran necesaria una formación permanente en este ámbito. Como podemos comprobar en la Figura 34, el 62,5\% de los encuestados afirman que es necesaria una formación constante para realizar este tipo de traducción, mientras que un $37,5 \%$ opina que no (véase bloque 3 , pregunta 44 ).

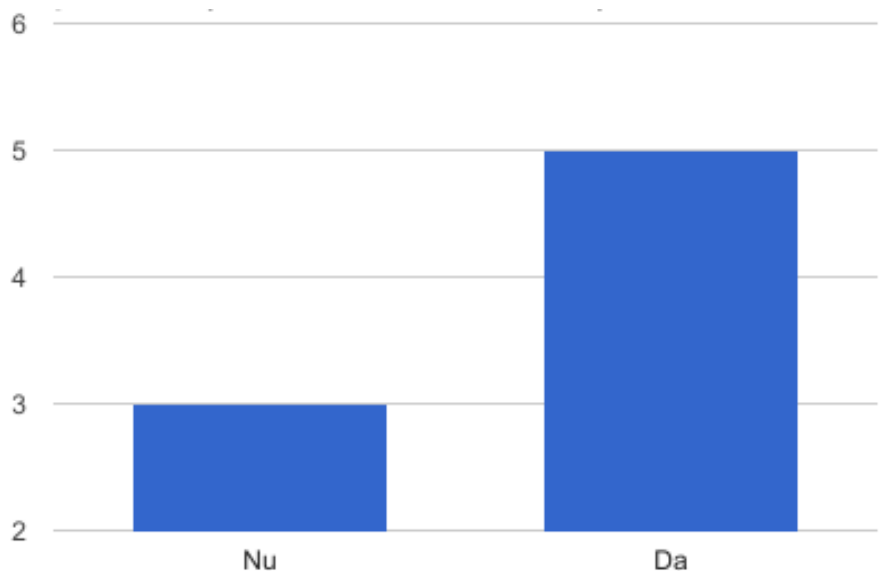

Figura 34. Formación permanente ${ }^{71}$

Los comentarios que algunos de los traductores han redactado para justificar la elección de la respuesta sostienen los datos recabados:

Comentarios

No permanente, pero es necesaria al principio de esta profesión.

\footnotetext{
${ }^{71}$ Figura 34. Formación permanente $\rightarrow \mathrm{Nu}=\mathrm{No}$; $\mathrm{Da}=$ Sí.
} 
Para tener acceso a las novedades e implementarlas en el trabajo.

Esta profesión supone un cambio y una evolución continúa, de los subtítulos escritos a mano a los subtítulos electrónicos.

En cuanto al número y al tipo de cursos de traducción audiovisual que existen actualmente en Rumanía (resultados en la Figura 35), un 85,7\% de los encuestados considera que no son suficientes para este tipo de traducción. Sin embargo, el 14,3\% valora de forma positiva la formación actual que se imparte en algunas universidades (véase bloque 3, pregunta 45).



Figura 35. Número adecuado de cursos específicos ${ }^{72}$

Como en el caso de otras preguntas, los comentarios que algunos participantes han formulado justifican sus respuestas:

\begin{tabular}{|l|}
\hline Comentarios \\
\hline Sí, pero la experiencia es muy importante. \\
\hline Los cursos universitarios son pocos e incompletos. \\
\hline $\begin{array}{l}\text { Existe solamente un curso impartido por la Facultad de Inglés (Bucarest), pero no muy } \\
\text { amplio. }\end{array}$ \\
\hline Existen solamente en algunas ciudades y muchas veces no son accesibles para todos. \\
\hline
\end{tabular}

${ }^{72}$ Figura 35. Número adecuado de cursos específicos $\rightarrow{ }^{*} \mathrm{Nu}=\mathrm{No} ;{ }^{*} \mathrm{Da}=$ Sí. 
No he cursado y tampoco sé si existen este tipo de cursos.

Como se aprecia en los comentarios, los cursos específicos de traducción audiovisual que existen actualmente en Rumanía son escasos, dado que algunos de los encuestados desconocen su existencia. Además, los que se imparten parece que no aportan la información y la preparación necesaria para este tipo de traducción, tal como se expone en algunos comentarios:

Traductor 1: Son insuficientes, te lo puedo asegurar, pero por otra parte tampoco existe un mercado adecuado para este tipo de profesión. Los alumnos realizan unos cursos, [...] en uno por ejemplo he impartido yo también una master class en Bucarest. Los alumnos acumulan muchos conocimientos, pero no los pueden poner en práctica más tarde porque este mundo de la traducción audiovisual es, relativamente, un mundo cerrado. Es muy difícil entrar en este círculo...

Traductor 2: No sé si existe alguno. Yo he ganado experiencia en el puesto de trabajo. Todo lo que he aprendido en la parte práctica de esta profesión, es porque he trabajado. No he hecho ningún curso específico de traducción audiovisual, empecé a trabajar y utilicé diferentes programas de subtitulación, aprendí la parte práctica, lo que tienes que hacer, lo que tienes que evitar...

Traductor 3: Seguramente no existen bastantes cursos para formarse en esta profesión.

Otro componente importante para impartir los cursos es proporcionar a los estudiantes equipos técnicos adecuados, y por tanto se decidió preguntar si las universidades están preparadas en este sentido (véase bloque 3, pregunta 46). 


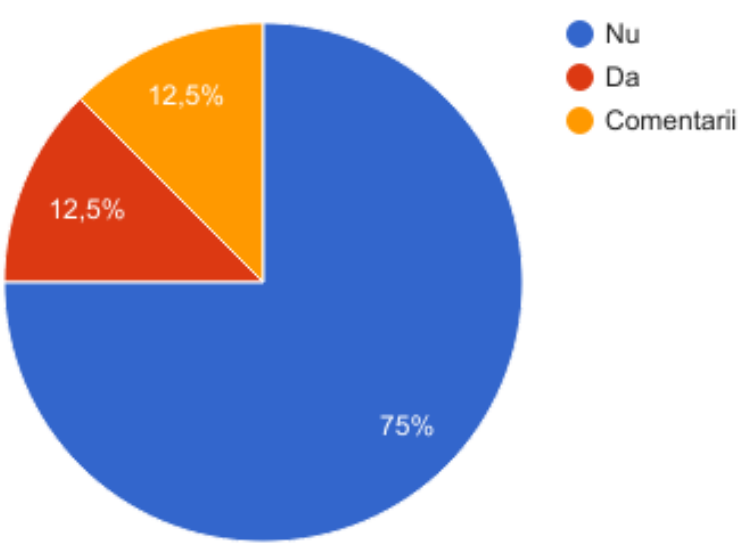

Figura 36. Valoración de los equipos técnicos de los cursos universitarios ${ }^{73}$

Tal como se observa en la anterior figura, el $75 \%$ de los traductores de textos audiovisuales encuestados consideran que las universidades que imparten estos cursos en Rumanía no tienen equipos técnicos adecuados. Otro 12,5\% estima que sí, mientras que el $12,5 \%$ restante prefiere comentar esta situación de la siguiente manera:

\begin{tabular}{|l|}
\hline Comentarios \\
\hline No conozco la situación general. \\
\hline Por falta de presupuesto. \\
\hline $\begin{array}{l}\text { No todas las universidades tienen la capacidad técnica y los recursos humanos } \\
\text { necesarios para preparar los traductores audiovisuales. }\end{array}$ \\
\hline
\end{tabular}

Además, uno de los tres profesionales entrevistados vinculado a este ámbito nos corroboró los comentarios anteriores:

Traductor 3: [...] En Rumanía, seguramenete se podría mejorar la dotación técnica.

Uno de los factores más importantes del proceso de enseñanza orientada a la traducción audiovisual es indudablemente el docente. Por tanto, la última pregunta de esta sección está dedicada a la valoración académica (véase bloque 3, pregunta 47). Así, se

\footnotetext{
${ }^{73}$ Figura 36. Valoración de los equipos técnicos de los cursos universitarios $\rightarrow{ }^{*} \mathrm{Nu}=\mathrm{No}$; ${ }^{*} \mathrm{Da}=\mathrm{Sí} ;{ }^{*}$ Comentarii $=$ Comentarios. 
preguntó a los profesionales si consideran que los profesores que imparten este tipo de formación tienen la preparación necesaria.

47. ¿Considera que los profesores que imparten este tipo de formación tienen la preparación necesaria?

\begin{tabular}{|l|c|c|c|}
\hline $\begin{array}{l}\text { Opciones } \\
\text { respuesta }\end{array}$ & de & $\begin{array}{c}\text { Recuento } \\
\text { respuestas }\end{array}$ & Porcentaje \\
\hline Sí & 8 & 2 & $25,0 \%$ \\
\hline No & 8 & 2 & $25,0 \%$ \\
\hline
\end{tabular}

Tabla 39. La formación de los docentes

Podemos observar que las opiniones están igualmente repartidas, puesto que tenemos un porcentaje idéntico del $25 \%$ en las dos opciones de respuesta ofrecidas. Sin embargo, llama la atención que el 50\% de los encuestados prefirieron no contestar o valorar esta pregunta, aunque casi todos los traductores manifestaron su opinión en el apartado de comentarios:

\begin{tabular}{|l|}
\hline Comentarios \\
\hline No conozco profesores que impartan estos cursos. \\
\hline No lo sé. \\
\hline Los profesores sí, pero no disponen de los equipos técnicos necesarios. \\
\hline Depende de cada caso. \\
\hline Sí, porque tienen experiencia profesional. \\
\hline $\begin{array}{l}\text { La mayoría de los profesores son o pueden ser muy buenos traductores de textos } \\
\text { literarios, técnicos, etc., pero las traducciones audiovisuales son de otro ámbito, que } \\
\text { solo puedes conocer después de varios de experiencia, algo que ellos no tienen. La } \\
\text { traducción audiovisual es muy diferente de la traducción literaria. }\end{array}$ \\
\hline
\end{tabular}

Los comentarios son diversos y tal como comentaba uno de los encuestados "depende de cada caso", dado que principalmente se enfatiza la necesidad de experiencia 
profesional para impartir estos cursos y, además, equipos técnicos adecuados que se emplean en la traducción audiovisual.

Entre las conclusiones de este apartado, dedicado a la valoración académica por parte de la profesión, hemos podido observar que la evaluación de la necesidad de los cursos específicos de la traducción audiovisual presenta una distribución uniforme entre las opiniones afirmativa y negativa. Sin embargo, la mitad de los encuestados opina que la práctica puede suplir la preparación técnica que se imparte en algunos cursos universitarios.

En cuanto a la oferta de estos cursos que existen y se imparten actualmente en Rumanía, la mayoría considera que es insuficiente. Además, un porcentaje escaso de traductores, a pesar de tener una larga trayectoria en este ámbito, desconoce la existencia de este tipo de formación o la considera inaccesible, especialmente por motivos geográficos o económicos.

Dado que los dos factores fundamentales que pueden tener impacto en la viabilidad de los cursos son la parte técnica y la parte docente, se ha podido comprobar que la adecuación técnica también podría suponer un problema por falta de presupuesto, y por tanto puede incapacitar la implementación práctica. En cuanto a los docentes de dichos cursos, de nuevo sucede que la escasez técnica influye en la calidad del curso, e implícitamente puede tener impacto también en la evaluación del docente.

\subsubsection{Competencias}

Como expusimos en el epígrafe 3.6 de este estudio, las competencias son habilidades fundamentales que un traductor audiovisual necesita para desarrollar esta profesión a nivel experto. Por tanto, consideramos relevante indagar sobre las competencias específicas y genéricas que definen a este gremio en Rumanía, y cuyas preguntas componen el bloque final de nuestra encuesta.

\subsubsection{Competencias específicas ${ }^{74}$}

Teniendo en cuenta la complejidad de la profesión del traductor de textos audiovisuales, ¿qué cualidades y destrezas específicas considera que son imprescindibles para ser un

\footnotetext{
${ }^{74}$ Retomadas del trabajo sobre didáctica de la traducción audiovisual en España de Cerezo Merchán (2012).
} 


\begin{tabular}{|c|c|c|c|}
\hline Opciones de respuesta & $\begin{array}{c}\text { Total } \\
\text { respuestas }\end{array}$ & $\begin{array}{l}\text { Recuento } \\
\text { respuestas }\end{array}$ & Porcentaje \\
\hline $\begin{array}{l}\text { 1. Conocimiento exhaustivo de la } \\
\text { lengua meta }\end{array}$ & 8 & 6 & $75,0 \%$ \\
\hline 5. Capacidad de síntesis y paráfrasis & 8 & 6 & $75,0 \%$ \\
\hline 2. Dominio de la lengua origen & 8 & 5 & $62,5 \%$ \\
\hline $\begin{array}{l}\text { 3. Buen conocimiento de las culturas } \\
\text { de trabajo }\end{array}$ & 8 & 5 & $62,5 \%$ \\
\hline 4. Creatividad lingüística & 8 & 5 & $62,5 \%$ \\
\hline $\begin{array}{l}\text { 9. Destrezas para realizar una sincronía } \\
\text { perfecta: lingüística e imagen }\end{array}$ & 8 & 2 & $25,0 \%$ \\
\hline $\begin{array}{l}\text { 10. Dominar las técnicas, estrategias y } \\
\text { terminología específicas de la } \\
\text { traducción audiovisual }\end{array}$ & 8 & 2 & $25,0 \%$ \\
\hline $\begin{array}{l}\text { 11. Dominio de estrategias de búsqueda } \\
\text { de recursos y documentación } \\
\text { específicos de la TAV }\end{array}$ & 8 & 2 & $25,0 \%$ \\
\hline $\begin{array}{l}\text { 12. Excelente manejo de programas } \\
\text { específicos de TAV (subtitulación, } \\
\text { doblaje, etc.) }\end{array}$ & 8 & 2 & $25,0 \%$ \\
\hline $\begin{array}{l}\text { 7. Conocimientos de las características } \\
\text { de diferentes géneros audiovisuales }\end{array}$ & 8 & 1 & $12,5 \%$ \\
\hline $\begin{array}{l}\text { 8. Capacidad de comunicación escrita } \\
\text { para redactar traducciones adecuadas }\end{array}$ & 8 & 1 & $12,5 \%$ \\
\hline $\begin{array}{l}\text { 13. Conocimiento de principios } \\
\text { metodológicos y de aspectos } \\
\text { profesionales que rigen la TAV }\end{array}$ & 8 & 1 & $12,5 \%$ \\
\hline $\begin{array}{l}\text { 6. Comprender la especificidad del } \\
\text { texto audiovisual por la interacción de } \\
\text { diferentes códigos semióticos }\end{array}$ & 8 & 0 & $0,0 \%$ \\
\hline $\begin{array}{l}\text { 14. Conocimiento de las características } \\
\text { y convenciones de la traducción } \\
\text { audiovisual }\end{array}$ & 8 & 0 & $0,0 \%$ \\
\hline $\begin{array}{l}\text { 15. Conocimiento de los aspectos } \\
\text { económicos, profesionales y del } \\
\text { mercado }\end{array}$ & 8 & 0 & $0,0 \%$ \\
\hline 16. Otros (especifique por favor) & 8 & 0 & $0,0 \%$ \\
\hline
\end{tabular}


Como se puede apreciar en la tabla anterior, las competencias específicas señaladas por nuestros encuestados con un porcentaje más elevado (y bastante similar), son las siguientes:

1. Conocimiento exhaustivo de la lengua meta $(75,5 \%)$

5. Capacidad de síntesis y paráfrasis $(75,5 \%)$

2. Dominio de la lengua origen $(62,5 \%)$

3. Buen conocimiento de las culturas de trabajo $(62,5 \%)$

4. Creatividad lingüística $(62,5 \%)$

Empleando las categorías del modelo competencial de Kelly (2002) para englobar los resultados recogidos, podemos afirmar lo siguiente: observamos que las competencias que destacan son las de tipo comunicativo-textual, tanto en la lengua meta como el la lengua origen, y la capacidad de síntesis y paráfrasis, seguidas por las de tipo cultural, lo que implica un buen conocimiento de las culturas de trabajo; y finalmente, por las de tipo instrumental-profesional, como por ejemplo las destrezas para realizar una sincronía perfecta (diálogos e imagen), el dominio de las técnicas, estrategias y terminología específicas de la traducción audiovisual, el dominio de estrategias de búsqueda de recursos y documentación específicos de la TAV, así como el excelente manejo de programas específicos de TAV (subtitulación, doblaje, etc.).

\subsubsection{Competencias genéricas ${ }^{75}$}

Teniendo en cuenta la complejidad de la profesión del traductor de textos audiovisuales, ¿qué cualidades y destrezas genéricas considera que son imprescindibles para ser un buen profesional? Marque cinco competencias genéricas que considera fundamentales para ejercer esta profesión.

\begin{tabular}{|l|c|c|c|}
\hline Opciones de respuesta & $\begin{array}{c}\text { Total } \\
\text { respuestas }\end{array}$ & $\begin{array}{c}\text { Recuento } \\
\text { respuestas }\end{array}$ & Porcentaje \\
\hline $\begin{array}{l}\text { 11. Capacidad para trabajar bajo } \\
\text { presión temporal }\end{array}$ & $\mathbf{8}$ & $\mathbf{7}$ & $\mathbf{8 7 , 5 \%}$ \\
\hline 4. Preocupación por la calidad & $\mathbf{8}$ & $\mathbf{5}$ & $\mathbf{6 2 , 5 \%}$ \\
\hline 15. Rápida resolución de problemas & $\mathbf{8}$ & $\mathbf{5}$ & $\mathbf{6 2 , 5 \%}$ \\
\hline
\end{tabular}

${ }^{75}$ Procedentes del Proyecto Tuning (2003). 


\begin{tabular}{|l|c|c|c|}
\hline 5. Capacidad crítica y autocrítica & $\mathbf{8}$ & $\mathbf{4}$ & $\mathbf{5 0 , 0 \%}$ \\
\hline $\begin{array}{l}\text { 7. Habilidad para buscar y analizar } \\
\text { información procedente de diversas } \\
\text { fuentes }\end{array}$ & $\mathbf{8}$ & $\mathbf{4}$ & $\mathbf{5 0 , 0 \%}$ \\
\hline $\begin{array}{l}\text { 13. Capacidad para adecuarse a los } \\
\text { requisitos del encargo }\end{array}$ & $\mathbf{8}$ & $\mathbf{4}$ & $\mathbf{5 0 , 0 \%}$ \\
\hline $\begin{array}{l}\text { 1. Capacidad de análisis } \\
\text { 2. Capacidad de aprender }\end{array}$ & 8 & 3 & $37,5 \%$ \\
\hline $\begin{array}{l}\text { 3. Capacidad de aplicar el conocimiento } \\
\text { a la práctica }\end{array}$ & 8 & 1 & $12,5 \%$ \\
\hline $\begin{array}{l}\text { 6. Conocimientos de la profesión y la } \\
\text { situación del mercado del trabajo }\end{array}$ & 8 & 1 & $12,5 \%$ \\
\hline 14. Espíritu negociador & 8 & 1 & $12,5 \%$ \\
\hline 8. Trabajar en equipo & 8 & 0 & $0,0 \%$ \\
\hline 9. Capacidad para motivar y liderar & 8 & 0 & $0,0 \%$ \\
\hline $\begin{array}{l}\text { 10. Capacidad para formular y gestionar } \\
\text { proyectos }\end{array}$ & 8 & 0 & $0,0 \%$ \\
\hline 12. Compromiso ético & 8 & 1 & $12,5 \%$ \\
\hline 16. Otros (especifique por favor) & 8 & $0,0 \%$ \\
\hline
\end{tabular}

Tabla 41. Competencias genéricas traductores

\section{Comentarios}

Conexiones de ideas y capacidad de adaptación.

Tal como se puede apreciar en la tabla anterior, las competencias genéricas destacadas por los traductores audiovisuales son las siguientes:

11. Capacidad para trabajar bajo presión temporal $(87,5 \%)$

4. Preocupación por la calidad $(62,5 \%)$

15. Rápida resolución de problemas $(62,5 \%)$

5. Capacidad crítica y autocrítica $(50,0 \%)$

7. Habilidad para buscar y analizar información procedente de diversas fuentes $(50,0 \%)$

13. Capacidad para adecuarse a los requisitos del encargo $(50,0 \%)$ 
La primera que destaca (87,5\%), y que además identifica la actividad que realiza este grupo de profesionales, es la capacidad para trabajar bajo presión temporal. Las siguientes competencias genéricas seleccionadas por los encuestados $(62,5 \%)$ son la preocupación por la calidad y la rápida resolución de problemas. Y por último, con un porcentaje del $50 \%$, se mencionan la habilidad para buscar y analizar información procedente de diversas fuentes, la capacidad crítica o autocrítica, y la capacidad para adecuarse a los requisitos del encargo. Las capacidades que adquieren menor importancia, en opinión de los traductores, son las relacionadas con el trabajo en equipo, capacidad para motivar y liderar, así como la capacidad para formular y gestionar proyectos o el compromiso ético.

Como conclusiones de este apartado dedicado a las competencias, hemos podido observar que entre las competencias específicas destaca el conocimiento exhaustivo de los dos idiomas de trabajo: la lengua meta y la lengua de origen. Asimismo, la siguiente competencia específica más señalada implica el conocimiento de las culturas implicadas, que aporta al profesional una capacidad de adaptación textual adecuada. A todo esto se integra, según la opinión de nuestros encuestados, la capacidad de síntesis y paráfrasis y la creatividad lingüística.

En cuanto a las capacidades genéricas, de acuerdo con los resultados, se distingue con un porcentaje elevado la capacidad para trabajar bajo presión temporal. Dadas las características laborales de esta profesión, este resultado no nos sorprende.

Las siguientes competencias seleccionadas son la preocupación por la calidad y la rápida resolución de problemas. Por último, destacan la capacidad crítica y autocrítica, junto a la capacidad para adecuarse a los requisitos del encargo y a la habilidad para buscar y analizar información de diversas fuentes.

En consecuencia, las competencias específicas y genéricas, anteriormente enunciadas, son las que caracterizan el grupo de profesionales de traductores audiovisuales que participaron en nuestra encuesta.

Como conclusiones generales del apartado 5.1, dedicado al análisis de las respuestas a la encuesta de los traductores de textos audiovisuales en Rumanía hemos podido observar que:

- La ubicación principal de los traductores audiovisuales en este país se divide entre Bucarest y la zona de Transilvania, donde se sitúa una de las más importantes empresas de distribución de productos audiovisuales extranjeros y doblaje. 
- Mayoritariamente, los traductores acreditan estudios que tienen como formación académica inicial la de origen filológico. Sin embargo, y especialmente mediante la experiencia profesional o por medio de cursos formativos dirigidos a este tipo de traducción, los profesionales perfeccionan la parte práctica, considerada fundamental en la traducción audiovisual.

- El número de traductores que ejerce esta profesión en régimen de freelancer es superior al número de profesionales contratados. No es un resultado sorprendente, dadas las características generales de esta profesión.

- En cuanto a los agentes que más solicitan este tipo de traducción, destacan las distribuidoras y las televisiones, tanto de Rumanía como del extranjero, puesto que los canales finales de distribución son las cadenas de televisión, el cine, los festivales o el DVD/ Blue-Ray, mientras que las combinaciones lingüísticas más usuales son inglés-rumano o francés-rumano.

- Generalmente, las normas o pautas y los programas específicos empleados para realizar el proceso de traducción audiovisual se proporcionan y vienen impuestos por las empresas empleadoras.

- Los materiales se suelen recibir por correo electrónico o File Transfer Protocol, y pueden materializarse en forma de guion, lista de diálogos o archivo audiovisual. Para realizar la traducción audiovisual, priman los diccionarios como materiales de apoyo, seguidos por los recursos terminológicos y especializados (bancos de datos terminológicos de temáticas y combinaciones lingüísticas distintas) o los recursos enciclopédicos.

- En cuanto a la valoración profesional, las características definidas generalmente por este gremio presentan las mismas particularidades y preocupaciones también para el grupo de traductores rumanos, como por ejemplo el trabajo bajo presión temporal, con altas exigencias de calidad, pero con una retribución no acorde con la labor realizada.

- La inexistencia en la actualidad en este país, de una asociación de traductores audiovisuales desampara este grupo, frente a las condiciones arbitrarias que imponen a veces algunas empresas empleadoras. Esto afecta especialmente a los derechos de autor, que se estipulan pero que no se respetan, o a las tarifas que varían en función de cada empleador y se aplican en diferentes formas: por minutos, horas, media hora, per film, por programa completo o por caracteres, 
pero siempre con un denominador común: precios bajos disimulados por medio de contratos de confidencialidad.

- El reconocimiento público tampoco es un factor extendido en esta profesión, pese a que la traducción de los productos audiovisuales extranjeros puede influir en su éxito en la lengua meta. Sin embargo, los traductores entrevistados dan prioridad a la calidad y la profesionalidad, a pesar de que el reconocimiento socioprofesional de esta labor no siempre es acorde a las expectativas de los profesionales que la ejercen.

- Respeto a la valoración de la formación: la escasez de cursos dirigidos a la traducción audiovisual (algunos de los encuestados desconocían esta modalidad formativa), se completa de algún modo con la experiencia que adquieren los traductores en las empresas donde ejercen la profesión. La falta de presupuesto se aprecia también en este ámbito, puesto que la preparación didáctica de los profesores no puede suplir los recursos técnicos inadecuados en algunos casos.

- En cuanto las competencias específicas y genéricas que los traductores encuestados han considerado fundamentales para desarrollar esta profesión, hemos podido observar que son las siguientes:

- Competencias específicas

$\checkmark$ 1. Conocimiento exhaustivo de la lengua meta $(75,5 \%)$

$\checkmark \quad$ 5. Capacidad de síntesis y paráfrasis $(75,5 \%)$

$\checkmark$ 2. Dominio de la lengua origen $(62,5 \%)$

$\checkmark$ 3. Buen conocimiento de las culturas de trabajo (62,5\%)

$\checkmark$ 4. Creatividad lingüística $(62,5 \%)$

- Competencias genéricas

$\checkmark$ 11. Capacidad para trabajar bajo presión temporal (87,5\%)

$\checkmark$ 4. Preocupación por la calidad $(62,5 \%)$

$\checkmark$ 15. Rápida resolución de problemas $(62,5 \%)$

$\checkmark$ 5. Capacidad crítica y autocrítica $(50,0 \%)$

$\checkmark$ 7. Habilidad para buscar y analizar información procedente de diversas fuentes $(50,0 \%)$

$\checkmark$ 13. Capacidad para adecuarse a los requisitos del encargo $(50,0 \%)$ 
En este apartado, dirigido a recabar información sobre el traductor audiovisual en Rumanía y su entorno laboral, hemos podido esbozar su perfil profesional por medio de la interpretación de los datos cuantitativos y cualitativos obtenidos mediante la encuesta y las entrevistas. No obstante, conscientes del número reducido de traductores que han respondido a la encuesta, no es nuestra intención generalizar los resultados. A través de los datos que mostramos, solo hemos intentado dar voz a un grupo de profesionales cuya situación profesional en la actualidad de este país consideramos imperante plasmar.

5.2. Análisis de datos e interpretación de resultados: empresas empleadoras de traductores audiovisuales

En este apartado expondremos los datos obtenidos en cada ítem de los cuestionarios que hemos realizado a las empresas empleadoras. Este cuestionario para empresas se compone de dos bloques. El primero incluye variables que definirán el perfil de la empresa y, por tanto, el perfil del traductor audiovisual al que contrata para realizar las traducciones de los productos audiovisuales extranjeros que distribuyen en el mercado rumano. El segundo aborda las competencias específicas y genéricas que los empleadores consideran esenciales para el profesional que realiza esta labor en Rumanía.

En la encuesta han participado voluntariamente 5 empresas de este país. El análisis de los datos cuantitativos que hemos recabado se complementará en algunas ocasiones con comentarios del cuestionario y con los datos cualitativos de la entrevista que hemos realizado durante la fase del estudio posterior a la encuesta, a una empresa que participó también en dicha encuesta.

\subsubsection{Perfil de la empresa}

5.2.1.1. Datos identificativos de la empresa

Consideramos que cualquier empresa del ámbito con una considerable experiencia en este mercado nos podría aportar datos valiosos sobre los profesionales que emplea para realizar la traducción audiovisual. Por tanto, la primera pregunta formulada en nuestra 
encuesta interrogaba sobre la antigüedad de la empresa en el mercado (en términos de años), y en consecuencia, sobre su experiencia en este ámbito (véase bloque 1, pregunta $1)$.

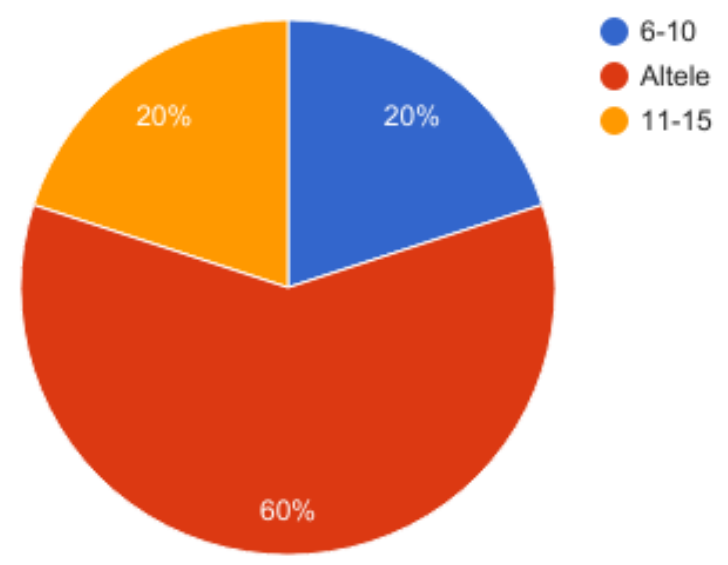

Figura 37. Antigüedad de la empresa en el mercado ${ }^{76}$

Podemos apreciar en la figura anterior que las empresas participantes en la encuesta están capacitadas para proporcionarnos la información que intentamos recabar mediante el cuestionario, puesto que el $20 \%$ lleva más de 10 años en el mercado rumano y entre el 60\% se incluyen las primeras que se constituyeron después del año 1989, y que, por tanto, cuentan con una antigüedad superior a los 20 años, tal como especificaron algunas en el apartado de "Otros".

\begin{tabular}{|l|}
\hline Comentarios \\
\hline Desde 1991. \\
\hline Desde 1996. \\
\hline
\end{tabular}

En cuanto a la ubicación de la empresa, todas las que participaron se sitúan en la capital (siguiente tabla), como suponíamos, de acuerdo con los datos que habíamos recopilado sobre la ubicación por parte de los traductores audiovisuales (véase bloque 1, pregunta 2).

\footnotetext{
${ }^{76}$ Figura 37. Antigüedad de la empresa en el mercado $\rightarrow{ }^{*} 6-10$ ani $=6-10$ años; $*$ Altele $=$ Otros; $*$ 11-15 ani $=11-15$ años. 


\begin{tabular}{|l|c|c|c|}
\hline 2. ¿En qué parte del país se ubica su empresa? \\
\hline Opciones de respuesta & $\begin{array}{c}\text { Total } \\
\text { respuestas }\end{array}$ & $\begin{array}{c}\text { Recuento } \\
\text { respuestas }\end{array}$ & Porcentaje \\
\hline Capital & 5 & 5 & $100 \%$ \\
\hline Muntenia & 5 & 0 & $0,0 \%$ \\
\hline Transilvania & 5 & 0 & $0,0 \%$ \\
\hline Oltenia & 5 & 0 & $0,0 \%$ \\
\hline
\end{tabular}

Tabla 42. Ubicación empresas

El tipo de clientes a los que prestan servicios dichas empresas es diverso (véase bloque 1, pregunta 3), tal como se puede apreciar en el siguiente gráfico:

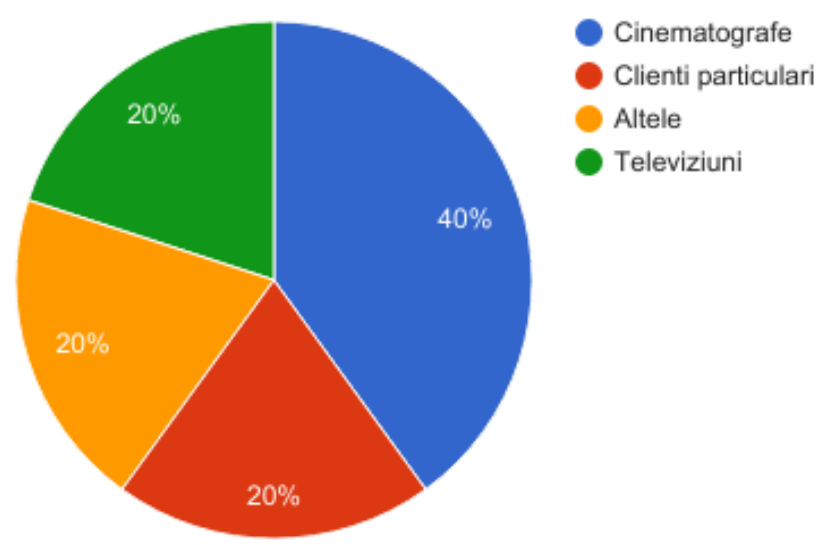

Figura 38. Tipo/s de empresa/s que suele/n solicitar su colaboración ${ }^{77}$

No obstante, podemos observar (Figura 38) que prevalecen los cines, con un 40\%, seguidos con un mismo porcentaje del $20 \%$ por las cadenas de televisión, los clientes particulares u otros tipos de clientes, que no se han especificado en la encuesta.

El número de empleados con que cuentan dichas empresas podría determinar, pensamos, la proporción de las actividades que realizan las empresas en el mercado rumano. Por ello, preguntamos en la encuesta por el número de empleados que tenían en plantilla (véase bloque 1, pregunta 4). Los resultados se muestran gráficamente en la siguiente figura, la Figura 39:

\footnotetext{
${ }^{77}$ Figura 38. Tipo/s de empresa/s que suele/n solicitar su colaboración $\rightarrow{ }^{*}$ Cinematografe $=$ Cines; $*$ Clienți particulari $=$ Clientes particulares; $*$ Altele $=$ Otros; $*$ Televiziuni $=$ Cadenas de televisión .
} 


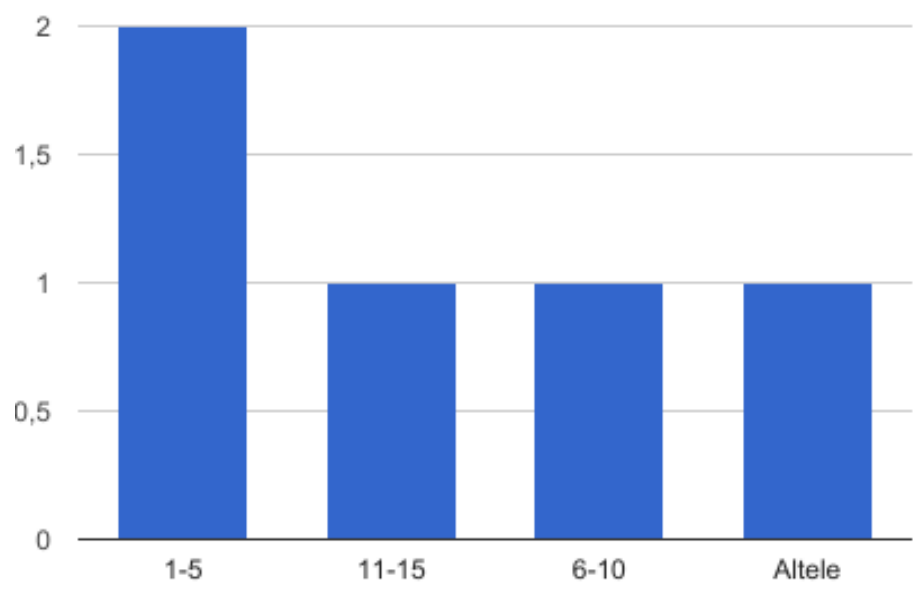

Figura 39. Número de empleados ${ }^{78}$

Como se puede observar, las respuestas revelan un número de trabajadores diverso, que va en proporción con la antigüedad en el mercado, según hemos podido comprobar al interpretar las respuestas del cuestionario.

A modo de conclusiones de este epígrafe, podemos apreciar que las empresas participantes en la encuesta tienen una amplia experiencia en el mercado rumano, dado que algunas se constituyeron muy poco tiempo después de la caída del régimen comunista (como por ejemplo, en los años 1992 o 1996). Sus ubicaciones coinciden con las localizaciones geográficas de los traductores, es decir, mayoritariamente en Bucarest. Esta coincidencia podría resultar un poco insólita, porque en la actualidad, y gracias a la accesibilidad y rapidez que ofrecen los soportes de Internet, el traductor audiovisual podría residir en cualquier parte del país, sin necesidad de esta proximidad geográfica a la empresa empleadora. En cuanto a los clientes que requieren los servicios de estas empresas, son principalmente los cines, seguidos por las cadenas de televisión y clientes particulares.

5.2.1.2. Relación con los traductores y las universidades

${ }^{78}$ Figura 39. Número de empleados $\rightarrow$ 1-5 angajați $=1-5$ empelados; $11-15$ angajați $=11-15$ empleados; $6-10$ angajați $=6-10$ empleados; Altele $=$ Otros . 
Puesto que el interés fundamental de nuestro estudio se dirige especialmente a los traductores audiovisuales en Rumanía, hemos utilizado esta pregunta para plantear a las empresas su relación con los traductores, tanto a nivel profesional como formativo.

Por tanto, la siguiente pregunta puede servir para definir la estabilidad laboral, que ofrecen las empresas a los traductores, es decir, si estos últimos trabajan en plantilla o si las primeras se ponen en contacto con ellos solo cuando tienen un encargo (véase bloque 1 , pregunta 5).

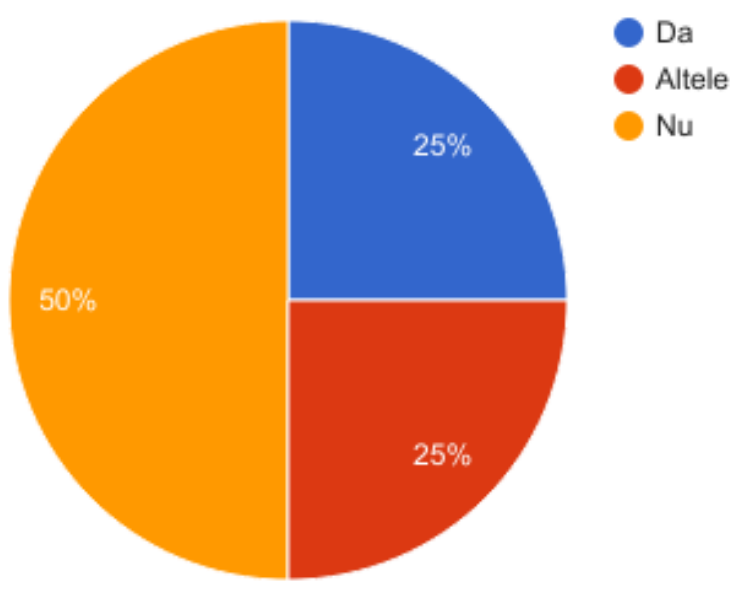

Figura 40. Traductores contratados ${ }^{79}$

Los resultados que se han obtenido se muestran en la Figura 40: el 50\% de las empresas encuestadas no tienen contratado permanentemente ningún traductor audiovisual. El 25\% de las empresas contestó afirmativamente (es decir, que sí lo tienen), mientras que el otro $25 \%$ contestó en la casilla de "Otros". Gracias a los comentarios que algunas empresas redactaron en este apartado, se puede observar que la mayoría de ellas solo solicitan las prestaciones de los traductores cuando las precisan:

\section{Comentarios}

Contactamos con los traductores cuando recibimos material para traducir.

No son empleados permanentes, solicitamos sus servicios cuando tenemos películas para traducir.

\footnotetext{
${ }^{79}$ Figura 40. Traductores contratados $\rightarrow{ }^{*} \mathrm{Da}=\mathrm{Sí} ;{ }^{*}$ Altele $=$ Otras; ${ }^{*} \mathrm{Nu}=$ No.
} 
La empresa no tiene traductores en la plantilla, solo colaboradores. Inicialmente teníamos traductores con contrato trabajando para esta empresa, pero desde el año 2003 hemos cesado los contratos con los traductores.

Podemos observar, por tanto, que la situación laboral de los traductores varía en función de la empresa y de la cantidad de trabajo, tal como precisa una de nuestras empresas entrevistadas:

Empresa entrevistada: Tenemos un traductor con el cual colaboramos, tenemos contrato directo con él, nuestro traductor trabaja con nosotros desde el inicio de nuestra empresa, desde el año 2010. De momento no necesitamos más, posiblemente en un futuro, si aumenta el número de películas que distribuimos, será necesario realizar más contratos.

Por lo que se refiere a los requisitos necesarios para contratar a un traductor de textos audiovisuales, hemos interrogado a las empresas sobre sus criterios de evaluación en función de la formación de los traductores, la experiencia, o ambas (véase bloque 1, pregunta 6). El resultado fue el que se muestra en la Figura 41: el 60\% de las empresas valora ambos aspectos, y el $40 \%$ valora solo la experiencia.

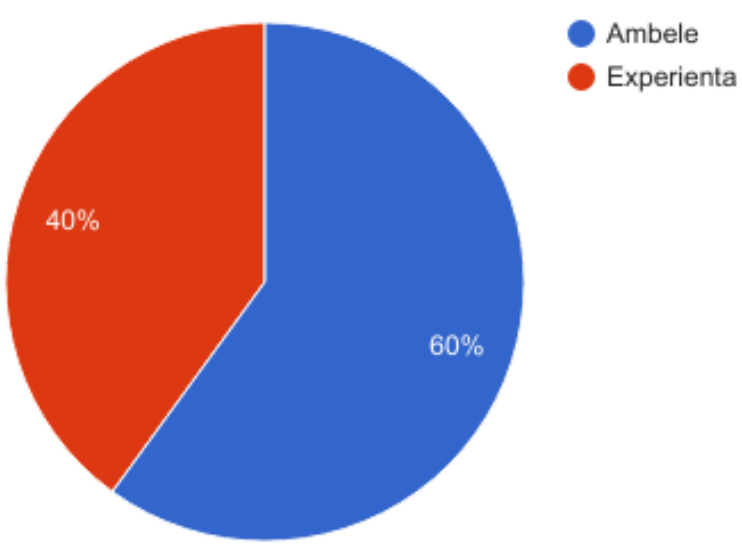

Figura 41. Tipo de requisitos ${ }^{80}$

${ }^{80}$ Figura 41. Tipo de requisitos $\rightarrow{ }^{*}$ Ambele $=$ Ambas; ${ }^{*}$ Experiența $=$ Experiencia. 
Se deduce, entonces, que las empresas no valoran tanto la formación como la experiencia. Esta afirmación se puede corroborar a tenor de lo que se expresó en los comentarios y también en la entrevista:

\section{Comentarios}

Traduciendo para numerosos programas, se necesitan conocimientos de varias áreas, entonces la formación universitaria en este perfil no es una condición necesaria, sino el conocimiento exhaustivo de la lengua rumana y de la lengua original del producto.

Empresa entrevistada: Cuenta muchísimo la experiencia, y en cierta medida también los estudios. Pero, como prueba, se le entrega una película y se correlaciona con la experiencia, comprobamos si la traducción nos gusta: suena bien, está correctamente escrita, el lenguaje es adecuado a la película. Son varios pasos los que seguimos, porque en la industria del filme los subtítulos y los caracteres se tienen que respetar, y también el tiempo, y el traductor tiene que tener experiencia, tiene que saber hacer esto porque si no, no puede realizar la traducción en la lengua rumana.

En cuanto a la forma de contratar a los traductores (los resultados de esta pregunta aparecen en la siguiente tabla, así como en los comentarios a continuación), el nivel de experiencia $(80 \%)$ es de nuevo el factor que tiene la mayor relevancia en el proceso. Estos datos son similares a los resultados que recabamos en los cuestionarios dirigidos a los traductores. Puesto que las empresas son las empleadoras, se puede entender la elección casi unánime de los traductores a la opción (similar) que se había propuesto en su encuesta (véase bloque 1, pregunta 7).

\begin{tabular}{|l|c|c|c|}
\hline 7. ¿De qué forma contrata a los traductores? \\
\hline Opciones de respuesta & $\begin{array}{c}\text { Total } \\
\text { respuestas }\end{array}$ & $\begin{array}{c}\text { Recuento } \\
\text { respuestas }\end{array}$ & Porcentaje \\
\hline Experiencia profesional & 5 & 4 & $80,0 \%$ \\
\hline Recepción de CV & 5 & 3 & $60,0 \%$ \\
\hline Recomendaciones & 5 & 3 & $60,0 \%$ \\
\hline
\end{tabular}




\begin{tabular}{|l|c|c|c|}
\hline Entrevista personal & 5 & 3 & $60,0 \%$ \\
\hline Otros & 5 & 1 & $20,0 \%$ \\
\hline
\end{tabular}

Tabla 43. Modalidad para contratar los traductores

\section{Comentarios}

La experiencia y la recomendación prima en este proceso. El traductor pasa una prueba y nosotros la revisamos, luego trabajamos con él, si todo está correcto.

Todos los traductores tienen que pasar una prueba, independientemente de la experiencia, el CV o las recomendaciones.

Según los comentarios de la empresa entrevistada, el número reducido de profesionales activos en esta área del mercado rumano permite a las empresas asociar la experiencia del traductor con su trabajo, lo que suele tener impacto en la selección:

Empresa entrevistada: Yo, personalmente, no he participado en la entrevista de nuestra traductora. Tenía una vasta experiencia de casi 14 años, que yo sepa en ese momento en el año 2010 no había muchos traductores audiovisuales en el mercado, especialmente en la capital, y prácticamente la oferta no era muy variada.

Se necesitaba experiencia cinematográfica, y como el mercado no era muy variado se sabía cómo iba cada uno, qué películas había traducido... no se ha entrevistado a muchas personas, pero yo no participé directamente.

Además del reducido número de profesionales, cabe destacar también el hermetismo de los traductores audiovisuales, tal como relataba uno de los entrevistados, en relación con la dificultad de poder ejercer esta profesión en el mercado rumano, incluso en el caso de que se disponga de experiencia profesional.

La siguiente pregunta está orientada a indagar sobre el porcentaje de empresas que dedica su actividad a otros tipos de encargos que no sean la traducción audiovisual (véase bloque 1, pregunta 8). En este sentido, el $80 \%$ de las empresas que participaron en nuestra 
encuesta se dedica únicamente a esta variedad de traducción, como se puede apreciar en la Figura 42.

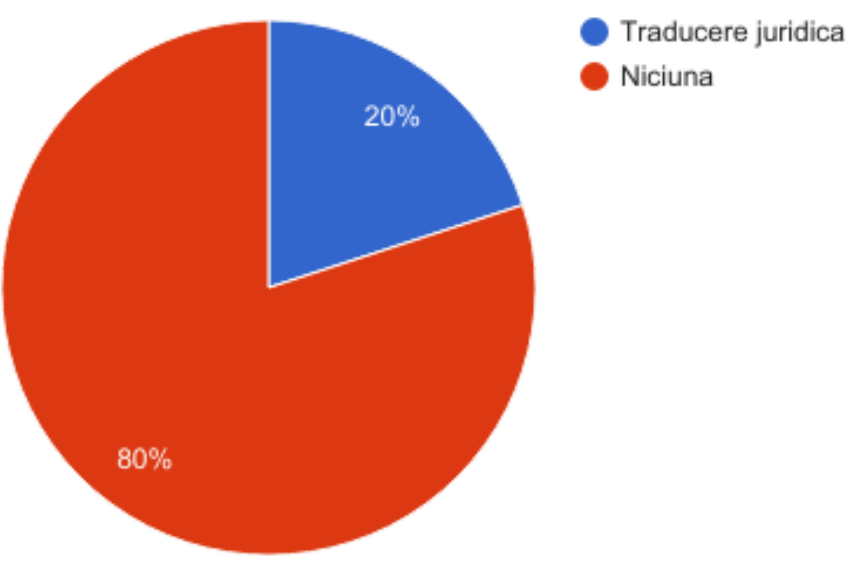

Figura 42. Otras variedades de traducción ${ }^{81}$

En cuanto al porcentaje de trabajo que las empresas encuestadas dedican solamente a la traducción audiovisual (véase bloque 1, pregunta 9), a la vista de las anteriores respuestas (Figura 42), de nuevo el $80 \%$ se dedican solamente a realizar este tipo de traducción, mientras que el $20 \%$ se dedica también a otros tipos de traducción.

A continuación, hemos decidido preguntar a las empresas sobre el tipo de público al que se dirigen con más frecuencia los productos audiovisuales extranjeros traducidos (véase bloque 1, pregunta 10). A la vista de los resultados, deducimos que los productos audiovisuales traducidos se dirigen tanto a los adultos como al público infantil, porque el $60 \%$ de las empresas se dedica a ambos grupos de destinatarios, mientras que en un porcentaje similar se dedica solamente al público adulto (20\%) o al público infantil $(20 \%)$.

${ }^{81}$ Figura 42. Otras variedades de traducción $\rightarrow{ }^{*}$ Traducere juridică $=$ Traducción jurídica; $*$ Nici una = Ninguna. 
4



Figura 43. El destinatario de los productos audiovisuales en la lengua meta ${ }^{82}$

En cuanto a la siguiente pregunta, que tiene que ver con las modalidades de traducción audiovisual más comunes (Figura 44), los resultados no son sorprendentes (véase bloque 1, pregunta 11). Los traductores audiovisuales ya habían destacado las mismas: la subtitulación y el doblaje. No obstante, podemos señalar que el doblaje (véase sección 2.1.2) podría reducir el monopolio de la subtitulación, tal como se puede observar en la siguiente figura, donde doblaje, y doblaje y subtitulación, comparten porcentajes $(40 \%)$.

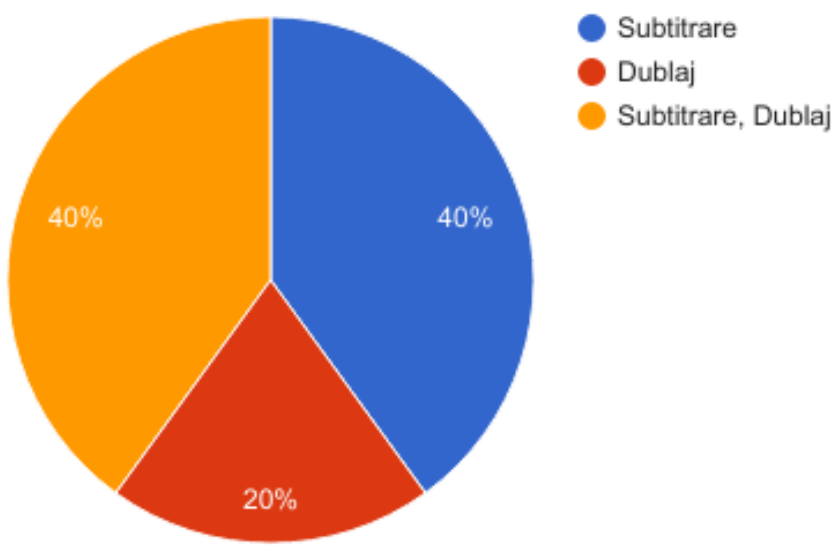

Figura 44. Modalidad de traducción audiovisual empleada ${ }^{83}$

\footnotetext{
${ }^{82}$ Figura 43. El destinatario de los productos audiovisuales en la lengua meta $\rightarrow$ Ambele $=$ Ambas; Adulți $=$ Adultos; Copii $\rightarrow$ Infantil.

${ }^{83}$ Figura 44. Modalidad de traducción audiovisual empleada $\rightarrow{ }^{*}$ Subtitrare $=$ Subtitulación; ${ }^{*}$ Dublaj = Doblaje; ${ }^{*}$ Subtitrare, Dublaj = Subtitulación, Doblaje.
} 
Sin embargo, parece que el proceso del doblaje conlleva la realización de otros tipos de acuerdos entre las empresas, más complejos que la subtitulación, tal como nos explica la empresa entrevistada:

Empresa entrevistada: Tenemos subtitulación y doblaje, de la subtitulación se encarga la traductora con la que colaboramos, y para el doblaje tenemos una empresa con la que colaboramos. Nuestra distribuidora tiene un contrato directamente con el estudio de doblaje. Entonces, por nuestra parte, no nos implicamos directamente en la parte de doblaje, en el sentido que el estudio de doblaje contacta directamente con Disney. Nosotros prácticamente vemos solo la versión final de la película.

Las combinaciones lingüísticas que se utilizan con más frecuencia (véase bloque 1, pregunta 12), de acuerdo con los datos que proporcionan las empresas (Tabla 45), son inglés-rumano y francés-rumano, seguidas por alemán-rumano y español-rumano. Este tipo de información era de esperar, puesto que los traductores audiovisuales encuestados habían marcado las mismas combinaciones. Asimismo, observamos que para el caso de las empresas ahora contemplado se añade también la combinación alemán-rumano, con un porcentaje del $40 \%$. No obstante, estos resultados muestran una oferta lingüística no excesivamente amplia, lo que a su vez podría restringir el mercado, y por lo tanto, la oferta en esta área profesional.

12. ¿En qué combinación lingüística, suele realizar las traducciones audiovisuales? (Puede marcar más de una opción)

\begin{tabular}{|l|c|c|c|}
\hline Opciones de respuesta & $\begin{array}{c}\text { Total } \\
\text { respuestas }\end{array}$ & $\begin{array}{c}\text { Recuento } \\
\text { respuestas }\end{array}$ & Porcentaje \\
\hline Inglés- Rumano & 5 & 5 & $100 \%$ \\
\hline Francés- Rumano & 5 & 3 & $60 \%$ \\
\hline Alemán-Rumano & 5 & 2 & $40 \%$ \\
\hline Español-Rumano & 5 & 1 & $20 \%$ \\
\hline Chino-Rumano & 5 & 0 & $0 \%$ \\
\hline
\end{tabular}


Tabla 44. Combinaciones lingüísticas

Dado que Rumanía es un país que consume una cantidad considerable de películas sudamericanas traducidas, decidimos preguntar específicamente por el uso de la combinación lingüística español-rumano, porque nos pareció extraño el porcentaje reducido en esta combinación recogido en los cuestionarios, tanto para las empresas como para los traductores. La respuesta siguiente destaca una vez más el predominio del inglés como lingua franca, pues la utilizan como relé para traducir al rumano otras lenguas:

Empresa entrevistada: No, no hemos tenido nunca esta combinación. Hemos distribuido la película Violeta pero el guion nos llegó en inglés, posiblemente el guion original se escribió en español, pero nosotros lo hemos recibido en inglés y que yo sepa los materiales internacionales circulan en inglés y nosotros los traducimos al rumano.

Los tipos de programas audiovisuales que se emplean para realizar la traducción audiovisual (véase bloque 1, pregunta 13) vienen determinados mayoritariamente por las empresas (80\%, Figura 45). Este alto porcentaje confirma los datos suministrados por los traductores cuando se les formuló la misma pregunta.

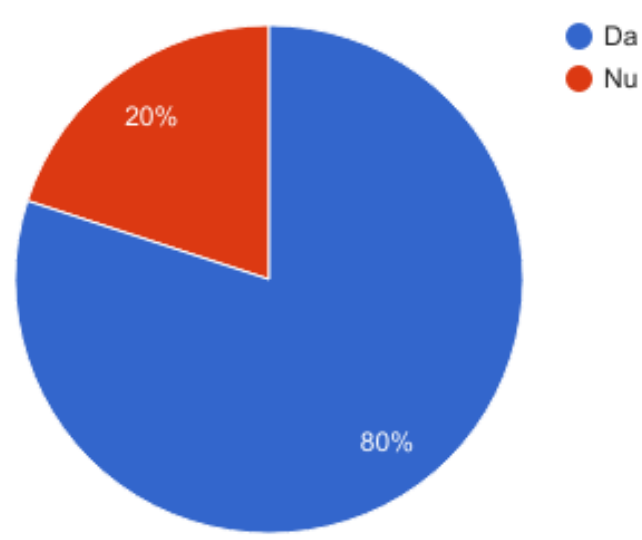

Figura 45. Los tipos de programa los impone la empresa ${ }^{84}$

${ }^{84}$ Figura 45. Los tipos de programa los impone la empresa $\rightarrow{ }^{*} \mathrm{Da}=\mathrm{Sí} ;{ }^{*} \mathrm{Nu}=\mathrm{No}$. 
En el apartado de comentarios correspondiente, algunos encuestados de los que contestaron negativamente han aportado algún comentario, donde se puede observar que no siempre es el traductor el que se encarga de la creación de los subtítulos:

\section{Comentarios}

Los traductores no necesitan programas especiales, solamente los editores que redactan los subtítulos. Los editores colaboradores utilizan programas especiales de la empresa o pueden elegir otros tipos de programas, con la condición que los ficheros obtenidos respeten las normas impuestas.

Asimismo, una empresa entrevistada ha explicado el proceso de traducción y los tipos de ficheros que se utilizan normalmente:

Empresa entrevistada: Del doblaje no nos encargamos nosotros, y para la subtitulación manda el estudio. Él impone un sistema online o simplemente prepara un Excel que se tiene que completar. La traductora se encarga de los ficheros finales, los ficheros traducidos en formato XML o RTF, que pueden ayudar a la realización de la copia final de la subtitulación.

Por lo que respecta a las restricciones o normas que reciben por parte de los clientes, la mayoría de las empresas (60\%) las impone siempre, y en un $40 \%$ de los casos las impone a veces, puesto que pueden varíar en función del encargo (véase bloque 1, pregunta 14).

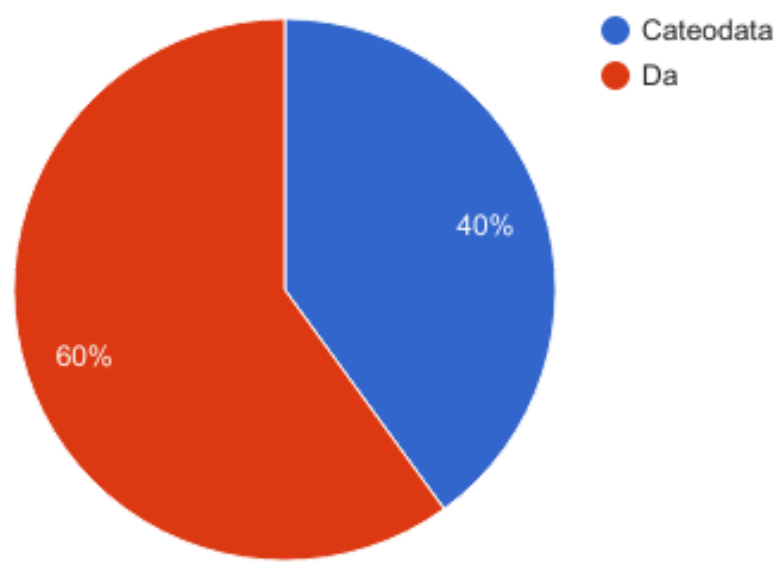

Figura 46. Los clientes imponen restricciones o normas ${ }^{85}$

${ }^{85}$ Figura 46. Los clientes imponen restricciones o normas $\rightarrow{ }^{*}$ Câteodată $=$ A veces; ${ }^{*}$ Da $=$ Sí. 
Sin embargo, en los comentarios asociados a la correspondiente pregunta podemos observar que estas normas tratan asuntos como el lenguaje utilizado en la lengua meta, indicaciones sobre títulos, canciones y nombres utilizados en los productos audiovisuales:

\begin{tabular}{|c|}
\hline Comentarios \\
\hline $\begin{array}{l}\text { Cuando se trata de películas inspiradas en libros, se mantiene el nombre de los } \\
\text { personajes, lugares u otras denominaciones que se transmiten en la lengua meta de la } \\
\text { misma forma. }\end{array}$ \\
\hline No poden \\
\hline $\begin{array}{l}\text { En general, en el caso de las películas dobladas la agencia colaboradora de la cual } \\
\text { recibimos la película establece la traducción de los nombres de los personajes; en } \\
\text { cuanto a las canciones, no se doblan, como mucho se subtitulan, pero solamente si son } \\
\text { relevantes para la narración cinematográfica. Evidentemente, las palabras vulgares no } \\
\text { se mencionan, se evitan parafraseándose para que el lenguaje no afecte la clasificación } \\
\text { que realiza el CNC (Centro Nacional de Cinematografía). El título lo traducimos } \\
\text { nosotros, no el traductor, y posteriormente lo enviamos a la agencia colaboradora para } \\
\text { aprobarlo. }\end{array}$ \\
\hline $\begin{array}{l}\text { Algunas cadenas no traducen los títulos en la lengua rumana, las canciones no se } \\
\text { traducen, solamente si son relevantes para la trama. Trabajando con más cadenas, sus } \\
\text { restricciones son diferentes. }\end{array}$ \\
\hline
\end{tabular}

Por lo que respecta a las restricciones que reciben las empresas por parte de los clientes (véase bloque 1, pregunta 15), estas se transmiten a su vez a los traductores, y se añade en algún caso alguna otra impuesta por la distribuidora o la empresa que se encarga de la difusión del material audiovisual extranjero en Rumanía (véase Figura 47). 


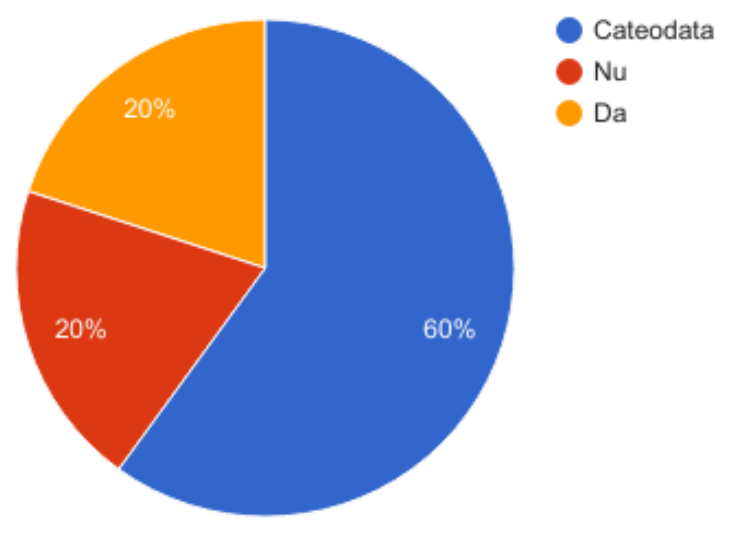

Figura 47. Las empresas imponen restricciones o normas a los traductores ${ }^{86}$

Tal como se especifica en algunos de los comentarios siguientes asociados a la pregunta, las restricciones pueden ser:

\begin{tabular}{|l|}
\hline Comentarios \\
\hline Depende de las demandas del estudio. \\
\hline No pueden utilizar palabras vulgares. \\
\hline $\begin{array}{l}\text { Sí, los traductores reciben algunas restricciones, pero la mayoría esta impuestas por los } \\
\text { clientes (por ejemplo evitar las palabras vulgares en las programas con audiencia } \\
\text { general) y otras impuestas por la política editorial de la empresa (por ejemplo aunque } \\
\text { la palabra "orgánico" se utiliza en muchos casos con el significado de "bio", nosotros } \\
\text { no la utilizamos porque hasta ahora no está registrada en el diccionario con este } \\
\text { significado). }\end{array}$ \\
\hline
\end{tabular}

Podemos observar, entonces, que las restricciones o normas tienen que ver mucho con el tipo de público o audiencia a la que va dirigido el producto. Esto se confirma en la entrevista, ya que que la utilización del lenguaje no apropiado para la audiencia puede ser sancionado por el CNA (Consejo Audiovisual Nacional):

Empresa entrevistada: Evidentemente, cuando se finaliza la traducción comprobamos la película en totalidad, con la traducción implementada. No se pueden utilizar algunos tipos de diálogos, palabras inadecuadas, tenemos mucho

\footnotetext{
${ }^{86}$ Figura 47. Las empresas imponen restricciones o normas a los traductores $\rightarrow{ }^{*}$ Câteodată $=$ A veces; ${ }^{*}$ Nu $=$ No; ${ }^{*}$ Da $=$ Sí. 
en cuenta el target, si se trata de audiencia general, si es con el acuerdo de los padres hasta los 12 años, estamos muy pendientes de la edad de la audiencia.

Por lo que se refiere al tipo de materiales que reciben los traductores por parte de las empresas empleadoras (véase bloque 1, pregunta 16), el 100\% de las mismas proporciona el archivo audiovisual, seguido por la lista de diálogos, en el caso de un $60 \%$ de las empresas, o el guion (40\%). La Tabla 46 que figura a continuación muestra esta información:

\begin{tabular}{|l|c|c|c|}
\hline 16. ¿Qué tipo de materiales se le proporciona al traductor? \\
\hline Opciones de respuesta & $\begin{array}{c}\text { Total } \\
\text { respuestas }\end{array}$ & $\begin{array}{c}\text { Recuento } \\
\text { respuestas }\end{array}$ & Porcentaje \\
\hline Video & 5 & 5 & $100 \%$ \\
\hline Lista de diálogos & 5 & 3 & $60 \%$ \\
\hline Guion & 5 & 2 & $40 \%$ \\
\hline Plantilla & 5 & 0 & $0,0 \%$ \\
\hline Otros (especifique, por favor) & 5 & 0 & $0,0 \%$ \\
\hline
\end{tabular}

Tabla 45. Materiales que le proporciona al traductor

La utilización del archivo con el material audiovisual puede facilitar la labor del traductor, tal como se explica en la entrevista:

Empresa entrevistada: La lista de diálogos con los tiempos. Si no existe la lista de diálogos con los tiempos y solamente el fichero de vídeo el traductor se las puede arreglar, pero es más difícil. Pero existen ficheros de vídeo donde puede ver el diálogo, tiempos, es ideal. Muchas veces se necesita el fichero de vídeo para darse cuenta del sexo de los personajes si es una chica, un chico, un perro, una planta... es muy importante porque muchas veces no te das cuenta con el guion.

El intercambio de materiales que se realiza entre las empresas empleadoras y los traductores audiovisuales se efectúa a veces mediante algún sistema informático o plataforma especial (véase bloque 1, pregunta 17). En nuestro caso, las empresas 
participantes en la encuesta han confirmado, en un $60 \%$ de los casos, el uso de este tipo de sistema. El 40\% restante realiza el intercambio de forma más sencilla, como se aprecia en el comentario que se muestra a continuación:

\section{Comentarios}

Los estudios socios imponen la plataforma. Uno de los estudios no tiene una plataforma especial, el traductor envía la traducción en formato RTF, después de mi revisión/corrección la envía otra vez las listas finales en formato XML, que luego nosotros enviamos al estudio.

La revisión lingüística era un proceso imprescindible en la época dictatorial, un proceso que incluía varias etapas, según algunos de los traductores entrevistados. La traducción se revisaba por un editor, y posteriormente por un lingüista que comprobaba el estilo. Dado que en la actualidad la presencia de un revisor lingüístico en las empresas es un aspecto del que en ocasiones se prescinde, hemos preguntado a las empresas sobre este importante factor en el proceso de traducción (véase bloque 1, pregunta 18). Los resultados obtenidos se muestran en la figura siguiente:

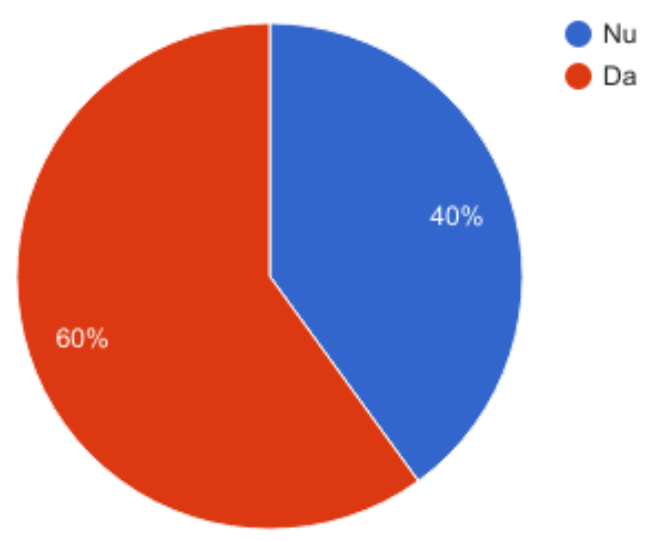

Figura 48. ¿Dispone de un revisor lingüístico ${ }^{87}$

Como se puede comprobar en la figura, el $60 \%$ de las empresas encuestadas emplean un revisor lingüístico para revisar las traducciones finales ya realizadas. Sin embargo, el $40 \%$ restante prescinde del servicio del revisor (tal como se había destacado en el capítulo 3), posiblemente para reducir gastos. Esta tarea se realiza, entonces, por

\footnotetext{
${ }^{87}$ Figura 48. ¿Dispone de un revisor lingüístico $? \rightarrow{ }^{*} \mathrm{Nu}=\mathrm{No} ;{ }^{*} \mathrm{Da}=$ Sí.
} 
otro tipo de personal, que desconocemos si tiene la formación adecuada para realizar esta labor:

Empresa entrevistada: No, una persona autorizada, no. Nosotros revisamos, como he dicho, previamente en una sala de cine revisamos cómo es el material final. Si es inadecuado, por supuesto lo arreglamos.

No obstante, tal y como hemos podido comprobar en la encuesta realizada a los traductores audiovisuales, la calidad de la traducción es muy importante para las empresas. Como se aprecia a continuación, el $80 \%$ de las empresas consideran que la calidad puede tener impacto en el éxito de una película (véase bloque 1, pregunta 19).



Figura 49. Relación de la calidad de la traducción con el éxito del producto en la lengua meta ${ }^{88}$

Por tanto, se exige una traducción perfecta en el plazo de trabajo, muchas veces inadecuado para la labor que se realiza, y en algunos casos se excluye la participación de un revisor lingüístico, lo que puede perjudicar la calidad de la traducción final. Con todo, si se considera la situación general de esta profesión, comprendemos la presión laboral que se ejerce sobre el gremio de estos profesionales en Rumanía, y en este sentido se pronunciaban los traductores entrevistados.

En cuanto a la relación que mantienen las empresas con las universidades para ofertar prácticas a los estudiantes de esta disciplina (véase bloque 1, pregunta 20), la respuesta que recibimos a la correspondiente pregunta fue un poco decepcionante, como se puede comprobar en los valores de la siguiente tabla (Tabla 47):

${ }^{88}$ Figura 49. Relación de la calidad de la traducción con el éxito del producto en la lengua meta $\rightarrow{ }^{*} \mathrm{Da}=$ Sí; ${ }^{*}$ Câteodată $=\mathrm{A}$ veces. 


\begin{tabular}{|c|c|c|c|}
\hline \multicolumn{4}{|c|}{$\begin{array}{l}\text { 20. ¿Su empresa facilita la realización de prácticas universitarias a los estudiantes de } \\
\text { traducción audiovisual? }\end{array}$} \\
\hline Opciones de respuesta & $\begin{array}{c}\text { Total } \\
\text { respuestas }\end{array}$ & $\begin{array}{l}\text { Recuento } \\
\text { respuestas }\end{array}$ & Porcentaje \\
\hline No & 5 & 4 & $80 \%$ \\
\hline A veces & 5 & 1 & $20 \%$ \\
\hline Sí & 5 & 0 & $0,0 \%$ \\
\hline
\end{tabular}

Tabla 46. Ofertar prácticas universitarias

Podemos observar que el $80 \%$ de las empresas que participaron en la encuesta no colabora con las universidades, y solamente un $20 \%$ de ellas colabora "a veces". Por tanto, adquirir experiencia en este ámbito profesional mediante la realización de prácticas universitarias en empresas es una práctica casi inexistente en Rumanía.

Tal como apuntaban los traductores (véase sección 5.1.3.), la experiencia se consigue cuando estás trabajando. Sin embargo, si no se dispone de experiencia, no se puede acceder al empleo, puesto que casi todas las empresas evalúan a los candidatos por medio de pruebas de traducción. Por tanto, y a efectos prácticos, la única forma de obtener experiencia es realizando traducciones a precios muy bajos, o incluso gratuitamente, tal y como explicaban los traductores en las entrevistas realizadas. Esta coyuntura beneficia a las empresas y perjudica, por un lado, a los estudiantes, que no disponen de posibilidades para realizar prácticas y ejercer esta labor en su proceso de aprendizaje; por otro, la coyuntura también perjudica a los profesionales, puesto que disminuye el porcentaje de trabajo al que pueden acceder, así como su salario y la percepción social del trabajo.

Por lo que se refiere a la formación continua que ofrecen las empresas a sus empleados (véase bloque 1, pregunta 21), y de acuerdo a los resultados obtenidos (véase Figura 50), se puede apreciar que el $80 \%$ de las empresas no se involucran en este proceso. Este resultado no es sorprendente, puesto que en la encuesta dirigida a los traductores (véase Tabla 27) hemos podido comprobar que la mayoría de ellos realiza cursos en el extranjero o en el propio país, pese a que algunos no se lo pueden permitir por precio o distancia. En cualquier caso, dichos cursos no se ofrecen por parte de las empresas. 


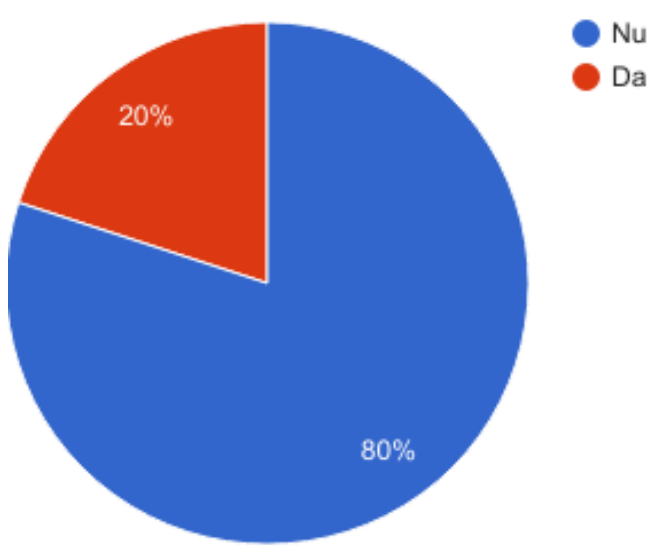

Figura 50. Oferta de formación continúa a los traductores por parte de las empresas ${ }^{89}$

Tal como hemos podido observar tanto en las respuestas de los cuestionarios como en las entrevistas (véase Figura 35 y Tabla 48), la oferta insuficiente de cursos por parte de las universidades también dificulta la formación previa y la formación continua en esta disciplina. Por ello, consideramos necesario incluir en la encuesta a las empresas una pregunta sobre la preparación por medio de estos cursos, con la intención de intentar averiguar si dicha formación habilita a los futuros profesionales de traducción audiovisual para poder ejercer esta profesión en las empresas del mercado rumano (véase bloque 1, pregunta 22).

22. ¿Considera que la formación universitaria en la traducción audiovisual en Rumanía es adecuada para ejercer posteriormente esta profesión?

\begin{tabular}{|l|c|c|c|}
\hline Opciones de respuesta & $\begin{array}{c}\text { Total } \\
\text { respuestas }\end{array}$ & $\begin{array}{c}\text { Recuento } \\
\text { respuestas }\end{array}$ & Porcentaje \\
\hline Sí & 5 & 2 & $40 \%$ \\
\hline No & 5 & 1 & $20 \%$ \\
\hline A veces & 5 & 1 & $20 \%$ \\
\hline No lo sé & 5 & 1 & $20 \%$ \\
\hline
\end{tabular}

Tabla 47. La adecuación de la formación universitaria en la traducción audiovisual en Rumanía

Como se puede apreciar, los resultados obtenidos son heterogéneos, puesto que las opiniones son variadas. El $40 \%$ de las empresas entrevistadas aprecian positivamente

\footnotetext{
${ }^{89}$ Figura 50. Oferta de formación continúa a los traductores por parte de las empresas $\rightarrow{ }^{*} \mathrm{Nu}=\mathrm{No}$; ${ }^{*} \mathrm{Da}=\mathrm{Sí}$.
} 
la formación universitaria en esta disciplina en Rumanía. Mientras que, con un porcentaje inferior, del 20\%, las demás consideran que la formación no es adecuada o lo es solamente "a veces". La selección de la respuesta puede estar relacionada con la escasa formación práctica, ya que muchas empresas consideraban que los estudiantes no disponen de conocimientos suficientes en este sentido, tal como hemos podido observar anteriormente (véase Tabla 48). Esta visión se corrobora en los siguientes comentarios:

\section{Comentarios}

Para poder desarrollar bien esta profesión se necesita experiencia que no se adquiere en las universidades.

Por último, el $20 \%$ de las empresas simplemente no sabe qué contestar a esta pregunta, lo que nos hace reflexionar sobre la limitada o inexiste relación entre las universidades que imparten cursos de traducción audiovisual y las empresas empleadoras de profesionales con esta especialidad. Por ello, si se contempla la situación actual en este país, consideramos que una colaboración entre las empresas y las universidades, tanto del país como del extranjero, podría ser beneficiosa para los futuros profesionales.

Como conclusiones de este epígrafe y conforme a los datos que hemos recabado en la encuesta a las empresas, podemos concluir que el $\mathbf{5 0 \%}$ de las empresas encuestadas no tienen en la plantilla traductores audiovisuales, pese a que el $80 \%$ de ellas dedican su actividad solamente a la traducción audiovisual. Por tanto, la situación laboral de los traductores audiovisuales en Rumanía es similar a la de los profesionales de otros países que pertenecen a este gremio, ya que las empresas ofrecen únicamente, y mayoritariamente, contratos de trabajador autónomo.

Los criterios de evaluación de los traductores establecidos por el $\mathbf{6 0 \%}$ de las empresas son tanto la experiencia, como los estudios. Sin embargo, dado que la prueba de traducción es la modalidad que prevalece para seleccionar los candidatos, la experiencia (que se adquiere por medio del trabajo y no del estudio), acaba determinando la contratación.

En cuanto al destinatario de los productos audiovisuales traducidos, el $60 \%$ de las empresas opina que el producto se dirige tanto al público infantil como al adulto. De acuerdo con el análisis de los resultados recabados en la encuesta dirigida a los 
traductores, la subtitulación y el doblaje son las dos modalidades de traducción audiovisual más empleadas actualmente en Rumanía.

Asimismo, la demanda de combinaciones lingüísticas es bastante reducida: el porcentaje más alto $(100 \%)$ corresponde a la combinación lingüística inglés-rumano, seguido con un $60 \%$ por el par francés-rumano, y por un $40 \%$ en el caso del alemánrumano.

Los tipos de programas que se utilizan para realizar esta labor están en el $80 \%$ de los casos impuestos por las empresas. Las normas y restricciones que imponen el $60 \%$ de las empresas consisten generalmente en la utilización de un vocabulario adecuado y acorde al público al que se dirige el producto audiovisual en la lengua meta, para así poder respetar las exigencias del CNA (Consejo Audiovisual Nacional). Los materiales que las empresas envían a los traductores son en el $\mathbf{1 0 0 \%}$ de los casos archivos audiovisuales, que pueden facilitar la identificación de personajes, seguidos por las listas de diálogos y los guiones. El intercambio de materiales entre las empresas empleadoras y los profesionales se realiza mediante plataformas especiales $(60 \%$ de los casos). En cuanto a la revisión final de la traducción, el $60 \%$ de las empresas dispone de un revisor lingüístico, mientras que un porcentaje inferior del $40 \%$ prescinde de sus servicios, pese a que el $\mathbf{8 0 \%}$ de las empresas considera que la traducción audiovisual final del producto puede tener un impacto significativo en el éxito del mismo.

En cuanto la relación entre las empresas empleadoras y las universidades, se puede afirmar que es prácticamente nula, puesto que las empresas no ofrecen prácticas. Dichas empresas tampoco consideran suficientes los cursos impartidos por las universidades. Estos cursos, en teoría, deberían servir para que los estudiantes puedan llegar a formar parte, posteriormente, del mercado profesional audiovisual rumano.

\subsubsection{Competencias}

Tal como hemos expuesto al principio de la sección 5.2, la segunda parte de la encuesta dirigida a las empresas empleadoras la dedicamos a las competencias específicas y genéricas, dado que consideramos importante analizar las cualidades y destrezas que estas consideraban imprescindibles para ser un buen profesional en este ámbito en Rumanía. Los resultados obtenidos para las competencias específicas se muestran en la siguiente tabla. 


\subsubsection{Competencias específicas}

Teniendo en cuenta la complejidad de la profesión del traductor de textos audiovisuales, ¿qué cualidades y destrezas específicas considera que son imprescindibles para ser un buen profesional? Marque cinco competencias específicas que considera fundamentales para ejercer esta profesión.

\begin{tabular}{|c|c|c|c|}
\hline Opciones de respuesta & $\begin{array}{c}\text { Total } \\
\text { respuestas }\end{array}$ & $\begin{array}{l}\text { Recuento } \\
\text { respuestas }\end{array}$ & Porcentaje \\
\hline $\begin{array}{l}\text { 1.Conocimiento exhaustivo de la } \\
\text { lengua meta }\end{array}$ & 5 & 5 & $100 \%$ \\
\hline 2. Dominio de la lengua origen & 5 & 5 & $100 \%$ \\
\hline 4. Creatividad lingüística & 5 & 3 & $60 \%$ \\
\hline 5.Capacidad de síntesis y paráfrasis & 5 & 3 & $60 \%$ \\
\hline $\begin{array}{l}\text { 6. Comprender la especificidad del } \\
\text { texto audiovisual por la interacción } \\
\text { de diferentes códigos semióticos }\end{array}$ & 5 & 3 & $60 \%$ \\
\hline $\begin{array}{l}\text { 12. Excelente manejo de programas } \\
\text { específicos de TAV (subtitulación, } \\
\text { doblaje, etc.) }\end{array}$ & 5 & 3 & $60 \%$ \\
\hline $\begin{array}{l}\text { 3. Buen conocimiento de las culturas de } \\
\text { trabajo }\end{array}$ & 5 & 2 & $40 \%$ \\
\hline $\begin{array}{l}\text { 9. Destrezas para realizar una sincronía } \\
\text { perfecta: lingüística e imagen }\end{array}$ & 5 & 2 & $40 \%$ \\
\hline $\begin{array}{l}\text { 10. Dominar las técnicas, estrategias y } \\
\text { terminología específicas de la } \\
\text { traducción audiovisual }\end{array}$ & 5 & 1 & $20 \%$ \\
\hline $\begin{array}{l}\text { 11. Dominio de estrategias de búsqueda } \\
\text { de recursos y documentación } \\
\text { específicos de la TAV }\end{array}$ & 5 & 1 & $20 \%$ \\
\hline $\begin{array}{l}\text { 13. Conocimiento de principios } \\
\text { metodológicos y de aspectos } \\
\text { profesionales que rigen la TAV }\end{array}$ & 5 & 1 & $20 \%$ \\
\hline $\begin{array}{l}\text { 7. Conocimientos de las características } \\
\text { de diferentes géneros audiovisuales }\end{array}$ & 5 & 0 & $0,0 \%$ \\
\hline $\begin{array}{l}\text { 8. Capacidad de comunicación escrita } \\
\text { para redactar traducciones adecuadas }\end{array}$ & 5 & 0 & $0,0 \%$ \\
\hline $\begin{array}{l}\text { 14. Conocimiento de las características } \\
\text { y convenciones europeas de la } \\
\text { traducción audiovisual }\end{array}$ & 5 & 0 & $0,0 \%$ \\
\hline
\end{tabular}




\begin{tabular}{|l|c|c|c|}
\hline $\begin{array}{l}\text { 15. Conocimiento de los aspectos } \\
\text { económicos, profesionales y del } \\
\text { mercado. }\end{array}$ & 5 & 0 & $0,0 \%$ \\
\hline 16. Otros (especifique por favor) & 5 & 0 & $0,0 \%$ \\
\hline
\end{tabular}

Tabla 48. Competencias específicas empresas

Como se puede apreciar en la tabla anterior, las competencias específicas más destacadas por las empresas empleadoras rumanas encuestadas son las siguientes:

1. Conocimiento exhaustivo de la lengua meta (100\%)

2. Dominio de la lengua origen $(100 \%)$

4. Creatividad lingüística $(60 \%)$

5. Capacidad de síntesis y paráfrasis $(60 \%)$

6. Comprender la especificidad del texto audiovisual por la interacción de diferentes códigos semióticos $(60 \%)$

12. Excelente manejo de programas específicos de TAV (subtitulación, doblaje, etc.) $(60 \%)$

Se puede apreciar, en consecuencia, que, según el modelo competencial de Kelly (2002), las principales competencias específicas destacadas por las empresas son de tipo comunicativo-textual, tanto en la lengua meta como el la lengua origen, seguidas por las de tipo instrumental-profesional, como por ejemplo la comprensión de la especificidad del texto audiovisual por la interacción de diferentes códigos semióticos o el excelente manejo de programas específicos de TAV (subtitulación, doblaje, etc.).

Si contrastamos las competencias específicas seleccionadas por las empresas empleadoras con las competencias específicas seleccionadas por los profesionales de traducción audiovisual de este país (véase sección 5.1.4.1.), podemos observar que la selección es similar. Este hecho da solidez empírica y metodolgica a nuestro estudio, ya que la realidad se observa de la misma manera desde dos puntos de vista diferentes.

\subsubsection{Competencias genéricas}

Para este tipo de competencias, se ha planteado una pregunta similar a la anterior a las empresas empleadoras, cuyos resultados se muestran en la siguiente Tabla 50: 




Tabla 49. Competencias genéricas empresas

Las competencias genéricas destacadas principalmente por las empresas empleadoras encuestadas son las siguientes:

4. Preocupación por la calidad (100\%)

11. Capacidad para trabajar bajo presión temporal (100\%) 
13. Capacidad para adecuarse a los requisitos del encargo (100\%)

7. Habilidad para buscar y analizar información procedente de diversas fuentes (80\%)

3. Capacidad de aplicar el conocimiento a la práctica (60\%)

15. Rápida resolución de problemas $(60 \%)$

En el caso de las competencias genéricas, tanto las empresas empleadoras, como los traductores encuestados (véase sección 5.1.4.2.) han catalogado en las primeras dos posiciones de la lista la preocupación por la calidad y la capacidad para trabajar bajo presión temporal. Como en el caso de las competencias específicas, este hecho da solidez empírica y metodolgica a nuestro estudio, ya que la realidad se observa de la misma manera desde dos puntos de vista diferentes. A continuación, las empresas sitúan la habilidad para buscar y analizar la información pertinente, así como la capacidad de coordinar el conocimiento con la práctica y la rápida resolución de problemas. A modo de conclusiones de este apartado dedicado a las competencias, cabe destacar que hemos podido observar que, entre las competencias específicas, según la selección que han realizado las empresas empleadoras, destaca en primer lugar el conocimiento exhaustivo de los dos idiomas de trabajo: la lengua meta y la lengua origen. Asimismo, la siguiente competencia específica más señalada es la comprensión de la especificidad del texto audiovisual por la interacción de diferentes códigos semióticos, que aporta al profesional una capacidad de adaptación textual adecuada. Junto con todo esto se menciona, el excelente manejo de programas específicos de TAV (subtitulación, doblaje, etc.), un factor fundamental a la vista de las respuestas obtenidas de la encuesta.

En cuanto a las capacidades genéricas, de acuerdo con los resultados, se evidencian (con un porcentaje similar) la preocupación por la calidad, la capacidad para trabajar bajo presión temporal y la capacidad para adecuarse a los requisitos del encargo. A efectos prácticos, se trata de las mismas capacidades genéricas seleccionadas por los profesionales de este país (véase Tabla 42).

La siguiente competencia genérica seleccionada es la habilidad para buscar y analizar información. Y por último, se destaca la capacidad de aplicar el conocimiento a la práctica, así como la rápida resolución de problemas.

Como conclusión general del apartado 5.2, dedicado a las empresas empleadoras en Rumanía, hemos podido observar, a la vista de sus respuestas, que:

- Las empresas empleadoras que participaron en la encuesta cuentan, en algunos casos, con una antigüedad en el mercado rumano de más de 20 años, en los que 
han dedicado su actividad a la traducción audiovisual en este país. Por tanto, pese a su reducido número, la amplia experiencia que aportan podría compensar la exigua cantidad.

- La ubicación principal de las empresas empleadoras en el ámbito de la traducción audiovisual en Rumanía se sitúa en Bucarest, puesto que el 100\% de las empresas participantes tienen la sede en la capital.

- El tipo de clientes a los que prestan servicios es diverso. Sin embargo, destacan los cines y las cadenas de televisión, que son los que distribuyen la cantidad más importante de productos audiovisuales extranjeros en el país.

- El número de empleados en plantilla con que cuentan estas empresas varía en función de su antigüedad en el mercado y de la recepción de encargos de traducción audiovisual de productos extranjeros. El número de empresas que incluyen en su plantilla traductores audiovisuales es bastante reducido, puesto que se les contacta en función de las necesidades, o estos colaboran como trabajadores autónomos.

- Pese a que un número elevado de las empresas valora tanto la experiencia como la formación de los traductores, los comentarios recabados permiten observar que la experiencia se evalúa en mayor medida (idéntica observación a la realizada por los profesionales de la traducción audiovisual, tal como se destaca en la Figura 33). A la hora de contratar a los traductores, la experiencia ocupa un lugar fundamental, en términos de los criterios aplicados. Sin embargo, se evalúan también las recomendaciones. En algunos casos, y pese a las recomendaciones y al $\mathrm{CV}$, la prueba de traducción es la modalidad decisiva para seleccionar candidatos.

- Las empresas encuestadas no seleccionan de forma específica el destinatario de los productos que traducen, y dedican su actividad tanto a la traducción audiovisual infantil como a la orientada a adultos.

- En cuanto a las modalidades de traducción audiovisual más empleadas en la actualidad en Rumanía, y pese a que en nuestro cuestionario habíamos enumerado varios tipos (además de haber añadido un apartado de "Otros" por si los participantes querían incluir alguna otra), imperan la subtitulación, seguida por el doblaje, en este caso utilizado como modalidad de traducción para los productos dirigidos al público infantil. 
- Las combinaciones lingüísticas más presentes en los encargos que reciben las empresas son similares a las mencionadas por los profesionales (lógicamente). En concreto, destaca la combinación inglés-rumano, seguida por francés-rumano, así como alemán-rumano, y por último, la combinación español-rumano. El número limitado de combinaciones lingüísticas puede repercutir también en el porcentaje de trabajo disponible para los traductores en Rumanía, puesto que una hipotética variedad mayor podría ampliar el mercado profesional.

- Los programas específicos (software) empleados en esta actividad profesional son impuestos generalmente por las empresas. En algunos casos se les proporcionan a los editores/técnicos, dado que son ellos los que elaboran los subtítulos, en vez de los traductores audiovisuales.

- Por lo que respecta a las restricciones o normas que imponen los clientes a las empresas empleadoras, estos suelen referirse principalmente a temas relacionados con el vocabulario o a la traducción de canciones (si es el caso), o a nombres o palabras que aún no tienen su equivalente en el diccionario de la lengua rumana. Estas restricciones y normas se transmiten, como era de esperar, a los profesionales de la traducción.

- En cuanto al tipo de materiales que reciben los traductores de las empresas empleadoras, estos suelen ser archivos audiovisuales, dado que este tipo de material puede facilitar la labor del traductor. En otros casos se utilizan también la lista de diálogos o el guion. El intercambio de materiales se realiza mediante plataformas especiales, que imponen algunas veces los clientes, o en ocasiones el intercambio se lleva a cabo en formato RTF y XML.

- La revisión lingüística se considera un proceso importante en la traducción audiovisual (aunque se elimina en ocasiones por parte de las empresas para suprimir gastos). En Rumanía, por ello, algunas empresas encuestadas la llevan a cabo, puesto que la calidad de la traducción final puede influir en el éxito del producto en la lengua meta (en su opinión).

- Por lo que respecta a la relación entre las empresas empleadoras y las universidades que imparten cursos formativos específicos, esta es casi nula, dado que las empresas consideran que este tipo de cursos no aporta a los futuros profesionales la preparación necesaria para realizar este tipo de traducción. El interés por la formación continua de los profesionales contratados es también limitado (por lo que respecta a las empresas). Algunos profesionales actualizan su 
formación mediante cursos realizados en el extranjero, mientras que otros ignoraban la existencia de estos planes formativos.

- En cuanto a las competencias específicas y genéricas que las empresas empleadoras consideran fundamentales para desarrollar esta profesión, destacan las siguientes:

- Competencias específicas

$\checkmark$ 1. Conocimiento exhaustivo de la lengua meta (100\%)

$\checkmark$ 2. Dominio de la lengua origen (100\%)

$\checkmark$ 4. Creatividad lingüística $(60 \%)$

$\checkmark$ 5. Capacidad de síntesis y paráfrasis (60\%)

$\checkmark$ 12. Excelente manejo de programas específicos de TAV (subtitulación, doblaje, etc.) $(60 \%)$

- Competencias genéricas

$\checkmark$ 4. Preocupación por la calidad (100\%)

$\checkmark$ 11. Capacidad para trabajar bajo presión temporal (100\%)

$\checkmark$ 13. Capacidad para adecuarse a los requisitos del encargo (100\%)

$\checkmark$ 7. Habilidad para buscar y analizar información procedente de diversas fuentes $(80 \%)$

$\checkmark$ 3. Capacidad de aplicar el conocimiento a la práctica (60\%)

$\checkmark$ 15. Rápida resolución de problemas (60\%)

En este apartado, que se ha dedicado a obtener información sobre las empresas empleadoras de Rumanía, hemos podido analizar el perfil actual que existe en el mercado rumano, y hemos utilizado para ello datos cuantitativos y cualitativos que hemos recabado mediante encuestas y entrevistas. Asimismo, estos datos han contribuido a llevar a cabo una descripción del perfil del traductor audiovisual rumano, ya que se ha contrastado su estado actual desde distintas perspectivas.

No obstante, conscientes del reducido tamaño de la muestra con que hemos contado, y tal y como expusimos al inicio de este capítulo, no tenemos intención de generalizar los resultados, sino simplemente de exponer los datos recabados, datos que a 
su vez se han obtenido de los traductores y las empresas implicados, en un intento de cruzar resultados y obtener una imagen de la realidad lo más completa y real posible. 


\section{Capítulo 6: Conclusiones y perspectivas de futuro}

En este capítulo final de la presente tesis doctoral expondremos las principales conclusiones que se derivan de nuestro estudio por lo que se refiere a su objetivo general y sus objetivos específicos. Como recordamos, el objetivo general de nuestra investigación es describir y analizar el perfil formativo y socioprofesional del traductor audiovisual en la actualidad en Rumanía, a través de la valoración de los propios profesionales que desarrollan esta labor y de las empresas empleadoras que ofertan servicios de traducción audiovisual en este país. Este objetivo principal, como indicamos en la Introducción y en el Capítulo 4, abarca cinco objetivos específicos que hemos ido abordando a lo largo del estudio y cuyo logro expondremos también en este capítulo.

Asimismo, formularemos las líneas de investigación futuras que se derivan de nuestra investigación actual y de nuestra aportación a este ámbito de estudio.

Sin embargo, conscientes de la limitación muestral de nuestro estudio, debemos señalar que nuestra pretensión en esta investigación no es en absoluto generalizar, sino más bien describir el perfil socioprofesional actual del traductor audiovisual en Rumanía. Por otra parte, cabe destacar que la aportación de los participantes otorga cierto rigor a esta investigación, dado que los datos fueron proporcionados por sujetos determinados y que nuestro diseño de estudio persigue no tanto una "representatividad" de elementos de una población, sino más bien una cuidadosa y controlada elección de casos con ciertas características, especificadas previamente en el planteamiento del problema (Hernández, Fernández y Baptista, 2006: 190). Como expusimos en nuestro capítulo metodológico, en algunos enfoques el número de "casos" estudiados carece relativamente de importancia, y lo importante es el potencial de cada "caso" para ayudar al investigador en el desarrollo de comprensiones teóricas sobre el área estudiada de la vida social (Taylor y Bogdan, 1987: 108).

\subsection{Valoración de objetivos y resultados alcanzados}

\subsubsection{Objetivo específico 1: Describir y destacar las modalidades de traducción audiovisual que se utilizan en Rumanía}

Para comprender y explicar el uso de las modalidades de traducción audiovisual en Rumanía, hemos considerado necesario llevar a cabo un breve recorrido en el Capítulo 
1 por la historia del cine rumano desde su origen hasta la actualidad, considerando las etapas, las técnicas y las ideologías por las que ha pasado. Tal y como hemos visto, Rumanía fue uno de los primeros países que se embarcó en la aventura cinematográfica para hacer posible "la maravilla del siglo", que proporcionaría al público "una experiencia feérica" (L’Independence Roumaine, 1897). El cine atravesó en Rumanía las dos guerras mundiales, la época dictatorial y la época de transición, y se convirtió (junto a la televisión, muchos años más tarde) en una forma de entretenimiento, de manipulación ideológica en algunas épocas, al tiempo que contribuyó a la creación de nuevas profesiones.

En el Capítulo 2 hemos realizado una breve revisión sobre los aspectos históricos de la traducción audiovisual en Rumanía, y hemos descrito los orígenes de las dos modalidades más utilizadas (la subtitulación y el doblaje) para poder situar posteriormente al profesional de la traducción audiovisual en el mercado rumano.

Hemos podido observar que Rumanía es uno de los países de la antigua Europa del Este que emplea mayoritariamente como modalidad de traducción audiovisual la subtitulación, tanto para cine como para televisión. Sea por motivos políticos, económicos o de habitus (Bordieu, 1972: 178), este tipo de traducción lleva mucho tiempo siendo la más empleada para traducir la avalancha de programas y películas de origen extranjero que se ha producido desde 1989 en el panorama audiovisual rumano.

El cambio del sistema económico-político del año 1989 en Rumanía influye en el ámbito audiovisual rumano, de modo que, en los primeros años que transcurren a partir de esta fecha, los medios audiovisuales sufren su propia revolución y evolución. Los nuevos formatos televisivos y programas son supervisados por el Consejo Nacional Audiovisual (CNA), que actualmente es la única autoridad de reglamentación del dominio audiovisual. Paulatinamente, la aparición de varias cadenas de televisión privadas, que emiten programas dedicados exclusivamente al público infantil o películas del género live action de Disney, dirigidas a todo tipo de público, tal como hemos podido ver en la sección 5.2.1.2, ha contribuido a la aparición y desarrollo del doblaje, modalidad poco habitual en Rumanía antes del año 1989. El voice-over es la otra modalidad de traducción audiovisual presente en el mercado rumano, aunque menos empleada que la subtitulación o el doblaje, pese a su antigüedad en el mercado rumano. Esta práctica se utiliza en Rumanía en la emisión de los documentales de producción ajena o de entrevistas a personas extranjeras. 
Tal como hemos comentado, la liberación de la dictadura significó la liberación de las fronteras, del racionamiento del consumo audiovisual, dado que la única cadena de televisión que emitía se vio escoltada por muchas otras cadenas con programa de emisión continuo y con una amplia variedad de programas. Asimismo, la evolución tecnológica, reflejada en la aparición de productos audiovisuales en formato DVD, CD, UMD (Universal Media Disc) y BD (Blu-ray), contribuyó al aumento del número de producciones audiovisuales que tienen que pasar por un proceso de traducción para ser consumidas en Rumanía y, por tanto, repercutió en el número y el perfil de los profesionales que se dedican a la traducción audiovisual en la actualidad.

\subsubsection{Objetivo específico 2: Estudiar el entorno laboral de la traducción audiovisual en Rumanía}

En el Capítulo 3 hemos realizado una descripción preliminar del entorno laboral de la traducción audiovisual en Rumanía, y hemos recopilado datos de la bibliografía existente gracias a las entrevistas públicas concedidas por algunos profesionales de este ámbito y que desvelan algunas características de esta labor.

Hemos podido observar la evolución social y técnica que ha conocido esta profesión a lo largo del tiempo, al realizar una breve comparación entre las dos etapas fundamentales que marcan la historia de la traducción audiovisual en este país, antes y después del año 1989, en el doblaje y la subtitulación. Así, hemos descubierto que durante el periodo comunista solo un número escaso de profesionales se dedicaba a la traducción audiovisual, y que tanto estos como el trabajo que realizaban eran examinados constante y rigurosamente con la intención de que se ajustaran a la ideología del régimen, así como de censurar aquellos textos y fragmentos de productos audiovisuales extranjeros que se distanciaban de sus convicciones. Las rudimentarias técnicas de trabajo que tenían que emplear los traductores repercutían en las condiciones laborales de los profesionales y la censura aplicada distorsionaba en ocasiones el tipo de lenguaje y el argumento de los productos originales en la lengua meta. Estas barreras instauradas por el régimen también actuaron en detrimento del desarrollo lingüístico-cultural de los ciudadanos rumanos, puesto que los traductores solo utilizaban como material de apoyo los diccionarios, y muchas veces la imaginación, si el término desconocido no existía en ese único recurso disponible. 
No obstante, el cambio político que se produjo a partir de 1989 repercutió directamente sobre el perfil de los profesionales de este ámbito. A continuación, recogemos las principales repercusiones observadas:

- El mercado audiovisual amplía las ofertas de trabajo en este campo.

- El número reducido de traductores audiovisuales aumenta considerablemente.

- La censura audiovisual queda en la historia de esta profesión.

- El doblaje/voice-over realizado en coyunturas atípicas se adecua a las técnicas específicas que requiere el doblaje.

- La evolución tecnológica simplifica su labor.

- Los recursos para buscar materiales de apoyo se diversifican.

Sin embargo, aún perduran características que definen la labor de este gremio en la actualidad en Rumanía, y que Chaume (2000: 47-83) utilizaba para describir la situación de los traductores de textos audiovisuales en España hace 17 años, como por ejemplo:

- Vacío legislativo respecto a los profesionales de la traducción audiovisual, frente al reconocimiento de actores de doblaje, técnicos de sonido, directores de doblaje, etc.

- Inexistencia de legislación fiscal especifica adaptada a las características del mercado en este sector.

- Inexistencia de un colegio o asociación profesional que vele por unas prácticas profesionales justas y equitativas.

- Escasa oferta universitaria de cursos de especialidad.

Por otra parte, hemos considerado que para desarrollar la profesión del traductor audiovisual se necesita un conjunto de habilidades y destrezas, dado que las demandas del mercado requieren un perfil profesional polifacético y flexible para poder realizar diferentes tareas y adaptarse a nuevas situaciones. De esta forma, hemos partido de algunos estudios teóricos (Kelly, 2002; PACTE, 2003; el Proyecto Tuning, 2003 y Cerezo Merchán, 2012) para exponer las capacidades genéricas y específicas que tanto los profesionales de la traducción de productos audiovisuales como las empresas 
empleadoras del mercado actual en Rumanía podrían considerar esenciales para desempeñar este trabajo.

6.1.3. Objetivo específico 3: Determinar las competencias que ponen en ejercicio los traductores en su actividad profesional y requieren las empresas empleadoras

Otro objetivo de nuestra investigación fue desvelar las competencias generales y específicas consideradas esenciales desde el prisma del traductor audiovisual y de las empresas empleadoras en Rumanía. Por tanto, definimos el concepto de competencia genérica y específica en el epígrafe 3.6 de nuestra investigación para analizar posteriormente el tipo de habilidades y destrezas que se consideran necesarias para desarrollar la labor de traductor audiovisual.

Para definir las competencias genéricas, en nuestro estudio hemos utilizado las que se emplean en el Proyecto Tuning (2003) y se estructuran en tres categorías fundamentales que debe reunir el profesional de cualquier dominio: instrumentales, interpersonales y sistémicas.

Para definir las competencias específicas de los traductores hemos recurrido a Kelly (2002) y PACTE (2003). Por su parte, Kelly (2002) define la competencia traductora como una macrocompetencia que constituye el conjunto de capacidades, destrezas, conocimientos e incluso actitudes que reúnen los traductores profesionales y que intervienen en la traducción como actividad experta, que a su vez se desglosa en las subcompetencias que se relacionan para el éxito de la macrocompetencia. En su planteamiento destaca la subcompetencia estratégica, dado que es la que gobierna este proceso amparada por una variedad de otras subcompetencias, que son: la comunicativa y textual, la cultural, la temática, la instrumental profesional, la psicofisiológica y la interpersonal. Por su parte, el grupo PACTE (2003) sostiene que todo traductor requiere un conocimiento experto que no posee todo hablante bilingüe, y un conocimiento básicamente operativo que está formado por varias subcompetencias que actúan de manera relacional sustentadas, también, por el componente estratégico. Además, partiendo de la hipótesis formulada por Chaume (2003) los traductores de textos audiovisuales necesitarán determinadas competencias comunes que nos permitan distinguir su perfil del de otros traductores que solo realicen traducciones de textos escritos. Por tanto, utilizamos el listado de competencias específicas de traducción audiovisual propuesto por Cerezo Merchán (2012), tras un amplio repaso de lo que otros 
expertos han establecido sobre qué debe saber, qué debe saber hacer y qué actitud debe tener un buen profesional de la traducción audiovisual.

Así pues, a partir de las características esbozadas en el objetivo 2 y definidas en el Capítulo 3, a las que asociamos la valoración que han realizado los traductores y las empresas de las listas de competencias que incluíamos en la encuesta (epígrafe 5.1.4 y 5.2.2 del capítulo 5), podemos afirmar que las competencias específicas son las siguientes (cada competencia está asociada a un color, en las dos columnas de la siguiente tabla):

\section{A. Competencias especificas}

\begin{tabular}{|c|c|}
\hline \multicolumn{2}{|c|}{ Competencias específicas valoradas por grupo de población } \\
\hline Traductores & Empleadores \\
\hline $\begin{array}{l}\text { Conocimiento exhaustivo de la lengua } \\
\text { meta }(75,5 \%)\end{array}$ & $\begin{array}{l}\text { Conocimiento exhaustivo de la lengua } \\
\text { meta }(100 \%)\end{array}$ \\
\hline Capacidad de síntesis y paráfrasis $(75,5 \%)$ & Dominio de la lengua origen $(100 \%)$ \\
\hline Dominio de la lengua origen $(62,5 \%)$ & Creatividad lingüística $(60 \%)$ \\
\hline $\begin{array}{l}\text { Buen conocimiento de las culturas de } \\
\text { trabajo }(62,5 \%)\end{array}$ & Capacidad de síntesis y paráfrasis $(60 \%)$ \\
\hline Creatividad lingüística $(62,5 \%)$ & $\begin{array}{l}\text { Comprender la especificidad del texto } \\
\text { audiovisual por la interacción de } \\
\text { diferentes códigos semióticos }(60 \%)\end{array}$ \\
\hline & $\begin{array}{l}\text { Excelente manejo de programas } \\
\text { específicos de TAV (subtitulación, } \\
\text { doblaje, etc.) }(60 \%)\end{array}$ \\
\hline
\end{tabular}

Tabla 50. Competencias específicas valoradas por grupo de población

Tal como apreciamos, de las cinco competencias específicas seleccionadas por los dos grupos de población, cuatro de ellas coinciden, aunque situadas en diferentes posiciones, en función del porcentaje recibido por parte de los encuestados. Este resultado remarca que, tanto el grupo de profesionales como el de las empresas empleadoras valoran, en términos generales las mismas destrezas y habilidades para realizar esta 
profesión en Rumanía, que son: conocimiento exhaustivo de la lengua meta, capacidad de síntesis y paráfrasis, dominio de la lengua origen y creatividad lingüística.

Asimismo, cabe destacar que el conocimiento de la cultura de las lenguas de trabajo, que habían seleccionado los traductores, no se distingue entre las capacidades marcadas por las empresas. Además, tal como hemos podido observar en el epígrafe 5.2.1.2, la experiencia se convierte en el mejor aval de los profesionales, puesto que el excelente manejo de programas específicos de traducción audiovisual es uno de los requisitos fundamentales para la selección de los candidatos, tal como aparece en el resultado de las empresas. También tenemos que precisar que en este grupo (la columna de la derecha de la tabla anterior) hay seis capacidades, puesto que la última tenía el mismo porcentaje con las tres anteriores y por tanto no la podíamos excluir de la tabla.

Por tanto, podemos estimar que, siguiendo el modelo competencial de Kelly (2002) para englobar estas competencias específicas de traducción audiovisual, ambos grupos de población coinciden en la importancia de la competencia comunicativa y textual y de la competencia temática. Sin embargo, se distinguen en la relevancia de la competencia cultural definida por el grupo de traductores y de la competencia instrumental definida por el grupo de empresas.

Por lo que se refiere a las otras competencias específicas que habíamos redactado como opción de selección para nuestros encustados (profesionales y empresas empleadoras), tal como hemos podido observar en la sección 5.1.4.1 y 5.2.2.1 del presente estudio, pese a que tienen un porcentaje más bajo, siguen siendo seleccionadas por ambos grupos. En este sentido, con un porcentaje del $25 \%$ y $12,5 \%$ por parte de los profesionales, y del $40 \%$ y $20 \%$ por parte de las empresas empleadoras, se distinguen las competencias de tipo instrumental, como por ejemplo: las destrezas para realizar una sincronía perfecta (lingüística e imagen), dominar las técnicas, estrategias y terminología específicas de la traducción audiovisual, así como el dominio de estrategias de búsqueda de recursos y documentación específicos de la traducción audiovisual.

Además, si realizamos una comparación en términos generales de las competencias obtenidas en nuestro estudio con las competencias específicas que definen los profesionales de traducción audiovisual y las empresas empleadoras en España, según Cerezo Merchán (2012: 389), podemos observar que son las mismas que determinan nuestros dos grupos de estudio, profesionales y empresas empleadoras, en Rumanía. 


\section{B. Competencias genéricas}

\begin{tabular}{|c|c|}
\hline \multicolumn{2}{|c|}{ Competencias genéricas valoradas por grupo de población } \\
\hline Traductores & Empleadores \\
\hline $\begin{array}{l}\text { Capacidad para trabajar bajo presión } \\
\text { temporal }(87,5 \%)\end{array}$ & Preocupación por la calidad (100\%) \\
\hline Preocupación por la calidad $(62,5 \%)$ & $\begin{array}{l}\text { Capacidad para trabajar bajo presión } \\
\text { temporal }(100 \%)\end{array}$ \\
\hline Rápida resolución de problemas $(62,5 \%)$ & $\begin{array}{l}\text { Capacidad para adecuarse a los requisitos } \\
\text { del encargo }(100 \%)\end{array}$ \\
\hline Capacidad crítica y autocrítica $(50,0 \%)$ &  \\
\hline 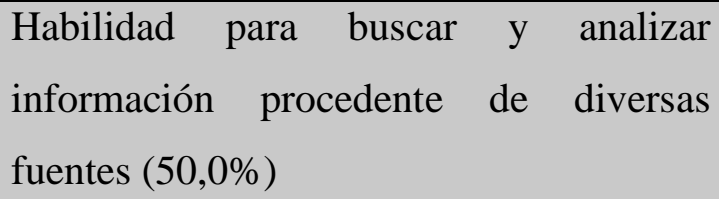 & $\begin{array}{l}\text { Capacidad de aplicar el conocimiento a la } \\
\text { práctica }(60 \%)\end{array}$ \\
\hline $\begin{array}{l}\text { Capacidad para adecuarse a los requisitos } \\
\text { del encargo }(50,0 \%)\end{array}$ & Rápida resolución de problemas $(60 \%)$ \\
\hline
\end{tabular}

Tabla 51. Competencias genéricas valoradas por grupo de población

En cuanto a las capacidades genéricas (cada competencia está asociada a un color, en las dos columnas de la tabla anterior), en primer lugar tenemos que especificar que en esta tabla figuran de nuevo seis en ambas columnas (traductor y empresa), puesto que las últimas tres seleccionadas por los traductores tienen un porcentaje igual (50\%), y las últimas dos marcadas en la columna de las empresas empleadoras tienen el mismo porcentaje $(60 \%)$.

Se puede apreciar que de las seis capacidades genéricas que aparecen en la tabla, cinco coinciden en ambas columnas. Sin embargo, se puede observar que el orden de estas competencias varía en los dos grupos. Cabe precisar que tanto los profesionales como las empresas posicionan en los primeros dos niveles la capacidad para trabajar bajo presión temporal y la preocupación por la calidad, factores que podemos afirmar que caracterizan la profesión del traductor audiovisual, y que además puntualizaban los 
profesionales y las empresas empleadoras en la encuesta y en las entrevistas que hemos realizado para este estudio (véase la sección 5.1.1.4 y 5.2.1.2).

Asimismo, destacan también la rápida resolución de problemas, así como la habilidad para buscar y analizar información procedente de diversas fuentes y la capacidad para adecuarse a los requisitos del encargo.

Las únicas competencias genéricas que no coinciden en la lista de las primeras cinco precisadas por los dos grupos son la capacidad crítica y autocrítica (seleccionada por los traductores) y la capacidad de aplicar el conocimiento a la práctica (seleccionada por las empresas empleadoras).

Sin embargo, si realizamos el análisis de las otras competencias genéricas que habíamos redactado como opción de selección para nuestros encuestados (profesionales y empresas empleadoras), como se observa en la sección 5.1.4.2 y 5.2.2.2 del presente estudio, la diferencia entre las competencias seleccionadas es considerable. En este caso, los profesionales puntuan, aunque con un porcentaje mas bajo $(37,5 \%$ y $12,5 \%$ ) la capacidad de análisis o la capacidad de aprender, así como la capacidad de aplicar el conocimiento a la práctica. Sin embargo, la única seleccionada por el grupo de las empresas empleadoras que coincide con las del grupo de los profesionales es la relacionada con los conocimientos de la profesión y la situación del mercado del trabajo.

Pese a estas ligeras diferencias finales, es importante destacar que la analogía de las primeras cinco competencias seleccionadas por los dos grupos (profesionales y empresas) representa una coordinación casi perfecta entre la oferta y demanda, en lo que concierne a las cualidades y destrezas necesarias en esta área del mercado profesional rumano.

\subsubsection{Objetivo específico 4: Describir el entorno formativo de la traducción audiovisual en Rumanía}

Tal como hemos expuesto en el epígrafe 3.5 del presente estudio, los profesionales de la traducción audiovisual de este país tienen, mayoritariarmente, como base para ejercer esta profesion, formación académica en Filología o lenguas extranjeras. Sin embargo, tal como hemos podido apreciar en la sección 5.1.1.2, posteriormente algunos continúan su preparación mediante cursos especializados en el extranjero o son, simplemente, autodidactas, y desarrollan sus competencias a través de la práctica realizada en el mercado laboral. 
Esto concuerda con lo descubierto en el Capítulo 3 trás realizar un breve repaso por la oferta académica en traducción audiovisual que ofrecen en la actualidad las universidades rumanas. En este repaso hemos podido comprobar la escasez de los cursos específicos dirigidos a la formación teórica y práctica de la traducción audiovisual. La Universidad Politécnica de Timișoara ofrece formación en este ámbito mediante un curso transversal de subtitulación, y la Universidad Babeș Bolyai de Cluj proporciona este tipo de formación a través de un Máster Europeo en Traducción. Asimismo, la Universidad de Bucarest incorpora desde el año 2008 en su Máster para la Traducción Literaria y Contemporanea (MTTLC) un curso de preparación específica en el ámbito de la traducción audiovisual durante cuatro semestres, tanto para la subtitulación como doblaje, bajo la credencial Traducción para la Subtitulacion y Doblaje.

Dado que a nosotros, a pesar de varios intentos de búsqueda de información especializada para definir concretamente la formación especifica en este ámbito, nos ha sido imposible localizar más fuentes informativas adecuadas, no nos soprende el desconocimiento de este tipo de formación que señalaba uno de nuestros entrevistados (véase la sección 5.1.3).

Por tanto, podemos apreciar que actualmente Rumanía, pese a ser un gran consumidor de productos audiovisuales extranjeros, que necesariamente requieren el servicio de profesionales de la traducción audiovisual y cuyos resultados pueden tener influencias culturales, puesto que redundan en el éxito de la película, tal como apreciamos en la sección 5.2.1.2, dedica una inversión limitada a este aspecto. Los primeros perjudicados en el sector de la traducción audiovisual son los principiantes en esta profesión, puesto que una escasa formación teórica y práctica dificultará su incorporación en el mercado. Por otra parte, también se ven afectados los profesionales que ejercen esta profesión, dado que una actualización continúa de las capacidades genéricas en este ámbito es fundamental por el desarrollo de las nuevas tecnologías, que son las herramientas de trabajo del traductor. Y por último, pero no por ello menos importante en este proceso, se verá afectado también el público al que va dirigido el producto final, puesto que la traducción final en la lengua meta depende de las habilidades y destrezas del traductor audiovisual, condicionada a su vez por su formación previa.

Asimismo, señalamos que una relación efectiva entre las universidades y las empresas podría suplir momentánemente la falta de cursos en este ámbito, y a efectos prácticos, podría ser beneficiosa para ambas, así como para los futuros profesionales, que 
tendrían la posibilidad de perfeccionar sus habilidades prácticas previamente a la incorporación en el mercado laboral rumano en este ámbito.

Tras exponer los datos anteriores y en línea con los comentarios de los participantes en el estudio, consideramos que actualmente en Rumanía la formación académica específica en este tipo de traducción demanda un incremento educativo importante para los actuales y los futuros profesionales en este ámbito.

\subsubsection{Objetivo específico 5: Conocer el perfil laboral de las empresas que proporcionan servicios de traducción audiovisual en Rumanía}

Los datos que hemos recabado y hemos analizado en el epígrafe 5.2 de nuestro estudio, sobre las empresas que proporcionan servicios de traducción audiovisual en Rumanía, nos han permitido identificar sus características fundamentales.

Hemos podido apreciar que algunas se han constituido poco tiempo después de la revolución del año 1989, dado que según los datos obtenidos, la antigüedad mínima señalada por las empresas es de siete años y la máxima de más de veinte. En cuanto a su ubicación, podríamos decir que Bucarest es el núcleo de esta actividad, dado que la mayoría tienen la sede en esta ciudad, y en menor medida en la parte oeste del país (en Transilvania), donde está ubicada otra empresa importante en este ámbito (tal como comentamos en el epígrafe 2.1.2).

Respecto a los clientes que requieren sus servicios, el abanico de demanda se divide entre los cines, las cadenas de televisión o los clientes particulares, así como la plataforma web Netflix, como señalaban algunos encuestados (véase el epígrafe 5.1.1.3). El número de empleados (en plantilla y autónomos) de que disponen varía en función de la antigüedad que tienen en el mercado y de la cantidad de encargos de traducción audiovisual de productos extranjeros que reciben, y suele situarse entre 1 y 15 , pero también puede ser más elevado. En cuanto el número de traductores contratados en plantilla por las empresas, este es bastante reducido, puesto que en la mayoría de ocasiones los contratan únicamente cuando los necesitan, o ejercen en régimen de colaboradores.

Por otra parte, las empresas suelen contratar a los traductores mediante la revisión de su CV, de una entrevista o por recomendaciones. Sin embargo, el mayor aval de los candidatos es su experiencia, puesto que la selección se efectúa mediante una prueba de 
traducción (véase la sección 5.2.1.2.) y su resultado prevalece sobre todos los criterios enunciados anteriormente.

Tal como hemos presentado en epígrafe 2.1.1, Rumanía es un país subtitulador, y por tanto, la mayoría de las empresas se dedican a esta modalidad de traducción audiovisual, y en menor medida al doblaje, pese a que en los últimos años han incrementado la práctica de esta última modalidad. Las combinaciones lingüísticas que destacan son inglés-rumano y francés-rumano, así como, aunque en una proporción limitada, alemán-rumano y español-rumano.

Generalmente son las empresas las que imponen el tipo de programa específico que emplea el traductor o el editor de subtítulos, así como las normas o restricciones que reciben de los clientes, y que delimitan, a su vez, la labor de los profesionales de traducción audiovisual.

El intercambio de materiales entre empresa y traductor se suele realizar a través de correo electrónico y de plataformas FTP. Las empresas normalmente proporcionan a los traductores archivos audiovisuales, listas de diálogos o guiones, pero no plantillas para subtítulos, como suelen hacer muchas empresas (sobre todo multinacionales) en otros países. Posteriormente, la taducción final del producto audiovisual en la lengua meta se le envía al cliente en formato RTF y XML. También llama la atención que algunas empresas empleen editores o técnicos, aunque en un porcentaje escaso, para realizar el pautado en el caso de la subtitulación (22,2\%) o el ajuste en el caso del doblaje $(33,3 \%)$. Ignoramos la razón de esta situación, puesto que ninguno de los encuestados lo ha especificado en el apartado de comentarios. Sin embargo, la situación hasta cierto punto habitual, a día de hoy en otros países, como por ejemplo España, es que los traductores hagan también el pautado/ajuste, dado que reciben formación sobre la realización de estas técnicas.

La revisión lingüística se aplica a la traducción final en la lengua meta, aunque tal como hemos podido apreciar en el epígrafe 5.1, en algunos comentarios de los traductores, en ocasiones se trata de un proceso rutinario con cambios impuestos por el revisor o la empresa, a pesar de la disconformidad del profesional.

Asimismo, es bastante sorprendente la escasa información que tienen las empresas sobre la formación específica en este ámbito, puesto que la mayoría de las empresas participantes en nuestro estudio no considera adecuada la formación práctica previa en esta disciplina. Además, la relación casi inexistente entre las empresas y las universidades 
que ofertan cursos específicos de traducción audiovisual dificulta la incorporación de los principiantes en el ámbito profesional este país.

A modo de conclusión, retomamos y remarcamos la importancia, y al mismo tiempo la necesidad, de un vínculo entre las empresas y las universidades en este país, puesto que entre ambas podrían formar a los nuevos profesionales, coordinando la formación académica teórica con la práctica, dos pilares fundamentales en el desempeño de la labor de los traductores de textos audiovisuales.

\section{Objetivo general. Describir y analizar el perfil formativo y socioprofesional del traductor audiovisual en la actualidad en Rumanía.}

La triangulación de los datos recabados en nuestro estudio, que ha dado respuesta a nuestros objetivos específicos, nos permite también alcanzar el objetivo general de nuestro estudio. Gracias a esta triangulación, podemos establecer que el perfil formativo y socioprofesional del traductor audiovisual en la actualidad en Rumanía se estructura del siguiente modo:

- Perfil formativo: Pese a que son de diferentes edades y a que llevan un número distinto de años dedicados a esta profesión, la mayoría de los traductores audiovisuales tienen como formación académica inicial los estudios filológicos. Paulatinamente, se han ido formando en traducción audiovisual bien a través de la experiencia profesional, bien a través, en un número reducido de casos, de cursos específicos realizados en Rumanía o en el extranjero. Asimismo, posicionan en primer lugar como manera de formación más adecuada en este ámbito la experiencia profesional, y posteriormente los cursos específicos, lo que es lógico si tenemos en cuenta que actualmente las universidades que ofertan este tipo de cursos no cubren las necesidades prácticas de esta disciplina o que, por su escasa difusión, algunos traductores pueden desconocer.

- Perfil socioprofesional: La profesión del traductor audiovisual experimentó un cambio sustancial después de la revolución del año 1989, dado que el incremento de las nuevas cadenas de televisión privada, con programas específicos para cada tipo de público, amplió el mercado laboral. El profesional actual en este país se define por los siguientes aspectos: 
- Las combinaciones lingüísticas que destacan son inglés-rumano y francésrumano, puesto que son las que más solicitan los clientes. La limitación lingüística podría repercutir también en el mercado laboral, dado que restringe la actividad del gremio.

- Los clientes que demandan sus servicios son principalmente las distribuidoras y las cadenas de televisión, a las que se añaden puntualmente los festivales o los clientes particulares.

- En cuanto al sistema laboral, priman los contratos de colaboración, así como el régimen de freelancer, que determinan habitualmente esta profesión. Además, según comentan nuestros entrevistados, frecuentemente las empresas empleadoras prefieren contratar a estudiantes, puesto que estos están dispuestos a trabajar por tarifas más bajas con tal de adquirir experiencia profesional.

- La modalidad de traducción audiovisual que más emplean es la subtitulación, dado que es la más extendida y la que se utiliza desde el inicio de la traducción audiovisual en Rumanía por diferentes motivos (políticos, económicos o de habitus), tal como hemos podido observar en la sección 2.2.1 de este estudio. Sin embargo, el cambio sociopolítico ha contribuido a la variación de las modalidades de la traducción audiovisual, y el uso del doblaje ha ampliado el perfil profesional del traductor de textos audiovisuales en Rumanía.

- Las normas y las restricciones impuestas por algunos clientes a las empresas se transmiten al traductor, quien además recibe las de las propias empresas empleadoras. Generalmente, se trata de directrices de contenido del producto extranjero referentes a los nombres de los personajes, canciones, en caso de que aparezcan en el producto original, o la traducción del título en la lengua meta, entre otros.

- Los materiales que se intercambian entre las empresas y los traductores se transfieren vía correo electrónico o FTP y pueden ser guiones, listas de diálogos o archivos audiovisuales. Como materiales de apoyo para realizar la traducción audiovisual, priman los diccionarios, seguidos por los recursos terminológicos y especializados (bancos de datos terminológicos 
de temáticas y combinaciones lingüísticas distintas) o los recursos enciclopédicos.

- En cuanto al destinatario de los productos audiovisuales extranjeros traducidos, no se realiza una selección, dado que se dedican a la traducción de productos audiovisuales dirigidos tanto al público infantil como al público adulto. No obstante, es imprescindible determinar la franja de edad para adecuar el vocabulario empleado según las directrices del CNA (Consejo Audiovisual Nacional), que hemos expuesto en la sección 2.1 del presente estudio.

- La inexistencia en la actualidad, en este país, de una asociación de traductores audiovisuales desampara a este grupo, frente a las condiciones arbitrarias que imponen a veces algunas empresas empleadoras. Por otra parte, su hipotética existencia también ayudaría a regular los asuntos referentes a los derechos de autor, que se estipulan, pero no se respetan, y referentes a las tarifas, que varían en función de cada empleador y que se aplican tomando como referencia distintas unidades de medida (minutos, hora, media hora, por película completa, por programa completo, caracteres o reel), pero con un denominador común: precios bajos disimulados mediante contratos de confidencialidad.

"Finalmente, es una profesión", afirmaba una empresa a la que entrevistamos. Efectivamente, desde hace décadas es una profesión en este país, una profesión cuyo resultado disfrutamos a través de la pantalla y que cautiva a millones de usuarios, y cuyo denominador común es la pasión de los profesionales que se dedican a ella.

\subsection{Futuras líneas de investigación}

El propósito fundamental de esta tesis doctoral ha sido realizar una aproximación a la traducción audiovisual y al perfil del profesional que ejerce esta labor en Rumanía.

Se abren ahora diversas avenidas de investigación que podrían abordarse a partir del presente trabajo: 
1. Ampliar el número de sujetos de los dos grupos de población analizados en nuestro estudio (profesionales y empleadores). Esto podría aportar más datos sobre el tema analizado en la presente tesis doctoral y ayudar a corroborar sus conclusiones.

2. Incluir a los profesores o especialistas que imparten cursos específicos de esta disciplina en Rumanía como tercer grupo de población, con la finalidad de ampliar el espectro de visiones sobre la profesión en este país.

3. Analizar y describir las leyes y los derechos que amparan actualmente a los profesionales de la traducción audiovisual en Rumanía, tanto por parte del estado como de las empresas empleadoras.

4. Profundizar en las carencias académicas (teóricas o prácticas) que limitan la impartición de esta disciplina actualmente en Rumanía, y realizar propuestas formativas de mejora para el futuro.

5. Comparar las convenciones que se aplican en las distintas modalidades de traducción audiovisual en diferentes géneros audiovisuales en Rumanía y España, u otros países de interés.

6. Estudiar comparativamente la censura aplicada en el régimen político anterior y la aplicada en la actualidad en Rumanía en los productos audiovisuales, así como sus consecuencias en los textos meta.

Damos así por finalizado este estudio, que esperamos pueda contribuir a la descripción de una realidad y una profesión, cuya visibilidad e impacto investigador eran muy reducidos hasta la fecha. 


\section{Capítulo 7: Bibliografia}

AGOST, R. (1999) Traducción y doblaje: palabras, voces e imágenes. Barcelona: Ariel.

AGOST, R. (1997) La Traducció audiovisual el doblatge. Castelló de la Plana: Universitat Jaume I.

AMEZCUA, M. y GALVEZ TORO, A. (2002) Los modos de análisis en investigación cualitativa en salud: perspectiva crítica y reflexiones en voz alta. Rev. Esp. Salud Publica, vol.76, $\mathrm{n}^{\circ}$ 5, pp. 423-436.

ANGELELLI, C. (2014) The Sociological turn in translation and interpreting studies. Ámsterdam: John Benjamins.

BARTOLL, E. (2012) La subtitulació. Aspectes teòrics i pràctics. Universitat de Vic: Eumo Editorial.

BARTOLL, E. (2008) Paramètres per a una taxonomia de la subtitulació. Tesis doctoral inédita. Universitat Pompeu Fabra. Versión electrónica: http://hdl.handle.net/10803/7572 [Último acceso: 2 de marzo 2017].

BELTON, J. (1985) Technology and Aesthetics of Film Sound. Nueva York: Columbia University Press.

BERGER, P. y LUCKMANN, T. (1967) La construcción social de la realidad. Buenos Aires: Amorrortu.

BOURDIEU, P. (1972) Esquisse d'une théorie la pratique, précédé de trois études d'ethnologie kabyle. Geneva: Droz.

BRACE, I. (2008) Questionnaire Design (2nd ed.). Estados Unidos: Kogan page.

BRUYN, S. (1966) La Perspectiva Humana en Sociología. La Metodología de la Observación Participante. Buenos Aires: Amorrortu. 
CALVO ENCINAS, E. (2010) Análisis curricular de los estudios de traducción e interpretación en España: experiencia curricular del estudiantado. Granada:Universidad de Granada. Tesis doctoral. Disponible en: https://www.google.es/url?sa=t\&rct=j\&q=\&esrc=s\&source=web\&cd=1\&ved=0ah UKEwieo5L97fbSAhVrBcAKHYXVCBEQFggcMAA\&url=http\%3A\%2F\%2Fdig ibug.ugr.es\%2Fbitstream\%2F10481\%2F3488\%2F1\%2F1852574x.pdf\&usg=AFQj CNHK6Oh6-jDdDiDv3-dEWpGDYwX7Qw\&sig2=Ys-ko5XdQNTTUovssPyJow [Último acceso: 15 de marzo 2017].

CANALES CERÓN, M. (2006) Metodologías de investigación social: introducción a los oficiós. Santiago de Chile: Lom Ediciones.

CANTACUZINO, I. (1965) Momente din trecutul filmului romanesc. Bucarest: Editura Academiei Republicii Socialiste România.

CANTACUZINO,I. (1971) Contribuții la istoria cinematografiei în România 1896-1848. Bucarest: Editura Academiei Republicii Socialiste România.

CARANFIL, T. (1988) În căutarea filmului pierdut. Bucarest: Editura Meridiane.

CARANFIL, T. (1984) Vârstele peliculei. Bucarest: Editura Meridiane.

CASTRO, X. (2001) "El traductor de pel·lícules". En Duro Moreno (coord.) La traducción para el doblaje y la subtitulación. Madrid: Cátedra, pp. 267-298.

CĂLIMAN, C. (2000) Istoria filmului românesc 1897 - 2000. Bucarest: Editura Fundaţiei Culturale Române.

CEREZO MERCHÁN, B. et al. (2016) La traducción para el doblaje en España: mapa de convenciones. Castelló de la Plana: Publicacions de la Universitat Jaume I.

CEREZO MERCHÁN, B. (2012) La didàctica de la traducción audiovisual en España: Un estudio de caso empírico-descriptivo. Tesis doctoral. Castellón de la Plana. Universitat Jaume I. Disponible www.tesisenred.net/bitstream/handle/10803/83363/bcerezo.pdf?sequence [Último acceso: 27 de marzo 2017]. 
CHAUME, F. ( 2013) Panorámica de la investigación en traducción para el doblaje. TRANS. REVISTA DE TRADUCTOLOGÍA 17/2013. Disponible en: http://www.trans.uma.es/trans_17/Trans17_013-034.pdf. [Último acceso: 15 de marzo 2017].

CHAUME, F. (2012) Audiovisual Translation: Dubbing. Londres/Nueva York: Routledge.

CHAUME, F. (2004) Cine y traducción. Madrid: Cátedra.

CHAUME, F. (2003) "Teaching audiovisual translation: Some methodological proposals". En Luis Pérez González (ed.) Speaking in Tongues: Language across Contexts and Users. Universitat de València: Publicacions de la Universitat de València. pp. 271-302.

CHAUME, F. y AGOST, R. (2001) "Horizontes cercanos: La consolidación académica de la traducción audiovisual”. En Chaume, F. y Agost, R. (Eds.) La traducción en los medios audiovisuales. Castelló de la Plana: Publicacions de la Universitat Jaume I.

CHAUME, F. y GARCÍA DE TORO, C. (2001) "El doblaje en España: angilicismos frecuentes en la traducción de textos audiovisuales". Rivista Internazionale di Tecnica della Traduzione, $\mathrm{n}^{\circ}$ 6, pp. 119-137.

CHAUME, F. (2000) “Aspectos profesionales de la traducción audiovisual”. En Dorothy Kelly (ed.) La traducción y la interpretación en España hoy: perspectivas profesionales. Granada: Editorial Comares, pp. 47-83.

CHAVES, M. J.(2000) La traducción cinematografica: el doblaje. Huelva: Servicio de Publicaciones de la Universidad de Huelva.

COMTE, A. (1896) The positive philosophy of Auguste Comte. Londres: G. Bell \& Sons.

CRESWELL, J. W. (2009) Research Design: Qualitative, Quantitative, and Mixed Methods Approaches. Los Angeles: Sage Publications, Inc. 
CRESWELL, J. W. (2005) Educational research: Planning, conducting, and evaluating quantitative and qualitative research. Upper Saddle River, Nueva York: PrenticeHall.

CRESWELL, J. W. y CLARK, V. L. (2011). Designing and conducting mixed methods research (2nd ed.). Thousand Oaks, CA: Sage.

CRESWELL, J. W. y CLARK, V. L. (2007). Designing and conducting Mixed Methods research. Thousand Oaks, CA: Sage.

DARBELNET, J. (1970) “Traduction littérale ou traduction libre?”. META, vol. 15, n 2 , pp. 88-94.

DE BARRERA, J. (2008) Metodología de la investigación, una comprensión holística. Caracas: Ediciones Quirón - Sypal.

DÍAZ-CINTAS, J. y REMAEL, A. (2007) Audiovisual translation: subtitling. Kinderhood, Nueva York: St. Jerome.

DÍAZ-CINTAS y ORERO, P. (2010) “Voiceover and dubbing." En Yves Gambier y Luc van Doorslaer (eds.). Handbook of Translation Sudies, vol.1, Amsterdam/Philadlphia, Benjamins, pp. 441-445.

DÍAZ-CINTAS, J. (2003) Teoría y práctica de la subtitulación inglés-español. Barcelona: Ariel.

DÍAZ CINTAS, J. (2001) La traducción audiovisual. El subtitulado. Salamanca: Ediciones Almar.

DURO, M. y AGOST, R. (2001) La Traducción para el doblaje y la subtitulación. Madrid: Cátedra.

DURKHEIM, E. (1938) The Rules of Sociological Method. Nueva York: Free Press.

DUȚĂ, M. (1976) “Scurt istoric”. En Cantacuzino, I. y Gheorghiu (eds.) Cinematograful românesc contemporan 1949-1975. Bucurest: Editura Meridiane, pp.37-46. 
FONTCUBERTA, J. (2001) "La traducción en el doblaje o el eslabón perdido". En Miguel Duro (coord.) La traducción para el doblaje y la subtitulación. Madrid: Cátedra, pp 299-314.

FRANCO, E., MATAMALA, A. y ORERO, P. (2010) Voice-over Translation. An Overview. Nueva York/ Oxford/ Viena: Peter Lang.

GAMBIER, Y. (2003) "Introduction - Screen Transadaptation: Perception and Reception. Screen Translation”. The Translator, vol. 9, n² 2, Mánchester: St. Jerome Publishing, pp. 171-189.

GAMBIER, Y. y GOTTLIEB, H. (2001) (Multi)Media Translation. Concepts, Practices and Research. Ámsterdam: John Benjamins.

GAMBIER, Y. (2000) "Le profil du traducteur pour écrans.” Daniel Gouadec (éd.) Formation des traducteurs, Actes du colloque international de Rennes, 2425.9.1999. París: Maison du Dictionnaire, pp. 89-94. Disponible en: http://www.erudit.org/fr/revues/meta/2004-v49-n1-meta733/009015ar/_[Último acceso: 24 de marzo 2017].

GARCÍA YEBRA, V. (1982) Teoría y práctica de la traducción. Madrid: Gredos.

GEORGAKOPOULOU, P. (2009) "Subtitling for the DVD Industry”. En Díaz Cintas, J. y Anderman, G. (eds.) Audiovisual Translation: Language Transfer on Screen. Nueva York: Palgrave Macmillan, pp. 21-35.

GILABERT, A., LEDESMA, I. y TRIFOL, A. (2001) “La sincronización y la adaptación de guiones cinematográficos". En Duro Moreno (coord.) La traducción para el doblaje y la subtitulación. Madrid: Cátedra, pp.325-330.

GHEORGHIU-CERNAT, M.(1983) Filmul şi armele. Bucarest Editura Meridiane.

GHEORGHIU, M. y PĂTRĂSCOIU, C. (1976) “Temeliile cinematografiei nationale. Structuri si perpective." En Cantacuzino, I. y Gheorghiu (eds.) Cinematograful românesc contemporan 1949-1975. Bucarest: Editura Meridiane, pp.29-37. 
GRINNELL, R. M. (1997) Social work research and evaluation: Quantitative and qualitative approaches ( $5^{\mathrm{a}}$ ed.). Itasca, Illinois: E.E. Peacock Publishers.

GRINNELL, R. M. y UNRAU, Y. A. (2007) Social work research and evaluation: Foundations of evidence-based practice (8a Ed.). Nueva York: Oxford University Press.

HANSEN, G. (1997) "Success in Translation". Perspectives Studies in Translatology, vol. $5, \mathrm{n}^{\mathrm{o}} 2$, pp. 201-210.

HERNÁNDEZ, R. FERNÁNDEZ, C. y BAPTISTA, P. (2010) Metodología de la investigación. México: McGraw-Hill Interamericana.

HERNÁNDEZ, R., FERNÁNDEZ, C. y BAPTISTA, P. (2006) Metodología de investigación. $4^{\mathrm{a}}$ edición. México: McGraw-Hill.

HERNANDEZ, R. Y MENDOZA, C. P. (2008) El matrimonio cuantitativo cualitativo: El paradigma mixto. En J. L. Alvarez Gayou (Presidente), 6to. Congreso de Investigación en Sexología. Congreso efectuado por el Instituto Mexicano de Sexologia, A. C. y la Universidad Juarez Autonoma de Tabasco. Villahermosa, Tabasco, México.

HURTADO ALBIR, A. (2001) Traducción y Traductología. Introducción a la Traductología. Madrid: Cátedra.

HURTADO ALBIR, A. (1996) "La enseñanza de la traducción directa "general". Objetivos de aprendizaje y metodologia”. En Hurtado Albir, A. (ed.): Estudis sobre la Traducció. Castelló de la Plana: Publicacions de la Universitat Jaume I, pp. 3156.

HURTADO, I. y TORO, J. (1998) Paradigmas y Métodos de Investigación en tiempos de cambios. Caracas: Episteme consultores.

JANESICK, V. J. (1998) "The dance of qualitative research design: methaphor, methodolatry, and meaning”. En Denzin, N.K., Lincoln, Y.S. (eds.) Strategies of qualitative inquiry. Thousand Oaks, Sage, pp. 35-85. 
JIMÉNEZ-DOMÍNGUEZ, B. (2000) Investigación cualitativa y psicología social crítica. Revista Universidad de Guadalajara, nº17, Dossier Investigación cualitativa en salud. Disponible en: http://www.cge.udg.mx/revistaudg/rug17/3investigacion.html [Último acceso: 05 de marzo de 2017].

IAROSSI, G. (2005) The Power of Survey Design: A User's Guide for Managing Surveys, Interpreting Results and Influencing Respondent. Washinton, D.C.: World Bank.

IVARSSON, J. (1992) Subtitling for the media. A Handbook of an Art. Estocolmo: Transedit.

IVARSSON, J. Y CARROLL, M. (1998) Subtitling. Simrishamn: Transedit.

KELLY, D. (2005) A Handbook for Translator Trainers. A Guide to Reflective Practice. Mánchester: St. Jerome.

KELLY, D. (2002) “La competència traductora: bases para el diseño curricular”. Puentes 1, pp. 9-20.

KUHN, T. (1971) La estructura de las revoluciones científicas. México: Fondo de Cultura Económica.

LEBOREIRO ENRÍQUEZ, F. y POZA YAGÜE, J. (2001) “Subtitular: toda una ciencia... y todo un arte". En Miguel Duro (coord.) La traducción para el doblaje y la subtitulación. Madrid: Cátedra, Pp. 315-323.

LEÓN, O. G. y MONTERO, I. (2003) Métodos de Investigación en psicología y Educación ( $3^{\text {a }}$ edición). Madrid: McGraw-Hill.

LUKIĆ, N. (2012) "Introducción a la traducción aplicada al voice-over: La traducción de documentales y entrevistes". En Actas II Congreso Sociedad Española de Lenguas Modernas. Sevilla: SELM, pp.187-205.

LUYKEN, G. M. et al. (1991) Overcoming language barriers in television: dubbing and subtitling for the European audience. Mánchester: European Institute for the Media.

MANVELL, R. (1944) Film. Buenos Aires: Eudeba. 
MARTÍ FERRIOL, J.L. (2012) "Nueva aproximación al cálculo de velocidades de lectura de subtítulos". TRANS, $n^{o}$ 16, pp. 39-48. Diponible en: http://www.trans.uma.es/trans_16/Trans16_039-048.pdf [Último acceso: 20 de enero 2017].

MARTÍ FERRIOL, J. L. (2010) Cine independiente y traducción. Valencia: Tirant lo Blanch.

MARTÍ FERRIOL, J. L. (2006) Estudio empírico y descriptivo del método de traducción para doblaje $y$ subtitulación. Diponible en: http://www.tesisenred.net/handle/10803/10568 [Último acceso: 20 de enero 2017].

MARTÍNEZ SIERRA, J. (2012) Introducción a la traducción audiovisual. Murcia: Servicio de Publicaciones de la Universidad de Murcia.

MARTÍNEZ SIERRA, J. (2004) Estudio descriptivo y discursivo de la traducción del humor en textos audiovisuales. El caso de Los Simpson. Tesis doctoral presentada en el Departamento de Traducción y Comunicación de la Universitat Jaume I $<$ http://www.tdx.cbuc.es/>. [Último acceso: 05 de febrero de 2017].

MAYORAL, R. (2001) Aspectos epistemológicos de la traducción. Castellón: Servei de Publicacions, Universitat Jaume I.

MAYORAL, R. (1999) “Nuevas perspectivas para la traducción audiovisual”. Granada: Sendebar, $n^{\circ} 13$, pp. 123-140.

MAYORAL, R. (1993) "La traducción cinematográfica, el subtitulado". Granada: Sendebar, $n^{\circ} 4$, pp. 45-68.

MERINO, R. (2006) “Spanish Translations of Joyce'Exiles.” En Malcom Coulthard and Patricia Anne Odber de Baubeta (eds). The Knowledges of the Translator: From Literary Interpretation to Machine Classification. Lewiston, NY: Edwin Mellen, pp. 219-298.

MERINO, R. (2001) “Traducciones Censuradas Inglés- Español”. En Pajares, E., Merino, R., y Santamaria, J. M (eds). Trasvases culturales: Literatura, cine, traducción 3. Bilbao: UPV/EHU, pp. 287-295. 
MERTENS, D. (2005) Research and evaluation in Education and Psychology: Integrating diversity with quantitative, qualitative, and mixed methods. Thousand Oaks: Sage.

MIHAIL, J. (1967) Filmul românesc de altădată. Bucarest: Editura Meridiane.

MONZÓ NEBOT, E. (2006) “¿Somos profesionales? Bases para una sociologia de las profesiones aplicada a la traduccion”. En Parada, A. y Díaz Fouces, O. (eds.) Sociology of Translation. Vigo: Sevicios de Publicaciones de Universidad de Vigo, pp 155-176.

MUÑOZ MIQUEL, A. (2014) El perfil del traductor médico: análisis y descripción de competencias especificas para su formación. Tesis doctoral. Castellón de la Plana. Universitat Jaume I. Disponible en: http://repositori.uji.es/xmlui/handle/10234/124584 [Último acceso: 27 de marzo 2017].

NEWMARK, P. (1981) Approaches to Translation. Oxford y Nueva York: Pergamon Press.

NEWMARK, P. (1998) A textbook of translation. Hetfordshire: Prentice Hall Europe.

NIDA, E. A. (1964) Toward a Science of Translating with Special Reference to Principles and Procedures Involved in Bible Translating. Leiden: E. J. Brill.

OPROIU, C. (1976) “Un sfert de veac de film românesc.” En Cantacuzino, I. y Gheorghiu (eds.) Cinematograful românesc contemporan 1949-1975. Bucarest: Editura Meridiane, pp.10-29.

ORERO, P. (2009) “Voice-over in Audiovisual Translation”. En Gunilla Anderman, G. y Díaz Cintas, J. (eds) Audiovisual Translation. Language Transfer on Screen. Londres: Palgrave Macmillan, pp. 130-139.

ORERO, P. (2005) “La traducción de entrevistas para voice-over”. En Zabalbeascoa, P., Santamaría, L., Chaume, F. (eds.) La traducción audiovisual: Investigación, enseñanza y profesión. Granada: Comares, pp. 213-222. 
PACTE (2003) "Building a Translation Competence Model". En Fabio Alves (ed.) Triangulating Translation: Perspectives in Process Oriented Research. Ámsterdam: John Benjamins. Disponible en: http://grupsderecerca.uab.cat/pacte/sites/ grupsderecerca.uab.cat/pacte/files/2003PACTEBenjamins0.pdf [Último acceso: 22 de febrero 2017 ].

PANAIA, M. (2007) Una revisión de la sociología de las profesiones desde la teoría crítica del trabajo en la Argentina. Disponible en: http://archivo.cepal.org/pdfs/2008/S2008114.pdf [Último acceso: 27 de marzo 2017].

PSATHAS, G. (1973) Phenomenological Sociology: Issues and Applications. Nueva York: John Wiley.

PYM, A. (2006) Sociocultural aspects of translating and interpreting. Ámsterdam, Filadelfia : John Benjamins.

PYM, A. (1997) Pour une ethique du traducteur. Ottawa: Presses de l'Université d'Ottawa.

RACOVICEANU, P. (1971) “De la teatru la film”. En Cantacuzino, I. (ed.) Contributii la istoria cinematografiei in Romania 1896-1848. Bucarest: Editura Academiei Republicii Socialiste Romania, pp.140-155.

RÎPEANU, T. (2004) Filmat în România. Bucarest: Editura Fundaţiei PRO.

ROBYNS, C. (1994) “Translation and Discursive Identity”, en Poetics Today, núm. 15, pp. 405-428.

RODRÍGUEZ, G., GIL, J. y GARCÍA, E. (1996) Métodos de investigación cualitativa. Málaga: Aljibe.

SCHUTZ, A. (1962) El problema de la realidad social. Buenos Aires: Amorrortu.

STAKE, R. (2006) Evaluación comprensiva y evaluación basada en estándares. Barcelona: Editorial Graó. 
TAYLOR, S. J. y BOGDAN, R. (1992) Introducción a los métodos cualitativos de investigación. Buenos Aires: Paidós.

TAYLOR, S. J. y BOGDAN, R. (1987) Introducción a los métodos cualitativos de investigación: la búsqueda de significados. Barcelona: Paidós.

TAYLOR, S. J. y BOGDAN, R. (1984) Introducción a los métodos cualitativos de investigación. $4^{\mathrm{a}}$ edición. Barcelona: Paidós.

TODD, Z., y NERLICH, B. (2004) "Future directions". En Z. Todd, B. Nerlich, S. McKeown y D. Clarke (eds.) Mixing methods in psychology. Hove, East Sussex: Psychology Press, pp. 231-237.

VENUTI, L. (2004) The Translation studies reader. Nueva York: Routledge.

VENUTI, L. (1995) The translator's invisibility: A history of translation. Nueva York: Routledge.

WILENSKY, H.L. (1964) “The professionalization of everyone?” American Journal of Sociology, $\quad \mathrm{n}^{\mathrm{o}} \quad 70 . \quad$ Disponible en: http://garfield.library.upenn.edu/classics1980/A1980KU16200001.pdf [Último acceso: 7 de enero 2017].

WILLIAMS, J. y CHESTERMAN, A. (2002) The Map. A Beginner's Guide to Doing Research in Translation Studies. Mánchester: St. Jerome.

WHITMAN-LINSEN, C. (1992) Through the Dubbing Glass. The Synchronization of American Motion Pictures into German, French and Spain. Berna: Peter Lang.

WOLF, M. (2007) Constructing a sociology of Translation. Ámsterdam: John Benjamins.

YÁNIZ ÁLVAREZ, C. (2006) Planificar desde competencias para promover el aprendizaje: el reto de la sociedad del CONOCIMIENTO PARA el profesorado universitario. Bilbao: Universidad de Deusto. 
YÁÑIZ ÁLVAREZ, C. (2004) “Convergencia europea de las titulaciones universitarias. El proceso de adaptación: fases y tareas”. Revista de la Red Estatal de Docencia Universitaria. vol. $4, \mathrm{n}^{\circ} 1$.

\section{Webgrafía}

Arhiva Națională de Filme. Disponible en: http://www.anf-cinemateca.ro/independentaromaniei-1912 [consulta realizada el 25/08/2016].

Historia Filmului Românesc. Disponible http://www.istoriafilmuluiromanesc.ro/filme-romanesti 6 [consulta realizada el 17/08/2016].

Lista filmelor artistice românești. Disponible en: https://ro.wikipedia.org/wiki/Lista_filmelor_artistice_rom\%C3\%A2ne\%C8\%99ti_din_p erioada_1911\%E2\%80\%931947 [consulta realizada el 28/08/2016].

Filmul Românesc. Disponible en: https://ro.wikipedia.org/wiki/Filmul_rom\%C3\%A2nesc_p\%C3\%A2n\%C4\%83_\%C3\% AEn_1948 [consulta realizada el 28/08/2016].

"Odessa în flăcări": propagandă până în pânzele albe. Disponible en: http://www.evz.ro/odessa-in-flacari-propaganda-pana-in-panzele-albe-933164.html [consulta realizada el 01/09/20016].

Legea Naţionalizării din $1948 . \quad$ Disponible en: http://enciclopediaromaniei.ro/wiki/Legea_Na\%C5\%A3ionaliz\%C4\%83rii_din_1948 [consulta realizada el 28/08/2016]. 
Republica Socialistă România. Disponible https://ro.wikipedia.org/wiki/Republica_Socialist\%C4\%83_Rom\%C3\%A2nia [consulta realizada el 8/08/2015].

Un certain regard. Disponible en: https://es.wikipedia.org/wiki/Un_certain_regard [consulta realizada el 3/11/2016].

Legea $n r .504$ din 2002. Legea audiovizualului. Disponible en: http://legislatie.resursepentru-democratie.org/legea/504-2002.php[consulta realizada el 04/01/ 2016].

Dublaj. Diponible en: http://ro.wikipedia.org/wiki/Dublaj [consulta realizada el 20/09/2013].

De unde au invățat românește filmele străine. Disponible en: http://www.capital.ro/detalii-articole/stiri/de-unde-au-invatat-romaneste-filmele-straine157531.html [consulta realizada el 25/10/2015].

Study on the use of subtitling. The potential of subtitling to encourage foreign language learning and improve the mastery of foreign languages. Disponible en: http://eacea.ec.europa.eu/llp/studies/documents/study_on_the_use_of_subtitling/rapport _final-en.pdf [consulta realizada 10/08/2016].

Dublarea filmelor în limba română e cea mai respinsă propunere legislativă din ultima vreme. Disponible en:http://www.cinemarx.ro/stiri-cinema/dublarea-filmelor-in-limbaromana-e-cea-mai-respinsa-propunere-legislativa-din-ultima-vreme/[consulta realizada el 15/02/2016].

Vreti filme dublate sau subtitrate? - Sondaj Ziare.com. Disponble en: http://www.ziare.com/media/televiziune/vreti-filme-dublate-sau-subtitrate-sondaj-ziarecom-1092879 [consulta realizada el 19/08/2016].

Raport de activitate al CNA pe anul 2013. Disponible en: http://www.cdep.ro/caseta/2014/05/22/hp14011_CNA13.pdf [consulta realizada el 20/01/2017].

Asociația pentru Promovarea Filmului Romanesc. Disponible en: http://www.creativeeurope-media.eu/festivals/organisers/item/938-transilvania-international-film-festival14th-edition[consulta realizada el 9/01/2017]. 
Centrul Național al Cinematografiei România. Disponible en: http://cnc.gov.ro/[consulta realizada el 12/01/2017].

Salariul de bază minim brut pe țară, majorat începând cu 1 mai 2016. Disponible en: http://gov.ro/ro/guvernul/sedinte-guvern/salariul-de-baza-minim-brut-pe-tara-majoratincepand-cu-1-mai-2016/ [consulta realizada el 15/02/2017].

Hotărârea nr. 376/2016 privind aprobarea Nomenclatorului domeniilor și al specializărilor/programelor de studii universitare și a structurii instituţiilor de invăţământ superior pentru anul universitar 2016-2017. Disponible en: http://lege5.ro/Gratuit/geytsnztg4zq/hotararea-nr-376-2016-privind-aprobareanomenclatorului-domeniilor-si-al-specializarilor-programelor-de-studii-universitare-sia-structurii-institutiilor-de-invatamant-superior-pentru-anul-universitar/ [consulta realizada el 19/03/2017].

Povestile Vioricai Bucur "tanti cu desenele animate" inainte de 1989. Disponible en: https://www.historia.ro/sectiune/portret/articol/povestile-vioricai-bucur-tanti-cudesenele-inainte-de-1989 [consulta realizada el 15/02/2016]. 
Anexos 


\section{ANEXO I}

\section{CHESTIONAR TRADUCATORI}

Ma numesc Laura Vulpoiu, si acest chestionar este o parte importante din teza mea de doctorat, care trateaza situatia actuala a traducatorului audiovizual in Romania, studiu care se realizeaza sub coordonarea prof. Dr. Beatriz Cerezo Merchán (Universitatea Valencia) si prof. Dr. José Luis Martí Ferriol (Universitatea Jaime I).

In aceasta teza doctorala ne propunem sa studiem si sa descriem perfilul traducatorului audiovisual vazut din prisma profesionalului si a angajatorului. De aceea avem nevoie de opinia dumneavoastra si consideram ca aceasta colaborare poate contribui la imbunatirea academica si profesionala a acestei activitati.

Intrebarile chestionarului se structureaza in patru parti; prima parte trateaza perfilul actual al traducatorului audiovisual, in a doua si a treia incercam sa facem o evaluare profesionala si academica a profesionalilor din acest domeniu. lar ultima parte include competentele, care considerati ca sunt necesare in aceasta profesie.

Sunt necesare 10-20 minute pentru a raspunde la urmatoarele intrebari, de forma anónima. In cazul in care doriti sa primiti informatii despre rezultatele obtinute puteti sa ne scrieti email-ul dumneavostra (nu este obligatoriu).

Date de contact: Laura Vulpoiu

Telefon: 0034/ 635.104.709

Titlul proiectului de teza de doctorat: Traducerea audiovizuala si profilul traducatorului audiovizual in Romania

\section{Profilul traducatorului}

1. Indicati varsta dumnevoastra

Marca solo un óvalo.

25-35

$35-45$

45-55

Otras

2. Indicati nivelul dumnevostra de experienta ca traducator Marca solo un óvalo.

3-5

$5-10$

10-15

Otras 
3. In ce parte a tarii locuiti?

Marca solo un óvalo.

Oltenia

Muntenia

Transilvania

Capitala

Comentarii

4. Ce tip de studii aveti ? (Puteti sa marcati mai multe optiuni, daca este cazul)

Selecciona todos los que correspondan.

$\square$ Autodidact (lecturi, practica profesionala)

Studii de Filologie

Studii de Traducere

$\square$ Studii de Doctorat

$\square$ Formare interna in firme

Altele (specificati, va rog)

5. Ati realizat cursuri de specialitate de traducere audiovizuala in Romania sau in alte tari? Selecciona todos los que correspondan.

Romania

$\square$ Alte tari

Ambele

Comentarii

6. Ce tip de cursuri?

Marca solo un óvalo.

Universitare

Nu universitare

Altele (specificati, va rog)

7. In ce modalitate de traducere audiovizuala ati realizat studiile?

Selecciona todos los que correspondan.

Subtitrare

Dublaj

Voice-over

$\square$ Traducere de jocuri video

Altele (specificati va rog)

Otro:

8. Ce tip de contract aveti ?

Marca solo un óvalo.

\section{Freelancer}

Contract cu firma

Altele (specificati, va rog) 
9. Ce fel de firme solicita mai mult colaborarea dumneavostra?

Selecciona todos los que correspondan.
$\square$ Distribuitori
Televiziuni
$\square$ Firme de traduceri
Clienti particulari
Altele (specificati, va rog)

10. In ce tip de firma va desfasurati activitatea?

Marca solo un óvalo.

Se dedica doar la realizarea traducerilor audiovizuale

Se dedica la realizarea de diferite tipuri de traducere

$\bigcirc$ Altele (specificati, va rog)

11. Dumnevoastra realizati doar aceasta profesie sau mai multe relationate sau nu cu traducerea?

Marca solo un óvalo.

\section{Doar traducere audiovizuala}

Traducere audiovizuala si alte activitati profesionale (specificati care in partea de comentarii)

\section{Comentarii}

12. Ce modalitate de traducere audiovizuala utilizati mai frecvent? (Puteti marca mai multe optiuni) Marca solo un óvalo.

Dublaj

$\bigcirc$ Subtitrare

$\bigcirc$ Voice-over

$\longrightarrow$ Traduceri de jocuri video

Altele (specificati, va rog)

13. In ce combinatie lingvistica realizati traducerea audiovizuala? (Puteti marca mai multe optiuni) Selecciona todos los que correspondan.
$\square$ Engleza-Romana
Franceza-Romana
- Spaniola-Romana
Germana-Romana
Chineza-Romana
$\square$ Altele (specificati, va rog)

$\square$ Otro: 
14. Pentru ce tip de public traduceti cu mai multa frecventa ?

Marca solo un óvalo.

Copii

Adulti

Ambele

Altele (specificati, va rog)

Otro:

15. Care este canalul final de distributie pentru traducerile dumneavoastra? (Puteti sa marcati mai multe optiuni)

Selecciona todos los que correspondan.

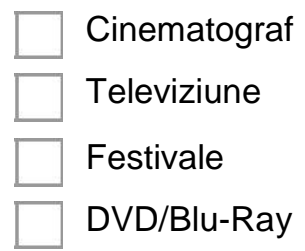

Altele (specificati, va rog)

16. De unde sunt clientii sau firmele pentru care realizati traducerile? Marca solo un óvalo.
Romania
Alte tari
Romania si alte tari
Comentarii
Otro:

17. Pentru a realiza traducerile ce tipuri de programe folositi? (Puteti sa marcati mai mult de o optiune)

Selecciona todos los que correspondan.

Programe gratuite

Programe comerciale cumparate

Programe speciale de la firma care le contacteaza

Altele (specificati, va rog)

18. Folositi programe speciale de traducere audiovizuala (Win Caps, Fab Subtitler, etc.? Marca solo un óvalo.

$\mathrm{Da}$ (in acest caz specificati in comentarii care sunt)

$\mathrm{Nu}$

Comentarii 
19. De ce utilizati acest tip de programe?

Selecciona todos los que correspondan.

Sunt formaturi care se permit in acest sector

Impuse de client/firma

$\square$ Calitate

Pret

Altele (specificati, va rog)

Otro:

20. Care este materialul pe care il primiti pentru a realiza traducerea?

Selecciona todos los que correspondan.

$\square$ Lista de dialoguri

Scenariu

Video

Altele (specificati, va rog)

21. Care este modalitatea de a primi si a trimite materialele?

Selecciona todos los que correspondan.

$\square$ Email

Dropbox

File Transfer Protocol

$\square$ Altele (specificati, va rog)

22. De cat timp dispuneti pentru a realiza traducerea?

Marca solo un óvalo.
3-5 zile
5-10 zile
10-15 zile
Altele (specificati va rog)

23. Considerati ca timpul de care dispuneti pentru a realiza traducerea este: Marca solo un óvalo.

Putin

$\bigcirc$ Mult

Destul

Altele (specificati va rog)

24. Considerati ca timpul de care dispuneti influienteaza in calitatea traducerii? Marca solo un óvalo.
$\bigcirc \mathrm{Nu}$
$\mathrm{Da}$
Cateodata
Comentarii 
25. Ce tip de materiale obinuiti sa consultati cand realizati traducerea? Selecciona todos los que correspondan.

Resurse lexicografice

Resurse terminologice si specializate (banci de date terminologice cu tamatica si combinatii diferite)

Resurse textuale (Gutenberg, Oxford Text Archive o Biblegateway)

Altele (specificati va rog)

26. Cine decide titlul filmului care se traduce?

Selecciona todos los que correspondan.

$\square$ Traducatorul

Distribuitorul

Altele (specificati va rog)

27. Exista un revizor lingvistic care corecteaza traducerea finala? Marca solo un óvalo.

$\mathrm{Da}$ (in acest caz explicati pe scurt cum se realizeaza acest proces in comentarii)

$\mathrm{Nu}$

Cateodata

28. La subtitrare cine realizeaza impartirea textului pe titluri (raspundeti daca realizati traducerea pentru subtitrari)

Selecciona todos los que correspondan.

$\square$ Traducatorul

Tehnicul

Altele (specificati va rog)

29. La dublaj si voice-over cine realizeaza ajustarea (raspundeti daca realizati traducerea pentru dublaj)

Marca solo un óvalo.

Traducatorul

Tehnicul

Altele (specificati va rog)

30. Ce tip de conventii si norme urmati pentru a realiza traducerea audiovizuala (subtitrare, dublaj, etc).

Selecciona todos los que correspondan.

Conventii generale extrase din carti de traducere audiovizuala

Conventii facilitate de client

Altele (specificati va rog) 


\section{CHESTIONAR TRADUCATORI}

31. Firmele care va contracteaza/contacteaza va impun norme sau restrictii in traducerea, pe care o realizati?

Marca solo un óvalo.



32. Pot modifica idea originala a filmului aceste norme sau restrictii impuse? Marca solo un óvalo.
$\bigcirc \mathrm{Da}$
$\mathrm{Nu}$
Cateodata
$\bigcirc$ Comentarii

33. Ati aplicat vreodata autocenzura in traduceri pentru a atenua limbajul folosit? Marca solo un óvalo.
$\bigcirc \mathrm{Da}$
$\bigcirc \mathrm{Nu}$
$\bigcirc$ Cateodata

34. Taxa pe care o aplicati este pe: Selecciona todos los que correspondan.
$\square$ Ore
Minute
Subtitlu
Rola
$\square$ Tip de program complet
$\square$ Altele (specificati va rog)

35. In contractul pe care il semnati este stipulat vreun drept de autor? Marca solo un óvalo.

$\mathrm{Da}$

$\mathrm{Nu}$

Altele (specificati, va rog)

\section{Evaluare profesionala}




\section{CHESTIONAR TRADUCATORI}

36. Pe scara Likert de 1 la 5 , cat considerati ca succesul unui film depinde intr-o mare parte de traducerea realizata, fie film, serial sau documentar?

Marca solo un óvalo.

1: Foarte putin

2: Putin

3: Cat de cat

4: Destul

5: Mult

37. A primit vreo recunoastere publica vreuna din traducerile, pe care le-ati realizat? Marca solo un óvalo.

$\mathrm{Da}$

$\mathrm{Nu}$

Altele

Comentarii

38. Remuneratia, pe care o primeste de la contractant influienteaza calitatea traducerii? Marca solo un óvalo.



39. Sunteti multumit de profesia, pe care o aveti?

Marca solo un óvalo.
$\bigcirc \mathrm{Da}$
$\bigcirc \mathrm{Nu}$
Comentarii

40. Daca ati putea ati schimba profesia pe care o realizati?

Marca solo un óvalo.

$\mathrm{Da}$

$\mathrm{Nu}$

Cometarii

41. Considerati ca este valorata munca traducatorului audiovisual in Romania?

(Specificati in comentarii de ce da sau de ce nu)

Marca solo un óvalo.

$\mathrm{Da}$

$\mathrm{Nu}$

Comentarii 
42. Considerati ca pirateria influienteaza in: (Puteti sa marcati mai mult de o optiune) Selecciona todos los que correspondan.

Volumul de munca

Conditii de munca

Imagine sociala

Altele (specificati va rog)

\section{Evaluare academica}

43. Considerati, ca studiile pe care le aveti sunt suficiente pentru a realiza aceasta profesie?

Marca solo un óvalo.

$\bigodot^{\mathrm{Da}}$
$\mathrm{Nu}_{\text {Comentarii }}$

44. Considerati ca este nevoie de o pregatire continua pentru a realiza aceasta profesie (cursuri, conferinte, etc), si de ce?

Marca solo un óvalo.
$\mathrm{Da}$
$\mathrm{Nu}$
Comentarii

45. Considerati ca in prezent in Romania exista suficiente cursuri de formare si/sau universitare pentru acest tip de traducere, si de ce?

Marca solo un óvalo.

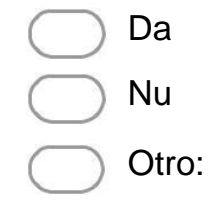

46. Considerati ca universitatile sunt dotate cu echipament tehnic adecvat pentru a pregati traducatorii audiovizuali?

Marca solo un óvalo.

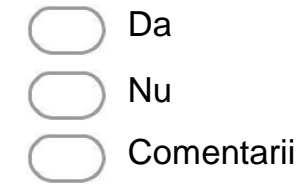

47. Considerati ca profesorii de traducere audiovizuala au pregatirea necesara, si de ce? Marca solo un óvalo.

$\mathrm{Da}$

$\mathrm{Nu}$

Comentarii

\section{Competente}

Avand in vedere complexitatea acestei profesii, datorita faptului ca este necesar sa combine traducerea cu elemente filmice (de sunet si imagine), pentru a nara o istorie, ce calitati, aptitudini considerati ca sunt 
importante pentru a fi un bun profesional? Marcati cinci, care considerati ca sunt fundamentale:

\section{A. Competente specifice}

Selecciona todos los que correspondan.

1. Cunoasterea exhaustiva a limbii tinta

2. Cunoasterea exhaustiva a limbii native

3. Cunoasterea culturii limbilor folosite

4. Creativitate lingvistica

5. Capacitate de sinteza si parafraza

6. Intelegerea complexitatii textului audiovizual, caracterizata prin interactiunea diferitelor coduri semiotice

7. Cunoasterea caracteristicilor diferitelor genuri audiovizuale

8. Capacitate de comunicare scrisa pentru redactarea adecvata a traducerii

9. Aptitudini pentru a realiza o sincronie perfecta: lingvistica si de imagine

10. O buna cunoastere a tehnicilor, strategiilor si terminologiei specifice traducerii audiovizuale

11. Cunoasterea metodelor de cautare de resurse si documente specifice traducerii audiovizuale

12. Utilizare excelenta de programe specifice de TAV (subtitrare, dublaj, etc.)

13. Cunoasterea principiilor metodologice si de aspect profesional ce solicita TAV

14. Cunoasterea caracteristiciilor si conventiilor europene de TAV

15. Cunoasterea profesiei si situatiei pietei de munca in acest sector

16. Altele (specificati, va rog)

\section{B. Competente generale}

\section{Selecciona todos los que correspondan.}

1. Capacitate de analiza

2. Capacitate de studiu

3. Capacitate de a aplica in practica cunostintele teoretice

4. Preocupare pentru calitate

5. Capacitate critica si autocritica

6. Cunoasterea profesiei si situatiei ei pe piata de munca

7. Abilitate pentru a cauta si analiza informatii provenite din diferite surse

8. Munca in echipa

9. Capacitate pentru a motiva si a lidera

10. Capacitate pentru a formula si a conduce proiecte

11. Capacitate de munca sub presiune temporala

12. Compromis etic

13. Capacitate pentru a se adapta la cerintele stipulate

14. Spirit negociator

15. Rezolvarea rapida de problema

16. Altele (specificati va rog) 


\section{CHESTIONAR FIRME}

\section{PROFILUL FIRMEI}

1 .De cat timp s-a infiintat firma dumneavoastra?

Marca solo un óvalo.

3-5

6-10

$11-15$

Altele

2. In ce parte a tarii se situeaza firma dumneavoastra?

Marca solo un óvalo.

$\bigcirc$ Oltenia

Muntenia

Transilvania

Capitala

3. Ce fel de firme obisnuiesc sa solicite mai mult serviciile dumneavoastra?

Selecciona todos los que correspondan.

Televiziuni

Distribuitori

Clienti particulari

Cinematografe

Altele

4. In firma dumnevoastra aveti traducatori angajati permanent sau ii angajati/contactati cand primiti materialul de tradus (film, serial, etc.)?

Marca solo un óvalo.
$\mathrm{Da}$
$\mathrm{Nu}$
Altele

5. Cati angajati are firma dumnevoastra cu contract?

Marca solo un óvalo.

$1-5$

6-10

$11-15$

Altele 


\section{CHESTIONAR FIRME}

6. Cand angajati/contactati un traducator ce valorati mai mult ? Marca solo un óvalo.

Studii

Experienta

Ambele

7. Care este modul de a angaja /contacta traducatorii?

Selecciona todos los que correspondan.

$\square$ Interviu personal

Receptie de CV

$\square$ Recomandari

$\square$ Experienta profesionala

$\square$ Altele

8. In afara de traducere audiovizuala, ce alte modalitati de traducere realizeaza firma dumneavoastra?

Selecciona todos los que correspondan.

$\square$ Traducere juridica

Traducere literara

$\square$ Traducere tehnica

- Traducere medicala

Traducere stiintifica

$\square$ Traducere publicitara

$\square$ Niciuna

9. Care este procentajul de activitate in firma dumnevoastra dedicat traducerii audiovizuale?

Marca solo un óvalo.

$20 \%$

$40 \%$

$60 \%$

$80 \%$

Altele

10. Pentru ce tip de public se traduce cu mai multa frecventa in firma dumneavoastra? Marca solo un óvalo.

Copii

Adulti

Ambele

Altele 


\section{CHESTIONAR FIRME}

11. In functie de gen, ce modalitate de traducere utilizati cu mai multa frecventa pentru produsele straine?

Selecciona todos los que correspondan.
Subtitrare
Dublaj
Voice-over
Altele

12. Ce tip de asociere lingvistica folositi pentru traduceri? (Puteti marca mai mult de o optiune)

Selecciona todos los que correspondan.
Engleza-Romana
Franceza-Romana
- Spaniola-Romana
$\square$ Germana-Romana
$\square$ Chineza-Romana
$\square$ Altele

13. Tipurile de programe, care se folosesc in procesul de traducere audiovizuala, sunt impuse de firma sau este alegerea traducatorului? Marca solo un óvalo.
$\mathrm{Da}$
$\mathrm{Nu}$
Altele

14. Primiti vreo restrictie din partea clientilor in procesul de traducere (titlu, cantece, etc.)? Marca solo un óvalo.
$\mathrm{Da}$
$\mathrm{Nu}$
Cateodata

15. Impuneti vreo norma sau restrictie in procesul de traducere, traducatorilor pe care ii angajati sau contractati?

Marca solo un óvalo.

$\mathrm{Da}$

$\mathrm{Nu}$

Cateodata

16. Ce tip de materiale ii proportionati traducatorului?

Selecciona todos los que correspondan.

Lista de dialoguri

Scenariu 
17. Firma dumneavoastra are vreun sistem informatic sau plataforma pentru a realiza schimbul de materiale cu traducatorii?

Marca solo un óvalo.

$\mathrm{Da}$

$\mathrm{Nu}$

Altele

18. Firma dumnevoastra dispune de un revizor lingvistic, pentru a realiza feedback traducerilor realizate?

Marca solo un óvalo.

$\mathrm{Da}$

$\mathrm{Nu}$

Cateodata

19. Considerati ca succesul unui film depinde de asemenea de calitatea traducerii? Marca solo un óvalo.

$\mathrm{Da}$

$\mathrm{Nu}$

Cateodata

20. Firma dumnevoastra faciliteaza studentilor de traducere audiovizuala realizarea practicii universitare?

Marca solo un óvalo.

$\mathrm{Da}$

$\mathrm{Nu}$

Altele

21. Firma dumnevoastra contribuie la pregatirea continua a traducatorilor angajati? Marca solo un óvalo.

$\mathrm{Da}$

$\mathrm{Nu}$

Cateodata

22. Considerati ca pregatirea universitara in traducerea audiovizuala in Romania este adecvata pentru a realiza dupa aceea, aceasta profesie?

Marca solo un óvalo.

$\mathrm{Da}$

$\mathrm{Nu}$

Altele

\section{Competente}

Avand in vedere complexitatea acestei profesii; ce calitati, aptitudini considerati ca sunt importante pentru a angaja/contacta un profesional din acest domeniu? Marcati cinci competente specifice si cinci competente generice, care considerati ca sunt fundamentale in aceasta profesie. 
A. Competente specifice

Selecciona todos los que correspondan.

1. Cunoasterea exhaustiva a limbii tinta

2. Cunoasterea exhaustiva a limbii native

3. Cunoasterea culturii limbilor folosite

4. Creativitate lingvistica

5. Capacitate de sinteza si parafraza

6. Intelegerea specificitatii textului audiovisual, caracterizata prin interactiunea diferitelor coduri semiotice

7. Cunoasterea caracteristicilor genurilor audiovizuale

8. Capacitate de comunicare scrisa pentru redactarea adecvata a traducerii

9. Aptitudini pentru a realiza o sincronie perfecta: lingvistica si imagine

10. O buna cunoastere a tehnicilor, strategiilor si terminologiei specifice traducerii audiovizuale

11. Cunoasterea metodelor de cautare de resurse si documente specifice traducerii audiovizuale

12. Utilizarea excelenta a programelor specifice de TAV (subtitrare, dublaj, etc.)

13. Cunoasterea principiilor metodologice si de aspect profesional ce solicita TAV

14. Cunoasterea caracteristicilor si conventiilor europene de TAV

15. Cunoasterea profesiei si situatiei pietei de munca in acest sector

16. Altele

\section{B. Competente generice}

\section{Selecciona todos los que correspondan.}

1. Capacitate de analiza

2. Capacitate de studiu

3. Capacitatea de a pune in practica cunostintele teoretice

4. Preocupare pentru calitate

5. Capacitate critica si autocritica

6. Cunoasterea profesiei si situatiei ei pe piata de munca

7. Abilitate pentru a cauta si analiza informatii provenite din diferite surse

8. Munca in echipa

9. Capacitate pentru a motiva si pentru a conduce

10. Capacitate pentru a elabora si a dirija proiecte

11. Capacitate de munca sub presiune temporala

12. Compromis etic

13. Capacitate pentru a se adapta cerintelor stipulate

14. Spirit negociator

15. Rezolvarea rapida a problemelor

16. Altele 


\begin{abstract}
ANEXO II
Cuestionario (profesionales)

Me llamo Elena Laura Vulpoiu, y este cuestionario es una parte importante de mi tesis doctoral, que trata la situación actual del traductor audiovisual en Rumanía. Este estudio se realiza bajo la dirección de la Dra. Beatriz Cerezo Merchán (Universitat de València) y del Dr. José Luis Martí Ferriol (Universitat Jaume I).

En la presente investigación nos proponemos estudiar y describir el perfil del traductor audiovisual, presentado bajo dos puntos de vista: el del profesional y el del empleador. Por este motivo necesitamos su opinión y consideramos que su colaboración puede contribuir a la mejora académica y profesional de esta actividad.

Las preguntas del cuestionario se estructuran en cuatro partes: la primera trata sobre el perfil actual del traductor audiovisual, en la segunda y en la tercera intentamos realizar una evaluación profesional y académica de los profesionales en este dominio. Y la última parte incluye una lista con algunas competencias específicas y generales que ustedes consideráis que son necesarias para esta profesión.

Se necesitan 10-20 minutos para contestar a las siguientes preguntas, y la encuesta es totalmente anónima. Sin embargo, en el caso en que ustedes deseáis recibir información sobre los resultados obtenidos, ustedes podéis dejar su dirección de correo electrónico al final del cuestionario.
\end{abstract}

Datos de contacto: Elena Laura Vulpoiu (lauravulpoiu@gmail.com)

Teléfono: 0034/ 635.104.709

Título del proyecto de tesis doctoral: La traducción audiovisual y el perfil del traductor audiovisual en Rumanía.

\title{
1. Perfil del traductor
}

1. Indique la edad que tiene

Marca solo un óvalo.

25-35

35-45

45-55

Otro:

2. ¿En qué región del país vive?

Marca solo un óvalo.

Oltenia

Muntenia

Transilvania

Capital

Otro:

3. Indique sus años de experiencia como traductor

Marca solo un óvalo.

3-5

6-10

11-15

Otro: 
4. ¿Qué tipo de formación tiene? (Puede marcar más de una opción)

Selecciona todos los que correspondan.

Autodidacta (lecturas, práctica profesional, aprendizaje de los compañeros)

Estudios de Filología

Estudios de Traducción

Formación interna en empresas

Otro:

5. ¿Ha realizado cursos específicos de traducción audiovisual en Rumanía o en otros países?

Selecciona todos los que correspondan.

Dumanía

Otros países

Ambos

Otro:

6. ¿Qué tipo de cursos?

Marca solo un óvalo.

Universitarios

No universitarios

Ambos

Otro:

7. ¿En qué modalidad/es de TAV ha recibido la formación? Selecciona todos los que correspondan.

Subtitulación

Doblaje

Voice-over

Traducción de videojuegos

$\square$ Otro:

8. ¿Qué tipo de contrato tiene? Marca solo un óvalo.

\section{Freelancer}

Contratado en empresa

Otros (especifique, por favor)

Otro: 
9. ¿Qué tipo/s de empresa/s suele/n solicitar más su colaboración?

Selecciona todos los que correspondan.

Distribuidoras

Cadenas de televisión

Empresas de traducción

Clientes particulares

Otro:

10. ¿En qué tipo de empresa trabaja?

Marca solo un óvalo.

Empresa dedicada únicamente a la traducción audiovisual

Empresa dedicada a diversos tipos de traducción

Otro:

11. ¿Se dedica únicamente a la traducción audiovisual o también realiza otras actividades profesionales relacionadas o no con la traducción?

Marca solo un óvalo.

Únicamente a la traducción audiovisual

A la traducción audiovisual y a otras actividades profesionales (especifique a cuáles en el apartado de comentarios de esta pregunta)

Otro:

12. ¿Qué modalidad de traducción audiovisual utiliza con más frecuencia? (Puede marcar más de una opción)

Marca solo un óvalo.

Doblaje

Subtitulación

Voice-over

Traducción de videojuegos

Otro:

13. ¿En qué combinación lingüística, suele realizar las traducciones audiovisuales?

(Puede marcar más de una opción)

Selecciona todos los que correspondan.

Inglés- Rumano

Francés- Rumano

Español-Rumano

Alemán-Rumano

Chino-Rumano

Otro: 
2017-6-11 Cuestionario (profesionales)

14. ¿Para qué tipo de público traduce con más frecuencia?

Marca solo un óvalo.

Infantil

Adultos

Ambos

Otro:

15. ¿Cuál es el canal final de distribución para sus productos? (Puede marcar más de una opción)

Selecciona todos los que correspondan.

Cine

Televisión

Festivales

DVD/Blu-Ray

Otro:

16. ¿Dónde se ubican los clientes o las empresas para los que trabaja?

Marca solo un óvalo.

Rumanía

Otros países

Ambos

Otro:

17. ¿Qué tipos de programas utiliza para realizar las traducciones? (Puede marcar más de una opción)

Selecciona todos los que correspondan.

$\square$ Programas gratuitos

Programas comerciales de pago

Programas propios de las empresas que le contratan

Otro:

18. ¿Utiliza programas específicos de traducción audiovisual (WinCaps, Fab Subtitler, etc)?

Marca solo un óvalo.

Sí (en este caso, especifique cuáles en el apartado de comentarios de esta pregunta)

No

Otro: 
19. ¿Por qué suele utilizar estos tipos de programas?

Selecciona todos los que correspondan.

Formatos en que permiten trabajar

$\square$ Imposición del cliente/empresa

Calidad

$\square$ Precio

Otro:

20. ¿Cuál es el material que recibe previamente para realizar este trabajo?

Selecciona todos los que correspondan.

Lista de diálogos

Guion

Video

Otro:

21. ¿Cuál es el medio de intercambio de materiales?

Selecciona todos los que correspondan.

$\square$ Email

Dropbox

File Transfer Protocol

Otro:

22. ¿De cuanto tiempo disponéis para realizar la traducción?

Marca solo un óvalo.

3-5 días

5-10 días

10-15 días

Otro:

23. ¿Considera que el tiempo de que dispone para realizar el trabajo es suficiente? Marca solo un óvalo.

Poco

Mucho

Bastante

Otro:

24. ¿Estima que el tiempo de que dispone influye en la calidad de la traducción? Marca solo un óvalo.

No

Sí

A veces

Otro: 
25. ¿Qué tipo de materiales de apoyo suele utilizar para realizar el trabajo?

Selecciona todos los que correspondan.

Recursos lexicográficos (diccionarios)

Recursos terminológicos y especializados (bancos de datos terminológicos de temáticas y combinaciones lingüísticas distintas)

Recursos textuales (Gutenberg, Oxford Text Archive o Biblegateway)

$\square$ Otro:

26. ¿Quién decide el título de la película que traduce?

Selecciona todos los que correspondan.

El traductor

La distribuidora

Otro:

27. ¿Existe un revisor lingüístico que corrige la traducción una vez finalizada? Marca solo un óvalo.

Sí (en caso afirmativo, explique brevemente el proceso que se sigue en el apartado de comentarios de esta pregunta)

No

A veces

Otro:

28. ¿En la subtitulación, quién realiza el pautado? (Conteste si se dedica a la subtitulación)

Selecciona todos los que correspondan.

El traductor

El técnico

Otro:

29. ¿En el doblaje y voice over, quién realiza el ajuste? (Conteste si se dedica al doblaje) Marca solo un óvalo.

El traductor

El técnico

Otro:

30. ¿Qué tipo de convenciones sigue para realizar la traducción audiovisual (subtitulación, doblaje, etc)?

Selecciona todos los que correspondan.

Convenciones generales extraídas de libros especializados en

TAV Convenciones que facilita el cliente

Otro: 
31. ¿Las empresas que le contactan/contratan le imponen algunas pautas o restricciones en la traducción cuando realiza el trabajo?

Marca solo un óvalo.

Sí

No

A veces

Otro:

32. ¿Tienen repercusión en el trabajo final estas pautas o restricciones?

Marca solo un óvalo.

Sí

$\bigcirc$ No

A veces

Otro:

33. ¿Ha aplicado alguna vez en sus traducciones la autocensura para suavizar el lenguaje utilizado?

Marca solo un óvalo.

Sí

No

A veces

Otro:

34. Suele cobrar el trabajo realizado por: (Puede marcar más de una opción)

Selecciona todos los que correspondan.

$\square$ Horas

Minutos

$\square$ Subtítulo

$\square$ Rollo (reel)

Tipo de programa completo

Otro:

35. ¿En su contrato se estipula algún derecho de autor? Marca solo un óvalo.

Sí

No

Otro:

\section{Valoración de la profesión}


36. ¿Con una escala Likert del 1 al 5 , cuánto considera que influye una buena traducción en el éxito de audiencia de un producto audiovisual, ya sea una película, serie o documental?

Marca solo un óvalo.

1: Muy poco

2: Poco

3: Algo

4: Bastante

5: Mucho

37. ¿Ha recibido alguna de sus traducciones algún reconocimiento público?

Marca solo un óvalo.
Sí
No
Otro:

38. ¿La remuneración que percibe por parte del contratante influye en la calidad de la traducción?

Marca solo un óvalo.

Sí

No

A veces

Otro:

39. ¿Está contento con la profesión que ejerce?

Marca solo un óvalo.

Sí

No

Otro:

40. ¿Si pudiera cambiaría su profesión por otra?

Marca solo un óvalo.

Sí

No

Otro:

41. ¿Considera que está verdaderamente valorado el trabajo del traductor audiovisual en Rumanía? Especifique por qué sí o por qué no en el apartado de comentarios de esta pregunta.

Marca solo un óvalo.

Sí

No

Otro: 
42. Considera que la piratería influye en (puede marcar más de una opción):

Selecciona todos los que correspondan.

El volumen de trabajo

Las condiciones laborales

La imagen social

Otro:

\section{Valoración de la formación}

43. ¿Considera que la formación académica que tiene es suficiente para desempeñar este trabajo?

Marca solo un óvalo.

Sí

No

Otro:

44. ¿Considera que se necesita una formación permanente para poder ejercer esta profesión (cursos, congresos, etc)?

Marca solo un óvalo.

Sí

No

Otro:

45. ¿Considera que actualmente en Rumanía existen suficientes cursos universitarios y no universitarios para este tipo de traducción?

Marca solo un óvalo.

Sí

No

Otro:

46. ¿Considera que las universidades están dotadas con los equipos técnicos adecuados para preparar a los traductores audiovisuales?

Marca solo un óvalo.

Sí

No

Otro:

47. ¿Considera que los profesores que imparten este tipo de formación tienen la preparación necesaria?

Marca solo un óvalo.

Sí

No

Otro:

\section{Competencias}


Teniendo en cuenta la complejidad de la profesión del traductor de textos audiovisuales, ¿qué cualidades y destrezas, tanto específicas como genéricas, considera que son imprescindibles para ser un buen profesional? Marque cinco competencias específicas y cinco competencias genéricas, que considera fundamentales para ejercer esta profesión.

A. Competencias específicas Selecciona todos los que correspondan.

1. Conocimiento exhaustivo de la lengua meta.

2. Dominio de la lengua origen.

3. Buen conocimiento de las culturas de trabajo.

4. Creatividad lingüística.

5. Capacidad de síntesis y paráfrasis.

6. Comprender la especificidad del texto audiovisual por la interacción de diferentes códigos semióticos.

7. Conocimientos de las características de diferentes géneros audiovisuales.

8. Capacidad de comunicación escrita para redactar traducciones adecuadas.

9. Destrezas para realizar una sincronía perfecta: lingüística e imagen.

10. Dominar las técnicas, estrategias y terminología específicas de la traducción audiovisual. TAV.

11. Dominio de estrategias de búsqueda de recursos y documentación específicos de la

12. Excelente manejo de programas específicos de TAV (subtitulación, doblaje, etc.)

13. Conocimiento de principios metodológicos y de aspectos profesionales que rigen la TAV.

14. Conocimiento de las características y convenciones europeas de la traducción audiovisual.

15. Conocimiento de los aspectos económicos, profesionales y del mercado.

16. Otros (especifique por favor)

B. Competencias genéricas Selecciona todos los que correspondan. 
1. Capacidad de análisis.

2. Capacidad de aprender.

3. Capacidad de aplicar el conocimiento a la práctica.

4. Preocupación por la calidad.

5. Capacidad crítica y autocrítica.

6. Conocimientos de la profesión y la situación del mercado del trabajo.

7. Habilidad para buscar y analizar información procedente de diversas fuentes.

8. Trabajar en equipo.

9. Capacidad para motivar y liderar.

10. Capacidad para formular y gestionar proyectos.

11. Capacidad para trabajar bajo presión temporal.

12. Compromiso ético.

13. Capacidad para adecuarse a los requisitos del encargo.

14. Espíritu negociador.

15. Rápida resolución de problemas.

16. Otros (especifique por favor) 


\section{Cuestionario empresas empleadoras}

Me llamo Elena Laura Vulpoiu, y este cuestionario es una parte importante de mi tesis doctoral, que trata la situación actual del traductor audiovisual en Rumanía. Este estudio se realiza bajo la dirección de la Dra. Beatriz Cerezo Merchán (Universitat de València) y del Dr. José Luis Martí Ferriol (Universitat Jaume I).

En la presente investigación nos proponemos estudiar y describir el perfil del traductor audiovisual, presentado bajo dos puntos de vista: el del profesional y el del empleador. Por este motivo necesitamos su opinión y consideramos que su colaboración puede contribuir a la mejora académica y profesional de esta actividad.

Las preguntas del cuestionario se estructuran en cuatro partes: la primera trata sobre el perfil actual del traductor audiovisual, en la segunda y en la tercera intentamos realizar una evaluación profesional y académica de los profesionales en este dominio. Y la última parte incluye una lista con algunas competencias específicas y generales que ustedes consideráis que son necesarias para esta profesión.

Se necesitan 10-20 minutos para contestar a las siguientes preguntas, y la encuesta es totalmente anónima. Sin embargo, en el caso en que ustedes deseáis recibir información sobre los resultados obtenidos, ustedes podéis dejar su dirección de correo electrónico al final del cuestionario.

Datos de contacto: Elena Laura Vulpoiu (lauravulpoiu@gmail.com)

Teléfono: 0034/ 635.104.709

Título del proyecto de tesis doctoral: La traducción audiovisual y el perfil del traductor audiovisual en Rumanía.

\section{Perfil de la empresa}

1. ¿Cuánto tiempo lleva su empresa en el mercado?

Marca solo un óvalo.

\section{3-5}

6-10

$11-15$

Otros

Otro:

2. ¿En qué parte del país se ubica su empresa?

Marca solo un óvalo.

Oltenia

Muntenia

Transilvania

Capitala

3. ¿Qué tipo/s de empresa/s suele/n solicitar más su colaboración?

Selecciona todos los que correspondan.

Cadenas de telavisión

Distribuidoras

Clientes particulares

Cines

Otro: 
4. ¿Cuántos empleados tiene, contratados y freelancers?

Marca solo un óvalo.

$1-5$

6-10

$11-15$

Otro:

5 ¿Tiene traductores contratados o los contrata en el mismo momento del encargo? Marca solo un óvalo.

$\bigcirc$ Sí

Si

No

Otro:

6. ¿Cuándo contrata un traductor qué es más importante entre los siguientes requisitos? Marca solo un óvalo.

Formación

Experiencia

Ambas

7. ¿De qué forma contrata a los traductores?

Selecciona todos los que correspondan.

$\square$ Entrevista personal

Recepción de CV

Recomendaciones

Experiencia profesional

Otro:

8. ¿Además de la traducción audiovisual, a qué otras variedades de traducción se dedica su empresa?

Selecciona todos los que correspondan.

$\square$ Traducción jurídica

Traducción literaria

Traducción técnica

Traducción médica

Traducción científica

$\square$ Traducción publicitaria

Ninguna 
9. ¿Cuál es el porcentaje de trabajo que su empresa dedica a la traducción audiovisual? Marca solo un óvalo.
$20 \%$
$40 \%$
$60 \%$
$80 \%$
Otro:

10. ¿Qué género audiovisual se traduce con más frecuencia en su empresa?

Marca solo un óvalo.
Infantil
Adultos
Ambos
Otro:

11. En función del género ¿qué modalidad de traducción utiliza con más frecuencia para los productos extranjeros?

Selecciona todos los que correspondan.
- Subtitulación
Doblaje
$\square$ Voice-over
Otro:

12. ¿En qué combinación lingüística, suele realizar las traducciones audiovisuales? (Puede marcar más de una opción)

Selecciona todos los que correspondan.



Otro:

13. ¿Los tipos de programas que se utilizan en el proceso de traducción audiovisual los impone su empresa o es la elección del traductor?

Marca solo un óvalo.
Sí
No
Otro:

14. ¿Recibe algunas restricciones por parte de las productoras sobre el proceso de traducción (título, canciones, etc.)?

Marca solo un óvalo. 
Otro:

15. ¿Impone algunas pautas o restricciones en la traducción a los traductores que tiene contratados o contacta?

Marca solo un óvalo.

Sí

No

A veces

Otro:

16. ¿Qué tipo de materiales se le proporciona al traductor?

Selecciona todos los que correspondan.

Lista de diálogos

Guion

Video

Otro:

17. ¿Su empresa tiene algún sistema informatizado o plataforma para el intercambio de materiales con los traductores?

Marca solo un óvalo.

Sí

No

Otro:

18. ¿Tiene un revisor lingüístico en su empresa, para dar feedback a las traducciones realizadas por el traductor?

Marca solo un óvalo.
Sí
No
A veces
Otro:

19. ¿Considera que el éxito de una película depende también en una gran parte de la calidad de la traducción?

Marca solo un óvalo.
Sí
No
A veces
Otro:

2017-6-11 Cuestionario empresas empleadoras

20. ¿Su empresa facilita la realización de prácticas universitarias a los estudiantes de traducción audiovisual?

Marca solo un óvalo. 
Sí

No

Otro:

21. ¿Su empresa ofrece formación continua a sus traductores?

Marca solo un óvalo.
Sí
No
A veces
Otro:

22. ¿Considera que la formación universitaria en la traducción audiovisual en Rumanía es adecuada para ejercer posteriormente esta profesión?

Marca solo un óvalo.

Sí

No

Otro:

\section{Competencias}

Teniendo en cuenta la complejidad de la profesión del traductor de textos audiovisuales, ¿qué cualidades y destrezas, tanto específicas como genéricas, considera que son imprescindibles para ser un buen profesional? Marque cinco competencias específicas y cinco competencias genéricas, que considera fundamentales para ejercer esta profesión.

\section{A. Competencias específicas}

Selecciona todos los que correspondan.

1. Conocimiento exhaustivo de la lengua meta

2. Dominio de la lengua origen

3. Buen conocimiento de las culturas de trabajo

4. Creatividad lingüística

5. Capacidad de síntesis y paráfrasis

6. Comprender la especificidad del texto audiovisual por la interacción de diferentes códigos semióticos

7. Conocimientos de las características de diferentes géneros audiovisuales

8. Capacidad de comunicación escrita para redactar traducciones adecuadas

9. Destrezas para realizar una sincronía perfecta: lingüística e imagen

10. Dominar las técnicas, estrategias y terminología específicas de la traducción audiovisual

11. Dominio de estrategias de búsqueda de recursos y documentación específicos de la TAV 
13. Conocimiento de principios metodológicos y de aspectos profesionales que rigen la TAV

14. Conocimiento de las características y convenciones europeas de la traducción audiovisual

15. Conocimiento de los aspectos económicos, profesionales y del mercado

16. Otros (especifique por favor)

B. Competencias genéricas

Selecciona todos los que

correspondan.

1. Capacidad de análisis

2. Capacidad de aprender

3. Capacidad de aplicar el conocimiento a la práctica

4. Preocupación por la calidad

5. Capacidad crítica y autocrítica

6. Conocimientos de la profesión y la situación del mercado del trabajo

7. Habilidad para buscar y analizar información procedente de diversas fuentes

8. Trabajar en equipo

9. Capacidad para motivar y liderar

10. Capacidad para formular y gestionar proyectos

11. Capacidad para trabajar bajo presión temporal

12. Compromiso ético

13. Capacidad para adecuarse a los requisitos del encargo

14. Espíritu negociador

15. Rápida resolución de problemas

16. Otros (especifique por favor) 


\begin{abstract}
ANEXO III
Interviu Traducător 1

Intrebare: Majoritatea traducătorilor au pregatire filologică, considerați că este suficientă pentru TAV?

Traducător 1: Nu, nu cred că este suficientă, dar uneori ajută. Dar, nu cred că majoritaea au pregătire filologică, părerea mea. Cred, că mulţi dintre ei au pornit dinspre alte meserii și de multe ori este util să ai o meserie tehnică. De exemplu dacă ai de tradus un documental sau lucruri din aste mai complicate este vorba de vocabular. Cred că înainte de toate îți trebuie pasiune și talent, restul sunt adiacente.

\section{Intrebare: Credeți că există suficiente cursuri de acest tip în România?}

Traducător 1: Sunt insuficiente pot să-ţi spun sigur, dar pe de altă parte nici nu există o piață de desfacere. Adică, ei urmează niște cursuri, ai facut un interviu de altfel cu un coleg al nostru cu Stănescu, care este profesor la facultate și are chiar și un curs în acest sens, la care am fost și eu și am facut un master class și vreau să spun că acumulează foarte mult, dar nu au cum să se desfăsoare mai târziu, pentru că e relativ o lume închisă. Adică, ai apucat să traduci bine, nu, iarăşi bine. Vreau să spun că lumea asta este închisă deseori și pentru mine, e foarte complicat să pătrunzi în lumea asta.

\section{Intrebare: Cu atâția ani de carieră pe care îi aveți?}

Traducător 1: Nu, nu are legatură una cu alta și de multe ori poate să joace în defavoarea ta pentru că preferă studenți care o fac gratis în ideea să acumuleze experiență, sau fie pe sume foarte mici. Sau își imaginează că eu aș lua sume mari, ceea ce este greșit în toate cazurile. Pe vremuri exista ceea ce se cheamă certificatul de traducător, culmea este că și acum după atâția ani mi l-au cerut. Eu mi l-am luat în primul an de facultate, deși eram studentă la limbi străine franceză și engleză. Acum mai nou, nici o plată nu se mai poate face fără acest certificat de traducător, dar pe de altă parte nimeni nu verifică traducerile care apar aşa cum ar fi normal, sau cineva care să urmarească, este vorba de subtitrare și mai ales comentariile de pe margine. E foarte usor să le faci atunci când nu ești direct implicat, plus că în România din păcate nu se respectă așa ca în străinatate, așa cum ar fi normal, nu se respectă ideea asta.
\end{abstract}


Intrebare: Considerați că universităţile au echipament și profesori adecvați pentru a pregăti traducători audiovizuali?

Traducător 1: Profesori categoric că sunt și existau inclusiv când am facut eu facultatea și chiar și atunci exista un laborator destul de performant pentru anii '76-'80 când am facut eu. Dar, nu-mi dau seama cum functionează acum în universități.

Intrebare: Considerați că o colaborare între universități și firme ar putea îmbunătăți pregătirea în acest domeniu?

Traducător 1: Da, cred că ar fi benefică și cu atât mai mult cu Spania unde în momentul de față există suficiente seriale, filme care vin de acolo, fie din America de Sud și categoric că ar conta o colaborare între unii și alții. Plus că și spaniolii ca și românii vorbesc foarte repede, cred că ar fi bine și pentru unii și pentru alții să poată colabora.

\section{Intrebare: Este necesar un revizor lingvistic?}

Traducător 1: Da, categoric. Vreau să spun, că din nou paradoxal, până în '89 la televiziunea națională singura care există era așa: aveai un text pe care ți-1 punctai, adică vedeai pâna unde să fie replica respectivă, replica nu trebuia să fie foarte lungă, trebuia să o ții suficient pe ecran ca să poata să citească chiar și semianalfabeții de la țară. Adică era idea că trebuie să înţeleagă “nea Gheorghe" așa spuneam între noi. Deci, tu trebuia să citești de trei ori fiecare text în parte ca cel care nu era obișnuit să citeasca rapid, să poată să înteleagă ce ai scris tu acolo. Deci, aveai un text în original după care puteai porni sau cel mai adesea nu aveai nimic și atunci ascultai, și dădeai înainte și înapoi la nesfârşit până reușeai să întelegi ce a spus celălalt, pentru că sigur și actorul avea un regizor care îi spunea “joacă cât mai natural, deci nu e nevoie să vorbesti foarte clar." După ce făceai acest text era bătut la mașină și era revăzut de un redactor, redactorul verifica să nu ai greșeli de mașină, deci să nu scrii aiurea un cuvânt. După care venea un expert în lingvistică și care se numea stilist și era separat plătit ca să stilizeze frazele. Îți dai seama câte erau de facut? Ca să nu mai zicem că exista și o cenzură, pe care o cunoaștem și care o făceai din start știai că nu ai voie să spui biserică, etc. Era mult mai revizuit atunci decât în actualitate. De exemplu, pe vremea aceea îți făcea observație că ai greșit ceva, chiar te durea sau țineai minte să nu mai greșesti altădată. Acum traducătorilor poți să le spui de o mie de ori, că puțin le pasă. Ei spun că nu sunt foarte bine plătiţi, că trebuie să facă cât mai repede și că este suficient de bine ce au făcut acolo. Adică, nu au dorința asta neapărat 
de perfecțiune, foarte rar se intamplă ; sau au momente în care se vede clar că erau odihniți când au început traducerea și spre final o mai greșesc...

\section{Intrebare: Am observat că taxa aplicată este pe minut, film, program...}

Traducător 1: Pe minute, eu nu știu, așa cum ar fi normal. De obicei se face pe film și este o plată extrem de proastă, noi tot am așteptat să fie la același nivel european pentru că tot am intrat în Europa. Dar nu s-a întamplat și a ramas în continuare prost plătită, adică mult muncit și prost plătit.

\section{Intrebare: Dacă ar fi să concretăm prețul, pentru că nimeni nu răspunde este ca un} secret în România, cam cât se plăteste pe film, de exemplu?

Traducător 1: Nu cred că este un secret, cred că variază foarte mult de la o firmă la alta, si cred că de asta nu răspunde nimeni. În principiu este cam $100 €$ pe film ceea ce este extraordinar de puțin. Prețurile sunt foarte proaste.

\section{Intrebare: La dublaj?}

Traducător 1: Pentru a intrepreta iți spun eu. Am participat la un film, am avut 12 replici şi au fost $50 €$ impozabili, deci am rămas cu $30 €$ pentru un dublaj Disney. Este extraordinar de puțin, mai puțin decât un taxi ca să poți ajunge dintr-o parte în alta. Și am mai facut odată un dublaj unde erau mai multe replici și pentru că sunt eu și s-au putut lăuda mi-au dat $300 €$ din nou ipozabili, dar a fost o excepție și m-au rugat să nu spun pentru că de obicei mai mult de 50-100€ nu sunt. Si știu, îmi aduc aminte că pentru "Epoca de gheață", deși era o foarte bună actriță din România, care a luat cu total 150€. Mi se pare o sumă absolut umilitoare, dar pe de altă parte îţi face plăcere, îți face plăcere să faci chestia asta şi ei pe asta mizează. Este o lume foarte închisă pe care unii o stăpanesc și alţii muncesc.

\section{Intrebare: Și pentru a face traducerea?}

Traducător 1: A, nu știu. Pentru filmul european pot să-ți spun că era $75 €$ un film, festivalul filmului european. Dar în principiu sunt confindențiale, idea este că de obicei se semneaza contracte de confidențialitate. Normal nu ar trebui să le spun nici eu, dar sunt furioasă. E normal să nu le spună, nu insista pentru că nu le spun. Așa cum și eu cred că lumea trebuie să știe. Așa cum pe vremuri la cinematecă era vreo $6 \$$ pe vremea aceea, întotdeauna s-a plătit deosebit de prost, dar pasiunea e prea mare.

Intrebare: Există o asociație a traducătorilor audiovizuali în România? 
Traducător 1: Există mai multe sindicate, nu fac parte din nici unul pentru că nimeni nu mi-a solicitat participarea, dar nu știu concret. În mod normal ar trebui să fim uniți, pentru că așa poate am reuși ceva, dar orgoliul e mai mare decât restul și atunci e foarte complicat și de aici caștigă doar ceilalți.

\section{Intrebare: Ce este necesar să fii un bun profesional în acest domeniu?}

Traducător 1: Contează foarte mult să fii pasionat, să fii văzut suficiente filme sau suficiente programe în franceză și engleză, vorbesc de aceste limbi pentru că sunt cele de care mă ocup. Cred că tot timpul trebuie să știi ce înseamnă vocabular nou, să le notezi din când în când pentru că nu se știe când ai nevoie. Să vezi cât mai multe filme și nu neapărat cu simț critic și să zici apropo de traducere "vai cum a putut să spună așa ceva?" ci doar să sesizezi fară să faci comentariile și să te gandesti că tu nu ai să cazi data viitoare în aceeași capcană, pentru că uneori se poate întampla. Esențial este să-ți iubești meseria, dar și publicul indiferent care ar fi, fie că este vorba de niște participanți la o conferință sau doar se uita la televizor la un film. Și mai ales să cauți in dicționare, ele trebuie să arate în toate casele așa cum arată la mine, foarte jerpelite pentru că tot timpul caut în dicționare, nu doar pe net ci și în dicționare, pentru că netul nu îl verifică nimeni atât de tare pe cât au fost inițial verificate dicționarele. În mod paradoxal, dar suntem o țară a paradoxului, până in '89 erau mult mai verificate. Este caracteristica noastră, nimeni nu respectă pe nimeni și se poate și mai rău, nu mă refer că era mai bine la comunisti să ne înţelegem bine, ci este o chestie de profesionalism, dar posibil la un moment dat să revină.

\section{Intrebare: Sperăm, nu?}

Traducător 1: Eu că sunt decan de optimism, declar o academie de optimism.

\section{Intrebare: Cum credeți că se poate îmbunătăți situația profesională a traducătorului}

\section{audiovizual în țara noastră?}

Traducător 1: Nu-mi dau seama cum, dar cred că cu cât mai multe burse. După revolutie imediat a luat un avânt extraordinar engleza, pentru că englezii și americanii au oferit burse de specializare pentru studenți, vorbesc acum. Pe când francezii au ramas mult în urmă, și nici spaniolii nu s-au omorat în burse și asta se vede pentru că lumea nu stăpânește suficient de bine limba, deși exista un liceu francez și spaniol la Bucuresti chiar și pâna în '89.

\section{Intrebare: Să investim în educație?}


Traducător 1: Nu doar în educație, în șederea în țările în care se vorbește limba respectivă, în șederea în familie cum se făcea pe vremuri, dacă ai văzut filmele lui Louis de Funès, în Franța cu Anglia. Trebuie făcut foarte multă vreme schimbul, ca să se fixeze limbile respective și să fie limba aceea vorbită, pentru că doar din cărţi nu ajută. La rândul meu dacă nu aș fi văzut atât de multe filme cu ce am învățat la facultate nu ar fost suficient, pentru că nu se putea călători până în '89, dar de la filme. Acum putem călători, oferițile burse celor tineri, pot învața limba, obiceiuri și pot face prieteni, un fel de piramidă perfectă din care toată lumea nu are decât de câștigat pentru că știm foarte bine câte conflicte au pornit în lumea asta din cauza unor nefericite traduceri.

Vă mulțumim foarte mult pentru timpul acordat. 


\section{Interviu Traducător 2}

Intrebare: Majoritatea traducătorilor au pregătire filologică, considerați că este suficientă pentru TAV?

Traducător 2: Nu.

\section{Intrebare: Cu ce se poate compensa?}

Traducător 2: Este și partea practică pe care o înveți la locul faptei. Sunt lucruri care nu se fac în facultate și nu au nici o treabă cu limba, cu punctajul, felul în care poți împărți subtitlurile cum intră cum ies, sunt multe lucruri care țin de practică.

Intrebare: Credeți că există suficiente cursuri de acest tip în România?

Traducător 2: Eu nu știu să existe nici unul.

Intrebare: Aveți multă experiență, eu știu că există unul la București.

Traducător 2: Eu experiența am castigat-o numai unde am lucrat. Tot ce am învățat pe partea practică am învățat pentru că am lucrat.

\section{Intrebare: De cursuri nu stiți?}

Traducător 2: Nu, nu am făcut cursuri anume de TAV, mi-am găsit locul de muncă și acolo am lucrat pe diferite programe, softuri de subtitrare unde înveți și partea practică, adică ce trebuie să faci, ce trebuie să eviți, etc.

Intrebare: Putem spune că experiența înlocuieste cursurile?

Traducător 2: Cam așa. Orice curs fară experiență până nu faci cu mâna ta...

Intrebare: Considerați că o colaborare între universități și firme ar putea îmbunătăți pregătirea în acest domeniu?

Traducător 2: Da, sigur.

Intrebare: Aveți contract permanent cu firma cu care colaborați?

Traducător 2: Da.

Intrebare: Pentru că în aceasta profesie nu prea este normal să ai o stabilitate economică, nu? 
Traducător 2: Dacă ești angajat ca traducător da, cum să nu. Bine la noi nimic nu este foarte stabil.

\section{Intrebare: Este necesar un revizor lingvistic?}

Traducător 2: De obicei se foloseste și cred că este mult mai bine să mai vadă și alti ochi traducerea ta, ajută pentru că fiecare citește în modul lui și eu sunt obisnuită cu felul în care vorbesc și traduc, dar un alt ochi poate vede greșelile scrise, îi sună ciudat și atunci ajută și se folosc redactori.

\section{Intrebare: Deci există?}

Traducător 2: Da, dar traducătorul trebuie să fie de acord pentru că este stăpân pe traducerea lui, acceptă sugestiile făcute de redactori. În alte firme sunt cam impuse, în unele traducătorul are ultimul cuvânt, în altele redactorul, depinde de firma. Nu poți să te contrazici cu ei sunt foarte "deștepți” știu tot.

Intrebare: Taxa pe care o aplicați este pe ore, pe minute, etc.?

Traducător 2: Sunt foarte multe feluri de taxe si pe oră, pe minut, eu nu prea sunt de acord cu nici una. Sunt și tarifele fixe, dar fírmele impun, unele te plătesc la minut, altele pe subtitluri, altele pe film, pe jumătate de oră, pe 20 de minute. Unii nu vor să plătească nici măcar spațiul pe care îl tastezi și te plătesc doar pe caracter, pauzele sunt excluse și eu mam hotărat să scriu fără spații. Evaluarea practicii și a timpului se estimează cu prețuri cat mai mici.

\section{Intrebare: Următoarea întrebare se adresează prețurilor, o temă tabu?}

Traducător 2: Contractele cam peste tot sunt confidențiale și nu se discută deschis despre tarife. Unii plătesc o taxă fixă, alții pe minut, alții mai plătesc și pe cuvânt, dar în cazul traducerilor juridice. În cazul subtitrării este vorba despre vizionarea filmului, traducerea si redactarea. Traducerea și gata fără să vezi filmul poate să iasă foarte prost, nu poți să vezi ce se întamplă și poți să scrii numai prostii. Îți dau un exemplu "I get it" poate să însemne multe lucruri dacă nu ai nici un fel de text nu știi ce înseamnă poate fi “înțeleg, o iau".

\section{Intrebare: Dacă ar fi să specificăm în general anumite prețuri pentru subtitrarea unui film cam cât s-ar plăti, în general nu în particular?}

Traducător 2: Poți să cauți pe internet. Eu personal nu am cum să spun. Probabil există niște grille de plată. Variază și variază destul de mult. 


\section{Intrebare: De la firmă la firmă variază mult?}

Traducător 2: Eu zic că da.

\section{Intrebare: Există o asociație a traducătorilor audiovizuali în România?}

Traducător 2: Nu știu.

Intrebare: Nu? Eu am căutat date, dar nu apare în particular, a traducătorilor în general, da.

Traducător 2: Cred că suntem în minoritate, pentru că nu există foarte multă muncă pe latura asta, la acte sunt mai multe de făcut. Dar filme sunt cateva titluri care apar la televizor sau cinema, se repetă foarte mult și tu îl traduci o dată nu de mai multe ori.

\section{Intrebare: Da este adevărat.}

Traducător 2: O dată făcute răman făcute în firma respectivă.

\section{Intrebare: Drepturi de autor aveți, în general când se semnează un contract?}

Traducător 2: Dreptul de autor este implicit, m-am născut cu el.

\section{Intrebare: Se plăteste?}

Traducător 2: Eu îl cedez, cesionez sau nu. De exemplu dacă eu lucrez pentru o firmă și fac o traducere și eu spun că această traducere nu vreau să ajungă și la altă firmă, dar dacă nu vrei, dau altcuiva să facă traducerea.

\section{Intrebare: Deci condiționează, este ca să fie?}

Traducător 2: Da, tu spui da și asta e. Îți spune ai muncit o dată, te-am plătit pentru el. Dar la o carte de exemplu ai scris-o o dată și gata, dar cartea respectivă o pot cumpăra trei milioane de persoane. Cam așa este și cu traducerea de film. Eu nu lucrez pentru șapte firme, nu este normal ca tu să dai munca mea mai departe.

\section{Intrebare: Nu e normal, dar se face...}

Traducător 2: Da, se face si se face pe la spate, cam așa ceva. Nu pot să vorbesc la modul general, dar cred că se practică. Este foarte greu să câștigi în lupta asta, să spui că e dreptul tău. Verbal spun "da, așa este, dar...fac cum vreau eu."

Intrebare: De asta întrebam de o asociație, dacă există și ați fi uniți să vă apărați împreună drepturile. 
Traducător 2: Poate că sunt mulți traducători tineri, care vor să plece pe drumul acesta și acceptă să lucreze pe foarte puțini bani pentru că sunt firme care nu țin la calitate și acceptă.

\section{Intrebare: Cum s-ar spune comandă prețurile și nu calitatea?}

Traducător 2: Probabil, cu toate că au pretenție la calitate, dar cu prețuri mici, nu știu.

\section{Intrebare: Ce este necesar să fii un bun profesional în acest domeniu?}

Traducător 2: Îți dau un exemplu, eu a trebuit să aleg o colegă nouă și am fost nevoită să o testez. Și, deși a tradus foarte bine și natural în limba romana, pe partea tehnică nu putea să facă pur și simplu punctajul, să introducă subtitlurile. Nu putea să înțeleagă că o replică intră unde se aude. Nu a putut să facă partea tehnică. Este nevoie și de asta, dacă nu știi să faci degeaba traduci tu foarte frumos. Mulți nu înțeleg partea tehnică a subtitrării, că tu ai o bucătică mică de timp și trebuie să fie o sinteză a conținutului. Ca subtitlul intră unde trebuie nu înainte nici după. Este ideal să știi foarte bine limba ta, să știi să faci reducție de text, să adaptezi cu alte cuvinte, pentru că noi vorbim mult mai repede decat citim și atunci orice text trebuie puțin scurtat. Dacă pui tot ce auzi într-un film este posibil ca spectatorii să nu poată să citească, de aceea este nevoie de adaptare, care este foarte importantă. Cred că este vorba de puțin talent și mult exercitiu. Sunt multe pe care le înveți făcând.

\section{Intrebare: Cum credeți că se poate îmbunătăți situația profesională a traducătorului audiovizual în țara noastră?}

Traducător 2: Cred că se angajează foarte greu traducători, majoritatea preferă să lucreze în sistem de colaborare ceea ce pentru traducători este o situație instabilă. Nu au o carte de muncă, nu au vechime, nu au nimic cu care să demonstreze că ei de fapt poate au lucrat 10 ani de zile. Perioadele de muncă vin în valuri, într-o lună poți să muncesti foarte mult, și în altă lună să stai, ceea ce e foarte obositor. Eu de exemplu, nu prea am lucrat opt ore ci totdeauna mai mult. Dacă ai un program normal este cu total altceva, dar nu se practică, este foarte greu să fii colaborator.

Intrebare: Văzută situația de nesiguranță și fluctuația muncii, și colaborator este bine, ai o stabilitate, nu?

Traducător 2: Da, dar lucrezi în timp limită. De exemplu ị̂ti da materialul azi și îți spune că în două zile trebuie să fie gata, trebuie să lucrezi noaptea, ești obosit greșești, dar lumea 
nu înțelege. Mai poate fi altă capcană, vrei să caștigi mai mult și tragi ca să ajungi la o sumă decentă cu care să poți trăi, nu este normal să te suprasoliciți.

Intrebare: Un film de 90 de minute în cât timp se poate subtitra?

Traducător 2: Eu aș spune că o săptămână. Un film care trebuie să-1 traduci, să-1 corectezi cred că o săptămană.

\section{Intrebare: În general aveți o săptămână?}

Traducător 2: Nu prea. Sunt cam 4-5 zile și mai puține când este nevoie.

Intrebare: Cam astea erau întrebările, dacă mai vreți să mai adăugați ceva important pentru traducători și drepturile lor?

Traducător 2: Este o meserie foarte, foarte frumoasă, trebuie să-ți placă filmul și eu sunt indragostită de film. Este o plăcere să faci lucrul acesta, cu toate că am văzut persoane care fac acest lucru și nu le place filmul, trebuie să-ți placă. Este o meserie frumoasă și trebuie promovată. Dar pe partea financiară nu auzi nici o dată că te angajează, nici măcar la TVR, care este televiziunea publică, traducătorii nu sunt angajați, redactorii da, dar traducătorii sunt colaboratori.

\section{Intrebare: Este vorba de instabilitate profesională, în general?}

Traducător 2: Da, mai multe contracte. Cred că și nouă ne-ar plăcea să lucrăm normal. Să vii acasă și să nu mai ai treabă, eu cel putin. Dar toti facem așa, sau extra își fac programul lor, dar este un program anormal. Plus nu există vacanțe, asigurări trebuie să le platesti singur, dacă nu, nu ai parte de beneficiile care le are un angajat normal, un contract de muncă.

Intrebare: Deci, cel mai important în această profesie este să ai pasiune ca să poți să supraviețuiesti, să compensezi celelalte părți?

Traducător 2: Probabil. Oamenii pasionați o fac de plăcere, iar ceilalți care nu, muncesc prea mult.

Vă mulțumim foarte mult pentru timpul acordat. 


\section{Interviu Traducător 3}

1. Care sunt taxele pe care le aplică un traducător audiovizual în România, când realizează o traducere?

Tarifele pentru fiecare traducere audiovizuală diferă de la companie, la companie, în funcţie de durata programului, de complexitatea conţinutului, de limba-sursă, de tipul materialului (film artistic, documentar etc...)

2. Există o asociație a traducătorilor audiovizuali în România? Dacă nu există, ar fi necesară?

Nu există o asemenea asociaţie. Da, ar fi extrem de necesară, deoarece meseria de traducător audiovizual are nevoie să fie privită cu mult mai multă consideraţie.

3. Ați realizat cursuri de specializare în traducere audiovizuală în România sau alte țări și ce fel de cursuri?

Din anul 2008 sunt profesor-asociat la Universitatea din Bucureşti, Catedra de Limba Engleză, Masteratul pentru Traducerea Textului Literar Contemporan (MTTLC), unde predau cursul Editare Media, traducere pentru Subtitrare şi Dublaj.

4. În ce an s-a realizat primul curs de traducere audiovizuală la Universitatea București?

Masteratul pentru Traducerea Textului Literar Contemporan (MTTLC), realizează acest curs din anul 2008.

5. În ce alte universități din țară se predau cursuri de traducere audiovizuală?

Nu ştiu cu certitudine, dar MTTLC este singurul program care oferă acest tip de curs pe perioada a 4 semestre.

6. Credeți că există suficiente cursuri în țara noastră pentru acest tip de traducere?

$\mathrm{Cu}$ siguranţă, nu.

7. Considerați că universitățile au echipament tehnic adecvat pentru a pregăti traducătorii audiovizuali în comparație cu alte țări? 
$\mathrm{Nu}$ ştiu care sunt dotările universităţilor din străinătate, dar în România, cu certitudine, se poate şi mai bine.

8. Considerați că este importantă pregătirea specializată, pentru a realiza această profesie?

Evident, având în vedere că există foarte multe persoane care cred că ştiu să facă traducere audiovizuală, numai că nu au nici experienţa, nici cunoştinţele necesare realizării acestui gen de muncă. Publicul trebuie să primească doar traduceri de calitate, realizate de profesionişti în domeniu, iar profesionalismul se poate obţine doar prin mulţi ani de experienţă sau în urma absolvirii unor cursuri de specialitate.

9. Considerați că o colaborare între universități și fírmele de traducere audiovizuală ar putea imbunătăți pregatirea în acest domeniu?

Această colaborare există deja în ceea ce priveşte Universitatea din Bucureşti şi Televiziunea Română de exemplu. Sigur că da, cu cât numărul acestor colaborări va creşte, cu atât mai repede ne vom bucura de traduceri tot mai profesionist realizate.

10. Cum credeți că se poate îmbunăți situația profesională a traducătorului audiovizual în țara noastra (dacă este cazul)?

Aşa cum spuneam mai devreme, cred că traducătorul audiovizual trebuie privit cu mult mai mult respect, deoarece are o meserie complicată şi foarte importantă, având în vedere numărul din ce în ce mai mare de programe subtitrate şi dublate. 


\section{Interviu Firmă}

Firmă: Ne ocupăm cu distribuția filmelor în cinematografe. Noi ne-am inființat în 2010, practic eu sunt de la început aici în poziţia de director de vânzari.

Întrebare: Ce fel de firme obisnuiesc să solicite mai mult serviciile dumneavoastră?

Firmă: Avem tot felul de categorii: animații, drame comedii, science fiction, titluri horror, practic acoperim toată franja de filme.

\section{Întrebare: În firmă aveți traducători contractați sau contactați?}

Firmă: Avem un traducător cu care colaborăm de la început, avem contract direct cu el, traducătorea noastră colaborează tot din 2010 cu noi. Deocamdată nu este necesar să colaborăm cu alții, poate pe viitor dacă se măreste marja de filme va fi necesar să încheiem şi alte contracte.

Întrebare: Când contractați un traducător ce considerați mai mult studii, experiență, ambele?

Firmă: Contează foarte mult experiența, bineînteles contează într-o oarecare măsura și studiile. Dar, ca probă se dă un titlu de film de test, și se corelează cu experiența, vedem dacă traducerea în sine ne place: sună corespunzator, este scrisă corect, limbajul este adecvat filmului. Sunt anumiţi pași care se urmăresc pentru că în aceasta industrie subtitlurile și caracterele trebuie respectate, timpii de asemenea, iar un traducător autorizat trebuie să aibă experiență, să știe altfel nu poate să realizeze traducerea în limba română.

Întrebare: De ce formă contractați traducătorii interviu personal, recepție de $\mathbf{C V}$, recomandări?

Firmă: Eu personal nu am participat la interviul traducătoarei noastre. Ea a fost oarecum preluată cu o experiența de 14 ani, din cate știu eu, la momentul respectiv în 2010 nu erau prea mulți traducători pe piață, mai ales în capitală, și practic oferta nu era variată. Se cerea experiență cinematografică, mai ales că piața nu era foarte largă, se știa care cum stă, ce filme a mai lucrat, nu am avut de intervievat foarte multe persoane, dar nu am participat direct.

\section{Întrebare: In afară de TAV, ce alt tip de traducere folosiți în firmă?}

Firmă: Mai există în firmă un tip de traducere, dar implică mai mult procesul de înscriere al fimului la registrul cinematografic, orice titlu vine cu un contract și acesta este obtinut de la Centrul Naţional de Cinematografie. Noi trebuie să le oferim traducerea legalizată 
în limba română, dar de această traducere nu se ocupă traducătoarea noastră, se ocupă o firmă de traducere, care se ocupă de documente.

Întrebare: Ce gen de filme se traduc cu mai multa frecvență în firma dumneavoastră pentru copii, adulți, ambele?

Firmă: Cred că live action a intrat puternic, în sensul că dacă inainte toată lumea asocia Disney cu desenele animate și filmele exclusiv pentru copii acum se rulează filme cu personaje, cu oameni, filme pentru copii puse în scenă cu actori reali cum ar fi Cinderella sau Frumoasa si Bestia, dar cum am zis și la inceput ne ocupăm de tot felul de filme. Dacă întrebați copiii normal că vor animații, dacă întrebăm adolescenții vor comedii și acțiune, încă se pune accent pe filmele 3D și formatele astea. Totul să fie în miscare, total să fie acțiune.

\section{Întrebare: In funcție de gen, ce modalitate utilizați subtitrare, dublaj?}

Firmă: Avem și subtitrare și dublaj, de subtitrare am discutat, se ocupă traducătoarea cu care colaborăm acum, iar de dublaj avem o firmă cu care colaborăm. Studioul nostru are contract în mod direct cu studioul de dublaj. Deci noi pe partea de dublaj nu ne implicăm, în sensul că dublajul ține legătura în mod direct cu Disney. Noi practic ne bucurăm de varianta finală a filmului.

Întrebare: Ce tip de asociere lingvistică se foloseste engleză-română, francezăromână, etc.?

Firmă: Engleză-română, cel mai mult.

\section{Întrebare: Spaniolă-română?}

Firmă: Nu, nu n-am avut. Am avut practic Violeta, dar scriptul a venit în limba engleză, chiar dacă probabil filmul, scriptul cel original a fost in spaniolă, noi 1-am primit în limba engleză și din cate știu materialele internationale circulă în limba engleză și noi le traducem în limba română.

Întrebare: Tipurile de programe care se folosesc în traducere sunt impuse de firmă sau este alegerea traducătorului?

Firmă: În ce sens, online?

\section{Întrebare: Pentru dublaj, de exemplu, subtitrare?}

Firmă: Pentru dublaj nu ne ocupăm noi, iar pentru subtitrare studioul comandă. El impune un sistem online sau pur și simplu pregătește un Excel care trebuie completat. Traducătoarea se ocupă de fișierele finale, fișierele traduse efectiv în format XML sau RTF care pot să ajute la realizarea copiei finale subtitrate. 
Întrebare: Din partea clienților primiți vreo restricție în ceea ce privește traducerea, cântece, titlu, etc.?

Firmă: Din câte știu, da, există niște norme mai ales de cântece, nume de personaje. Dar, cel mai bine cred că vă poate lămuri traducătoarea noastră, care sunt exemplele. Din câte știu eu, da, exista un cod, nu știu exact depinde de firmă.

\section{Întrebare: Firma dumneavoastră îi impune vreo restricție, normă?}

Firmă: Evident că după fiecare traducere noi verificăm filmul în sine cu tot cu traducerea implementată, nu are voie să folosească anumite dialoguri, cuvinte nepotrivite, se ține foarte mult cont de target, dacă este de audiență generală, dacă este cu acordul părinților pană la 12 ani, adică se ține cont de vârsta normal.

Întrebare: Ce tip de materiale îi proporționați traducătorului lista de dialoguri, etc.? Firmă: Lista de dialoguri cu timpi. Dacă nu există lista de dialoguri cu timpi și există doar fișiere video se poate descurca doar că mult mai greu. Dar există și fișiere video la care să urmarească și dialogul cu timpi, este ideal. De multe ori este nevoie de fișierul video ca să-și dea seama de sexul personajului respectiv dacă este vorba de o fată, de un băiat, de un cățel, plantă este foarte important de multe ori nu-ţi dai seama din script.

Întrebare: Firma dumneavoastră dispune de un revizor lingvistic pentru a realiza feedback-ul la traduceri?

Firmă: Nu, o persoană autorizată nu. Noi le verificăm, cum am spus, într-o sală de cinema le verificăm, cum arată materialul final. Și dacă este nepotrivit, bineințeles îl reparăm.

Întrebare: Considerați că succesul unui film depinde într-o mare parte și de traducere?

Firmă: Da, cu siguranță, normal.

Întrebare: Firma dumnevoastră facilitează realizarea practicii TAV studenților?

Firmă: $\mathrm{Nu}$ am primit nici o cerere, nu.

Întrebare: Considerați că formarea în România, în TAV este adecvată?

Firmă: Eu cred că da. Eu personal cred că este importantă o școală, o pregătire pentru o astfel de meserie. Până la urmă este o meserie.

Întrebare: Formarea actuală este suficientă cu ce avem noi profesori, aparatură?

Firmă: Nu pot intra în aceste detalii pentru că nu știu exact ce se pune la dispoziție. Cred că un traducător ar putea da mai multe detalii.

Vă mulțumesc foarte mult pentru amabilitatea dumneavoastră. 


\section{ANEXO IV \\ Entrevista Traductor 1}

Pregunta: En su gran mayoría, los traductores tienen estudios de Filología, ¿consideráis que es suficiente para realizar traducción audiovisual?

Traductor 1: No, no creo que es suficiente, pero a veces ayuda. Pero, tampoco creo que la mayoría tiene formación filológica, mi opinión. Creo que muchos de ellos han empezado con otras profesiones y muchas veces es útil tener una formación técnica. Por ejemplo, si tienes que traducir un documental o cosas así más complicadas, se trata del vocabulario. Creo que antes que nada necesitas pasión y talento, lo demás es adyacente. Pregunta: ¿Consideráis que existen suficientes cursos específicos en Rumanía?

Traductor 1: Son insuficientes te lo puedo asegurar, pero por otra parte tampoco existe un mercado laboral extenso. Quiero decir, ellos se forman mediante unos cursos, además has realizado una entrevista con un compañero nuestro Stanescu, que es profesor en la facultad y que tiene un curso en este ámbito, con el que he colaborado yo también con un master class, y quiero decir que los alumnos acumulan muchísimos conocimientos, pero no se pueden desarrollar más tarde porque la traducción audiovisual es un mundo cerrado. Quiero decir, que si has empezado traducir, bien, y si no también. Este mundo es muy cerrado a veces para mí también, es muy complicado entrar en este mundo.

\section{Pregunta: ¿Pese a toda su carrera en este ámbito?}

Traductor 1: No tiene nada que ver una cosa con la otra y muchas veces puede jugar en tu desventaja, porque las empresas prefieren estudiantes que hacen el trabajo gratis con la idea de acumular experiencia o por muy poco dinero. También pueden imaginar que yo cobraría sumas exorbitantes, lo que es totalmente erróneo en todos los casos. Anteriormente existía lo que se llama la acreditación de traductor, el colmo es que después de ejercer esta profesión tantos años, las empresas aún me lo piden. Yo me lo saque en el primer año de carrera, pese a que era estudiante de idiomas francés e inglés. Ahora, como trámites laborales, no se realiza ningún pago sin este certificado, sin embargo nadie verifica las traducciones que aparecen, tal como sería normal, o alguien que compruebe los comentarios añadidos, hablo de la subtitulación. Es muy fácil hacer estas cosas cuando no estás implicado, además en Rumanía desafortunadamente no se respeta la calidad, así como en otros países, tal como sería normal, no se respeta esta idea. 
Pregunta: ¿Consideráis que las universidades tienen la dotación técnica y profesores adecuados para formar los traductores audiovisuales?

Traductor 1: Profesores seguramente sí y existían incluso cuando he cursado yo mi carrera, entonces existía un laboratorio bastante equipado para los años '76-' 80 cuando he estudiado yo. Pero en la actualidad no conozco mucho la situación en las universidades.

Pregunta: ¿Consideráis que una colaboración entre las universidades y las empresas empleadoras podría mejorar la formación en este ámbito?

Traductor 1: Sí, creo que sería muy beneficiosa y especialmente con España, donde actualmente existen muchas series, películas que vienen de allí o de América de Sur y categóricamente que sería importante una colaboración entre nosotros. Además, los españoles, como los rumanos hablan muy rápido, creo que sería mejor para ambos esta colaboración.

\section{Pregunta: ¿Es necesario un revisor lingüístico?}

Traductor 1: Sí, categóricamente. Quiero decir, que de nuevo paradójicamente, hasta el '89 la televisión nacional era la única que existía, y donde se hacía de la siguiente forma: tenías un texto que pautabas, o sea veías hasta donde tenía que ser la respectiva replica que no tenía que ser no muy larga, tenía que aparecer bastante tiempo en la pantalla para que puedan leer los semianalfabetos de los pueblos. La idea era que lo tenía que entender “el tío Jorge", así decíamos entre nosotros. Entonces, tú tenías que leer tres veces cada texto, para que el que no está acostumbrado a leer rápido, pueda entender lo que has escrito allí. Tenías un texto en original del cual podías hacer la traducción, o más a menudo no tenías nada y escuchabas, ponías adelante y atrás X veces la grabación, hasta que lograbas entender lo que había dicho el otro, porque seguramente el actor tenía un director que le decía "interpreta con naturalidad, no es necesario que hables muy claro." Cuando finalizabas la traducción el texto se escribía a la máquina y lo revisaba un editor, el editor verificaba que no había errores de redacción, que no escribías mal alguna palabra. Después venia un experto en lingüística que se llamaba estilista y le pagaban por separado para estilizar las frases. ¿Te das cuenta de cuántas cosas se tenían que hacer? Por no recordar que existía también la censura, que todos conocemos, y que aplicabas desde un principio, sabias que no podías decir "iglesia", etc. El texto era mucho más revisado antes que ahora. Por ejemplo, en esos tiempos si alguien te llamaba la atención porque te habías equivocado, te afectaba o lo recordabas, para no equivocarte otra vez. Ahora a los traductores les puedes decir mil veces, que poco les importa. Ellos dicen que 
no están bien remunerados, que tienen que hacer el trabajo muy rápido y que tiene suficiente calidad lo que han hecho allí. No existe esa voluntad de..., no necesariamente de perfección, o tienen momentos donde se observa que no estaban cansados cuando habían empezado la traducción y al final... se equivocaban de vez en cuando.

\section{Pregunta: Hemos observado que la tarifa se aplica por minuto, hora, programa...}

Traductor 1: Por minutos, yo no sé, tal como sería normal. Normalmente se hace por película y es una remuneración muy mala, nosotros hemos esperado que se eleve al nivel europeo, porque estamos en la Unión Europea. No ha pasado y aun siguen las mismas condiciones, mucho trabajo y precios bajos.

\section{Pregunta: Si pudiéramos concretar el precio, porque nadie lo dice, es como un secreto} en Rumanía, ¿cuánto se paga por la subtitulación de una película, por ejemplo?

Traductor 1: No creo que sea un secreto, creo que varía muchísimo de una empresa a otra y creo que por eso no te lo dice nadie. En principio son aproximadamente unos $100 €$ per film lo que significa poquísimo. Los precios son muy malos.

\section{Pregunta: ¿Y para el doblaje?}

Traductor 1: Para interpretar te lo digo yo. He colaborado en una película y tenía 12 réplicas y me han pagado $50 €$ gravables, por tanto me he quedado con $30 €$ para un doblaje Disney. Es muy poquito, menos de lo que te cobra un taxi para llevarte de un sitio a otro. Y he hecho hace tiempo otro doblaje donde tenía más réplicas y porque soy yo, y han podido alardear, me han dado $300 €$ de nuevo gravables, pero ha sido una excepción y me han pedido discreción porque normalmente no pagan más de 50-100€. Y sé y recuerdo que para la película animada Ice Age, pese a que se trataba de una de las mejores actrices de Rumanía, le han dado $150 €$. Me parece una suma vergonzosa, pero por otra parte te gusta, te gusta hacer esta cosa y ellos lo saben. Es un mundo muy cerrado donde unos son dueños y otros trabajan.

\section{Pregunta: ¿Y para realizar la traducción?}

Traductor 1: A, no lo sé. Para la película europea puedo decirte que eran $75 €$ para una película, el festival del filme europeo. Pero en principio son confidenciales, la idea es que casi siempre se firman contratos de confidencialidad. Normalmente yo tampoco tendría que decirlos, pero estoy furiosa. Es normal que no te lo digan, no insistas porque no te lo dirán. Aun así, yo también considero que la gente tiene que saberlo. Antes del '89, para la cinemateca, se cobraban unos $6 \$$ en esos tiempos, siempre se ha pagado muy mal, pero la pasión es demasiado grande.

\section{Pregunta: ¿Existe una asociación de los traductores audiovisuales en Rumanía?}


Traductor 1: Existen muchos sindicatos, yo no pertenezco a ninguno porque nadie ha solicitado mi colaboración, pero no sé, concretamente. Normalmente tendríamos que estar unidos porque de esta forma podríamos lograr algo, pero el orgullo es más grande que el interés y entonces es muy complicado, y de esta situación solamente salen ganando los demás (las empresas).

\section{Pregunta: ¿Qué se necesita para ser un buen profesional en este ámbito?}

Traductor 1: Es muy importante tener pasión, visionar bastantes películas o programas en francés e inglés, hablo de estos idiomas porque son con las que trabajo yo. Creo que todo el tiempo tienes que saber las novedades del vocabulario, apuntar las palabras de vez en cuando porque no se sabe cuándo las necesitarás. Ver muchas películas y necesariamente con espíritu crítico y decir sobre la traducción “¿cómo ha podido decir esta cosa?”, no solamente percatarte de los errores sin hacer comentarios y pensar que tú no puedes caer en la misma trampa de las palabras, porque nunca se sabe y a veces te puede pasar. Es esencial amar tu profesión y el público, independientemente de su nivel de cultura, ya sea para una conferencia o simplemente para visionar una película. Y sobre todo buscar en los diccionarios, deberían estar en todas las casas como en la mía, muy desgastados, porque todo el tiempo busco en los diccionarios, no solamente en internet. Internet no está tan verificado como estaban inicialmente los diccionarios, paradójicamente antes del '89, y no me refiero que era mejor en la época comunista, que quede claro, se trata de profesionalismo y esperemos que la profesionalidad se haga notar en la actualidad.

\section{Pregunta: Esperamos, ¿no?}

Traductor 1: ¡Yo, que soy decana de optimismo declaro una academia de optimismo!

Pregunta: ¿Cómo consideráis que se puede mejorar la situación profesional de los traductores audiovisuales en nuestro país?

Traductor 1: No sé cómo, pero creo que a base de ofrecer más becas. Después de la revolución, inmediatamente se ha desarrollado muchísimo el inglés, porque los ingleses y los americanos han ofrecido muchas becas para los estudiantes. Mientras los franceses se han quedado atrás y tampoco los españoles no han excedido en ofrecer becas y esto se nota porque la gente no domina suficientemente estos idiomas, pese a que existía un instituto francés y otro español en Bucarest, aún antes del '89.

\section{Pregunta: ¿Invertir más en educación?}

Traductor 1: No solamente en educación, en las estancias en los países que hablan la respectiva lengua, el intercambio entre familias como se hacía antiguamente, no sé si has visto las películas con Louis de Funès, los intercambios entre Francia e Inglaterra. Se 
necesita realizar este cambio para conocer las lenguas tal como se hablan, porque solamente de los libros no es suficiente. Por ejemplo, yo si no hubiera visto tantas películas solamente con lo que había aprendido en la universidad no hubiera tenido suficientes conocimientos, porque antes del ' 89 no podías viajar al extranjero, pero podías aprender de las películas. Ahora podemos viajar, se pueden ofrecer becas a los jóvenes, así pueden aprender el idioma, las costumbres, la cultura y pueden hacer amigos, un tipo de pirámide perfecta de la cual todo el mundo puede ganar, porque sabemos muy bien cuántos conflictos se han iniciado en este mundo por causa de una infeliz traducción.

\section{Le agradecemos muchísimo su tiempo y la información ofrecida.}




\section{Entrevista Traductor 2}

Pregunta: En su gran mayoría los traductores tienen estudios de Filología, ¿consideráis que es suficiente para realizar traducción audiovisual?

Traductor 2: No.

Pregunta: ¿Con que se puede equilibrar esta carencia?

Traductor 2: En este tipo de traducción existe la parte práctica, que la aprendes "en la escena"... hay cosas que no aprendes en la universidad y no tienen nada que ver con el lenguaje, el pautado, redactar los subtítulos, cuando entran y cuando salen...son muchas técnicas que implican práctica.

Pregunta: ¿Consideráis que existen suficientes cursos específicos en Rumanía?

Traductor 2: Yo no sé si existe alguno.

Pregunta: Existe uno en Bucarest...

Traductor 2: Yo he adquirido mi experiencia solamente donde he trabajado. Todo lo que he aprendido en la parte práctica, lo he aprendido porque he trabajado.

Pregunta: De los cursos no sabéis...

Traductor 2: No, no he hecho ningún curso específico de traducción audiovisual, he encontrado mi trabajo y allí he utilizado diferentes tipos de programas de subtitulación donde aprendes, también la parte práctica, lo que tienes que hacer, lo que tienes que evitar, etc.

Pregunta: Podríamos decir que la experiencia sustituye la formación.

Traductor 2: Algo parecido. Cualquier curso sin experiencia, hasta que no lo haces tú mismo...

Pregunta: ¿Consideráis que una colaboración entre las universidades y las empresas podría mejorar la formación en este dominio?

Traductor 2: Sí, seguramente.

Pregunta: ¿Tenéis contrato permanente con la empresa con la que trabajáis?

Traductor 2: Sí.

Pregunta: ¿Porque en esta profesión no es algo usual tener una estabilidad económica, no?

Traductor 2: Si estás contratado como traductor sí, como no. Bueno en nuestro país nada es muy estable.

Pregunta: ¿Es necesario un revisor lingüístico? 
Traductor 2: Habitualmente existe y creo que es necesario, porque es mucho mejor que comprueben otros ojos tu traducción, ayuda porque cada uno lee a su manera y yo estoy acostumbrada a mi forma de hablar y traducir, pero otra persona puede ver los errores escritos, y le suena raro, y entonces puede ser útil utilizar editores o revisores.

\section{Pregunta: Entonces existen.}

Traductor 2: Sí, pero el traductor tiene que estar de acuerdo porque es el dueño de su traducción, acepta las sugerencias de los editores. En otras empresas los cambios se imponen, en otras el traductor tiene la decisión, en otras el editor, depende de cada empresa. No los puedes contradecir porque ellos son muy "listos", lo saben todo.

Pregunta: ¿Suele cobrar el trabajo realizado por minuto, hora, programa completo? Traductor 2: Existen muchas formas: por minuto, hora, yo personalmente no estoy de acuerdo con ninguna. Se aplican también tarifas fijas, pero son las empresas las que las imponen, algunas pagan por minuto, otras por subtitulo, otras por media hora, 20 minutos. Algunas, por ejemplo, no quieren pagar ni el espacio, que de hecho tú lo tecleas, es tu tiempo, te pagan solamente por caracteres y las pausas no. La valoración de esta práctica y de nuestro tiempo se estima con precios muy bajos.

Pregunta: La siguiente pregunta se refiere a los precios, un tema tabú...

Traductor 2: Los contratos son normalmente confidenciales y no se habla abiertamente sobre precios. Unos pagan una tarifa fija, otros por minuto, otros pagan por palabra, pero en el caso de la traducción jurídica. En el caso de la subtitulación se trata de visionar la película, traducirla y redactarla. La traducción y ya está, sin ver la película puede salir muy mal, porque no puedes ver lo que pasa y puedes redactar tonterías. Te doy un ejemplo "I get it" puede significar muchas cosas, si no tienes ningún tipo de texto no sabes lo que significa, puede ser "entender o coger."

Pregunta: Si pudiéramos especificar en general ciertos precios para la subtitulación de una película, cuanto se pagaría en general, no en particular.

Traductor 2: Puedes buscar en Internet. Yo personalmente no te lo puedo decir. Probablemente existen unas cuadriculas de pago. Varían y varían bastante.

\section{Pregunta: ¿De empresa a empresa varía mucho?}

Traductor 2: Yo digo que sí.

Pregunta: ¿Existe una asociación de los traductores audiovisuales en Rumanía?

Traductor 2: No lo sé.

Pregunta: Hemos buscado información, pero no aparece, de los traductores en general sí. 
Traductor 2: Creo que somos minoría, porque no existe mucho trabajo en este ámbito, en el ámbito de la traducción jurídica, sí. Pero las películas son unos cuantos títulos que se emiten en la tele o en los cines y se repiten mucho, tú la película la traduces una vez y ya está.

\section{Pregunta: Sí, es cierto.}

Traductor 2: Una vez traducidas se las queda la empresa.

\section{Pregunta: ¿Derechos de autores tenéis, en general, cuando se firma un contrato?}

Traductor 2: Los derechos de autor son implícitos, "he nacido con ellos"...

\section{Pregunta: ¿Se paga?}

Traductor 2: Yo concedo mis derechos de autor o no, se supone. Por ejemplo, si yo trabajo para una empresa y realizo la traducción, digo que esta traducción no quiero que se conceda a otra empresa, pero si no estás de acuerdo, buscan otro traductor para hacerla.

\section{Pregunta: Es una condición, pero no se respeta...}

Traductor 2: Sí, tú dices sí y ya está. Te dicen que has trabajado una vez y te hemos pagado por ello. Pero, para un libro por ejemplo lo escribes una vez y ya está, ese libro te lo pueden comprar tres millones de personas. Eso pasa con la traducción de una película...Yo no trabajo para siete empresas, no es normal que tú pases mi trabajo a otros. Pregunta: No es normal, pero se hace...

Traductor 2: Sí se hace, y a escondidas, algo así. No puedo generalizar, pero creo que es una práctica normal en este ámbito. Es muy difícil ganar en esta lucha, decir que es tu derecho. Verbalmente te dicen que sí, es así, pero yo hago lo que quiero (empresa).

Pregunta: Por eso preguntaba por una asociación, si existe y ustedes están unidos, juntos pueden defender sus derechos...

Traductor 2: Posiblemente hay muchos traductores jóvenes, que se quieren dedicar a esta profesión y aceptan trabajar por muy poco dinero, porque existen empresas que no tienen mucho en cuenta la calidad y aceptan.

\section{Pregunta: Como diríamos, mandan los precios y no la calidad...}

Traductor 2: Probablemente, aunque pretenden calidad, pero a bajo coste.

Pregunta: ¿Qué se necesita para ser un buen profesional en este ámbito?

Traductor 2: Te doy un ejemplo, yo tuve que elegir una nueva compañera y tuve que examinarla. Y, pese a que había hecho una traducción muy bonita, natural del texto en la lengua rumana, en la parte técnica no sabía hacer un pautado, introducir los subtítulos. No podía comprender que una réplica entra donde se escucha. No pudo hacer la parte técnica. Esto es muy importante, si no la sabes, no sirve de nada traducir muy, muy bien. 
Muchos no entienden la parte técnica de la subtitulación, que tú tienes una parte muy pequeña de tiempo y tienes que sintetizar el contenido. Que el subtítulo entra donde y cuando se necesita, ni antes ni después. Es ideal saber muy bien la lengua para realizar la reducción del texto, adaptar las palabras, porque nosotros hablamos mucho más rápido que leemos, y entonces cualquier texto se tiene que abreviar. Si redactas todo lo que escuchas en la película, es posible que los espectadores no puedan leer, por eso es necesaria la adaptación del texto. Creo que se necesita talento y mucha práctica. Son muchas cosas que las aprendes practicando.

Pregunta: ¿Cómo consideráis que se puede mejorar la situación profesional de los traductores audiovisuales en nuestro país?

Traductor 2: Creo que se contratan muy difícilmente los traductores, la mayoría de las empresas prefieren trabajar en sistema de colaboración, lo que supone para los traductores una situación inestable. No se tiene contrato de trabajo, no se tiene antigüedad profesional, no se tiene nada para demostrar que, por ejemplo, se lleva trabajando diez años. El periodo de trabajo llega en olas, durante un mes puedes trabajar muchísimo y el mes siguiente estar sin hacer nada, es muy agotador. Yo por ejemplo, nunca he trabajo ocho horas, casi siempre he trabajado más. Si tienes un horario normal es totalmente diferente, pero no se practica, es muy difícil ser colaborador.

Pregunta: Vista la situación de inestabilidad y la oscilación del trabajo, ser colaborador te aporta más o menos una estabilidad en este ámbito...

Traductor 2: Sí, pero trabajas en tiempo límite. Por ejemplo te entregan el material hoy y te dicen que en dos días tiene que estar listo, tienes que trabajar por la noche, estás cansando, te equivocas, pero la gente no comprende. Además, puede transformarse en una trampa, quieres ganar más y te aceptas más trabajo para llegar a una suma decente para poder vivir, no es normal que lo aceptes todo.

Pregunta: ¿Para una película de 90 minutos en cuanto tiempo se puede realizar la subtitulación?

Traductor 2: Yo diría que en una semana. Una película que tienes que traducirla, verificarla, creo que una semana.

Pregunta: ¿Y tenéis una semana?

Traductor 2: No, normalmente. Son unos 4-5 días o menos si la necesitan.

Pregunta: Las preguntas que queríamos formular eran estas, pero si queréis añadir algo más sobre esta profesión... 
Traductor 2: Es una profesión muy, muy hermosa, tienen que gustarte las películas y yo estoy enamorada de ellas. Es un placer hacer este trabajo, aunque he visto personas que hacen este trabajo y no le gustan las películas, tienen que gustarte. Es una profesión maravillosa y la tenemos que promover. Pero en cuanto a su estabilidad laboral, nunca te proponen un contrato, ni por ejemplo la Televisión Rumana (TVR), que es una cadena de televisión pública, los traductores no están contratados, los editores sí, pero los traductores son colaboradores.

Pregunta: Se trata de la inestabilidad profesional en el mercado laboral...

Traductor 2: Sí, más contratos. Creo que a nosotros también nos gustaría trabajar en condiciones normales. Legar a casa y tener más trabajo, por lo menos yo. Pero todos hacemos igual un horario anormal. Además, no existen vacaciones, los seguros te los pagas sólo, si no, no tienes los beneficios que tiene un empleado normal con contrato de trabajo.

Pregunta: ¿Entonces, lo más importante en esta profesión es tener pasión para poder compensar las otras carencias?

Traductor 2: Probablemente. Las personas apasionadas la hacen por pasión, y los demás trabajan mucho, muchísimo.

Le agradecemos muchísimo su tiempo y la información ofrecida. 


\section{Entrevista Traductor 3 (correo electrónico)}

¿Qué tipo de tarifas aplica el traductor audiovisual en Rumanía cuando realiza un encargo?

Las tarifas para cada tipo de traducción audiovisual varían de empresa a empresa, dependiendo de la duración del programa, de la complejidad de su contenido, de la lengua original, del tipo de producto audiovisual (película, documental, etc...).

¿Existe alguna asociación de traductores audiovisuales en Rumanía? ¿Si no existe, considera que sería necesaria?

No existe ninguna asociación de este tipo. Sí, sería muy necesaria, dado que la profesión del traductor audiovisual necesita más valoración social.

¿Ha cursado algún curso de formación específica en Rumanía u otros países? ¿Qué tipo de curso/s?

Desde el año 2008 soy profesor asociado de la Universidad de Bucarest, en el Departamento de Inglés, a través del Máster para la Traducción del Texto Literario Contemporáneo (MTTLC), donde imparto el curso de Traducción para Subtitulación y Doblaje.

¿En qué año se impartió el primer curso de traducción audiovisual en la Universidad de Bucarest?

El Máster para la Traducción del Texto Literario Contemporáneo (MTTLC) imparte este curso desde el año 2008.

¿En qué otras universidades de este país se imparten cursos de traducción audiovisual?

No sé exactamente, pero el MTTLC es el único programa que ofrece este tipo de formación con una duración de cuatro semestres. 
¿Considera que existen suficientes cursos en nuestro país para este tipo de traducción?

Seguramente, no.

¿Considera que las universidades tienen la dotación técnica adecuada para la formación de traductores audiovisuales en comparación con otros países?

No conozco la dotación técnica de las universidades de otros países, pero en Rumanía, seguramente, se podría mejorar.

¿Considera que es importante la formación específica para ejercer este tipo de profesión?

Evidentemente, teniendo en cuenta que existen muchas personas que piensan que saben realizar la traducción audiovisual, aunque no tienen ni la experiencia, ni los conocimientos teóricos para ejercer esta profesión. El público tiene que recibir solamente traducciones de calidad, realizadas por profesionales de este ámbito, pero la profesionalidad solo se puede obtener después de muchos años de experiencia o formándose mediante cursos específicos.

¿Considera que una colaboración entre las universidades y las empresas empleadoras podría mejorar la formación en este ámbito?

Este tipo de colaboración existe entre la Universidad de Bucarest y la Televisión Rumana (TVR), por ejemplo. Claro que sí, si el número de colaboraciones incrementa, mejorará la calidad de las traducciones realizadas.

¿Cómo considera que se puede mejorar la situación profesional del traductor audiovisual en nuestro país (si es el caso)?

Tal como exponía anteriormente, creo que la profesión del traductor audiovisual se tiene que valorar con más respeto, porque es una profesión complicada y muy 
importante, teniendo en cuenta el número elevado de productos subtitulados y doblados actualmente. 


\section{Entrevista Empresa Empleadora}

Empresa: Nos encargamos de la distribución de las películas en los cines. La empresa se fundó en el año 2010. Yo, prácticamente, estoy trabajando aquí como directora de ventas desde su inicio.

Pregunta: ¿Qué tipo de empresas solicitan más sus servicios y que géneros distribuís?

Empresa: Tenemos todo tipo de categorías: animación, drama, comedia, ciencia ficción, terror. Prácticamente, cubrimos todos los tipos de películas.

Pregunta: ¿La empresa tiene traductores contratados o los contrata en el mismo momento del encargo?

Empresa: Tenemos una traductora con la que colaboramos desde el principio; tenemos contrato directamente con ella. De hecho, colabora con nosotros desde el 2010. En este momento no es necesario colaborar con otros. Posiblemente en un futuro, si crece el número de películas distribuidas, sea necesario realizar otros contratos.

Pregunta: ¿Cuándo contrata un traductor, qué requisito es más importante: los estudios, la experiencia o ambos?

Empresa: Cuenta mucho la experiencia, y por supuesto, cuentan de algún modo también los estudios. Pero, como prueba, se le entrega una película y se correlaciona con la experiencia; comprobamos si la traducción nos gusta: si suena bien, si está correctamente escrita, si el lenguaje es adecuado para la película... Son varios pasos los que seguimos, porque en la industria del filme los subtítulos y los caracteres se tienen que respetar, así como el tiempo. El traductor tiene que tener experiencia y tiene que saber hacer esto, ya que si no, no puede realizar la traducción en la lengua rumana.

Pregunta: ¿De qué forma contrata a los traductores: entrevista personal, recepción de $\mathrm{CV}$, recomendaciones, experiencia profesional...?

Empresa: Yo, personalmente, no he participado en la entrevista de nuestra traductora. Tenía una vasta experiencia casi 14 años; que yo sepa, en ese momento, en el año 2010, no había muchos traductores audiovisuales en el mercado, especialmente en la capital, y prácticamente la oferta no era muy variada. Se necesitaba experiencia cinematografica, y como el mercado no era muy variado, se sabía cómo iba cada uno, qué películas había traducido. No se han entrevistado muchas personas, pero yo no participe directamente.

Pregunta: ¿Además de la traducción audiovisual, a qué otras variedades de traducción se dedica su empresa? 
Empresa: En nuestra empresa se realiza otro tipo de traducción, pero se dedica más al proceso de inscripción de la película en el registro cinematográfico. Cualquier título de película viene con un contrato y este se obtiene del Centro Nacional de Cinematografía. Nosotros tenemos que entregarle la traducción legalizada en la lengua rumana, pero de esta traducción no se encarga nuestra traductora, sino una empresa de traducción que se encarga de la documentación.

Pregunta: ¿A qué público se dirigen con más frecuencia los productos audiovisuales que traduce su empresa?

Empresa: Creo que live action ha entrado muy fuerte en el mercado rumano. Anteriormente, todo el mundo asociaba Disney con las películas de animación y sus películas exclusivamente dirigidas al público infantil. Ahora hay películas con personas, películas dedicadas igualmente a los niños, pero con actores reales, como por ejemplo Cinderella o la Bella y la Bestia, pero como había dicho distribuimos cualquier tipo de película. Si preguntas a los niños, normalmente quieren dibujos animados, y si preguntas a los adolescentes, quieren comedias y acción; se han puesto muy de moda las películas en 3D y este tipo de formato. Todo tiene que ser movimiento y acción.

Pregunta: En función del género ¿qué modalidad de traducción se utiliza con más frecuencia para los productos extranjeros: subtitulación o doblaje?

Empresa: Tenemos subtitulación y doblaje. De la subtitulación se encarga nuestra traductora, con la que colaboramos, y del doblaje se encarga una empresa con la que colaboramos. Nuestra distribuidora tiene un contrato directamente con el estudio de doblaje. Entonces, por nuestra parte, no nos implicamos directamente en la parte de doblaje, en el sentido que el estudio de doblaje contacta directamente con Disney. Nosotros, prácticamente, vemos la versión final de la película.

Pregunta: ¿En qué combinación lingüística suelen realizar las traducciones audiovisuales inglés-rumano, francés-rumano, etc.?

Empresa: Inglés-rumano.

\section{Pregunta: ¿Y español-rumano?}

Empresa: No, no hemos tenido nunca esta combinación. Hemos distribuido la película Violeta, pero el guion nos llegó en inglés. Posiblemente el guion original se escribió en español, pero nosotros lo hemos recibido en inglés y, que yo sepa, los materiales internacionales circulan en inglés y nosotros los traducimos al rumano.

Pregunta: ¿Los tipos de programas que se utilizan en el proceso de traducción audiovisual los impone su empresa o los elige el traductor? 
Empresa: ¿En qué sentido, online?

\section{Pregunta: Para el doblaje, por ejemplo, o la subtitulación.}

Empresa: Del doblaje no nos encargamos nosotros, y para la subtitulación manda el estudio. Él impone un sistema online o, simplemente, prepara un Excel que se tiene que completar. La traductora se encarga de los ficheros finales, los ficheros traducidos en formato XML o RTF que pueden ayudar a la realización de la copia final de la subtitulación.

Pregunta: $\mathbf{¿}$ Recibe algunas restricciones por parte de los clientes sobre el proceso de traducción (título, canciones, etc.)?

Empresa: Que yo sepa, sí. Existen unas normas, sobre todo en las canciones, nombres de personajes... Pero creo que la traductora os puede explicar mejor qué restricciones se aplican. Sé que sí, existe un código, pero no sé exactamente cómo es, depende de la empresa.

\section{Pregunta: ¿Su empresa impone algunas pautas o restricciones en la traducción a la}

\section{traductora que tiene contratada?}

Empresa: Evidentemente, cuando se finaliza la traducción comprobamos la película en totalidad, con la traducción implementada. No se pueden utilizar algunos tipos de diálogos, palabras inadecuadas... Tenemos mucho en cuenta el target, si se trata de audiencia general, si es con el acuerdo de los padres hasta los 12 años. Estamos muy pendientes de la edad de la audiencia.

Pregunta: ¿Qué tipo de materiales se le proporciona al traductor: lista de diálogos, guion...?

Empresa: La lista de diálogos con los tiempos. Si no existe la lista de diálogos con los tiempos y solamente el fichero de video, el traductor se las puede arreglar, pero es más difícil. Pero existen ficheros de video donde puede ver el diálogo con los tiempos, es ideal. Muchas veces se necesita el fichero de video para darse cuenta del sexo de los personajes: si es una chica, un chico, un perro, una planta... Es muy importante, porque muchas veces no te das cuenta solo con el guion.

Pregunta: ¿Tiene un revisor lingüístico en su empresa, para dar feedback sobre las traducciones realizadas por el traductor?

Empresa: No, una persona autorizada no. Nosotros verificamos, como ya he dicho, en una sala de cine. Verificamos cómo es el material final. Si es inadecuado, por supuesto lo arreglamos. 
Pregunta: ¿Considera que el éxito de una película depende también, en gran parte, de la calidad de la traducción?

Empresa: Sí, claro, por supuesto.

Pregunta: ¿Su empresa facilita la realización de prácticas universitarias a los estudiantes de traducción audiovisual?

Empresa: No, no hemos recibido ninguna petición, no.

Pregunta: ¿Considera que la formación universitaria en la traducción audiovisual en Rumanía es adecuada para ejercer posteriormente esta profesión?

Empresa: Creo que sí. Personalmente, creo que es importante estudiar, hay que prepararse para este tipo de profesión. Porque finalmente es una profesión.

Pregunta: ¿La formación actual es suficiente con lo que tenemos nosotros: profesores, tecnología?

Empresa: No puedo entrar en estos detalles porque desconozco este entorno. Creo que un traductor podría dar más detalles.

Le agradecemos muchísimo su tiempo y la información ofrecida. 
ANEXO V

DISTRIBUTIA DE FILME DISTRIBUTION

2. FILME ÎN PREMIERA DUPA TPARA DE ORIGINE INTRE 2011 - 2015

ORIGIN OF FIRST-TIME RELEASE FEATURE FILMS BETWEEN 2011-2015

3. TOTAL FILME DE LUNG METRAJ DISTRIBUITE DUPA TPARA DE ORIGINE INNTRE 2011 - 2015

ORIGIN OF ALL RELEASED FEATURE FILMS BETWEEN 2011-2015

4. PRINCIPALII DISTRIBUITORI CU FILME ÎN PREMIERA ÎNTRE 2011-2015 FIRSTTIME RELEASE FEATURE FILMS ACCORDING TO MAJOR DISTRIBUTION COMPANIES BETWEEN 2011 - 2015

5. PRINCIPALII DISTRIBUITORI CU FILME DIFUZATE ÎNTRE 2011 - 2015 RELEASED FEATURE FILMS ACCORDING TO MAJOR DISTRIBUTION COMPANIES BETWEEN 2011 - 2015.

6. DISTRIBUITORI DE FILME DISTRIBUTION COMPANIES

\section{DISTRIBUŢIA DE FILME}

FILME ÎN PREMIERĂ DUPĂ ŢARA DE ORIGINE / ORIGIN OF FIRST-TIME RELEASE FEATURE FILMS

\begin{tabular}{|l|r|r|r|r|r|}
\hline $\begin{array}{l}\text { Tara de origine/ } \\
\text { Film origin }\end{array}$ & $\begin{array}{r}2011 \\
\%\end{array}$ & $\begin{array}{r}2012 \\
\%\end{array}$ & $\begin{array}{r}2013 \\
\%\end{array}$ & $\begin{array}{r}2014 \\
\%\end{array}$ & $\begin{array}{r}2015 \\
\%\end{array}$ \\
\hline $\begin{array}{l}\text { Românești/ } \\
\text { National films }\end{array}$ & 24 & 23 & 27 & 23 & 22 \\
\hline $\begin{array}{l}\text { Europene/ } \\
\text { European films }\end{array}$ & 49 & 42,37 & 13,64 & 11,98 & 10,14 \\
\hline Americane/ & 25,52 & 25,81 & 19,19 & 24,48 & 36,87 \\
\hline American films & 114 & 113 & 123 & 113 & 104 \\
\hline Alte ţări/ & 59,38 & 60,75 & 62,12 & 58,85 & 47,93 \\
\hline Others & 5 & 2,60 & 10 & 9 & 11 \\
\hline Total & 192 & 186 & 198 & 192 & 217 \\
\hline
\end{tabular}

TOTAL FILME DE LUNG METRAJ DISTRIBUITE ÎN CINEMATOGRAFE ORIGIN OF RELEASED FEATURE FILMS 2011 - 2015 


\begin{tabular}{|l|r|r|r|r|r|}
\hline $\begin{array}{l}\text { Tara de origine/ } \\
\text { Film origin }\end{array}$ & $\begin{array}{r}2011 \\
\%\end{array}$ & $\begin{array}{r}2012 \\
\%\end{array}$ & $\begin{array}{r}2013 \\
\%\end{array}$ & $\begin{array}{r}2014 \\
\%\end{array}$ & $\begin{array}{r}2015 \\
\%\end{array}$ \\
\hline $\begin{array}{l}\text { Româneşti/ } \\
\text { National films }\end{array}$ & 14,97 & 13,02 & 16,00 & 18,06 & 12,90 \\
\hline $\begin{array}{l}\text { Europene/ } \\
\text { European films }\end{array}$ & 152 & 131 & 130 & 127 & 160 \\
\hline Americane/ \\
American films & 41,60 & 30,47 & 28,89 & 27,97 & 36,20 \\
\hline Alte țări/ & 229 & 221 & 220 & 212 & 193 \\
Others & 28 & 51,40 & 48,89 & 46,70 & 43,67 \\
\hline TOTAL & 5,82 & 5,12 & 6,22 & 7,27 & 7,24 \\
\hline & 481 & 430 & 450 & 454 & 442 \\
\hline
\end{tabular}

DISTRIBUITORI CU FILME ÎN PREMIERĂ / FIRST-TIME RELEASE FEATURE FILMS ACCORDING TO DISTRIBUTION COMPANIES

$2011-2015$

\begin{tabular}{|c|c|c|c|c|c|}
\hline \begin{tabular}{|l} 
Distribuitori/ \\
Distribution companies \\
\end{tabular} & $2011 \%$ & $\begin{array}{r}2012 \\
\end{array}$ & $\begin{array}{r}2013 \\
\% \\
\end{array}$ & $\begin{array}{r}2014 \\
\% \\
\end{array}$ & $\begin{array}{r}2015 \\
\% \\
\end{array}$ \\
\hline \multirow[t]{2}{*}{ RO-IMAGE 2000} & 35 & 42 & 35 & 36 & 46 \\
\hline & 18,23 & 22,58 & 17,68 & 18,75 & 21,20 \\
\hline FREEMAN & & & & 10 & 28 \\
\hline ENTERTAINMENT & & & & 5,21 & 12,90 \\
\hline \multirow[t]{2}{*}{ INTERCOM FILM } & 20 & 14 & 23 & 26 & 24 \\
\hline & 10,42 & 7,53 & 11,62 & 13,54 & 11,06 \\
\hline \multirow[t]{2}{*}{ FORUM FILM ROMANIA } & 10 & 21 & 16 & 19 & 21 \\
\hline & 5,21 & 11,29 & 8,08 & 9,90 & 9,68 \\
\hline \multirow[t]{2}{*}{ INDEPENDENTA FILM } & 15 & 13 & 18 & 17 & 17 \\
\hline & 7,81 & 6,99 & 9,09 & 8,85 & 7,83 \\
\hline \multirow[t]{2}{*}{ ODEON CINEPLEX } & 13 & 12 & 17 & 19 & 15 \\
\hline & 6,77 & 6,45 & 8,59 & 9,90 & 6,91 \\
\hline CLOROFILM & $\begin{array}{r}7 \\
3,65\end{array}$ & $\begin{array}{r}2 \\
1,08\end{array}$ & $\begin{array}{r}3 \\
1,52\end{array}$ & \begin{tabular}{r|}
3 \\
1,56
\end{tabular} & $\begin{array}{r}12 \\
5,53\end{array}$ \\
\hline \multirow[t]{2}{*}{ CINE EUROPA } & & & & & 10 \\
\hline & & & & & 4,61 \\
\hline \multirow[t]{2}{*}{ TRANSILVANIA FILM } & 20 & 12 & 9 & 7 & 9 \\
\hline & 10,42 & 6,45 & 4,55 & 3,65 & 4,15 \\
\hline ASOCIATIA CULTURALA & 2 & 2 & 7 & & 5 \\
\hline MACONDO & 1,04 & 1,08 & 3,54 & & 2,30 \\
\hline MANDRAGORA & & & & & $\begin{array}{r}4 \\
184\end{array}$ \\
\hline \multirow[t]{2}{*}{ VOODOO FILM } & & & 2 & & 3 \\
\hline & & & 1,01 & & 1,38 \\
\hline \begin{tabular}{|l} 
PARLUX \\
ENTERTAINMENT
\end{tabular} & & & & & $\begin{array}{r}3 \\
1,38\end{array}$ \\
\hline \multirow[t]{2}{*}{ PARADA FILM } & & & 3 & & 3 \\
\hline & & & 1,52 & & 1,38 \\
\hline \begin{tabular}{|l} 
BML MOVIE \\
ENTERTAINMENT
\end{tabular} & & & & $\begin{array}{r}6 \\
3,13\end{array}$ & $\begin{array}{r}2 \\
0,92\end{array}$ \\
\hline $\begin{array}{l}\text { ALTI DISTRIBUITORI/ } \\
\text { OTHERS }\end{array}$ & $\begin{array}{r}70 \\
36,45\end{array}$ & $\begin{array}{r}68 \\
36,55\end{array}$ & $\begin{array}{r}65 \\
32,82\end{array}$ & $\begin{array}{r}49 \\
25,52\end{array}$ & $\begin{array}{r}15 \\
6,91\end{array}$ \\
\hline TOTAL & 192 & 186 & 198 & 192 & 217 \\
\hline
\end{tabular}


TOTALUL FILMELOR DIFUZATE PE DISTRIBUITORI / RELEASED FEATURE FILMS ACCORDING TO DISTRIBUTION COMPANIES

$2011-2015$

\begin{tabular}{|c|c|c|c|c|c|}
\hline $\begin{array}{c}\text { Distribuitori/ } \\
\text { Distribution companies }\end{array}$ & $2011 \%$ & $\begin{array}{r}2012 \\
\%\end{array}$ & $\begin{array}{r}2013 \\
\%\end{array}$ & $\begin{array}{r}2014 \\
\%\end{array}$ & $\begin{array}{r}2015 \\
\%\end{array}$ \\
\hline RO-IMAGE 2000 & $\begin{array}{r}66 \\
13,72 \\
\end{array}$ & $\begin{array}{r}75 \\
17,44 \\
\end{array}$ & $\begin{array}{r}70 \\
15,56 \\
\end{array}$ & $\begin{array}{r}68 \\
14,98 \\
\end{array}$ & $\begin{array}{r}82 \\
18,55\end{array}$ \\
\hline INDEPENDENTA FILM & $\begin{array}{r}43 \\
8,94 \\
\end{array}$ & $\begin{array}{r}36 \\
8,37 \\
\end{array}$ & $\begin{array}{r}46 \\
10,22 \\
\end{array}$ & \begin{tabular}{r|}
51 \\
11,23 \\
\end{tabular} & $\begin{array}{r}48 \\
10,86 \\
\end{array}$ \\
\hline INTERCOM FILM & $\begin{array}{r}65 \\
13,51\end{array}$ & $\begin{array}{r}43 \\
10,00\end{array}$ & $\begin{array}{r}47 \\
10,44\end{array}$ & $\begin{array}{r}45 \\
9,91 \\
\end{array}$ & $\begin{array}{r}44 \\
9,95\end{array}$ \\
\hline FREEMAN ENTERTAINMENT & & & & $\begin{array}{r}10 \\
2,20 \\
\end{array}$ & $\begin{array}{r}35 \\
7,92 \\
\end{array}$ \\
\hline FORUM FILM ROMANIA & $\begin{array}{r}15 \\
3,12 \\
\end{array}$ & $\begin{array}{r}28 \\
6,51 \\
\end{array}$ & $\begin{array}{r}26 \\
5,78 \\
\end{array}$ & $\begin{array}{r}26 \\
5,73 \\
\end{array}$ & $\begin{array}{r}31 \\
7,01 \\
\end{array}$ \\
\hline ODEON CINEPLEX & $\begin{array}{r}20 \\
4,16\end{array}$ & $\begin{array}{r}17 \\
3,95 \\
\end{array}$ & $\begin{array}{r}21 \\
4,67 \\
\end{array}$ & $\begin{array}{r}26 \\
5,73\end{array}$ & $\begin{array}{r}26 \\
5,88\end{array}$ \\
\hline TRANSILVANIA FILM & $\begin{array}{r}29 \\
6,03 \\
\end{array}$ & $\begin{array}{r}35 \\
8,14 \\
\end{array}$ & $\begin{array}{r}24 \\
5,33 \\
\end{array}$ & $\begin{array}{r}21 \\
4,63 \\
\end{array}$ & $\begin{array}{r}20 \\
4,52 \\
\end{array}$ \\
\hline CLOROFILM & $\begin{array}{r}35 \\
7,28 \\
\end{array}$ & $\begin{array}{r}18 \\
4,19 \\
\end{array}$ & $\begin{array}{r}17 \\
3,78 \\
\end{array}$ & $\begin{array}{r}11 \\
2,42 \\
\end{array}$ & $\begin{array}{r}17 \\
3,85 \\
\end{array}$ \\
\hline MEDIAPRO DISTRIBUTION & $\begin{array}{r}57 \\
11,85 \\
\end{array}$ & $\begin{array}{r}59 \\
13,72 \\
\end{array}$ & $\begin{array}{r}71 \\
15,78 \\
\end{array}$ & $\begin{array}{r}62 \\
13,66 \\
\end{array}$ & $\begin{array}{r}12 \\
2,71 \\
\end{array}$ \\
\hline ASOCIATIA CULTURALA MACONDO & $\begin{array}{r}2 \\
0,42 \\
\end{array}$ & $\begin{array}{r}5 \\
1,16 \\
\end{array}$ & $\begin{array}{r}13 \\
2,89 \\
\end{array}$ & $\begin{array}{r}13 \\
2,86 \\
\end{array}$ & $\begin{array}{r}10 \\
2,26 \\
\end{array}$ \\
\hline CINE EUROPA & & & & & $\begin{array}{r}10 \\
2,26 \\
\end{array}$ \\
\hline PARADA FILM & $\begin{array}{r}6 \\
1,25\end{array}$ & \begin{tabular}{r|}
4 \\
0,93
\end{tabular} & $\begin{array}{r}6 \\
1,33\end{array}$ & $\begin{array}{r}7 \\
1,54\end{array}$ & $\begin{array}{r}8 \\
1,81\end{array}$ \\
\hline VOODOOFILMS & $\begin{array}{r}9 \\
1,87 \\
\end{array}$ & $\begin{array}{r}5 \\
1,16 \\
\end{array}$ & $\begin{array}{r}8 \\
1,78 \\
\end{array}$ & $\begin{array}{r}5 \\
1,10 \\
\end{array}$ & $\begin{array}{r}7 \\
1,58 \\
\end{array}$ \\
\hline \begin{tabular}{|l|} 
ALTI DISTRIBUITORI/ \\
OTHERS * \\
\end{tabular} & $\begin{array}{r}134 \\
27,86 \\
\end{array}$ & $\begin{array}{r}105 \\
24,42 \\
\end{array}$ & $\begin{array}{r}101 \\
22,44 \\
\end{array}$ & $\begin{array}{r}109 \\
24,01 \\
\end{array}$ & $\begin{array}{r}92 \\
20,81 \\
\end{array}$ \\
\hline TOTAL & 481 & 430 & 450 & 454 & 442 \\
\hline
\end{tabular}

\section{NOTA:}

Poziţia „Alţi distribuitori” cuprinde un număr mare de filme proiectate în cadrul festivalurilor de film care sau desfăşurat in cursul anului. 


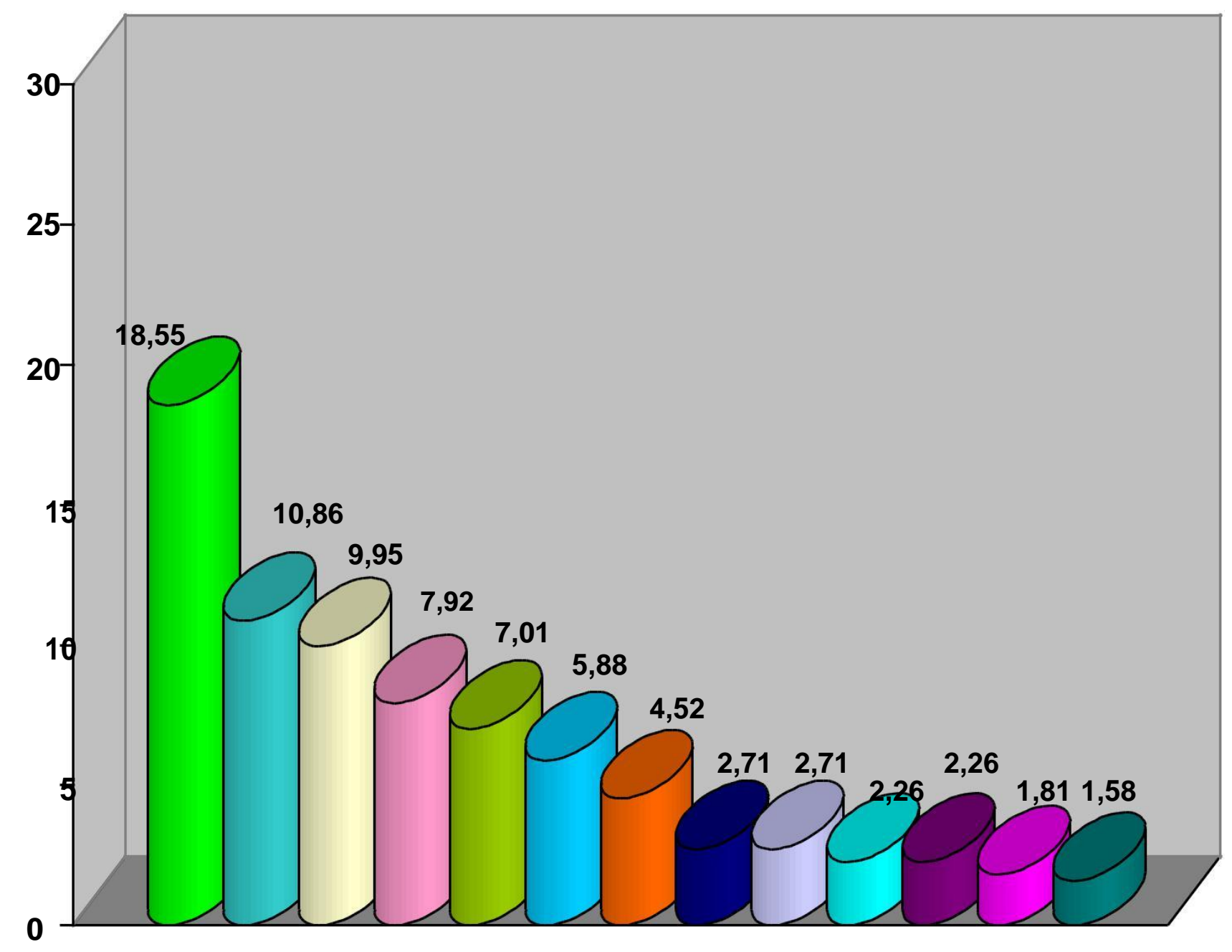

$\square$ Ro Image 2000 Intercom Film $\square$ Forum Film Romania Transilvania Film Media Pro Distributions Cine Europa Noodoofilms
Independenta Film

$\leftarrow$ Freeman Entertainment

$\square$ Odeon Cineplex

-Clorofilm

$\square$ Asociatia Culturala Macondo ¿Parada Film 
PRINCIPALII DISTRIBUITORI DE FILM

MAJOR DISTRIBUTION COMPANIES

\begin{tabular}{|c|c|c|c|}
\hline $\begin{array}{c}\text { Denumire / } \\
\text { Distribution companies }\end{array}$ & $\begin{array}{l}\text { Adresa / } \\
\text { Adress }\end{array}$ & $\begin{array}{l}\text { Director/ } \\
\text { Manager }\end{array}$ & $\begin{array}{l}\text { Producători } \\
\text { Distribuiţi/ } \\
\text { Film companies }\end{array}$ \\
\hline $\begin{array}{l}\text { ASOCIATIA } \\
\text { CULTURALA } \\
\text { MACONDO }\end{array}$ & $\begin{array}{l}\text { Strada C.A.Rosetti Nr.25, } \\
\text { Et.1, Ap.5, Sector 2, } \\
\text { Bucuresti }\end{array}$ & $\begin{array}{l}\text { Bacanu Daniela } \\
\text { director }\end{array}$ & Europeni \\
\hline $\begin{array}{l}\text { BML MUSIC } \\
\text { ENTERTAINMENT }\end{array}$ & $\begin{array}{l}\text { Strada Campia Libertatii } \\
\text { Nr.29,Scara D,Et.2,Ap.127 } \\
\text { Sector } 3 \\
\text { Bucuresti }\end{array}$ & $\begin{array}{l}\text { Boaje Sorin } \\
\text { administrator }\end{array}$ & Indiene \\
\hline CLOROFILM & $\begin{array}{l}\text { Strada I.C. Bratianu Nr.33 } \\
\text { Ap. } 13 \text {, Judet Cluj, Cluj - } \\
\text { Napoca }\end{array}$ & $\begin{array}{l}\text { Jakabffy B. Samu } \\
\text { administrator }\end{array}$ & Europeni, români şi alţii \\
\hline $\begin{array}{l}\text { FREEMAN } \\
\text { ENTERTAINMENT }\end{array}$ & $\begin{array}{l}\text { Strada Tokio Nr.11 } \\
\text { Sector } 1 \\
\text { Bucuresti }\end{array}$ & $\begin{array}{l}\text { Anca Sorina Truta } \\
\text { director general }\end{array}$ & Warner Bros,Sony Pictures \\
\hline FORUM FILM ROMANIA & $\begin{array}{l}\text { Bucureşti, Strada Ana } \\
\text { Davila Nr. 13, Et. 1, Ap. } \\
\text { biroul Nr. } 7 \text {, Sector } 5 \text {, } \\
\text { Bucuresti }\end{array}$ & $\begin{array}{l}\text { Elias Yaniv ZachI } \\
\text { administrator }\end{array}$ & Walt Disney Company. \\
\hline $\begin{array}{l}\text { INDEPENDENȚA } \\
\text { FILM }\end{array}$ & $\begin{array}{l}\text { Str. Logofat Luca Stroici } \\
\text { Nr.47, Et.3, Ap.6 } \\
\text { Sector 2, Bucureşti }\end{array}$ & $\begin{array}{c}\text { Antoine Bagnaninchi director } \\
\text { general }\end{array}$ & $\begin{array}{l}\text { Europeni şi independenţi } \\
\text { americani }\end{array}$ \\
\hline $\begin{array}{l}\text { INTERCOM FILM } \\
\text { DISTRIBUTION }\end{array}$ & $\begin{array}{l}\text { Strada Popa Rusu nr. 12, Et. } \\
1 \text {, Ap. } 2 \text {, Sector } 2 \text { Bucureşti }\end{array}$ & $\begin{array}{c}\text { Andreea Celesta Comanici } \\
\text { director general }\end{array}$ & $\begin{array}{l}\text { Twenty Century Fox, Warner } \\
\text { Bross., Columbia Pictures }\end{array}$ \\
\hline $\begin{array}{l}\text { MEDIAPRO } \\
\text { DISTRIBUTION }\end{array}$ & $\begin{array}{l}\text { Str. Studioului, nr.1, } \\
\text { B1.Cladirea Centrala a } \\
\text { Studiourilor MediaPro,et.1 } \\
\text { cam.141 Buftea, Jud. Ilfov }\end{array}$ & $\begin{array}{l}\text { Vasiliu Mihnea } \\
\text { Stefan } \\
\text { administrator }\end{array}$ & $\begin{array}{l}\text { Europeni, români, } \\
\text { independenti } \\
\text { americani }\end{array}$ \\
\hline $\begin{array}{l}\text { ODEON } \\
\text { CINEPLEX }\end{array}$ & $\begin{array}{l}\text { Strada Pictor G.D. Mirea } \\
\text { Nr. 6, Et. } 2 \text {, Sector } 1 \\
\text { Bucuresti }\end{array}$ & $\begin{array}{c}\text { Irina Crisan } \\
\text { director general } \\
\text { adjunct }\end{array}$ & $\begin{array}{l}\text { Twentieth Century Fox } \\
\text { International Corporation, Odeon }\end{array}$ \\
\hline PARADA FILM & $\begin{array}{l}\text { Str.Vasile Lascar Nr.30, et. } \\
\text { 6, ap.6 Duplex Camera } \\
\text { Nr.3,Sector } 2 \\
\text { Bucuresti }\end{array}$ & $\begin{array}{l}\text { Calin Peter Netzer } \\
\text { administrator }\end{array}$ & Romani \\
\hline RO IMAGE 2000 & $\begin{array}{l}\text { Str.Torentului nr. 2-4, bl. } \\
\text { Cladirea 3, ap.birou nr.4, } \\
\text { sect.2, Bucureşti }\end{array}$ & $\begin{array}{l}\text { Omer Oana Mihaela- } \\
\text { director general }\end{array}$ & $\begin{array}{l}\text { Paramount, Universal, Metro } \\
\text { Golldwyn Mayer, Dreamworks }\end{array}$ \\
\hline $\begin{array}{l}\text { TRANSILVANIA } \\
\text { FILM }\end{array}$ & $\begin{array}{l}\text { Str.G-ral Berthelot Nr.27 } \\
\text { Sc.A, Et.4, Ap. } 25 \\
\text { Sector 1, } \\
\text { Bucureşti }\end{array}$ & $\begin{array}{l}\text { Tudor Giurgiu/ } \\
\text { Oana Giurgiu } \\
\text { administrator }\end{array}$ & Europeni, români şi alţii \\
\hline
\end{tabular}




\begin{tabular}{|c|c|c|c|}
\hline VOODOO FILM & $\begin{array}{l}\text { Str.Serdarului Nr.5, Et. } \\
\text { Demisol, Sector 1, } \\
\text { Bucureşti }\end{array}$ & $\begin{array}{l}\text { Cristian Mungiu } \\
\text { administrator }\end{array}$ & Români \\
\hline ZAZU FILM & $\begin{array}{l}\text { Srtada Turnu Magurele } \\
\text { Nr.9, Sc.1, Et.8.Ap.35. } \\
\text { Sector } 4 \\
\text { Bucuresti }\end{array}$ & $\begin{array}{l}\text { Iacob Ana Cristina } \\
\text { administrator }\end{array}$ & Romani \\
\hline CINE EUROPA & $\begin{array}{l}\text { Calea Borsului Nr.45, } \\
\text { Oradea,Jud.Bihor }\end{array}$ & $\begin{array}{l}\text { Akos Szelenyi } \\
\text { administrator }\end{array}$ & Europeni \\
\hline MANDRAGORA & $\begin{array}{l}\text { Str.Fetesti Nr.4,Bloc F5, } \\
\text { Parter,Sc.B,Ap.16,Sect.3 } \\
\text { Bucuresti }\end{array}$ & Anamaria Puiu & Romani \\
\hline
\end{tabular}

PIATA DE CASETE VIDEO, D.V.D., C.D., UMD, B.D / VIDEO, D.V.D., C.D., U.M.D., B.D. MARKET

1. NUMARUL TITLURILOR DE FILME PE PIATA DE CASETE VIDEO, D.V.D., C.D, U.M.D., B.D.

NUMBER OF TITLES ON VIDEO, D.V.D., C.D, U.M.D., B.D. MARKET... .

2. TIRAJUL DE CASETE VIDEO, D.V.D., C.D., U.M.D., B.D. NUMBER OF PRINTS ON THE SELLING AND RENTAL VIDEO AND D.V.D., U.M.D., B.D. MARKET

3. NUMARUL FIRMELOR DE COMERCIALIZARE CU AMANUNTUL DE CASETE VIDEO, D.V.D., C.D., U.M.D. , B.D.

NUMBER OF OUTLETS SELLING BY RETAIL VIDEO, D.V.D., C.D., U.M.D.

4. NUMARUL FIRMELOR DE INCHIRIERE CASETE VIDEO, D.V.D., C.D., U.M.D., B.D.

NUMBER OF OUTLETS RENTING VIDEO, D.V.D., C.D, U.M.D.

5. DISTRIBUITORI MAJORI PE PIATA VIDEO, D.V.D., U.M.D., B.D. 
MAJOR DISTRIBUTION COMPANIES ON THE VIDEO, D.V.D.,

U.M.D. MARKET

1A. NUMĂRUL TITLURILOR DE FILME AFLATE ÎN EXPLOATARE ÎN CADRUL PIEŢII DE CASETE VIDEO, D.V.D, C.D,

U.M.D ŞI B.D/ NUMBER OF TITLES ON VHS, DVD, CD, U.M.D AND B.D

\begin{tabular}{|c|c|c|c|l|l|}
\hline ANUL/YEAR & 2011 & 2012 & 2013 & 2014 & 2015 \\
\hline $\begin{array}{c}\text { Număr titluri/ } \\
\text { Number of titles }\end{array}$ & 5813 & 3417 & 3365 & 3601 & 3320 \\
\hline
\end{tabular}

1B. NUMĂRUL TITLURILOR DE FILME LANSATE PE PIATA DE CASETE VIDEO, D.V.D, C.D, U.M.D ŞI B.D/

NUMBER OF TITLES RELEASED ON VHS, DVD, CD, U.M.D AND B.D

\begin{tabular}{|c|c|c|c|c|c|}
\hline ANUL/YEAR & 2011 & 2012 & 2013 & 2014 & 2015 \\
\hline $\begin{array}{c}\text { Număr titluri/ } \\
\text { Number of titles }\end{array}$ & 1900 & 1488 & 606 & 152 & 150 \\
\hline
\end{tabular}

2. TIRAJUL DE CASETE VIDEO, D.V.D, C.D SI U.M.D ÎNREGISTRATE LA C.N.C./ NUMBER OF PRINTS RELEASED ON THE SELLING AND RENTAL VIDEO, D.V.D. C.D AND U.M.D. MARKET

\begin{tabular}{|c|c|c|c|c|c|}
\hline ANUL/YEAR & 2011 & 2012 & 2013 & 2014 & 2015 \\
\hline $\begin{array}{c}\text { Tiraj/ } \\
\text { Number of prints }\end{array}$ & 1946651 & 945850 & 677150 & 402350 & 330170 \\
& & & & & \\
\hline
\end{tabular}


3. FIRME DE COMERCIALIZARE CU AMĂNUNTUL A FILMELOR PE

CASETE VIDEO, D.V.D, C.D, U.M.D ŞI B.D/ NUMBER OF OUTLETS

SELLING BY RETAIL VIDEO, D.V.D., C.D, U.M.D AND B.D

\begin{tabular}{|c|c|c|c|c|c|}
\hline ANUL/YEAR & 2011 & 2012 & 2013 & 2014 & 2015 \\
\hline $\begin{array}{c}\text { Număr firme la sfârşitul anului } \\
\text { Inr. of firms at the end of the year: } \\
\text { din care: } \\
\text {-înregistrate în cursul anului/ } \\
\text { registered during the yeari }\end{array}$ & 545 & 551 & 562 & 581 & 590 \\
\hline
\end{tabular}

4. FIRME DE ÎNCHIRIERE A FILMELOR PE CASETE VIDEO, D.V.D, C.D, U.M.D ŞI B.D/ NUMBER OF OUTLETS RENTING VIDEO, D.V.D., C.D, U.M.D AND B.D

\begin{tabular}{|c|c|c|c|c|c|}
\hline ANUL/YEAR & 2011 & 2012 & 2013 & 2014 & 2015 \\
\hline $\begin{array}{c}\text { Număr firme la sfârşitul } \\
\text { anului } \\
\text { Inr. of firms at the end of the } \\
\text { year: } \\
\text { din care: } \begin{array}{c}\text {-înregistrate în cursul } \\
\text { anului/ } \\
\text { registered during the year }\end{array}\end{array}$ & 496 & 503 & 512 & 540 \\
\hline
\end{tabular}

5.DISTRIBUITORI MAJORI PE PIAŢA DE CASETE VIDEO, D.V.D, C.D,U.M.D. ŞI B.D/ MAJOR DISTRIBUTION COMPANIES ON THE VIDEO, D.V.D. C.D, U.M.D. AND B.D MARKET

\begin{tabular}{|c|l|c|}
\hline Nr. crt. & $\begin{array}{l}\text { Denumire distribuitor/ } \\
\text { Distribution companies }\end{array}$ & $\begin{array}{c}\text { NUMAR } \\
\text { NOMBER }\end{array}$ \\
\hline 1. & PRO VIDEO & 153500 \\
\hline 2. & EMPIRE FILM & 87950 \\
\hline 3. & ODEON CINEPLEX & 62500 \\
\hline
\end{tabular}

Notă/Note:

Datele prezentate provin din Registrul cinematografiei/

Data provided by the Cinematographic Registre 